Marcelo Eduardo Cavicchia

\title{
DESENVOLVIMENTO DE MODELO NUMÉRICO PARA GERENCIAMENTO DE RECURSOS HÍDRICOS SUBTERRÂNEOS NA ÁREA DO PROJETO PILOTO DE RIBEIRÃO PRETO
}

Dissertação apresentada à Escola de Engenharia de São Carlos da Universidade de São Paulo, como parte dos requisitos para obtenção do Título de Mestre em Engenharia Civil (Hidráulica e Saneamento)

Orientador: Prof. Doutor Edson Cezar Wendland

São Carlos

(2007) 

Dedico este trabalho aos meus pais Luiz Roberto Cavicchia e Neide Ayub Cavicchia, e aos meus avós (em memória) Olga Cavicchia, Caetano Cavicchia, Youssef Ayub e Talge Maluf Ayub, exemplos de força, sabedoria e generosidade, pessoas a quem devo tudo. 


\section{AGRADECIMENTOS}

Ao Prof. Edson Wendland, pela grande colaboração, apoio e presteza na orientação deste trabalho, e pela amizade constituída.

Ao CNPq e à FAPESP, pelo apoio financeiro.

Aos funcionários do SHS, em especial a Sá, Pavi, Rose, Fernanda e Flávia pelo ótimo apoio técnico.

À Diretoria do comitê da Bacia CBH - PARDO, pela colaboração no acesso e levantamento de dados.

Ao Geólogo Heraldo Campos que, no papel de Facilitador Local do Projeto Piloto de Ribeirão Preto, foi de inestimável ajuda na obtenção de dados e apoio técnico.

Aos pesquisadores do IG, pelo apoio técnico e ótima recepção nessa instituição, em especial a Mara Iritani.

Aos colegas de LHC, em especial a Jorge, Quaresma, Rogério (Kid), Carlos, Anderson, Mariano, Luis, Fábio, Francisco, Patrick e Vinícius e Luiz Henrique, pela profunda troca de conhecimento, ajuda no desenvolvimento do projeto e, principalmente, pela ótima amizade.

Aos meus companheiros e amigos de república, irmãos que eu não tive, pela amizade, apoio técnico e psicológico, ótima convivência e intenso companheirismo: Serginho, Hugo, Tiago, Rapha, Léo (também pela ajuda tecnológica) e Guilherme (também pela ajuda no processamento de dados).

Aos meus familiares e amigos, que me apoiaram, incentivaram, emprestaram forças, ou simplesmente foram compreensíveis quando eu não pude estar presente:

Luiz, Neide, Chris, Neusa, Talginha, Filó e Walter, Malaque e Anízio, Airton, Fê, Má, Tony, Dé e Val, Marcos (branco), Maurício (bocão), Carlos (piá), João (Jones) e Bruno (UZT). 


\section{RESUMO}

Cavicchia, Marcelo Eduardo (2007). Desenvolvimento de modelo numérico para gerenciamento de recursos hídricos subterrâneos na área do Projeto Piloto de Ribeirão Preto. Dissertação de Mestrado Escola de Engenharia de São Carlos, Universidade de São Paulo, São Carlos, 2007.

Este projeto apresenta a construção de um modelo numérico do Sistema Aqüífero Guarani pelo Método de Elementos Finitos para auxiliar o gerenciamento de recursos hídricos subterrâneos na área do Projeto Piloto de Ribeirão Preto, localizada na região nordeste do Estado de São Paulo. Dados topográficos, hidrológicos e hidrogeológicos da região de interesse foram obtidos principalmente de mapas (impressos e digitais) e poços cadastrados junto a órgãos governamentais, em cooperação com o Grupo Coordenador do Projeto Piloto de Ribeirão Preto. Os dados levantados foram armazenados, processados e analisados utilizando ferramenta SIG, seguida da geração de mapas interpolados com características hidrogeológicas. Esses dados foram transferidos para o software de simulação SPA, onde se deu a construção da malha de elementos finitos e a atribuição dos parâmetros e condições de contorno ao modelo. Em seguida, foi feita uma análise de sensibilidade do modelo, e testadas algumas configurações de parâmetros hidrogeológicos e de taxas de recarga. O modelo apresentou bons resultados e desempenho, e, como parte de uma constante evolução, são propostas visitas de campo para verificação de dados para o seguimento desse projeto.

Palavras-chave: Aqüífero Guarani; modelo numérico, Projeto Piloto de Ribeirão Preto 


\section{ABSTRACT}

Cavicchia, Marcelo Eduardo (2007). Numerical model for ground water management in the Ribeirão Preto Pilot Project area. Master's Degree Dissertation - Escola de Engenharia de São Carlos, Universidade de São Paulo, São Carlos, 2007.

This work presents a numerical model for the Guarani Aquifer System management in the Ribeirão Preto Pilot Project area, located in the Northeast of São Paulo State. Topographical, hydrological and hydrogeological data of the region were obtained from printed and digital maps and well database recorded in governmental departments, in cooperation with the Ribeirão Preto Coordinating Group of the Pilot Project. The collected data were stored, processed and analyzed making use of GIS tool, followed by the generation of interpolated maps with hydrogeological parameters. These data were transferred to the SPA simulation software, which is based on the Finite Element Method. After mesh construction, and attribution of parameters and boundary conditions, a sensitivity analysis of the model was performed. Different hydrogeological parameter configurations were tested. The model proved to represent the established conceptual model adequately. However base flow data and field visits are necessary, in order to improve the model representativity.

Key words: Guarani Aquifer; Numerical Models; Ribeirão Preto Pilot Project. 


\section{Sumário}

RESUMO

ABSTRACT__ 6

1 INTRODUÇÃO__ 15

2 OBJETIVOS 17

3 REVISÃO BIBLIOGRÁFICA__ 18

3.1 SISTEMA AQÜÍFERO GUARANI _ 18

3.1.1 VISÃO GERAL__ 18

3.1.2 GEOLOGIA_ 22

3.1.3 ESTRUTURAS DE COMPARTIMENTAÇÃO

3.1.4 HIDROGEOLOGIA

3.1.5 CLIMA _ 26

3.1.6 DISPONIBILIDADE HÍDRICA 26

3.1.7 ÁREAS DE SUPEREXPLORAÇÃO__ 27

3.2 MODELAGEM _ 28

3.2.1 FÍSICO 29

3.2.2 MATEMÁTICO_L 29

3.3 INCERTEZA NOS MODELOS DE ÁGUA SUBTERRÂNEA___ 31

3.4 SOFTWARES DE SIMULAÇÃO __ 32

4 METODOLOGIA _ 34

4.1 ÁREA DE ESTUDO__ 34

4.1.1 PROJETO PILOTO DE RIBEIRÃO PRETO__ 34

4.1.2 LIMITES DA ÁREA DE ESTUDO __ 37

4.1.3 GEOLOGIA_ 38

4.1.4 HIDROGEOLOGIA 43

4.1.5 CAMADAS CONFINANTES E SEMICONFINANTES _ 46

4.1.6 PARÂMETROS HIDROGEOLÓGICOS

4.1.7 FLUXO SUBTERRÂNEO 50

4.1.8 SITUAÇÃO EM RIBEIRÃO PRETO__ 51

4.2 MODELO CONCEITUAL

4.2.1 UNIDADE HIDROESTRATIGRÁFICA _ 55

4.2.2 RECARGA_ 56

4.2.3 FLUXO_56 56

4.3 OBTENÇÃO E PROCESSAMENTO DE DADOS EM SIG _

4.3.1 OBTENÇÃO DE DADOS _ 58

4.3.1.1 Dados topográficos e superficiais da região___ 58

4.3.1.2 Dados geológicos subterrâneos ___ 59

4.3.2 PROCESSAMENTO DOS DADOS EM SIG _ 61

4.3.2.1 Geologia _ 61

4.3.2.2 Área de afloramento__ 67

4.3.2.3 Altimetria _ 68

4.3.2.4 Hidrografia

4.3.2.5 Potenciometria _ 72

4.3.2.6 Poços em operação___ 74

4.3.2.7 Perfis hidrogeológicos__ 75

4.4 MODELO NUMÉRICO__ 79 
4.4.1 FUNCIONAMENTO DO SPA _ 79

4.4.2 TIPOS DE DADOS _ 81

4.4.2.1 Estruturas 82

4.4.2.2 Contornos 83

4.4.3 MALHA DE ELEMENTOS FINITOS _ 85

4.4.4 PARÂMETROS HIDROGEOLÓGICOS_ 88

4.4.5 TAXA DE RECARGA E CONDIÇÕES DE CONTORNO ___ 89

5 RESULTADOS E DISCUSSÕES 92

5.1 AJUSTE DO MODELO NUMÉRICO

5.1.1 RIO PARDO E RIBEIRÃO DO TAMANDUÁ___ 93

5.1.2 RIOS NO AFLORAMENTO E DESCARGA REGIONAL LATERAL___ 94

5.1.3 POÇOS EM RIBEIRÃO PRETO __ 97

5.1.4 RIBEIRÃO DO ONÇA E TRECHOS DE RIOS EM RIBEIRÃO PRETO __ 99

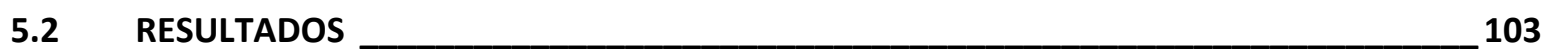

6 CONCLUSÃO__ 112 


\section{LISTA DE FIGURAS}

Figura 1: Fluxograma da metodologia adotada neste estudo $\ldots \ldots \ldots \ldots 17$

Figura 2: Mapa esquemático do Aqüífero Guarani (SG-SAG, 2006).....19

Figura 3: Áreas do SAG favoráveis à ocorrência de águas termais acima de 38 oc (mancha azul). A mancha na região central do mapa delimita área com temperatura superior a 60 ㄷ․ Mapa base adaptado de FORLIN E ROSA FILHO (2001) apud CHANG, 2001.21

Figura 4: Visão esquemática da geologia do SAG 23

Figura 5: Estratigrafia e sistema de fluxo entre seções geológicas do Sistema Aqüífero Guarani na região de Ribeirão Preto (SMA, $2004)$ 24

Figura 6: Marco estrutural da Bacia do Paraná com as três direções principais: NW, NE e EW de elementos tectônicos lineares (modificado ZALÁN ET AL., 1990) ...............................25

Figura 7: Área do Projeto Piloto de Ribeirão Preto (SMA/São Paulo \&

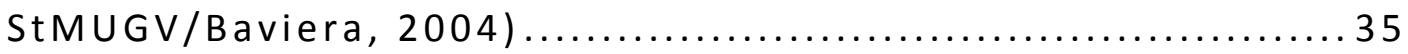

Figura 8: Articulação das folhas 1:50.000 na área da UGRHI - 4.......36

Figura 9: Nível de criticidade das sub-bacias da UGRHI 4 - Pardo ......37

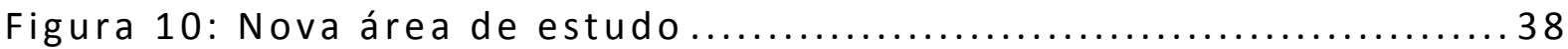

Figura 11: Geologia de superfície da área de estudo (IPT, 2000) ......40

Figura 12: Geologia e corte da região de estudo.....................40

Figura 13: Modelo hidrogeológico (KULLS, 2003 apud SMA/São Paulo \& StMUGV/Baviera, 2004 ) ................................... 45

Figura 14: Esquema dos principais meios de circulação nos derrames basálticos de Ribeirão Preto (FERNANDES ET AL., 2006).

Figura 15: Evolução do nível piezométrico no município de Ribeirão Preto (GUIDO, 2004)

Figura 16: Área de restrição e controle temporário no município de Ribeirão Preto (SMA/São Paulo \& StMUGV/Baviera, 2004) ....554

Figura 17: Poços contendo informações sobre topo do Aqüífero Guarani (m.s.n.m) 
Figura 18: Superfície do topo do Aqüífero Guarani (m.s.n.m.) ........63 63

Figura 19: Topo do Aqüífero Guarani no SPA (m.s.n.m) ............... 64

Figura 20: Isópacas dos sedimentos do Aqüífero Guarani

(DAEE/IG/IPT/CPRM, 2005) .............................. 65

Figura 21: Pontos com dados de base da Formação Botucatu (m.s.n.m)

Figura 22: Base do Aqüífero Guarani (m.s.n.m) no SPA ...............67 67

Figura 23: Área de afloramento do SAG ........................... 68

Figura 24: Topografia e hidrografia da região de estudo (m.s.n.m.)... 69

Figura 25: Altimetria no SPA (m.s.n.m) ............................. 70

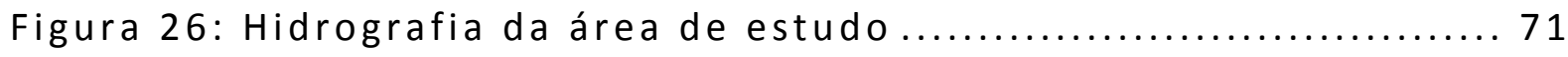

Figura 27: Pontos de carga hidráulica conhecida (m.s.n.m) ........... 72

Figura 28: Potenciometria - poços até a década de 50 (m.s.n.m) .....73

Figura 29: Isopotenciais do SAG, traçadas manualmente - década de 50

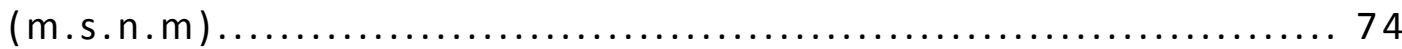

Figura 30: Municípios e distribuição dos poços em operação na área de

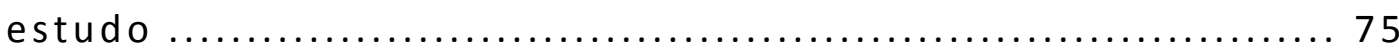

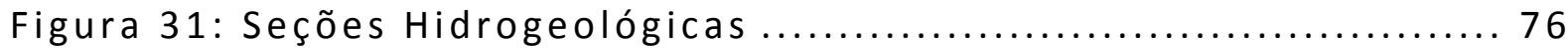

Figura 32: Perfil hidrogeológico do corte A-B ....................... 77

Figura 33: Perfil hidrogeológico do corte C-D ...................... 77

Figura 34: Perfil hidrogeológico do corte A-B $\ldots \ldots \ldots \ldots \ldots \ldots \ldots \ldots \ldots \ldots \ldots$

Figura 35: Fluxograma de dados através dos módulos do SPA ......... 80

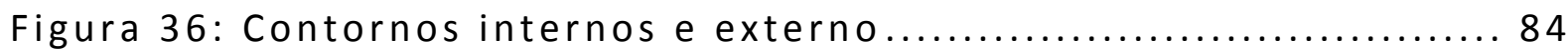

Figura 37: Detalhe dos contornos na área urbana de Ribeirão Preto .. 85

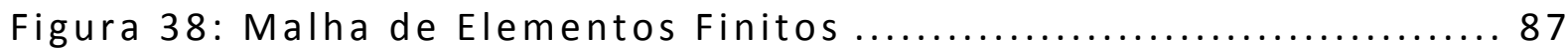

Figura 39: Detalhe da malha e contornos na área urbana de Ribeirão

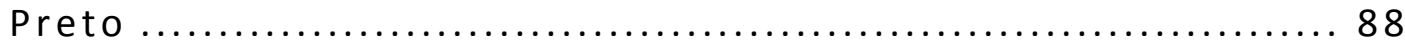

Figura 40: Cargas hidráulicas do Rio Pardo e do Ribeirão do Tamanduá

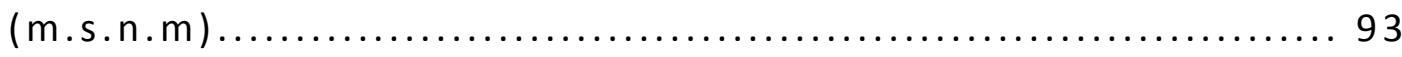

Figura 41: Diferença entre cota do terreno e nível potenciométrico do SAG $(m)$ - configuração 1 
Figura 42: Carga hidráulica dos rios da região aflorante (m.s.n.m) e descarga regional lateral.................................. 95

Figura 43: Diferença entre cota do terreno e nível potenciométrico SAG

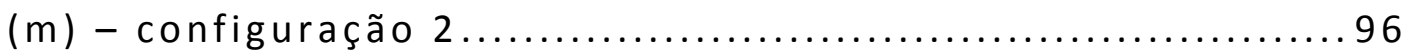

Figura 44: Carga hidráulica dos rios da região aflorante (m.s.n.m), descarga regional lateral e poços $\left(\mathrm{m}^{3} / \mathrm{ano}\right)$ em Ribeirão Preto

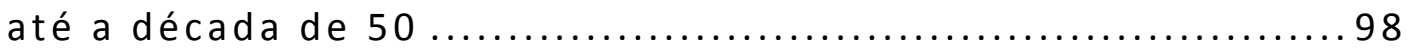

Figura 45: Diferença entre cota do terreno e nível potenciométrico do SAG $(m)$ - configuração 3 99

Figura 46: Carga hidráulica dos rios (m.s.n.m), descarga regional lateral e vazão em poços $\left(\mathrm{m}^{3} / \mathrm{ano}\right)$ em Ribeirão Preto 100

Figura 47: Diferença entre cota do terreno e nível potenciométrico do

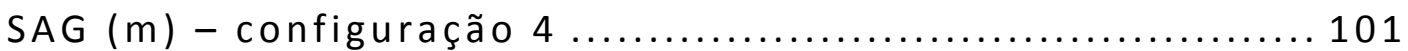

Figura 48: Diferença entre cota do terreno e nível potenciométrico do SAG (m) para a região de Ribeirão Preto-configuração $4 \ldots 102$

Figura 49: Reações nos rios 104

Figura 50: Isolinhas de potenciometria do SAG (m.s.n.m). ........... 105

Figura 51: Superfície potenciométrica (m.s.n.m.). ................... 106

Figura 52: Superfície potenciométrica para valores de $425 \mathrm{~mm} / \mathrm{a}$ de recarga direta e $20 \mathrm{~mm} /$ a para recarga indireta (m.s.n.m.). 107 Figura 53: Esquema de fluxo em zonas de transição entre a Formação Serra Geral e a Formação Botucatu (corte longitudinal no leito

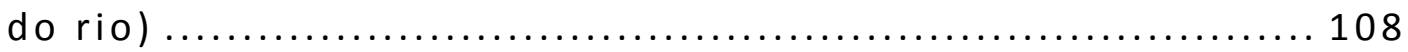

Figura 54: Afloramento do Aqüífero Guarani e cursos d'água ......... 109 Figura 55: Isolinhas para recarga indireta do SAG de 0,1 mm/a..... 111

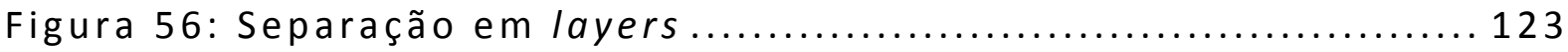

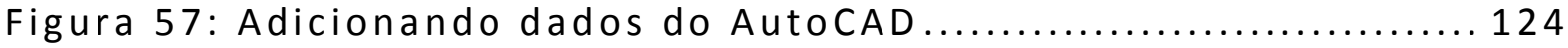

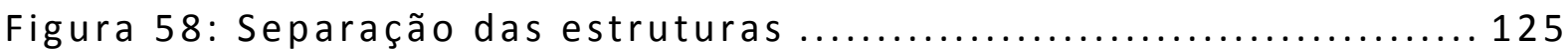

Figura 59: Exportação de dados vetoriais para shapefiles ............. 126

Figura 60: Estruturas passadas do AutoCAD para o ArcMap ........... 127

Figura 61: Informações para interpolação........................... 128

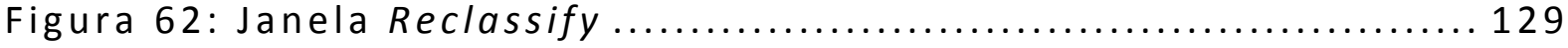


Figura 63: Raster para Pontos

130

Figura 64: Janela para extração de valores do raster para a shapefile

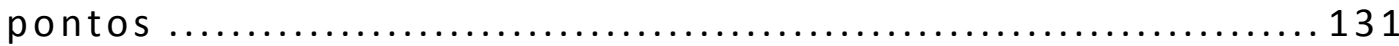

Figura 65: Janela para adição de campos ............................ 132

Figura 66: Cálculo das coordenadas X e Help ........................ 133

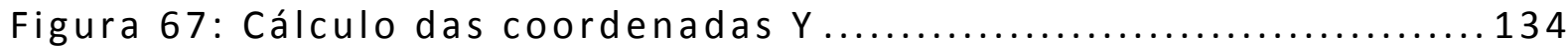

Figura 68: Inserção dos valores para cada ponto.....................135

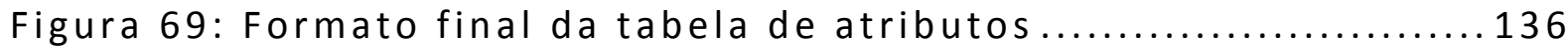




\section{LISTA DE TABELAS}

Tabela 1: Resumo das características geométricas e hidráulicas dos aqüíferos presentes na UGRHI 4 (adaptado de IPT, 2000).....49

Tabela 2: Valores de parâmetros hidrodinâmicos do SAG $\ldots . \ldots \ldots \ldots \ldots . \ldots 50$

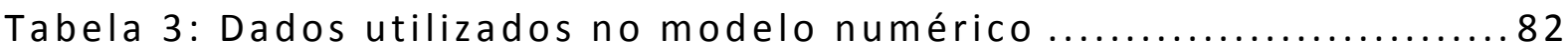

Tabela 4: Poços em funcionamento em Ribeirão Preto até a década de

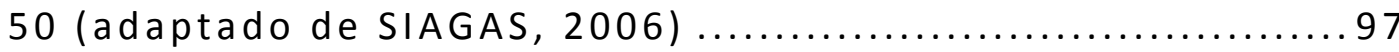




\section{LISTA DE SIGLAS}

ASG - Aqüífero Serra Geral

CMA - Construtor de Modelos de Aqüíferos (módulo do SPA)

DEM - Digital Elevation Model

FAS - Fluxo de Águas Subterrâneas (módulo do SPA)

GIA - Gerador de Imagens de Aqüíferos (módulo do SPA)

PSAG - Projeto Sistema Aqüífero Guarani

SAG - Sistema Aqüífero Guarani

SIG - Sistema de Informações Geográficas

SPA - Simulação de Processos em Aqüíferos (pacote computacional)

TP - Transporte de Poluentes (módulo do SPA)

VMA - Verificador de Modelos de Aqüíferos (módulo do SPA)

VPA - Visualizador de Processos em Aqüíferos (módulo do SPA) 


\section{INTRODUÇ̃̃O}

A partir da década de 50, tem sido atribuído aos reservatórios hídricos subterrâneos, em todo o mundo, um papel de destaque, por serem, cada vez mais, um meio de acelerar o desenvolvimento econômico e social, devido, principalmente, ao mau uso e à deposição de poluentes nos corpos d’água superficiais, bem como à sua inexistência em regiões mais secas.

Nesse contexto, o Sistema Aqüífero Guarani (SAG) assume importância indiscutível, tendo em vista sua extensão e abrangência, e representatividade para as economias adjacentes. Esse aqüífero possui aproximadamente 1,2 milhões $\mathrm{km}^{2}$, estendendo-se por quatro Países: Argentina (18,9\%), Brasil (70,8\%), Paraguai (6,0\%) e Uruguai (4,9\%). Cerca de 30 milhões de pessoas residem na região de abrangência do SAG (dessas, cerca de 4 milhões em áreas de afloramento). No Brasil, o aqüífero abrange partes das regiões Centro-Oeste, Sul e Sudeste, incluindo estados com grande importância econômica. Pode-se avaliar, então, sua importância e, conseqüentemente, a necessidade de se conhecer seu funcionamento e seu comportamento, proporcionando o desenvolvimento de uma política de proteção ambiental e de gestão de águas subterrâneas.

Com este intuito, áreas críticas nos países abrangidos pelo aqüífero foram escolhidas para serem estudadas mais detalhadamente (SG-SAG, 2007). Uma dessas áreas prioritárias de estudo tem seu centro localizado na cidade de Ribeirão Preto, sendo definida como Projeto Piloto de Ribeirão Preto (CALCAGNO, 2001). Esta área foi escolhida em função de sua importância e representatividade regional, por apresentar sinais de superexploração (GILBOA ET AL., 1976; CHANG, 2001) e pela quantidade de estudos já desenvolvidos na região.

Visando contribuir com o incremento do conhecimento do comportamento hidráulico do aqüífero na região, este projeto propõe a construção de um modelo numérico baseado no Método dos Elementos 
Finitos. O objetivo principal do modelo é servir como ferramenta de análise e gerenciamento dos recursos hídricos subterrâneos na área desse Projeto Piloto, como forma de assegurar a quantidade e a qualidade de seu manancial para as futuras gerações.

Para o desenvolvimento deste projeto, primeiramente foi feito um estudo global das características do Aqüífero Guarani, acompanhado de uma revisão dos trabalhos sobre a região de estudo ou que pudessem contribuir com o projeto como um todo. Em seguida foram compilados e organizados em ferramenta SIG dados sobre a fisiografia, hidrografia, poços de captação de água, hidrologia e hidrogeologia e geometria subterrânea da região de estudo.

A partir da análise desses dados foi proposto um modelo conceitual de funcionamento do aqüífero, com a definição de seus parâmetros hidrogeológicos iniciais. O modelo conceitual e os parâmetros hidrogeológicos foram ajustados conforme os primeiros resultados do modelo numérico.

Para a construção do modelo numérico foi utilizado o software SPA - Simulação de Processos em Aqüíferos (WENDLAND, 2003), desenvolvido no Laboratório de Hidráulica Computacional (LHC) do Departamento de Hidráulica e Saneamento (SHS) da Escola de Engenharia de São Carlos (EESC) da Universidade de São Paulo (USP).

Cabe ressaltar que um modelo numérico é uma ferramenta de contínua evolução, devendo ser incrementado conforme aumenta o grau de conhecimento do homem sobre a região de estudo. 


\section{OBJETIVOS}

O objetivo geral deste projeto é a construção de um modelo numérico do Sistema Aqüífero Guarani na região do município de Ribeirão Preto que auxilie na criação de uma política de preservação e no gerenciamento de recursos hídricos subterrâneos dessa área.

Para isso, foram definidos os seguintes objetivos específicos para o projeto:

- Revisão bibliográfica sobre o SAG e a área de estudo;

- Coleta e avaliação dos dados hidrogeológicos disponíveis;

- Definição de um modelo conceitual;

- Definição de parâmetros hidrogeológicos;

- Sistematização de dados em SIG;

- Disponibilização dos dados para o pacote SPA.

- Ajuste e aperfeiçoamento do modelo numérico de acordo com o seguinte fluxograma:

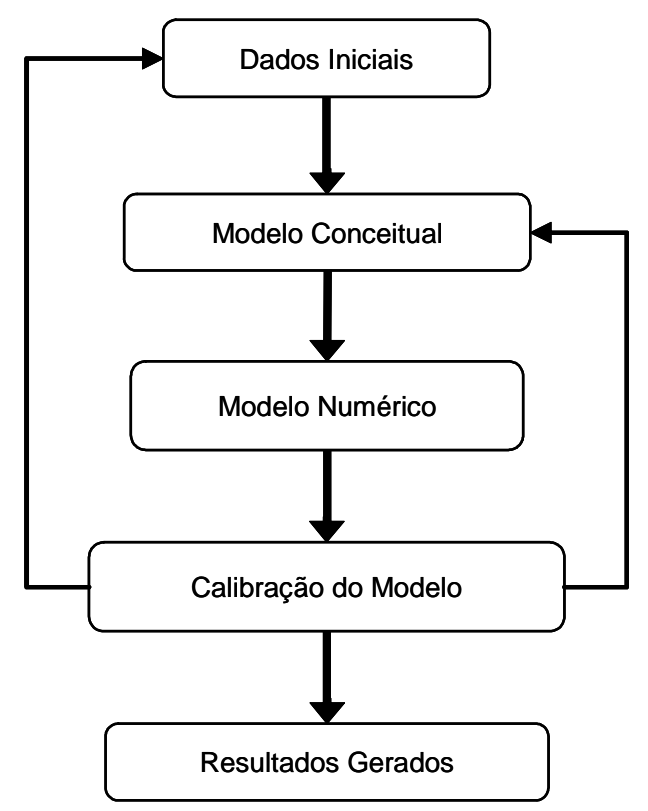

Figura 1: Fluxograma da metodologia adotada neste estudo 


\section{REVISÃO BIBLIOGRÁFICA}

\subsection{SISTEMA AQÜÍFERO GUARANI}

\subsubsection{VISÃO GERAL}

O Sistema Aqüífero Guarani é um recurso hídrico subterrâneo transfronteiriço localizado no centro-sul da América do Sul, entre os paralelos $12^{\circ}$ e $35^{\circ}$ de latitude Sul e $47^{\circ}$ e $65^{\circ}$ de longitude Oeste, abrangendo partes da Argentina, Brasil, Paraguai e Uruguai. Dada sua extensão e capacidade de armazenamento de água, constitui um dos recursos minerais mais importantes da região, e um dos maiores reservatórios subterrâneos de água do mundo (Figura 2 ).

Estendendo-se desde a Bacia Sedimentar do Paraná (Brasil, Paraguai e Uruguai) até a Bacia do Chaco Paraná (Argentina), tem uma área de cerca de 1,2 milhão de $\mathrm{km}^{2}$, sendo $840 \mathrm{mil} \mathrm{km²}$ no Brasil, 225,5 mil $\mathrm{km}^{2}$ na Argentina, $71,7 \mathrm{mil} \mathrm{km}^{2}$ no Paraguai e 58,5 mil km² no Uruguai (ARAÚJO ET AL., 1999).

No Brasil, localiza-se em áreas de grande importância sócioeconômica, como a região de Ribeirão Preto, onde exerce função estratégica e é indispensável para suprir sua demanda de água doce; segundo BORGHETTI ET. AL. (2001), uma população de cerca de 24,9 milhões de habitantes direta ou indiretamente faz uso de águas do SAG no Brasil. 


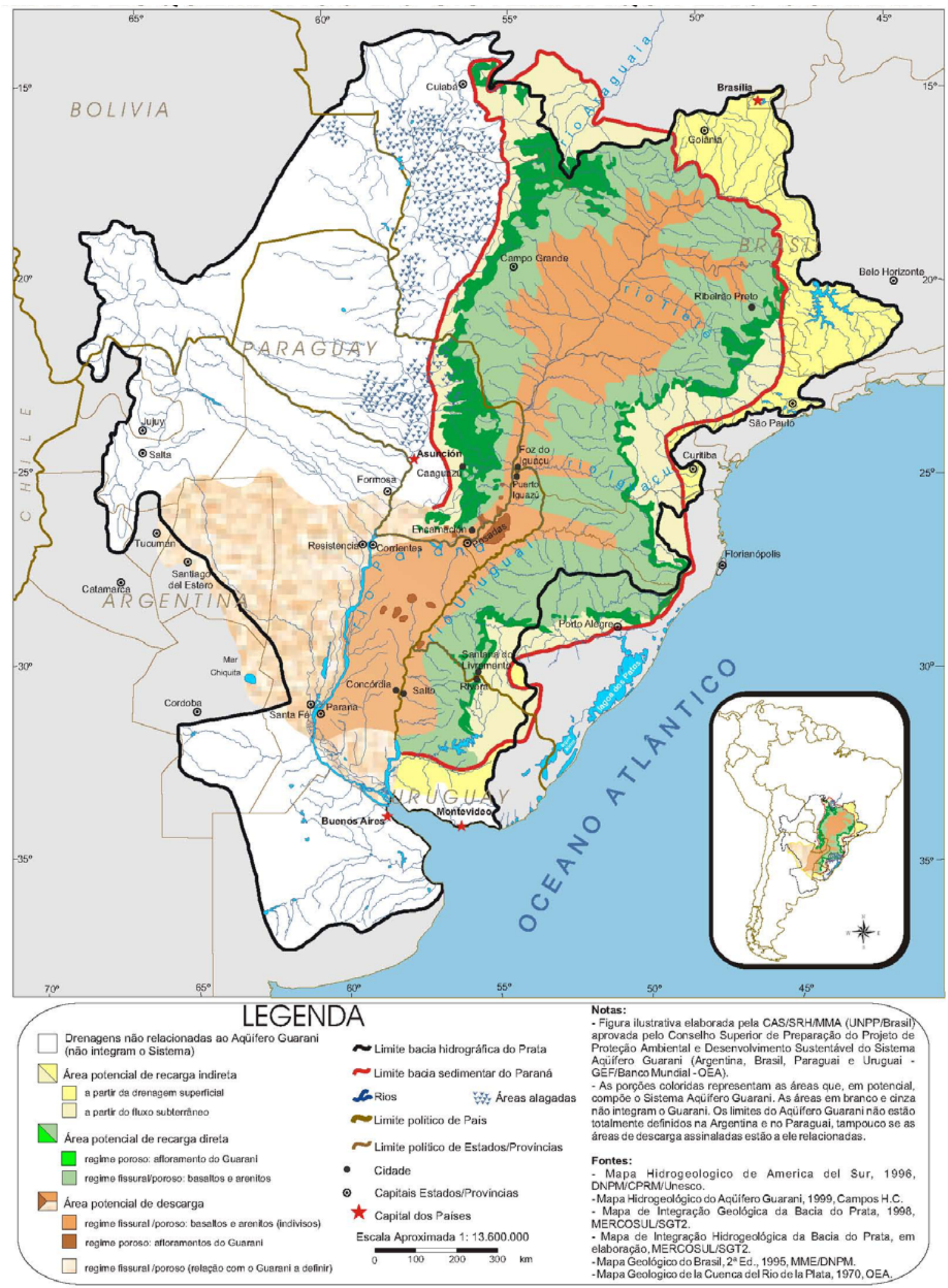

Figura 2: Mapa esquemático do Aqüífero Guarani (SG-SAG, 2006)

Segundo CHANG (2001), o estado de São Paulo responde por mais da metade dos poços existentes no país, seguido por Rio Grande do Sul 
(20\%), Mato Grosso do Sul (12\%), Paraná (10\%) e por Santa Catarina, Minas Gerais, Mato Grosso e Goiás, todos com participação inferior a $2 \%$. Em termos volumétricos, São Paulo extrai quase 2/3 da produção atual. Mato Grosso do Sul explora o equivalente a $12 \%$, seguido por Rio Grande do Sul (6\%) e Paraná (5\%). Os outros quatro estados exploram menos que $2 \%$ cada um.

A distribuição dos poços pelo tipo de uso revela que aproximadamente três quartos (77\%) destinam-se à captação de água para consumo urbano; os outros $23 \%$ estão divididos igualitariamente entre os usos rural e industrial. Já em termos volumétricos, a participação do uso urbano salta para $87 \%$, deixando $9 \%$ para o uso industrial e $4 \%$ para o uso rural.

O SAG, segundo CHANG (2001), apresenta gradientes geotérmicos variando entre 10 e $40^{\circ} \mathrm{C} / \mathrm{km}$, reportados para a Bacia do Paraná, e ressalta que regiões de altos gradientes sejam fontes potenciais de energia geotérmica. Uma estimativa da área do SAG com potencial de produção de águas termais com temperaturas superiores a $38{ }^{\circ} \mathrm{C}$, fornece um valor de $380.000 \mathrm{~km}^{2}$, equivalente a cerca de $45 \%$ da área de sua ocorrência no Brasil, ou 30\% da extensão total do SAG. Para a produção de águas com temperaturas mais elevadas, superiores a $60{ }^{\circ} \mathrm{C}$, a área potencial de ocorrência restringe-se a pouco mais de $30.000 \mathrm{~km}^{2}$, isto é, em torno de $4 \%$ e $3 \%$ da extensão do SAG no Brasil e no Mercosul, respectivamente. Entre as diversas aplicações da energia geotérmica destacam-se: secagem e armazenamento de grãos, secagem de madeiras, evisceração e limpeza de aves e desenvolvimento de centros de lazer e hidroterápicos. A sua utilização na geração de metano, a partir de resíduos orgânicos líquidos e sólidos, o torna uma fonte potencial de geração de energia limpa - uma solução que visa não somente lucros, mas principalmente a redução de danos ambientais, inerentes à atividade de criação animal em larga escala.

As áreas do SAG com potencial geotermal podem ser visualizadas na Figura 3. 


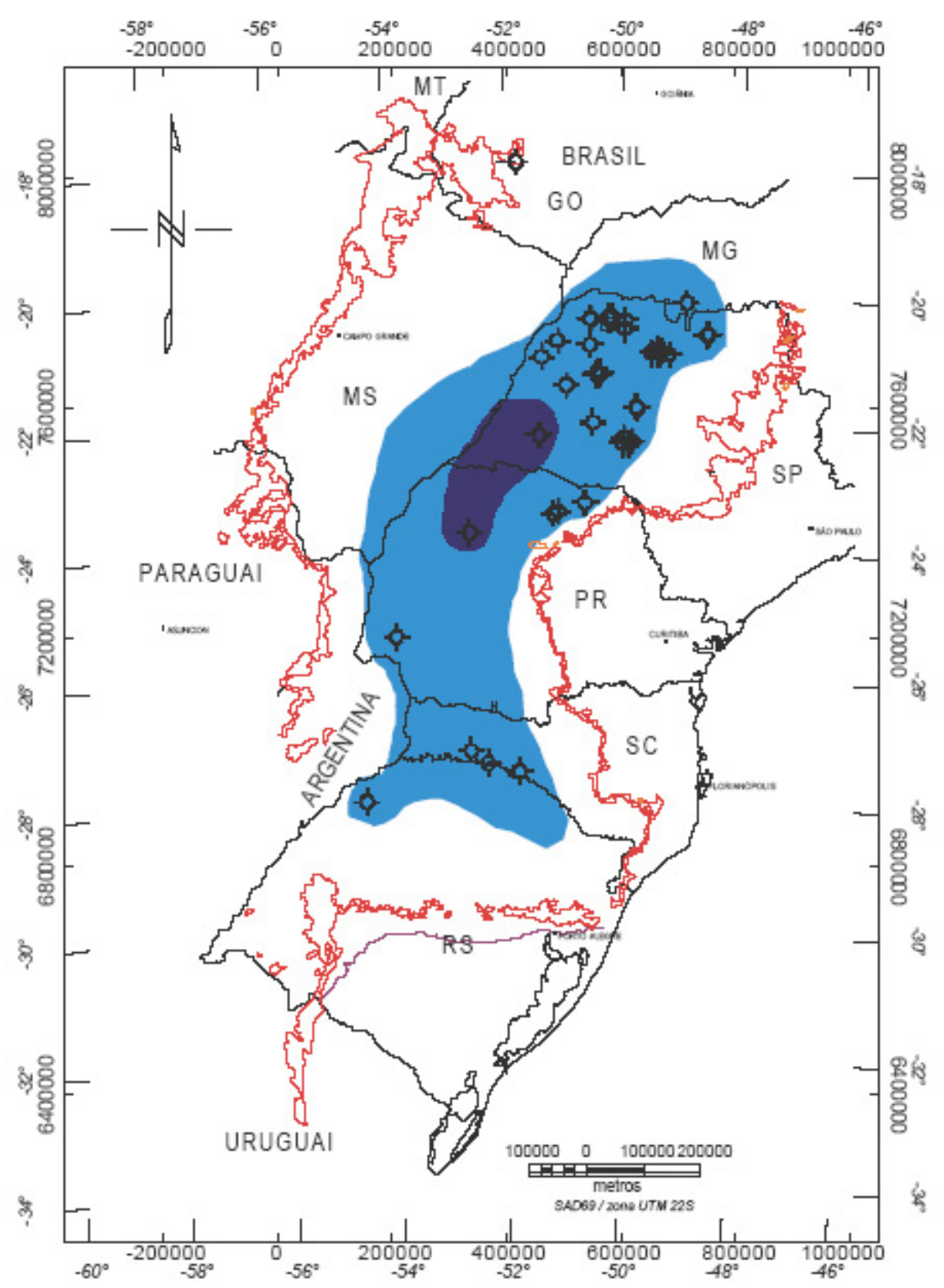

Figura 3: Áreas do SAG favoráveis à ocorrência de águas termais acima de $38^{\circ} \mathrm{C}$ (mancha azul). A mancha na região central do mapa delimita área com temperatura superior a $60^{\circ} \mathrm{C}$. Mapa base adaptado de FORLIN E ROSA FILHO (2001) apud CHANG, 2001.

Quando o assunto é contaminação, pode-se dizer que, no caso do Aqüífero Guarani, há uma preocupação por parte das autoridades e por entidades não governamentais devido à coincidência de áreas de afloramento com importantes áreas agrícolas e urbanas. Nas regiões agrícolas, o uso intenso de herbicidas e inseticidas no combate a pragas e doenças das plantações, somado ao uso de adubos químicos, poderá acarretar o aumento de nitratos na água (FRANTZ, 2005). 
O SAG, praticamente desconhecido até o início da década de 70, sofre hoje sérios problemas de superexplotação localizada, com mais de 2000 poços em suas bordas, atingindo profundidades de 300 a $1000 \mathrm{~m}$, e centenas de outros poços em áreas mais centrais, com profundidades que alcançam 1500 m (MONTEIRO, 2003).

\subsubsection{GEOLOGIA}

O Sistema Aqüífero Guarani é formado por um conjunto de rochas sedimentares predominantemente siliciclásticas e de origem continental, que incluem o final da seqüência permotriástica e a totalidade dos depósitos Mesozóicos confinados pelos derrames basálticos do Cretáceo Inferior.

Em sua grande maioria, trata-se de litologias arenosas depositadas por sistemas aluviais, fluviais e lacustres, sob condições de altas temperaturas e um regime variável de umidade (com predomínio de condições de aridez a semiaridez), com recorrentes episódios eólicos associados, alguns deles de importante potência (centenas de metros) e aos quais se relacionam as melhores características petrofísicas do aqüífero. Assim, é comum a presença, ainda que em forma subordinada, de estratos e lentes pelíticos e conglomeráticos intercalados às significativas sucessões arenosas Mesozóicas. Estas litologias e seus atributos espaciais (forma, extensão etc.) têm uma incidência particular e significativa nas características hidrodinâmicas de fluxo em escala local.

No Brasil, o Aqüífero Guarani é composto por arenitos que compreendem as Formações Pirambóia (Triássico) e Botucatu ( Jurássico) (Figura 4 ). 


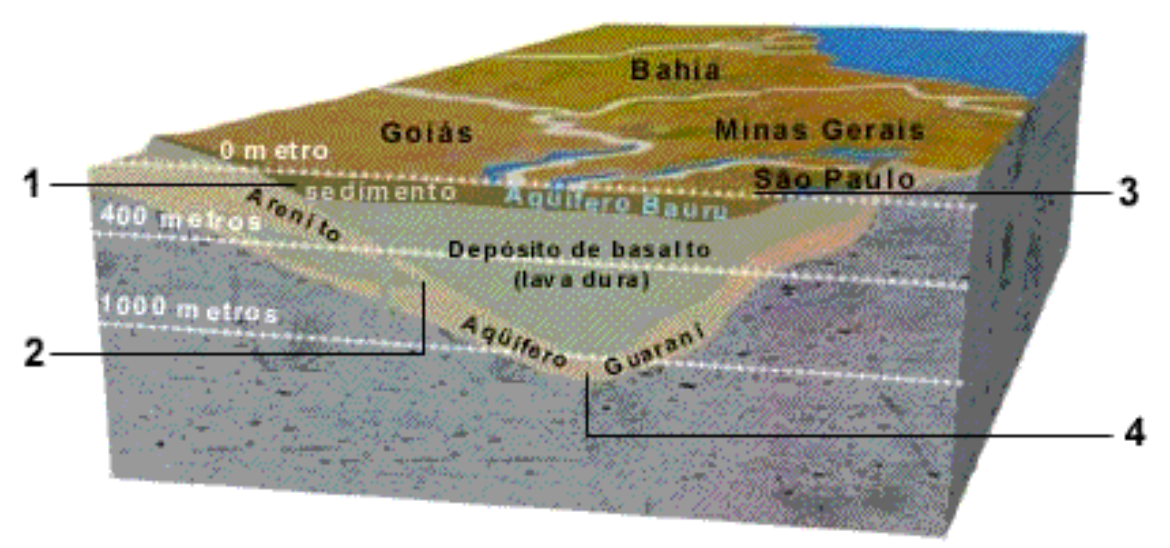

Figura 4: Visão esquemática da geologia do SAG

Os arenitos do período Jurássico, de origem eólica e maior produtividade hidráulica, constituem-se nos melhores reservatórios subterrâneos, enquanto os do Triássico, de origem flúviolacustre/eólica, possuem elevado nível de argila, comprometendo sua eficiência hidráulica.

O Aqüífero Guarani tem uma espessura média de 250 metros, variando de poucos metros (nas bordas da bacia) a aproximadamente $800 \mathrm{~m}$ (em sua parte central). Sua profundidade em relação ao nível do solo varia de zero (regiões de afloramento) até $1000 \mathrm{~m}$ (na Argentina).

A estrutura subjacente ao Aqüífero compreende uma formação de baixa permeabilidade e caracteriza-se como um aquitardo (Grupo Passa Dois). Sobrejacentes a Aqüífero estão sucessivas camadas de derrame basáltico, provenientes de atividade vulcânica do período Cretáceo (Formação Serra Geral), formando rochas consolidadas e descontínuas, caracterizadas em parte como aquitardo e em parte como aqüífero. Em alguns pontos, a Formação Serra Geral é ainda recoberta por arenitos do período Cretáceo caracterizados como um aqüífero (Grupo Bauru). A Figura 5 mostra uma seção geológica típica do conjunto desta estratificação geológica.

A Formação Serra Geral tem como principais condicionantes estruturais soerguimentos com formação de arcos e sistemas de falhas. Juntamente com as demais formações de rochas porosas que a revestem, 
atinge espessuras superiores a $1400 \mathrm{~m}$ na Argentina e $2200 \mathrm{~m}$ no Brasil (ARAÚJO ET AL., 1999).

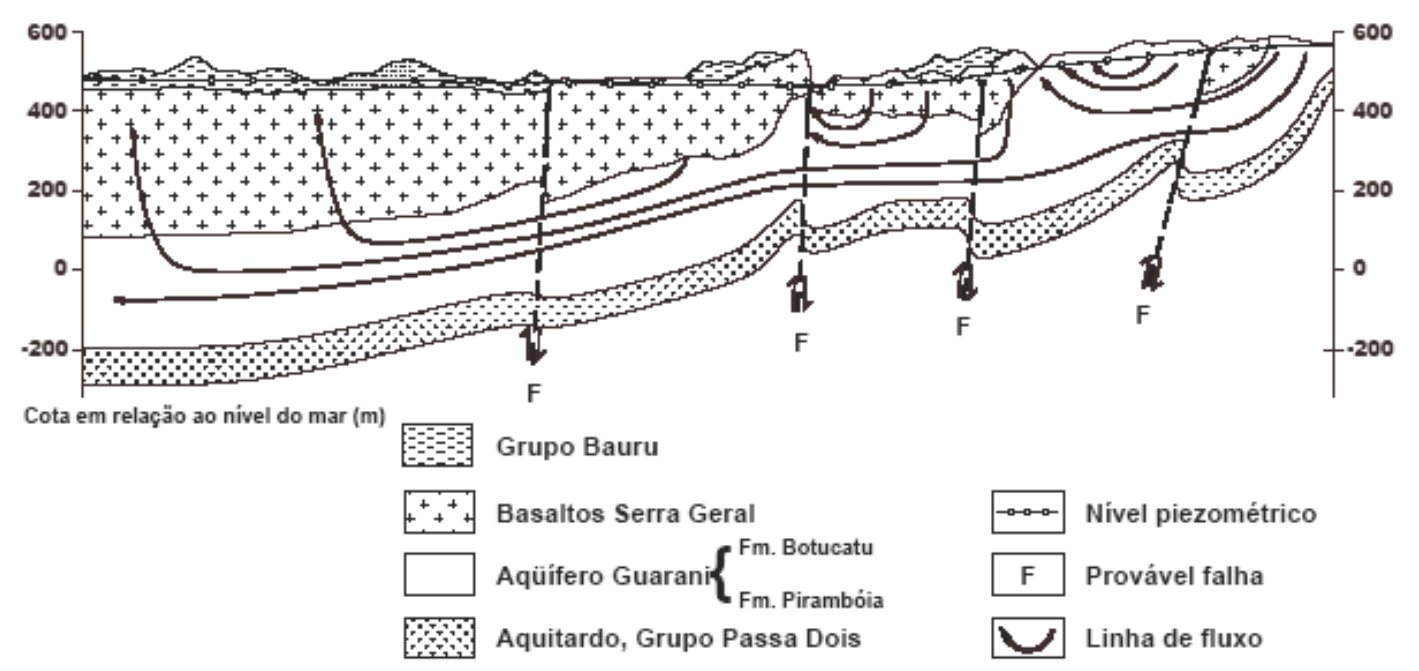

Figura 5: Estratigrafia e sistema de fluxo entre seções geológicas do Sistema Aqüífero Guarani na região de Ribeirão Preto (SMA, 2004)

\subsubsection{ESTRUTURAS DE COMPARTIMENTAÇÃO}

A Bacia do Paraná é delimitada, ao Norte, pelo Arco de Goiânia e Alto Paranaíba, que é uma deformação estrutural importante com forte tendência aeromagnética NW, associado a várias intrusões alcalinas, kimberlitos e diques de diabásio (Figura 6). Outros dois arcos de direção Noroeste, denominados Arco de Ponta Grossa e Rio Grande, influenciam em sua configuração e geram duas entradas semi-elípticas na margem leste da Bacia. Ambos constituem locais preferenciais para a localização de diques de diabásio e intrusões ígneas alcalinas. A direção NW, que evidencia um forte paralelismo dos eixos desses arcos, é uma das direções estruturais mais importantes da bacia, evidenciando um controle tectônico das zonas de debilidade de seu embasamento (ZALÁN ET AL., 1990). 


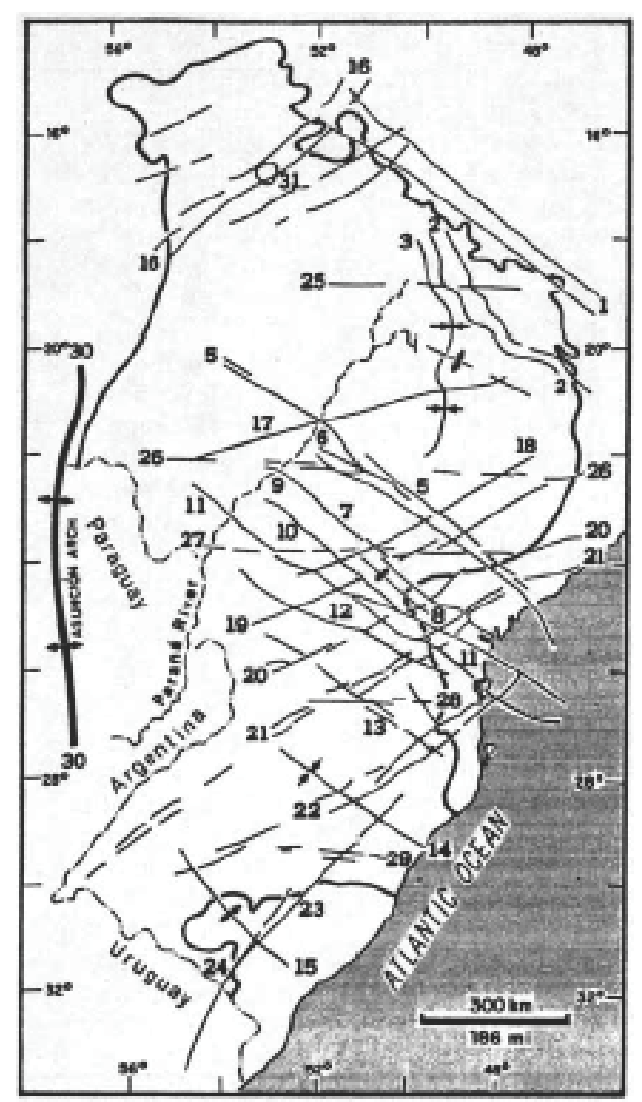

$A=A r c o, F=$ falla eimple, $F Z=$ zona de falla, $L=$ lineamiento de naturaleza desconocida.

(1): Alto Paranaiba A

(20): Tumaguan FZ

(2) : ferura de Goibnia

(21): Lancinha-Cubatao FZ

(3): eje de depocentro Ipiacu-

(22): Blamenau-Soledade FZ

Campine.

(23): Lean F

4): Alto de Candoro

5): Guapiara FZ

(24): Acoten

(6): Santo Anasticio F

(25): Cassilandia I

(26): Moji-Guacu/Dourados L

(7): Sĩo Jerónimo - Curuitivon.

(27): Sลีo Sebastih้o L

(28): Taqua.r. Verde L

(8): Pouta Grosea A

(29): Beato Gorçalves L

(9): Curitiba - Maringi FZ

(10), Rio Alonzo F

(30): Arunción A

(31): Arnguairha dome

(11): Cundido de Abrea -

Cumpo Mourno FZ

(12): Rio Piquini L

(13): Cacndor FZ

(14: Sinclinal de Tocres

(15): Rio Gande A

(16): Trassbra:

(17): Arncatuba L

(18): Guaruoe $F$

(19). Jacuting $F$

Figura 6: Marco estrutural da Bacia do Paraná com as três direções principais: NW, NE e EW de elementos tectônicos lineares (modificado ZALÁN ET AL., 1990)

\subsubsection{HIDROGEOLOGIA}

O Aqüífero Guarani é composto por uma unidade compartimentada de arenitos com valores elevados de condutividade hidráulica, que, em sua maioria, diminui com a profundidade devido a aumento da parte argilosa.

Sua recarga é provavelmente devida a dois mecanismos principais: infiltração direta através de sua zona de afloramento nos estados brasileiros (São Paulo, Goiás, Mato Grosso do Sul, Paraná e Santa Catarina), leste do Paraguai e norte do Uruguai e, indiretamente, através das formações sobrepostas que incluem o sistema de fraturas da Formação Serra Geral.

De fato, a zona aqüífera de basaltos nada mais é do que o prolongamento do aqüífero sedimentar sobrejacente, no caso as 
formações do Grupo Bauru. Este fato tem grande interesse prático porque, onde a capa sedimentar é pouco espessa ou descontínua, não oferecendo condições de captação, forma-se um meio aqüífero de transferência da água para o aqüífero fraturado.

Localmente, onde as espessuras do basalto se tornam pequenas ou as fraturas atinjam o topo desse sistema aqüífero, desde que os níveis potenciométricos do basalto sejam superiores àqueles do Aqüífero Guarani confinado, é possível a infiltração vertical descendente. Inversamente, onde os níveis potenciométricos do Aqüífero Guarani são maiores que os do sistema aqüífero sobrejacente, verificam-se fluxos ascendentes.

\subsubsection{CLIMA}

Dada sua extensão, uma grande variedade de características climáticas pode ser observada nas bacias que abrangem o Aqüífero. O clima da região varia de subtropical, em sua região norte, a temperado e quase semi-árido em sua parte mais ao sul. As temperaturas médias variam de $11^{\circ}$ a $19^{\circ} \mathrm{C}$ e as precipitações anuais variam de 1000 a 1800 mm, respectivamente nas regiões SW e NE (DNM, 1992).

Em território brasileiro, o SAG abrange duas zonas climáticas: Tropical Brasil Central e Temperado. Nos estados de Mato Grosso, Mato Grosso do Sul, Goiás, Minas Gerais e São Paulo predomina o clima Tropical Brasil Central Quente e Úmido a Mesotérmico Brando e Superúmido, com precipitação média anual entre 1200 e $1800 \mathrm{~mm}$. Nos estados do Paraná, Santa Catarina e Rio Grande do Sul predomina o clima Temperado Mesotérmico Superúmido, com precipitação média anual entre 1200 e $2000 \mathrm{~mm}$.

\subsubsection{DISPONIBILIDADE HÍDRICA}

FILI ET AL. (1998) estimam a reserva de água doce do aqüífero como suficiente para abastecer uma população de 5,5 bilhões de 
pessoas, a uma taxa de 100 litros/dia por habitante, por 200 anos. Atualmente, a quase totalidade da água explotada é para abastecimento público, por meio de poços de profundidade variando de algumas centenas a mais de $1000 \mathrm{~m}$.

FILI ET AL. (1998) estimam que as reservas de água armazenada alcancem $37000 \mathrm{~km}^{3}$, sendo $60 \mathrm{~km}^{3} /$ ano ativa e $40 \mathrm{~km}^{3} /$ ano explotável, com uma recarga natural de $160 \mathrm{~km}^{3} / \mathrm{ano}$.

ROCHA (1997) apresenta uma avaliação para a área do aqüífero, encontrando valores de $37000 \mathrm{~km}^{3}$ para a reserva permanente e 160 $\mathrm{km}^{3} /$ ano para reserva ativa.

Os parâmetros utilizados foram pluviometria média de 1500 $\mathrm{mm} / a n o$, espessura média de $250 \mathrm{~m}$, porosidade efetiva de $15 \%$ e coeficiente de armazenamento de $10^{-4}$. A área de recarga do aqüífero foi considerada de $150000 \mathrm{~km}^{2}$ e a área confinada, 1 milhão de $\mathrm{km}^{2}$.

REBOUÇAS (1976 e 1994) apud IPT (2000) calculou as reservas permanentes do SAG em aproximadamente $48000 \mathrm{~km}^{3}$, com recarga anual estimada em $166 \mathrm{~km}^{3} / \mathrm{a}$.

BORGHETTI ET. AL. (2001), considerando uma espessura média de $228 \mathrm{~m}$, uma área de 1194 milhões $\mathrm{km}^{2}$ e porosidade efetiva média de $17 \%$, encontrou um valor de cerca de $4600 \mathrm{~km}^{3}$ para a reserva permanente de água no SAG.

\subsection{7 ÁREAS DE SUPEREXPLORAÇÃO}

Segundo CHANG (2001), existem, pelo menos, duas regiões com fortes evidências de superexplotação do SAG - Ribeirão Preto e Bauru. Nestes dois municípios, em função de grandes rebaixamentos observados no nível de água (estático e dinâmico), que resultaram na desativação de inúmeros poços, foram, recentemente, contratados estudos de avaliação hidrogeológica.

Na região de Ribeirão Preto a situação é mais crítica, pois a extração anual de águas do SAG (95.700.000 $\mathrm{m}^{3}$ ) do município, segundo estudo realizado pela FIPAI (1996), é 13 vezes superior à recarga direta 
da chuva (7.168.127 $\left.\mathrm{m}^{3}\right)$. Para esse município, SINELLI (1984) registrou um rebaixamento da ordem de 15 a 20 metros na região central da área urbana; MONTENEGRO (1990) em sua simulação do aqüífero estimou que, considerando um aumento de $5 \%$ na demanda anual, o cone de depressão em 1995 apresentaria rebaixamentos da ordem de 60 metros e MONTEIRO (2003), aplicando técnicas geoestatísticas, também observou este extenso cone de rebaixamento na região urbana. O município já sente os efeitos de superexplotação, como rebaixamento e queda de vazão, que são principalmente ocasionados pela interferência de poços circunvizinhos, cujas distâncias físicas são cada vez mais reduzidas.

Já o município de Bauru, situado no centro do estado de São Paulo, apresenta um contexto hidrogeológico bem distinto do de Ribeirão Preto. Na região, ocorre uma área expressiva onde o basalto e parte da Formação Botucatu foram erodidos, como conseqüência de um evento tectônico pré-deposição Bauru, que colocou os sedimentos cretácicos sobre o SAG.

Diferentemente da situação de Ribeirão Preto, a recarga do aqüífero no município de Bauru encontra-se distante, exceto na região erodida. O grande rebaixamento de mais de $30 \mathrm{~m}$, observado em menos de 30 anos de exploração, tem sido responsável pela desativação de inúmeros poços e pela queda da vazão de produção. O rápido rebaixamento observado em alguns poços sugere que o SAG, na região de Bauru, em função da perturbação tectônica sofrida, deve estar compartimentado. Esta situação estrutural merece um exame mais preciso, visto que outras regiões do SAG podem apresentar contexto geológico similar.

\subsection{MODELAGEM}

O lançamento de novas tecnologias de informática propiciou um incremento no uso de ferramentas de modelação de aqüíferos, e grande 
parte das pesquisas relacionadas à área de hidrogeologia caminha neste sentido.

Mesmo assim, certas limitações são inerentes ao processo de modelação e precisam ser entendidas e estudadas para se conseguir um uso pleno e uma interpretação correta do modelo.

Algumas destas limitações são de conhecimento geral como, por exemplo: os modelos são baseados em hipóteses que tentam ser o mais fiel possível ao sistema real; que certos parâmetros do modelo são uma aproximação do que ocorre na realidade e dificilmente podem ser determinados com certeza absoluta; as equações que representam os processos podem ser ou não adequadas a um determinado modelo (KRESIC, 2003).

Há dois tipos principais de modelação, a saber: físico (real) e matemático (abstrato), que serão brevemente discutidos a seguir (KRESIC, 2003).

\subsubsection{FÍSICO}

Pode ser entendido como uma miniatura do real, representando fielmente o que se deseja estudar. Neste sentido podemos citar como exemplo os modelos de carros e aviões submetidos aos túneis de vento e as miniaturas de viadutos submetidas a certas cargas.

A modelação física de aqüíferos é empregada geralmente para fins educacionais e demonstrações, já que não é viável se construir um modelo que seja fiel ao real e sujeitá-lo às mesmas condições e processos aos quais o aqüífero natural está submetido.

\subsubsection{MATEMÁTICO}

Utiliza-se de equações matemáticas para representar condições e processos nos aqüíferos. Dependendo do tipo de equação envolvida, pode ser: 
I. Modelos empíricos: provém de dados de experimentos que se ajustaram a determinada função matemática. Apesar de geralmente serem limitados a condições específicas, podem se tornar parte importante de um processo de modelação mais complexo.

II. Modelo probabilístico: baseado nos conceitos de probabilidade e estatística, como distribuição normal, por exemplo. A principal restrição no uso deste tipo de modelo é que ele não é capaz de responder a algumas das perguntas dos usuários.

III. Modelo determinístico: assume que os processos e comportamentos do sistema são regidos por leis da Física. A maioria dos problemas usuais em hidrogeologia é resolvida com modelos determinísticos. Há basicamente dois grupos deste tipo de modelo, analíticos e numéricos, dependendo do tipo de equações matemáticas envolvidas, que serão descritos a seguir:

- Modelos analíticos: basicamente resolvem uma equação de fluxo de águas subterrâneas por vez, e o resultado pode ser aplicado a um ponto específico, ou a uma linha de pontos no aqüífero estudado. O resultado é válido para uma distância radial limitada, e qualquer ponto fora desse limite requer uma nova resolução das mesmas equações. Se o aqüífero for muito heterogêneo, o limite de aplicabilidade dos resultados é muito baixo, e a situação fica deveras complicada.

- Modelos numéricos: descrevem o aqüífero de interesse como um todo, fornecendo resultados para quantos forem os pontos especificados pelo usuário. A área de estudo é dividida em pequenas áreas (elementos, ou células), e uma equação básica de fluxo em águas subterrâneas é resolvida para cada uma delas, geralmente considerando seu balanço hídrico. A solução, neste caso, é dada por uma distribuição de cargas hidráulicas em pontos que representem a célula, geralmente em seu centro ou na 
intersecção entre elas. A equação diferencial de fluxo para cada célula é aproximada por uma equação algébrica, e o sistema é representado então por $\underline{\mathrm{n}}$ equações com $\underline{\mathrm{n}}$ variáveis, sendo $\underline{\mathrm{n}} \mathrm{o}$ número de elementos. Este sistema é solucionado numericamente (daí o nome do método), através de processos iterativos, dentre os quais podemos destacar o método de diferenças finitas e o de elementos finitos.

\subsection{INCERTEZA NOS MODELOS DE ÁGUA SUBTERRÂNEA}

O estudo da hidrologia subterrânea impõe algumas dificuldades adicionais em relação ao de hidrologia de superfície por motivos intrínsecos ao meio. Estes motivos estão todos relacionados às condições naturais que estabelecem especificidades ao entendimento do comportamento do fluxo subterrâneo e sua interação com o meio.

Considerando-se, comumente, grandes extensões como objeto de estudo, a variabilidade espacial do meio e o elevado custo de medições, o estudo sobre mananciais subterrâneos prioriza a hidrologia, em contraposição à hidráulica do sistema. Por essas razões está sujeito, principalmente, a determinações indiretas de seus parâmetros, variáveis e condições de contorno. Assim, a hidrologia subterrânea, ou hidrogeologia, caracteriza-se por englobar um vasto e fértil campo propício à aplicação de variados modelos e simulações. A grande variabilidade natural dos parâmetros hidráulicos, somada às diversas formações que permeiam o fluxo subterrâneo, e às tensões hidrológicas, permite aos pesquisadores numerosas considerações para simplificar a realidade da natureza e, assim, tornar viável seu estudo. Essas simplificações compõem a base do modelo conceitual adotado, e implementado pelo modelo matemático, para simular os mais variados processos e cenários no aqüífero. A implementação desses modelos, entretanto, requer dados que, juntamente com os modelos conceitual e matemático, são cercados de incertezas. Assim, o sucesso atribuído à execução desses modelos tem, como um de seus parâmetros principais, a 
análise e entendimento das incertezas envolvidas em seus dados, simplificações e previsões. Esses fatores concedem à modelagem e simulação computacional de recursos hídricos subterrâneos um caráter iterativo.

Algumas fontes prováveis de incerteza serão citadas a seguir (RABELO, 2005):

- Dados de estudos anteriores;

- Valores de cargas hidráulicas;

- Direções de fluxo;

- Parâmetros hidráulicos;

- Definição do modelo conceitual (simplificações);

- Desenvolvimento do modelo numérico;

- Erros de modelagem (condições de contorno, condições iniciais);

- Erros de discretização geométrica e temporal;

- Erros na solução numérica;

- Incerteza na aplicação de elementos de modelagem;

\subsection{SOFTWARES DE SIMULAÇÃO}

A expansão das atividades de simulação de águas subterrâneas pode ser confirmada pelo grande número de programas destinados a essa atividade em utilização no mercado. Há versões para todos os gostos e necessidades, utilizando-se dos mais variados métodos de modelação e de cálculo. Apesar da grande proliferação destes programas, o Brasil não conta com um programa próprio e de baixo custo para utilização em instituições de ensino, ou seja, depende de versões estrangeiras de alto custo (tanto pela licença de uso do programa, quanto pela aquisição do sistema operacional) e que, em alguns casos, não são totalmente adaptados às especificidades da atividade que se quer exercer.

As vantagens do SPA podem ser concentradas justamente nesses dois pontos, já que é uma versão nacional de um software para Linux; 
seu custo é baixo e suas características são adaptadas às condições brasileiras. Este projeto também incentiva a utilização do sistema operacional Linux em outros laboratórios de pesquisa, diminuindo assim grande parte dos custos da infra-estrutura necessária para equipálo.

Dentre as versões comerciais, podem ser citadas VISUAL MODFLOW, MODPATH, FEFlow, MicrofEM, GMS, MT3DMS, RT3D e FEMWATER como as mais utilizadas. 


\section{METODOLOGIA}

\section{1 ÁREA DE ESTUDO}

\subsubsection{PROJETO PILOTO DE RIBEIRÃO PRETO}

O estudo foi desenvolvido na área selecionada para o Projeto Piloto (Figura 7), sendo que fazem parte da área do Projeto Piloto os municípios de Ribeirão Preto, Serrana, Altinópolis, Cravinhos, Sertãozinho e Jardinópolis, totalizando uma superfície de cerca de $2.700 \mathrm{~km}^{2}$, e uma população de cerca de 720.000 habitantes.

O Projeto Piloto tem seu centro no município de Ribeirão Preto, localizado a cerca de $320 \mathrm{~km}$ da capital, parte nordeste do Estado de São Paulo. Esse município tem uma área de $651 \mathrm{~km}^{2}$ e uma população de 513.260 habitantes.

O município de Ribeirão Preto está localizado na área de afloramento do Aqüífero Guarani, onde há uma maior vulnerabilidade natural à poluição e um intenso uso da água subterrânea para o abastecimento público. Segundo CETESB (1997), o município de Ribeirão Preto é totalmente abastecido por água subterrânea, sendo que parte dos poços explora apenas o Aqüífero Guarani e outra parte dos poços recebe contribuição do Sistema Aqüífero Serra Geral. O fato de Ribeirão Preto ser um pólo de desenvolvimento regional em constante crescimento implica em maior demanda de água e também maiores riscos de contaminação dos recursos hídricos.

Também fazem parte da área do Projeto Piloto os municípios de Serrana, Altinópolis, Cravinhos, Sertãozinho e Jardinópolis, totalizando uma superfície de cerca de $2.700 \mathrm{~km}^{2}$, e uma população de cerca de 720.000 habitantes. 


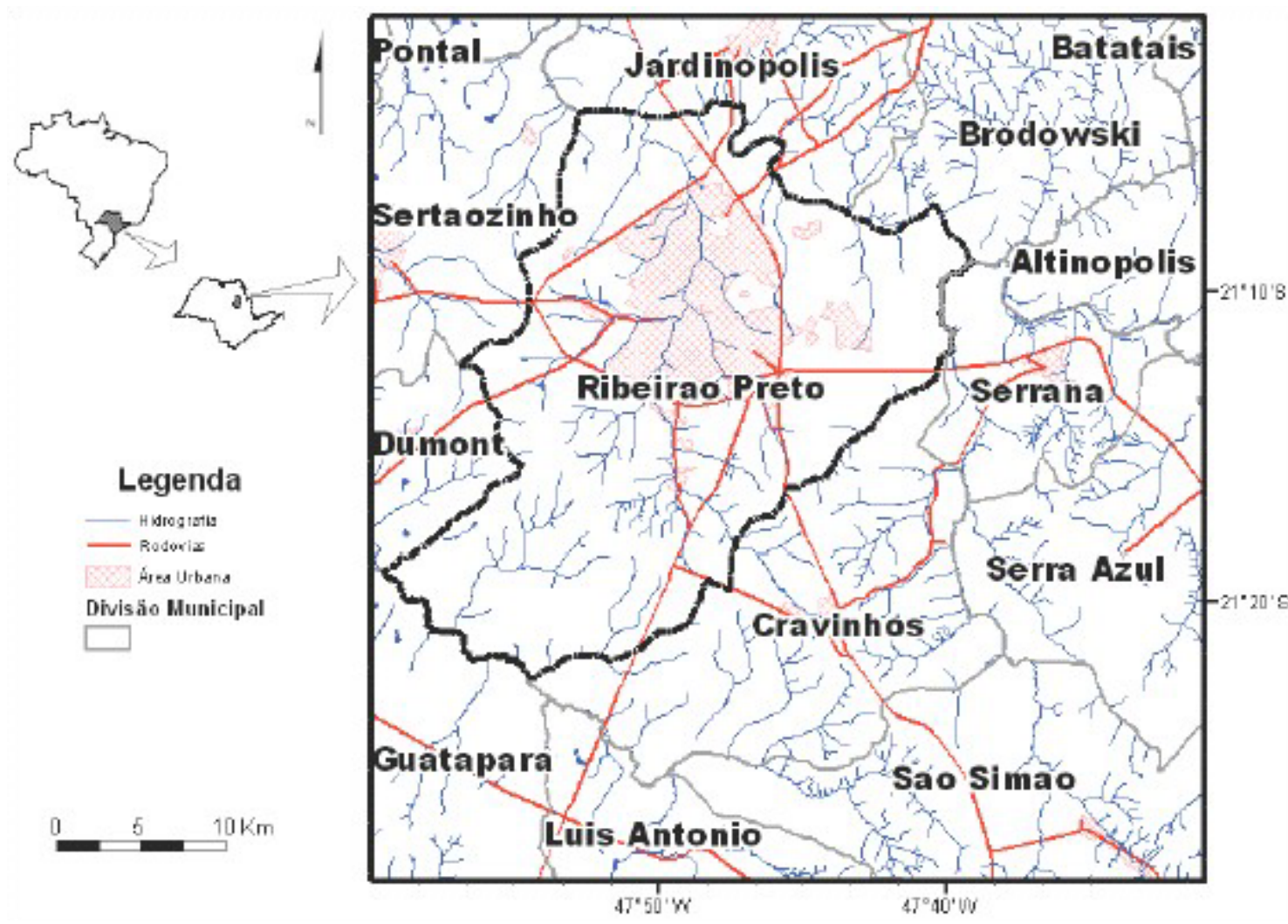

Figura 7: Área do Projeto Piloto de Ribeirão Preto (SMA/São Paulo \& StMUGV/Baviera, 2004)

A área definida para o Projeto Piloto está compreendida entre as coordenadas $21^{\circ}$ e $21^{\circ} 30^{\prime}$ de latitude Sul, e $47^{\circ} 30^{\prime}$ e $48^{\circ}$ de longitude Oeste, pertencente à Bacia Hidrográfica do Pardo e compreendendo as folhas topográficas de Ribeirão Preto, Serrana, Bonfim Paulista e Cravinhos (Figura 8). A área de estudo é classificada atualmente no Estado de São Paulo como pertencente à Unidade de Gerenciamento de Recursos Hídricos 4 (UGRHI 4 - Pardo), sub-bacia do Ribeirão da Prata/Ribeirão Tamanduá (número 2 na Figura 9). Segundo o estudo de IG/CETESB/DAEE (1997), a região é considerada uma das áreas críticas em termos de risco de poluição da água subterrânea em função da alta vulnerabilidade natural dos aqüíferos, em especial o Aqüífero Guarani. 


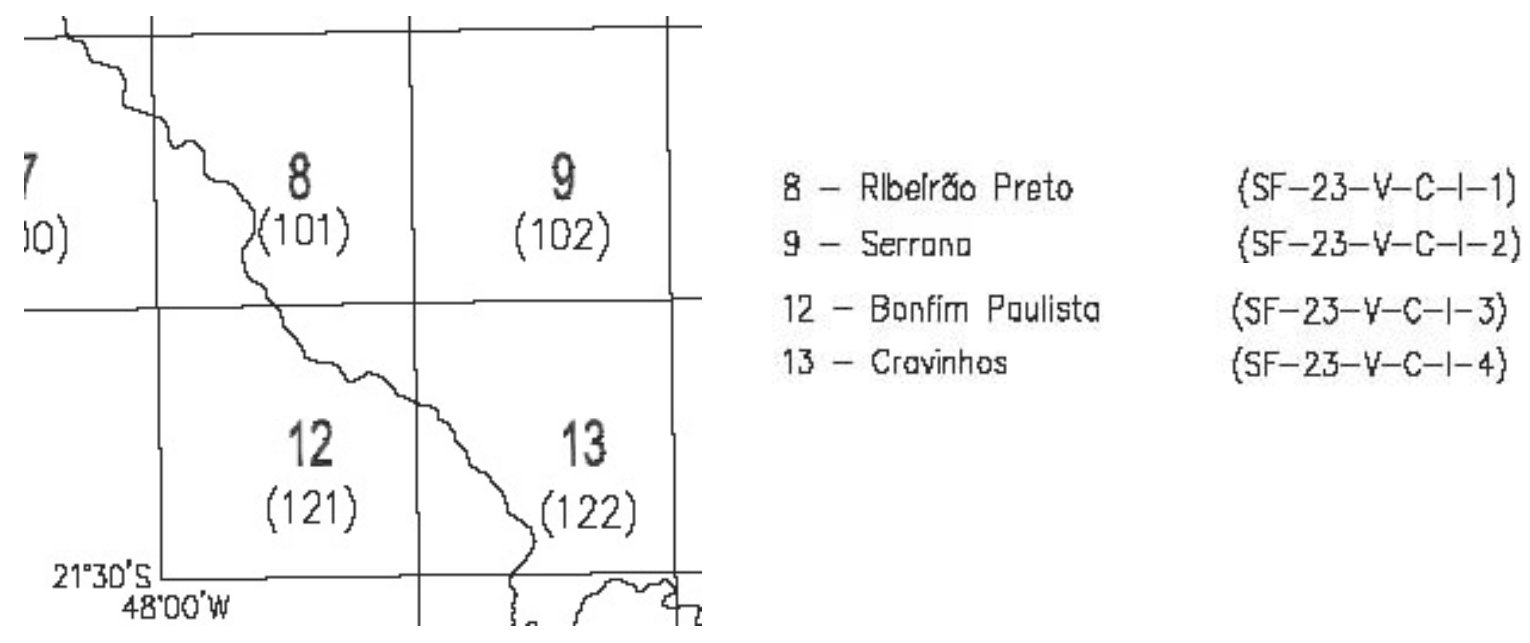

\section{Figura 8: Articulação das folhas 1:50.000 na área da UGRHI - 4}

Dos $137 \mathrm{~km}^{2}$ de afloramentos do Aqüífero Guarani no município de Ribeirão Preto, aproximadamente 40\% encontram-se urbanizados. A parte confinada encontra-se coberta principalmente pelos basaltos da Formação Serra Geral.

Nesta região destacam-se duas unidades aqüíferas:

- Aqüífero Guarani, composto pelos arenitos das Formações Botucatu e Pirambóia.

- Aqüífero Serra Geral, representado pelos basaltos da Formação Serra Geral e de circulação predominantemente característica de meio fraturado.

Considerando-se que as duas unidades aqüíferas encontram-se em conexão hidráulica através de seus contatos, a intensidade e o sentido do fluxo de recarga das águas subterrâneas variam em função do nível de fraturamento dos basaltos da Formação Serra Geral e da relação entre as cargas hidráulicas dos dois aqüíferos. 


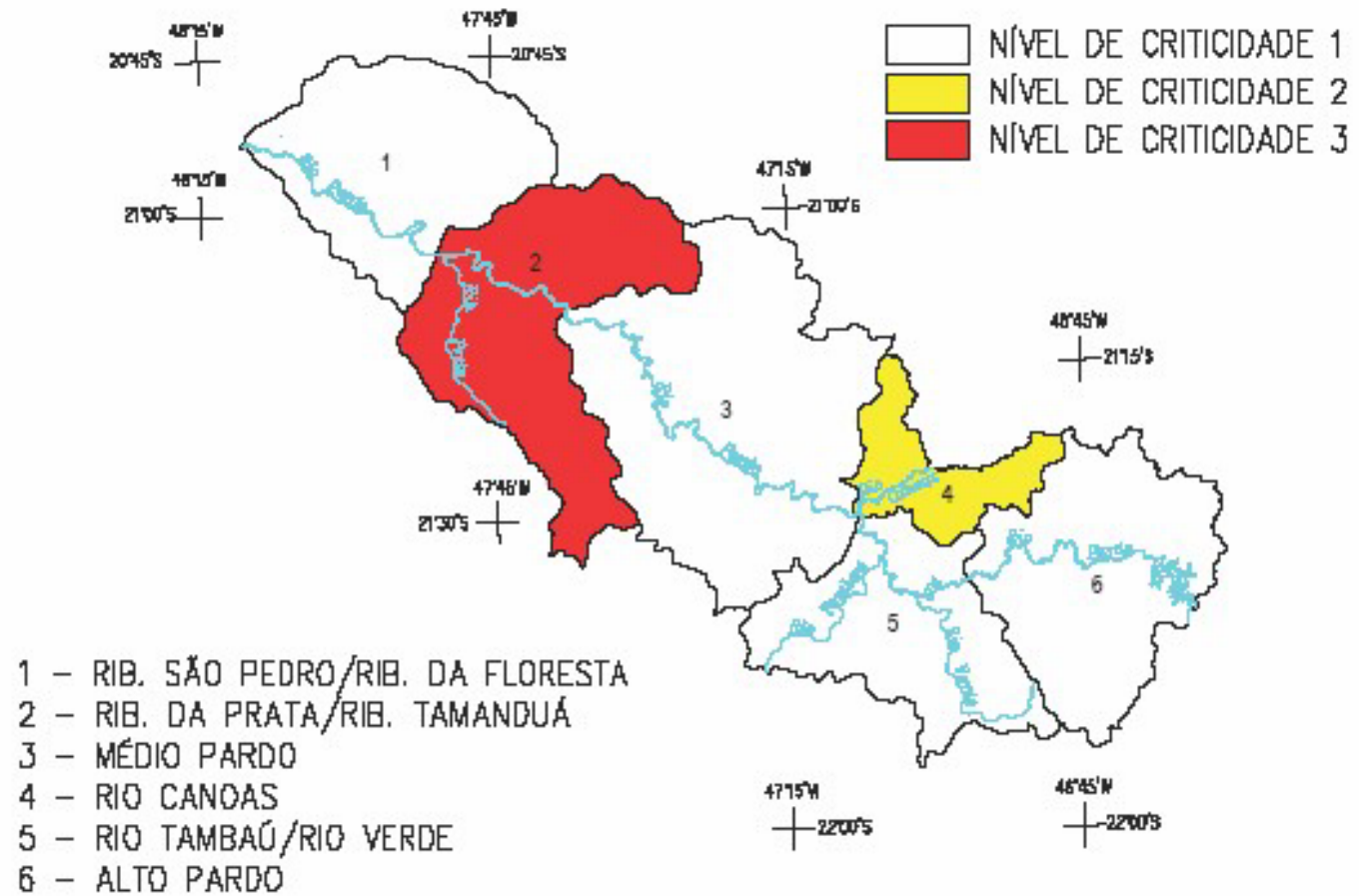

Figura 9: Nível de criticidade das sub-bacias da UGRHI 4 Pardo (IPT, 2000)

\subsubsection{LIMITES DA ÁREA DE ESTUDO}

Inicialmente, pretendia-se desenvolver este estudo em toda a área do Projeto Piloto. No decorrer do projeto, entretanto, verificou-se que a indisponibilidade de dados em regiões mais afastadas de Ribeirão Preto inviabilizava esse objetivo. Além disso, a área do Projeto Piloto de Ribeirão Preto foi definida levando-se em conta aspectos cartográficos, sem avaliação hidrológica.

Por isso, foi estabelecida uma nova área de estudo levando-se em conta os aspectos hidrogeológicos da região, bem como a disponibilidade de dados. A nova área está ilustrada na Figura 10. 


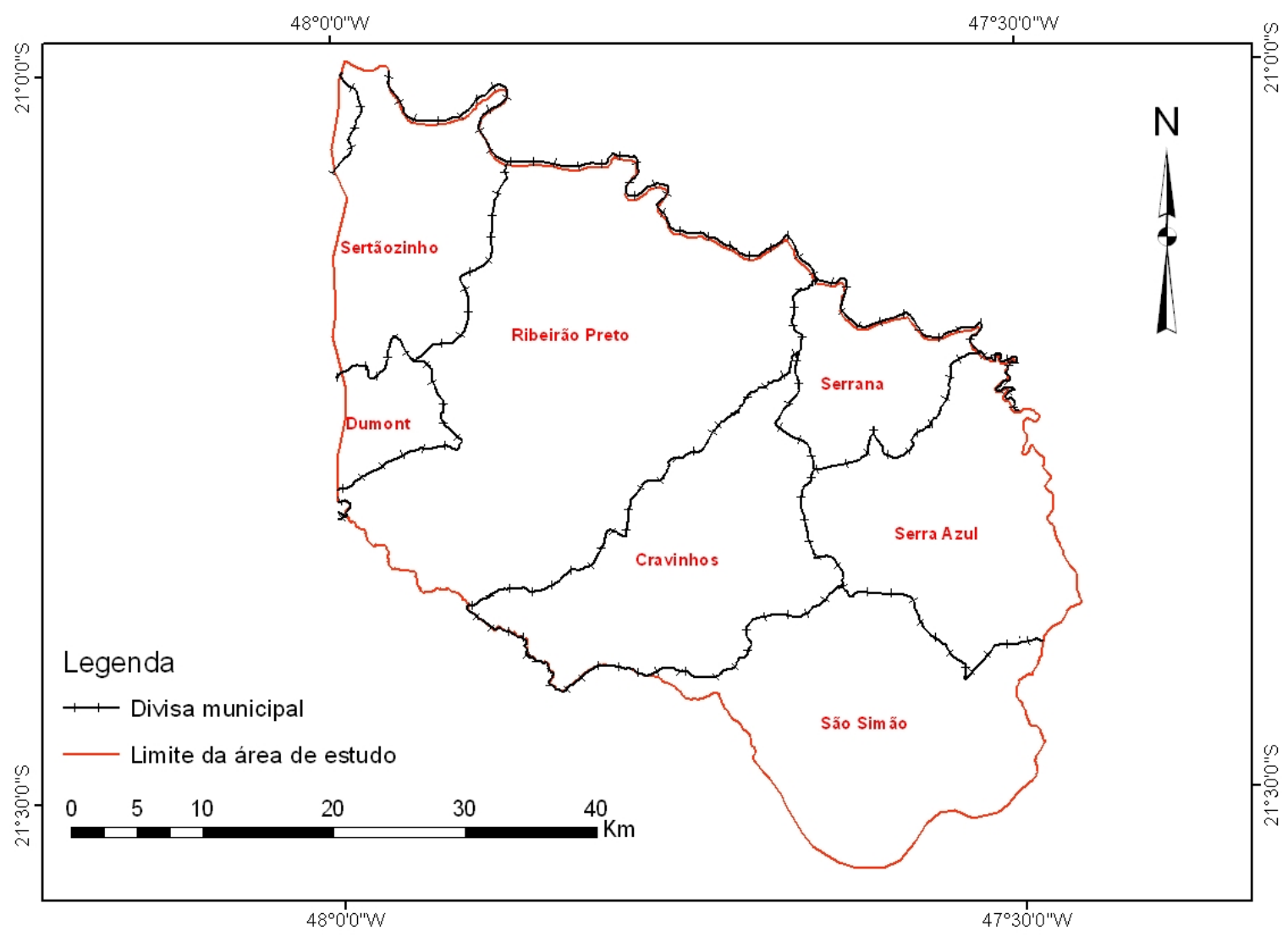

Figura 10: Nova área de estudo

Essa região de estudo abrange uma área de $2.000 \mathrm{~km}^{2}$, com $245 \mathrm{~km}$ de perímetro, e foi delimitada levando-se em conta os recursos hídricos da região. Os principais limites são: Rio Pardo ao Norte; Ribeirão da Onça e Ribeirão do Pântano ao Sul; Rio Pardo e Ribeirão da Prata a Leste; Córrego do Tamboril e divisor de águas superficiais a Oeste.

$\mathrm{Na}$ nova área de estudo estão contidos parcial ou integralmente os municípios de Cravinhos, Dumont, Ribeirão Preto, São Simão, Serra Azul, Serrana e Sertãozinho.

\subsubsection{GEOLOGIA}

A área de estudo localiza-se na região N-NE da Bacia Sedimentar do Paraná, caracterizada como uma bacia 
intracratônica. Nela, afloram três formações geológicas do grupo São Bento e depósitos cenozóicos.

A parte leste da área urbanizada de Ribeirão Preto está localizada na área de afloramento do Aqüífero Guarani. O aqüífero consiste de bancos de arenito de granulação fina a média da Formação Pirambóia (Triássico - Jurássico) e da Formação Botucatu (Jurássico - Cretáceo Inferior), de acordo com o mapa geológico de SINELLI (1970). Os arenitos eólicos e flúviolacustres de ambas as formações mostram uma espessura total de até 200 a 300 metros e são localmente cobertos por sedimentos arenosos a siltosos de idade Cenozóica com uma espessura de até 30 metros. Os arenitos são parcialmente interdigitados com intrusões de diabásio do Mesozóico. Na parte oeste da área urbanizada, o arenito Botucatu é coberto pelos basaltos da Formação Serra Geral (Jurássico - Cretáceo Inferior), alcançando uma espessura de mais de 100 metros.

Os arenitos da Formação Botucatu, que representam a parte superior do Aqüífero Guarani, apresentam um conteúdo de silte e argila menor que os arenitos da Formação Pirambóia.

A área de afloramento das Formações Botucatu e Pirambóia na região de estudo é de cerca de $540 \mathrm{~km}^{2}$, representando, aproximadamente, $27,5 \%$ de toda a área e está localizada exclusivamente a Leste.

Na Figura 11 é mostrada a geologia superficial da área de estudo. Esses dados foram obtidos de arquivos digitais resultantes do estudo feito por IPT (2000).

Na Figura 12 é mostrada a geologia da região de Ribeirão Preto com o corte Ribeirão Preto - Sertãozinho. 


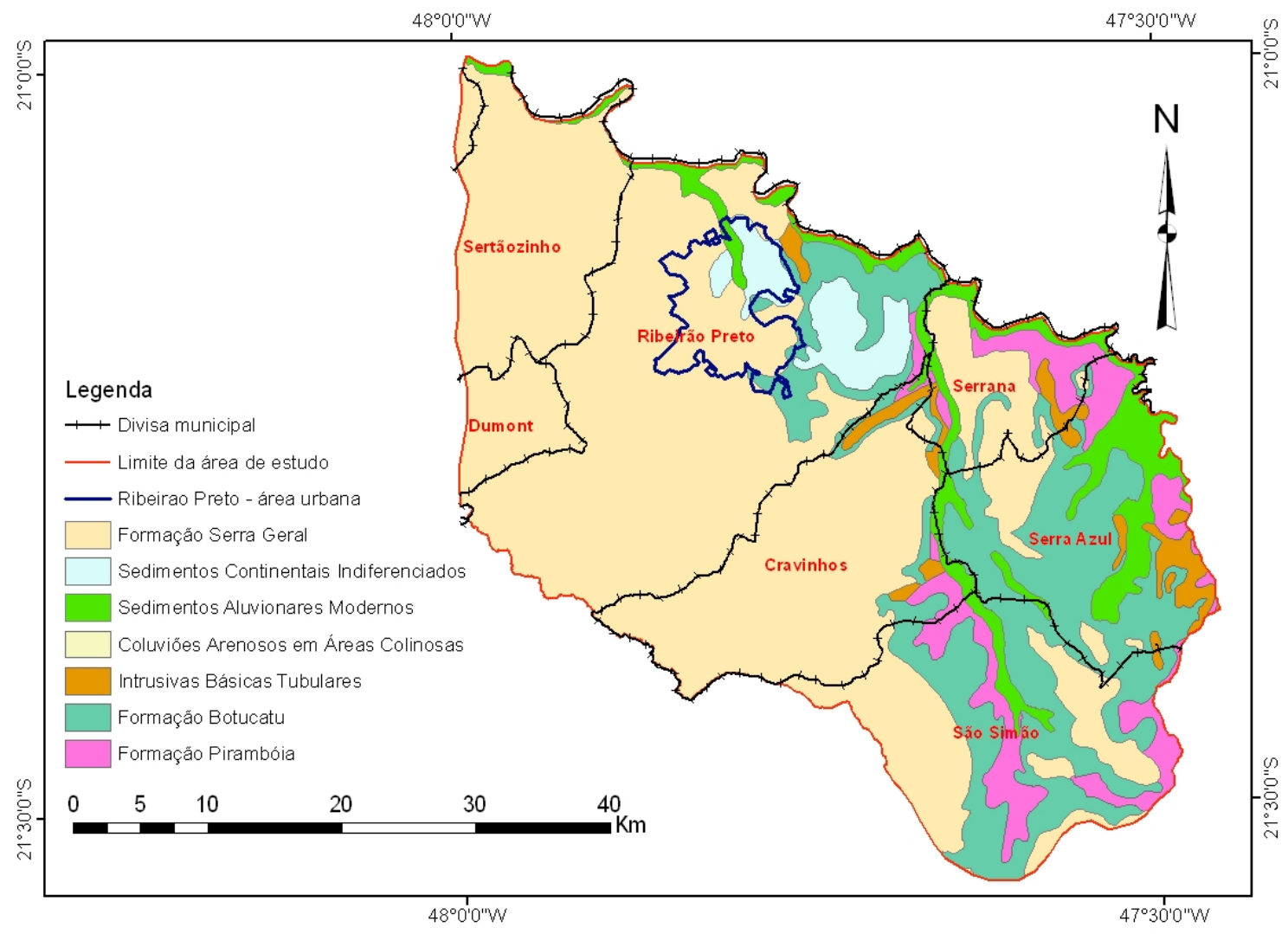

Figura 11: Geologia de superfície da área de estudo (IPT, 2000)
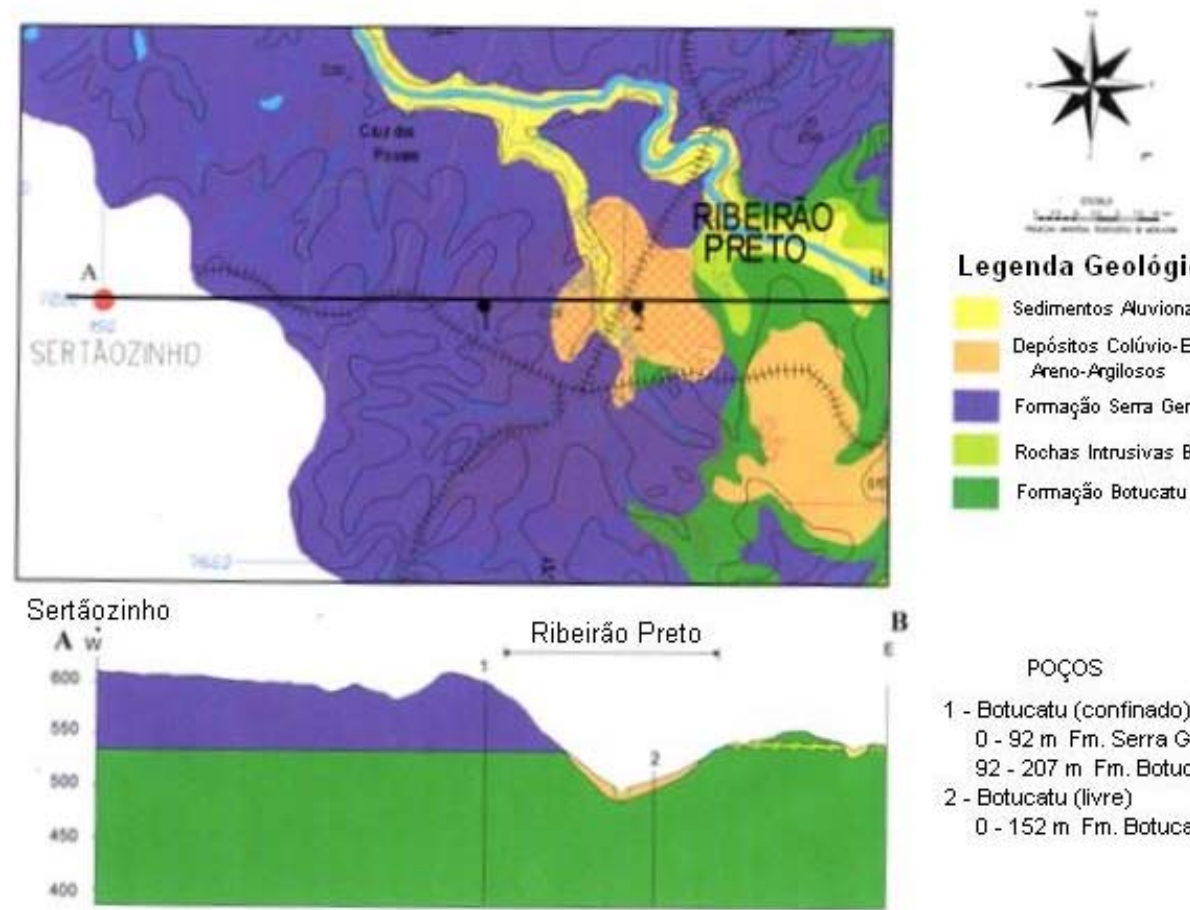

\section{Legenda Geológica}

Sedimentos Auvionares

Depósitos Colúvio-Euviais

Areno-Argilosos

Formação Serra Geral

Rochas Intrusivas Básicas

Formação Botucatu

\section{Poços}

1 - Botucatu (confinado)

0 - $92 \mathrm{~m}$ Fm. Serra Geral

92 - $207 \mathrm{~m}$ Fm. Botucatu

2 - Botucatu (livre)

$0-152 \mathrm{~m} F \mathrm{~m}$. Botucatu

Figura 12: Geologia e corte da região de estudo 
As três formações principais presentes na área de estudo são detalhadas a seguir, da base para o topo:

\section{- Formação Pirambóia}

Esta formação aflora no extremo Leste da área do município de Ribeirão Preto. É constituída por arenito avermelhado, com granulometria muito fina a média, e grãos hialinos (FIPAI, 1996). Às vezes apresenta-se síltico-argiloso na base, e grosseiro a conglomerático no topo da formação. Há predominância da estratificação plano-paralela, caracterizada pela alternância de lâminas síltico-argilosas e arenosas. As estratificações cruzadas, segundo FIPAI (1996), são do tipo tangencial de médio a grande porte; já CAETANO-CHANG e WU (1992) classificam-nas como de pequeno a grande porte, tabulares ou acanaladas, tangenciais na base, e plano-paralelas, intercalando lamitos e argilitos arenosos que representariam uma alternância cíclica de fáceis de canal fluvial e de transbordamento.

Estratigraficamente, a formação repousa sobre os depósitos da Formação Corumbataí por contato de discordância erosiva, e no topo há contato com os arenitos da Formação Botucatu por mudança litológica gradual, ou, localmente, por discordância erosiva (FIPAI, 1996). Sua idade é estimada como Mesozóica (Jurássico Superior - Triássico Superior).

\section{- Formação Botucatu}

A Formação Botucatu é caracterizada por arenitos avermelhados, finos a médios, que contém grãos foscos com boa seleção de alta esfericidade. Arenitos médios a conglomeráticos ocorrem sob a forma de lentes na porção inferior dos depósitos. De 
forma restrita, também, podem ocorrer leitos de argilito e siltito arenoso, com estratificação plano paralela (FIPAI, 1996).

Do ponto de vista estratigráfico, essa formação está sobre os depósitos da Formação Pirambóia por um contato concordante gradual ou, localmente, brusco. No topo, o contato com os derrames basálticos da Formação Serra Geral se dá por discordância ou interdigitação (FIPAI, 1996). A idade mais provável é do Jurássico Médio - Superior a Cretáceo Inferior.

Os arenitos da Formação Botucatu apresentam um conteúdo de silte e argila menor que os arenitos da Formação Pirambóia e compõe o principal sistema aqüífero do Aqüífero Guarani (ROCHA, 1997).

- Formação Serra Geral

Segundo FIPAI (1996), a Formação Serra Geral é representada por derrames de basalto toleíticos, às vezes com arenitos intertrapianos semelhantes aos da Formação Botucatu; e intrusivas básicas associadas tais como diques e sills. Os basaltos apresentam cor cinza escuro a negro, textura afanítica e estrutura maciça. A composição mineralógica é constituída essencialmente por labradorita zonada e clinopiroxênios. Minerais acessórios são apresentados por titânio - magnetita, apatita, quartzo e, raramente, olivina (IPT, 1981). Material vítreo ocorre nas bordas dos derrames. Os diques e sills não apresentam espessuras definidas. Está em contato com os arenitos da Formação Botucatu por interdigitação ou discordância.

A idade mais aceita para o vulcanismo é entre Jurássico Superior e Cretáceo Inferior.

A existência de arenitos eólicos intertrapianos indica um ambiente ainda desértico, quando do extravasamento da lava através de geoclaves e fraturas menores. 


\subsubsection{HIDROGEOLOGIA}

Segundo FIPAI (1996), as águas subterrâneas ocorrem em três níveis principais, associadas a três tipos de ambientes, a saber:

- Aqüífero Aluviões - Coluviões:

Este tipo de aqüífero ocorre nos sedimentos existentes ao longo dos cursos d’água dos córregos e do Rio Pardo e, como aqüífero suspenso, nos coluviões. O aqüífero se caracteriza por ser um meio poroso não confinado e estar em conexão hidráulica com a drenagem local. A litologia é composta por sedimentos não consolidados de areia fina em forma de lentes alternadas com areias siltosas a argilosas e siltes arenosos. Ensaios de permeabilidade indicam valores de $6,0 \times 10^{-7}$ a $1,9 \times 10^{-4} \mathrm{~m} / \mathrm{s}$ para condutividade horizontal e $1,4 \times 10^{-7}$ a $1,2 \times 10^{-5} \mathrm{~m} / \mathrm{s}$ para a condutividade vertical. A localização do Aqüífero Aluvião é sobrejacente ao Aqüífero Guarani na zona Leste, estando em comunicação hidráulica com este aqüífero maior.

- Aqüífero em Magmatitos Fraturados (Serra Geral):

As fraturas da rocha magmática básica possuem a capacidade de reservar e transmitir águas subterrâneas. Fraturas com pequenas aberturas são capazes de ter uma condutividade hidráulica da ordem de $10^{-5} \mathrm{~m} / \mathrm{s}$.

De acordo com MONTENEGRO ET AL. (1988), a espessura média desta unidade aqüífera, na região de Ribeirão Preto, é 65 m.

As características da rocha básica quanto à sua estrutura, nível e padrão de fraturamentos fornecem uma grande variedade de 
números relacionados a parâmetros hidráulicos. SINELLI e WERNICK (1970) definiram a direção 50N-60E e o sentido NE-SW para o escoamento subterrâneo nas fraturas. A ocorrência deste aqüífero está restrita às zonas Oeste, Central e Sul da área de estudo.

- Aqüífero Guarani (Botucatu/Pirambóia):

As águas subterrâneas reservadas nos poros do Aqüífero Guarani são de boa qualidade, e são utilizadas no abastecimento de toda a cidade de Ribeirão Preto e, complementarmente, no dos demais municípios. Este aqüífero é constituído pelo pacote saturado de arenitos das Formações Botucatu e Pirambóia. Do topo para base do aqüífero, nota-se a sucessão de arenitos finos a médios com grãos foscos e arredondados, selecionados a moderadamente selecionados, por arenitos siltosos a argilosos com grãos hialinos, sub angulosos e mal selecionados.

Na distribuição espacial distinguem-se as áreas da zona Leste e zona Nordeste da região com afloramentos das Formações Botucatu-Pirambóia, e as áreas da zona central, Sul, Oeste, Norte e Noroeste com afloramentos de magmatitos básicos (basaltos). As camadas do aqüífero mergulham no sentido EW (eixo do Rio Paraná).

Na Figura 13 é apresentado o modelo hidrogeológico para a região de estudo, com o esquema de fluxo subterrâneo entre os diferentes aqüíferos. 


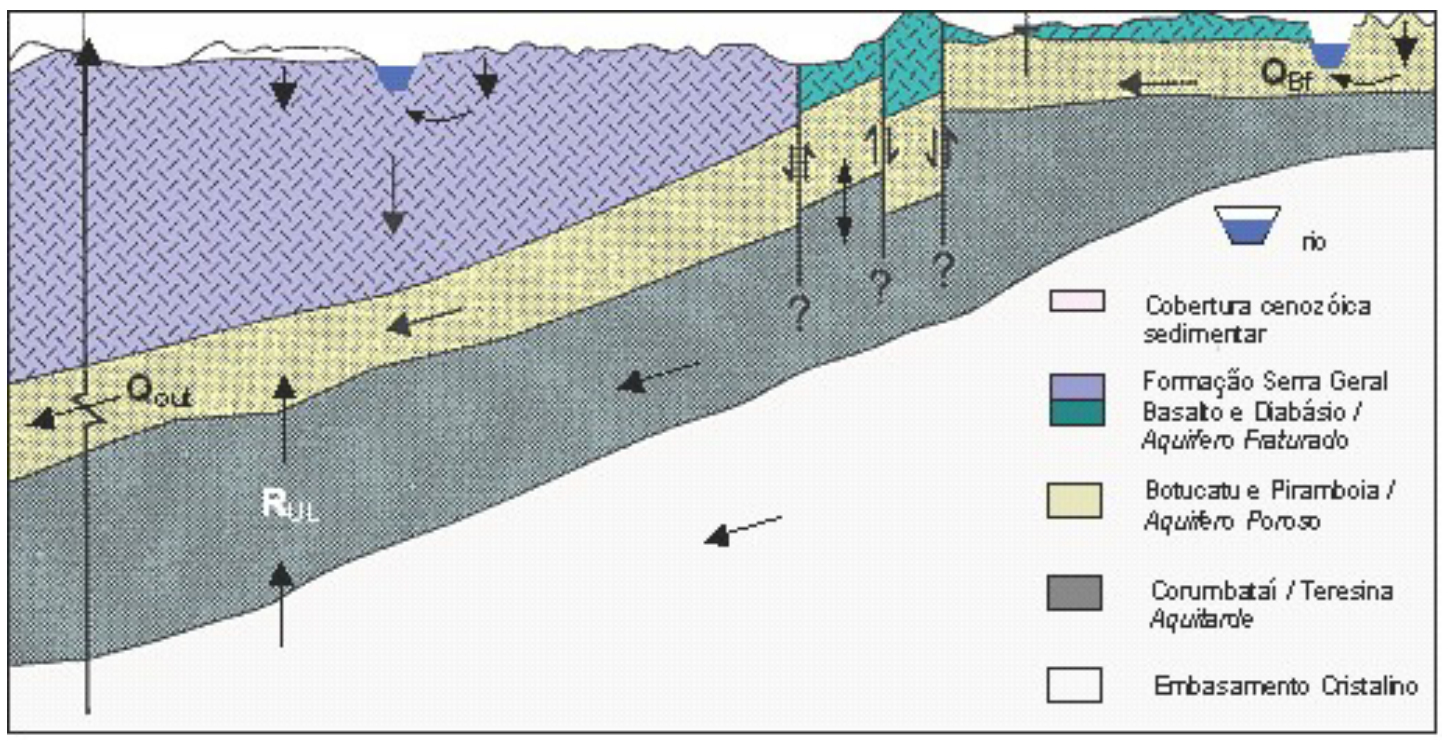

Figura 13: Modelo hidrogeológico (KULLS, 2003 apud SMA/São Paulo \& StMUGV/Baviera, 2004 )

Falhas, juntas e fraturas dos arenitos e basaltos estão dispostas principalmente nas direções nordeste e noroeste. Por isso, os caminhos preferenciais de fluxo das águas subterrâneas são presumidos nestas direções. Fraturas horizontais também parecem ter um papel importante no fluxo de água. Há um divisor de águas subterrâneas proeminente na parte leste da área urbanizada e uma depressão na parte oeste, causada pela exploração durante algumas décadas (a recente diminuição do nível estático foi estimada em $1,2 \mathrm{~m} / \mathrm{a})$. Este divisor e esta depressão são feições dominantes, influenciando principalmente o padrão de fluxo do aqüífero (SMA/São Paulo \& StMUGV/Baviera, 2004).

Na área de afloramento a leste, o Aqüífero Guarani é livre, enquanto que na área a oeste ele é, na maior parte, semiconfinado ou confinado devido à sobreposição dos basaltos da Formação Serra Geral. Nos vales do Córrego Ribeirão Preto e em outros rios, a espessura da cobertura das águas subterrâneas do SAG é geralmente menor que 50 metros. Nas áreas adjacentes, ela atinge mais de 100 metros (SMA/São Paulo \& StMUGV/Baviera, 2004). 


\subsubsection{CAMADAS CONFINANTES E SEMICONFINANTES}

O aquitardo da base do Aqüífero Guarani é constituído por diferentes litótipos, correspondentes à base da Formação Pirambóia e à Formação Corumbataí (de idade Paleozóica). São representadas, do topo para base, por arenitos argilosos, siltitos arenosos, argilitos folhelhos, bancos de calcário e eventuais intercalações de lentes arenosas de diferentes níveis (PIUCI E DINIZ, 1985 apud RABELO, 2005). Esse aquitardo funciona hidraulicamente como camada semiconfinante da base do Aqüífero Guarani, e, dependendo das cargas hidráulicas entre este e o Guarani, pode haver entrada ou saída de água por drenança. Pela inexistência de valores calculados de condutividade vertical, e pela característica das rochas, que indicam ser essa condutividade muito baixa, esta camada é comumente considerada como limite impermeável da base do Aqüífero Guarani (DAEE, 1974).

Pelas características gerais dos derrames basálticos, que incluem intercalações de arenitos, diaclasamentos verticais e horizontais, e por grandes linhas de descontinuidade transversais, o confinamento do topo do Aqüífero Guarani é caracterizado por uma camada semiconfinante (RABELO, 2005). Esta camada é definida pelo contorno estrutural da base da Formação Serra Geral, que se comporta como uma unidade aqüífera constituída por camadas com porosidade predominantemente secundária (por fraturamento), apresentando-se litologicamente homogênea e hidraulicamente anisotrópica, com circulação em meio fraturado; é um aqüífero em condições livres, funcionando como reservatório.

FERNANDES ET AL. (2006), estudando o modelo de circulação de água no Aqüífero Serra Geral, identificaram 4 derrames de basalto na região de Ribeirão Preto e Bonfim Paulista. 
A análise da estratigrafia e estruturas tectônicas desses derrames, em conjunto com a análise de dados de poços da região, tornou possível aos pesquisadores inferir que as fraturas horizontais e pelo menos parte das fraturas verticais, de origem tectônica, estão interconectadas e que o nível potenciométrico do Sistema Aqüífero Guarani ( $S A G$ ) está acima do contato com o Aqüífero Serra Geral (ASG), mas abaixo do nível d’água dos basaltos, pelo menos nas regiões próximas aos afloramentos do SAG. Isto indicaria um fluxo com componente vertical e descendente para as águas do SAG nessas regiões (Figura 14).

Esses autores, quanto ao contato entre os basaltos da Formação Serra Geral e os arenitos da Formação Botucatu, adotam a proposta de MALDANER ET AL. (2005) apud FERNANDES (2006) de que ele é contínuo e com ondulações cujo comprimento de onda é de cerca de $2 \mathrm{~km}$ e a amplitude varia de 50 a $100 \mathrm{~m}$ (Figura 14). Segundo os autores, essas ondulações devem corresponder ao paleorelevo de dunas da época da deposição dos arenitos da Formação Botucatu. Essa teoria vai contra o adotado usualmente, de que essas variações relativamente abruptas das cotas do contato entre as duas formações seriam devido a deslocamentos verticais e tectônicos. 


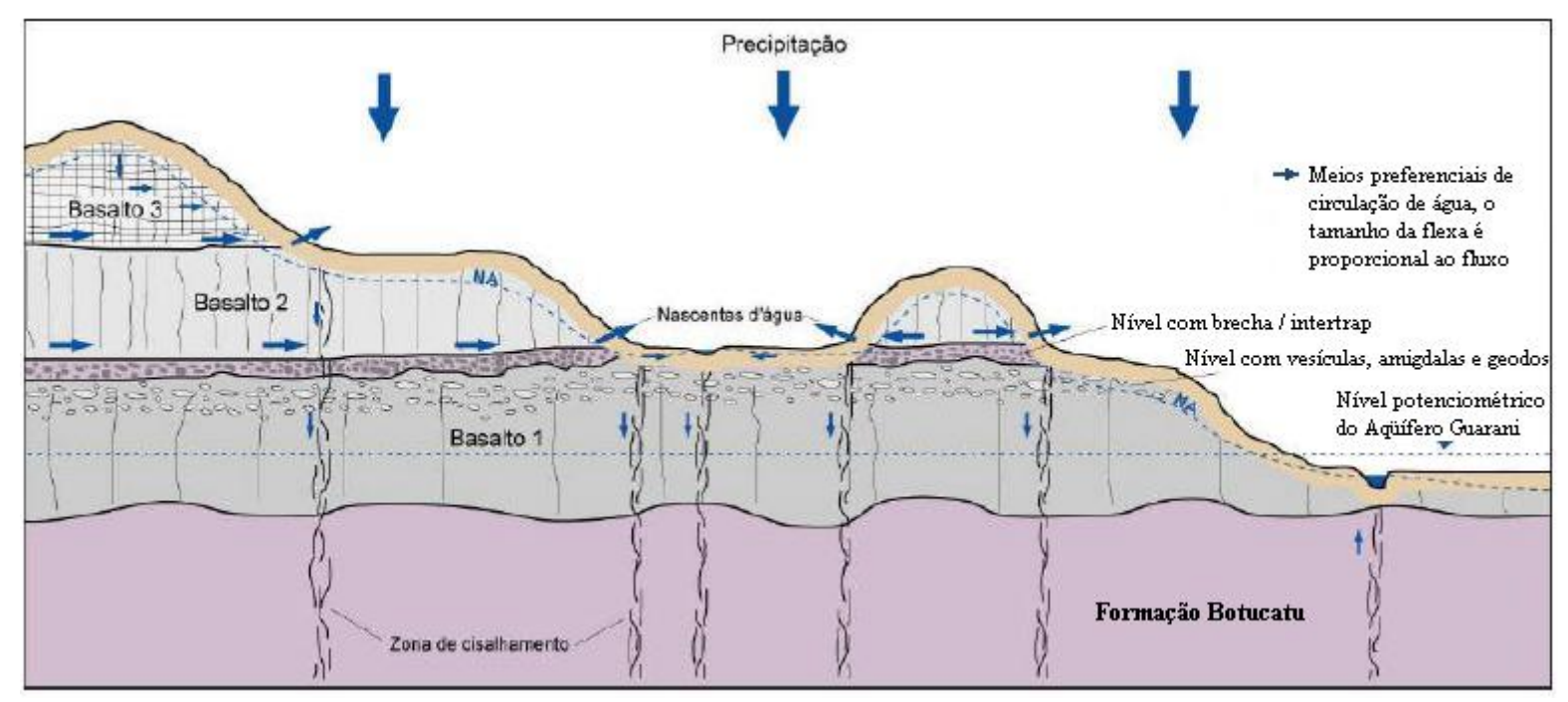

Figura 14: Esquema dos principais meios de circulação nos derrames basálticos de Ribeirão Preto (FERNANDES ET AL., 2006 )

\subsubsection{PARÂMETROS HIDROGEOLÓGICOS}

Uma das principais finalidades no estudo de um aqüífero é a determinação dos valores de seus parâmetros hidrodinâmicos, bem como os dos aqüíferos circunvizinhos. Os principais parâmetros de um aqüífero são a condutividade hidráulica (K), a transmissividade (T) e o coeficiente de armazenamento (S) e a espessura (E).

O IPT (2000), estudando a UGRHI 4 - PARDO, chegou aos valores apresentados na Tabela 1 para as formações geológicas nela existentes. 
Tabela 1: Resumo das características geométricas e hidráulicas dos aqüíferos presentes na UGRHI 4 (adaptadode IPT, 2000)

\begin{tabular}{|c|c|c|c|c|}
\hline \multirow{2}{*}{ AQÜífERO } & \multicolumn{2}{|c|}{ GEOMETRIA } & \multicolumn{2}{c|}{ HIDROGEOLOGIA } \\
\cline { 2 - 5 } & $\begin{array}{c}\text { Área aflorante } \\
\text { na UGRHI (\%) }\end{array}$ & $\begin{array}{c}\text { Espessura } \\
\text { média (m) }\end{array}$ & $\begin{array}{c}\text { Transmissividade } \\
\text { (m } \mathbf{2} / \mathbf{d})\end{array}$ & $\begin{array}{c}\text { Porosidade } \\
\text { efetiva (\%) }\end{array}$ \\
\hline Cenozóico & 6 & 30 & - & - \\
\hline Serra Geral & 24 & 150 & 1 a 95 & 1 a 5 \\
\hline $\begin{array}{c}\text { Guarani } \\
\text { livre }\end{array}$ & 23 & 250 & 40 a 500 & 25 \\
\hline $\begin{array}{c}\text { Guarani } \\
\text { confinado }\end{array}$ & 0 & 350 a 400 & 150 a 400 & 16 a 24 \\
\hline Passa Dois & 4 & 120 & $<10$ & - \\
\hline Tubarão & 11 & 1000 & 0,3 a 200 & 5 \\
\hline Cristalino & 32 & 200 & 0,1 a 200 & - \\
\hline
\end{tabular}

Devido às suas dimensões, o SAG apresenta uma grande variação nos valores de seus parâmetros hidrodinâmicos. Na Tabela 2 é representado um resumo dos valores encontrados ou adotados por alguns autores que estudaram as características hidrodinâmicas do SAG. 
Tabela 2: Valores de parâmetros hidrodinâmicos do SAG

\begin{tabular}{|c|c|c|c|c|}
\hline \multirow{3}{*}{ AUTOR/FONTE } & \multicolumn{4}{|c|}{ CARACTERÍSTICAS HIDRODINÂNICAS DO SAG } \\
\hline & \multirow[b]{2}{*}{$\begin{array}{l}\text { Transmissividade } \\
\left(\mathrm{m}^{2} / \mathrm{d}\right)\end{array}$} & \multirow[b]{2}{*}{$\begin{array}{l}\text { Condutividade } \\
\qquad(\mathrm{m} / \mathrm{s})\end{array}$} & \multicolumn{2}{|c|}{ Coeficiente de armazenamento } \\
\hline & & & $\begin{array}{c}\text { Livre } \\
\text { (porosidade } \\
\text { efetiva) }\end{array}$ & Confinado \\
\hline DAEE (1974) & $200-540$ & $4,0.10^{-5}$ & 0,25 & $1,0.10^{-5}-1,0.10^{-3}$ \\
\hline $\begin{array}{c}\text { MONTENEGRO } \\
(1990)\end{array}$ & $\begin{array}{l}280 \text { - } 1000 \text { (Sinelli } \\
\text { et. al., 1980) }\end{array}$ & $\begin{array}{c}4,0.10^{-5} \text { (DAEE, } \\
1974)\end{array}$ & 0,1 & $1,0.10^{-6}-1,0.10^{-4}$ \\
\hline IPT (2000) & $40-500$ & $\begin{array}{c}3,5.10^{-6}-4,5.10^{-5} \\
\text { (DAEE, 1984) }\end{array}$ & 0,25 & $\begin{array}{c}1,0.10^{-5}-1,0.10^{-3} \\
\text { (DAEE, 1974) }\end{array}$ \\
\hline GUIDO (2004) ${ }^{(1)}$ & $170-220$ & $1,0.10^{-5}-4,0.10^{-5}$ & 0,1 a 0,2 & $1,0.10^{-4}-5,0.10^{-4}$ \\
\hline $\begin{array}{c}\text { BORGHETTI ET } \\
\text { AL. (2004) }\end{array}$ & $150-800$ & $3,5.10^{-5}$ & 0,15 a 0,20 & $1,0.10^{-6}-1,0.10^{-4}$ \\
\hline $\begin{array}{l}\text { DAEE/IG/IPT/ } \\
\text { CPRM (2005) }\end{array}$ & 260 & $3,5.10^{-5}$ & 0,17 & $\begin{array}{c}1,0.10^{-3} \\
\text { (DAEE, 1974) }\end{array}$ \\
\hline RABELO (2005) ${ }^{(2)}$ & $9-1200$ & $2,8.10^{-5}$ & $\begin{array}{c}0,15 \text { a } 0,25 \\
\text { (DAEE, 1974) }\end{array}$ & $\begin{array}{c}1,0.10^{-5}-1,0.10^{-3} \\
\text { (DAEE, 1974) }\end{array}$ \\
\hline
\end{tabular}

\footnotetext{
${ }^{(1)}$ Estudando o município de Ribeirão Preto

${ }^{(2)}$ Estudando as bacias dos Rios Jacaré-Pepira e Jacaré-Guaçu
}

\subsubsection{FLUXO SUBTERRÂNEO}

Segundo o DAEE (1974), apesar da diferenciação litológica entre a Formação Botucatu e a Formação Pirambóia, em termos hidrodinâmicos estas unidades geológicas estão interligadas dentro de um mesmo sistema de fluxo de água subterrânea, não sendo possível, com os dados atuais, realizar uma diferenciação.

Nas áreas de afloramento do Aqüífero Guarani, os fluxos subterrâneos têm a tendência de escoar para as drenagens, comportamento característico de aqüíferos livres na região. Na porção confinada, de forma regional, o fluxo subterrâneo segue para o oeste do Estado (SILVA, 1983). De acordo com DAEE 
(1974), a inclinação natural da superfície potenciométrica na região nordeste do Estado de São Paulo é baixa, variando de 0,5\% a 3\%. A variação sazonal do nível estático do SAG observada por DAEE (1974) em alguns poços, inclusive em Ribeirão Preto mostrou variações de 1,8 a $3 \mathrm{~m}$.

Entretanto, em regiões de intensa exploração do Aqüífero Guarani, como na área urbana de Ribeirão Preto, observa-se um rebaixamento do nível potenciométrico, formando um extenso cone de rebaixamento devido ao bombeamento intensivo e à concentração de poços. Em algumas porções, o nível d’água chega a ultrapassar a base do Aqüífero Serra Geral, que atua como camada confinante (ou semiconfinante).

\subsubsection{SITUAÇÃO EM RIBEIRÃO PRETO}

Atualmente, de acordo com os registros existentes, 95 poços são destinados ao abastecimento público do município de Ribeirão Preto. O consumo per capita em 1970 era de 428 l/hab/dia segundo DAEE (1974), subindo para 547 l/hab/dia em 1996, de acordo com FIPAI (1996). A maior parte da população do município encontrase na área urbana, sendo abastecida pela rede pública. Se considerarmos a mesma taxa de consumo per capita adotada por FIPAI (1996) e a população existente em 2000, o volume explorado de água para abastecimento público fica em torno de 275.000 $\mathrm{m}^{3} / \mathrm{dia}$, ou seja, 8,25 milhões de $\mathrm{m}^{3} / \mathrm{mês}$. Entretanto, considera-se esta taxa de consumo elevada, sendo mais viável a projeção de um valor de até 350 l/hab/dia, incluindo perdas na rede, o que totalizaria um volume explotado de cerca de $176.000 \mathrm{~m}^{3} / \mathrm{dia}$.

Devido a problemas construtivos e, também, pelo rebaixamento do nível d’água, muitos poços na região encontram-se desativados e, quando mal conservados, podem ser uma ameaça à 
proteção da qualidade da água subterrânea, uma vez que são conexões diretas com o aqüífero.

A profundidade dos poços também vem crescendo ao longo dos anos. Acredita-se que este fato deve-se ao melhoramento das tecnologias de perfuração, necessidade de maiores transmissividades para aumento da produtividade dos poços e pelo rebaixamento do nível d’água, exigindo a perfuração de poços cada vez mais profundos.

Na Figura 15 é mostrada a evolução do rebaixamento do nível piezométrico do SAG no município de Ribeirão Preto (a evolução da área urbana está representada em vermelho), do ano de 1960 até 2002. As imagens foram geradas pelas simulações de GUIDO (2004) para a área do município de Ribeirão Preto. 

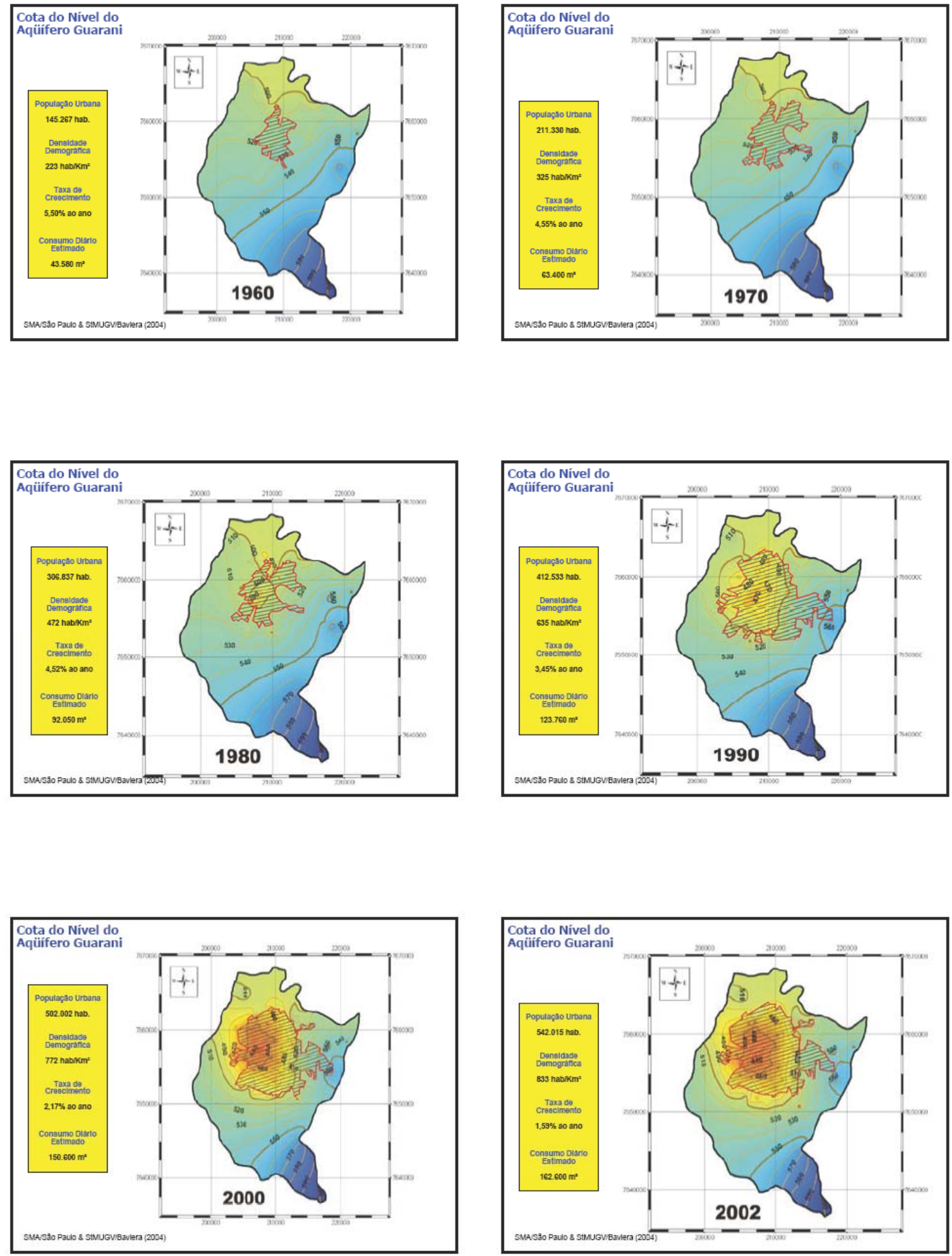

Figura 15: Evolução do nível piezométrico no município de Ribeirão Preto (GUIDO, 2004) 
Para tentar conter o avanço do rebaixamento e demais problemas no município de Ribeirão Preto, a Câmara Técnica de Saneamento e Água Subterrânea do CBH - Pardo propôs a classificação do município como Área Provável de Restrição e Controle conforme a Deliberação CRH n ${ }^{\circ} 52$, de 15 de abril de 2005. Essa área de restrição é mostrada na Figura 16.

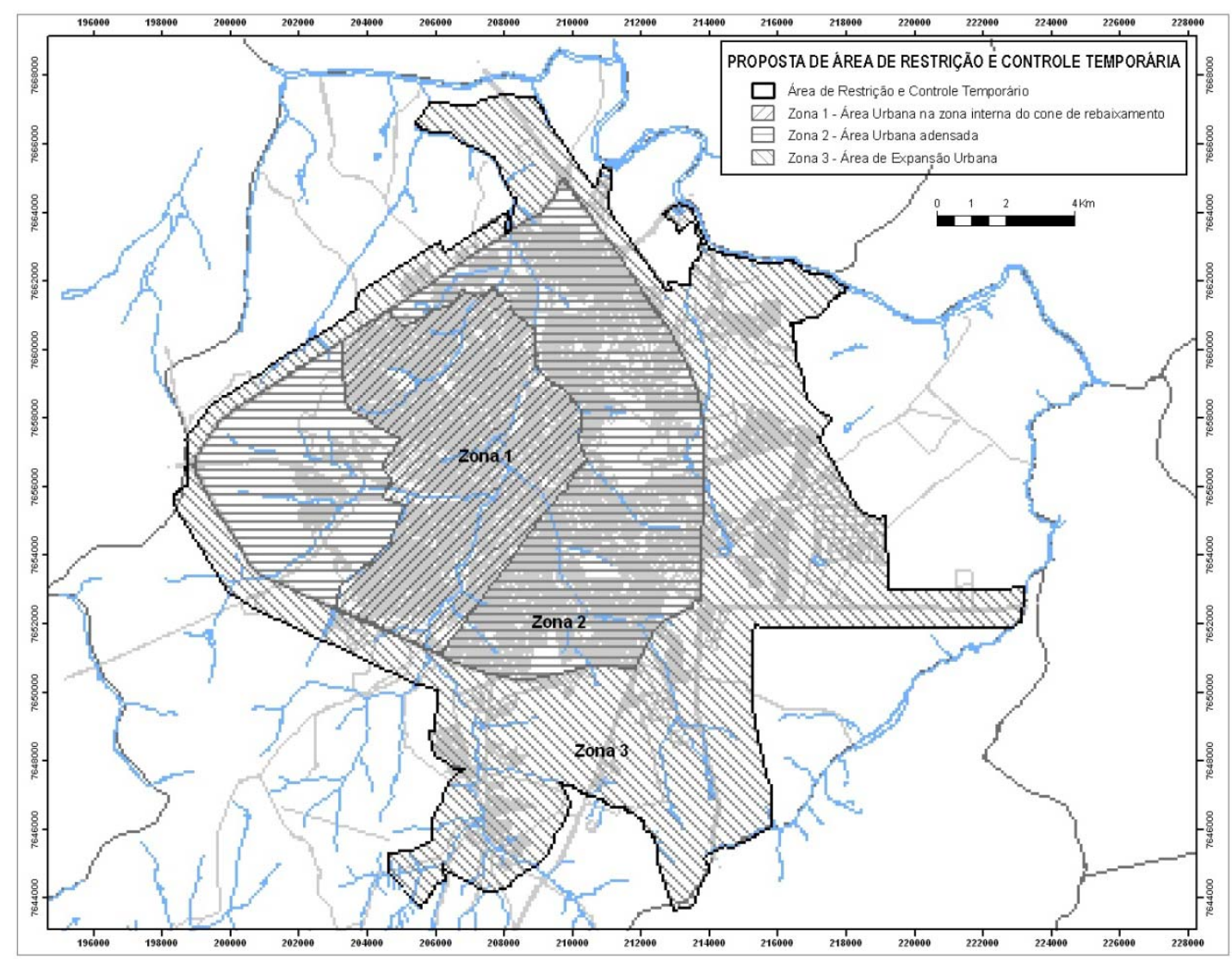

Figura 16: Área de restrição e controle temporário no município de Ribeirão Preto (SMA/São Paulo \& StMUGV/Baviera, 2004) 


\subsection{MODELO CONCEITUAL}

O modelo conceitual é uma parte fundamental no processo de construção de um modelo numérico, já que nele são detalhados todos os processos físicos do meio natural e as simplificações adotadas para esse meio.

Aqui também, por conseguinte, residem as principais causas de falhas e de imprecisão do modelo. A construção do modelo conceitual é um processo iterativo e ele está sempre em evolução, já que, se uma hipótese adotada para o modelo não for confirmada, ele deve ser revisto.

O modelo conceitual proposto para a área de estudo é direcionado à construção de um modelo numérico de fluxo subterrâneo. Todas as informações obtidas (descritas na Seção 4.1) visaram dar subsídios ao estabelecimento de unidades hidroestratigráficas, do balanço hídrico e do sistema de fluxo conceitual do modelo.

\subsubsection{UNIDADE HIDROESTRATIGRÁFICA}

As Formações Botucatu e Pirambóia foram consideradas como uma única unidade hidroestratigráfica, o Aqüífero Guarani, limitada inferiormente pela base da Formação Pirambóia e, superiormente, pelo topo da Formação Botucatu.

Essas formações foram consideradas uma única unidade aqüífera pelos seguintes motivos:

- Semelhança hidrogeológica;

- Isotropia e homogeneidade regionais;

- Paralelismo e regularidade de ocorrência. 


\subsubsection{RECARGA}

A recarga foi considerada, inicialmente, como a soma de:

- Recarga direta, que chega diretamente ao aqüífero pelas áreas de afloramento;

- Recarga indireta, que passa através de estruturas sobrejacentes ao aqüífero.

Foram definidos como áreas de recarga do Aqüífero Guarani os afloramentos das seguintes formações:

- Botucatu;

- Pirambóia;

- Sedimentos Aluvionares Modernos;

- Sedimentos Continentais Indiferenciados;

As duas últimas são regiões onde o Aqüífero Guarani é semiconfinado, ou seja, áreas de recarga indireta. Essa hipótese é baseada no fato de que, dada sua litologia e pequena espessura, existe interação entre elas e o Aqüífero Guarani.

\subsubsection{FLUXO}

Localmente, o Rio Pardo constitui-se na drenagem principal da área, tendo a maioria dos rios como afluentes. Assim, a tendência é que o fluxo subterrâneo seja também para o Rio Pardo.

As áreas a leste do domínio (regiões de afloramento do Guarani) funcionam como áreas de recarga, com drenagem própria. O excedente escoa subsuperficialmente para oeste, em direção à calha do Rio Paraná. 


\subsection{OBTENÇÃO E PROCESSAMENTO DE DADOS EM SIG}

Ferramentas SIG (Sistemas de Informações Geográficas) têm sido amplamente utilizadas para a organização e gerenciamento de grandes quantidades de dados de uma determinada região. De modo simplificado, um SIG combina layers (níveis de informação) de uma área de modo a fornecer uma melhor compreensão sobre esta área. A escolha dos layers a serem combinados depende do propósito, por exemplo: encontrar o melhor local para uma nova loja, analisar danos ambientais, observar crimes similares em uma cidade para detectar padrões.

Em águas subterrâneas, o SIG tem sido utilizado como a forma mais adequada de gerenciamento de grandes quantidades de dados: hidrológicos, formações geológicas, rios e lagos, poços etc.

Como ferramenta de gerenciamento de dados, o SIG dispõe de possibilidades de exportação e importação de arquivos em diversos formatos, que permitem compartilhar dados e recursos entre diferentes programas, e também de bons recursos de armazenamento, processamento e visualização.

Neste trabalho, a ferramenta SIG utilizada foi o software Arcview (ESRI, 2002), servindo de organizador e manipulador de dados que serão, posteriormente, disponibilizados para o software SPA - Simulador de Processos em Aqüíferos (WENDLAND, 2003). Esse processo de organização e manipulação permitiu fornecer ao modelo numérico todos os dados georreferenciados e separados em layers, de um modo que facilite a compreensão dos processos e características da região. No ANEXO 1, é apresentado um roteiro mais detalhado de utilização integrada dos softwares necessários neste projeto. 


\subsubsection{OBTENÇÃO DE DADOS}

Dados sobre a região foram fornecidos pelo Grupo Coordenador do Projeto Piloto de Ribeirão Preto, na forma de um arquivo para o software AutoCAD e uma compilação de todos os poços existentes na área de estudo.

Dados sobre a geologia da região também foram obtidos do Sistema de Informação de Águas Subterrâneas (SIAGAS, 2006).

Aqui cabe ressaltar a escassez de dados no cadastro de informações para a área de estudo, principalmente para as regiões mais distantes de Ribeirão Preto. Para discutir eventuais soluções para as dificuldades enfrentadas na aquisição de dados, foi realizada uma reunião no Instituto Geológico (IG/SMA). O relatório desta reunião está apresentado no ANEXO 2.

\subsubsection{Dados topográficos e superficiais da região}

Os dados referentes à topografia e características superficiais da região de estudo foram obtidos através de um mapa digital vetorial em escala 1:50.000 (IBGE, 1971) contendo as Folhas de Ribeirão Preto (SF-23-V-C-I-1), Serrana (SF-23-V-C-I-2), Bonfim Paulista (SF-23-V-C-I-3) e Cravinhos (SF-23-V-C-I-4).

Esse mapa contém dados referentes a:

o Altimetria, com curvas de nível espaçadas de $20 \mathrm{~m}$;

o Hidrografia, apenas com localização (coordenadas X e Y), sem cotas altimétricas;

o Rodovias e ferrovias de acesso, com localização (coordenadas $\mathrm{X}$ e $\mathrm{Y}$ );

o Divisão municipal;

o Área urbana de cada município e arruamento; 
o Articulação das Folhas do IBGE.

Dados de geologia superficial da região foram obtidos junto ao IPT (2000), pelo arquivo digital do Relatório n ${ }^{0} 40670$ ”Diagnóstico da situação atual dos Recursos Hídricos e estabelecimento de diretrizes técnicas para a elaboração do Plano da Bacia Hidrográfica do Rio Pardo - Relatório Final”.

Dados hipsométricos do Rio Pardo e afluentes foi obtida de cartas topográficas do IBGE para a região do Rio Pardo, na escala 1:10.000, obtidas junto à secretaria do IBGE de São Carlos.

Todos esses dados foram transportados para a ferramenta SIG, e convertidos de dados vetoriais e tabelas para shapefiles, que é o tipo de dado de entrada no software Arcview (ESRI, 2002).

\subsubsection{Dados geológicos subterrâneos}

Os dados geológicos subterrâneos utilizados foram obtidos, primariamente, através do banco de dados do Sistema de Informação de Águas Subterrâneas (SIAGAS, 2006) e, complementarmente, através da compilação fornecida pelo Grupo Coordenador do Projeto Piloto de Ribeirão Preto.

O SIAGAS (2006) foi a fonte inicial de informações de poços existentes na região de estudo. Infelizmente, esses dados, muitas vezes, apresentaram-se incompletos, incoerentes ou ausentes, sendo que a quantidade de dados consistentes e aproveitáveis é relativamente baixa para a dimensão da área de estudo. Constam, nesse cadastro de poços, dados referentes a: geologia, hidrogeologia, coordenadas (UTM L-O e N-S), município, data de instalação, uso, localidade e testes efetuados. 
Os dados de geologia, hidrogeologia, coordenadas (UTM L-O e N-S), data de instalação e uso dos poços desse cadastro estão representados, na forma de uma tabela, no ANEXO 3.

Foram selecionados dados referentes à:

o Cota de topo e base da Formação Serra Geral;

o Cota de topo e base da Formação Botucatu;

o Cota de topo e base da Formação Pirambóia (porém, com uma densidade muito baixa de dados).

Posteriormente, foi obtida junto à coordenadoria do Projeto Piloto de Ribeirão Preto, uma compilação de todos os poços existentes na área de estudo (PSAG, 2007, ${ }^{1}$ comunicação pessoal). Esses dados foram utilizados para preencher os vazios de dados, principalmente, na região dos municípios de Serra Azul, São Simão e Cravinhos. Essa compilação apresenta a ficha cadastral de cada poço, separadas por folha do IBGE.

Dessa compilação constam 432 poços no da área do Projeto Piloto de Ribeirão Preto, sendo 292 em atividade. Dos poços em atividade, 143 localizam-se no município de Ribeirão Preto.

Desses dados, foram aproveitados:

o Cota de topo e base da Formação Serra Geral;

o Cota de topo e base da Formação Botucatu;

o Nível estático do aqüífero (para toda a área).

\footnotetext{
${ }^{1}$ Comunicação feita por carta do dia 15 de Março de 2007, assinada pelo Facilitador Local do Projeto Piloto de Ribeirão, Dr. Heraldo Campos.
} 


\subsubsection{PROCESSAMENTO DOS DADOS EM SIG}

Todos os dados obtidos foram reunidos e transportados para a ferramenta SIG utilizada, transformados para o formato shapefile e georreferenciados.

Para se obter a superfície do terreno e a de topo e base dos aqüíferos existentes na área, os dados pontuais foram interpolados pelo método de krigagem ordinária. A unidade das cotas apresentadas é metros sobre nível médio do mar (m.s.n.m.).

\subsubsection{Geologia}

A fonte inicial dos dados de geologia subterrânea foi o SIAGAS - Sistema de Informação de Águas Subterrâneas (2006), entretanto a quantidade de poços que possuem dados geológicos é insuficiente para se realizar uma interpolação adequada em toda a área de estudo.

Esse problema foi sanado apenas após o fornecimento, pelo Grupo Coordenador de Ribeirão Preto, da compilação de todos os poços da região. Pela dificuldade de processamento desses dados, já que eles estão separados por ficha cadastral, só foram utilizados os necessários para o preenchimento dos vazios de dados. Os dados utilizados estão apresentados no ANEXO 5.

- Topo do Aqüífero Guarani

Dos poços cadastrados para a área, 145 apresentavam as cotas de topo do Aqüífero Guarani, sendo a maioria deles localizada na área urbana de Ribeirão Preto (Figura 17). 


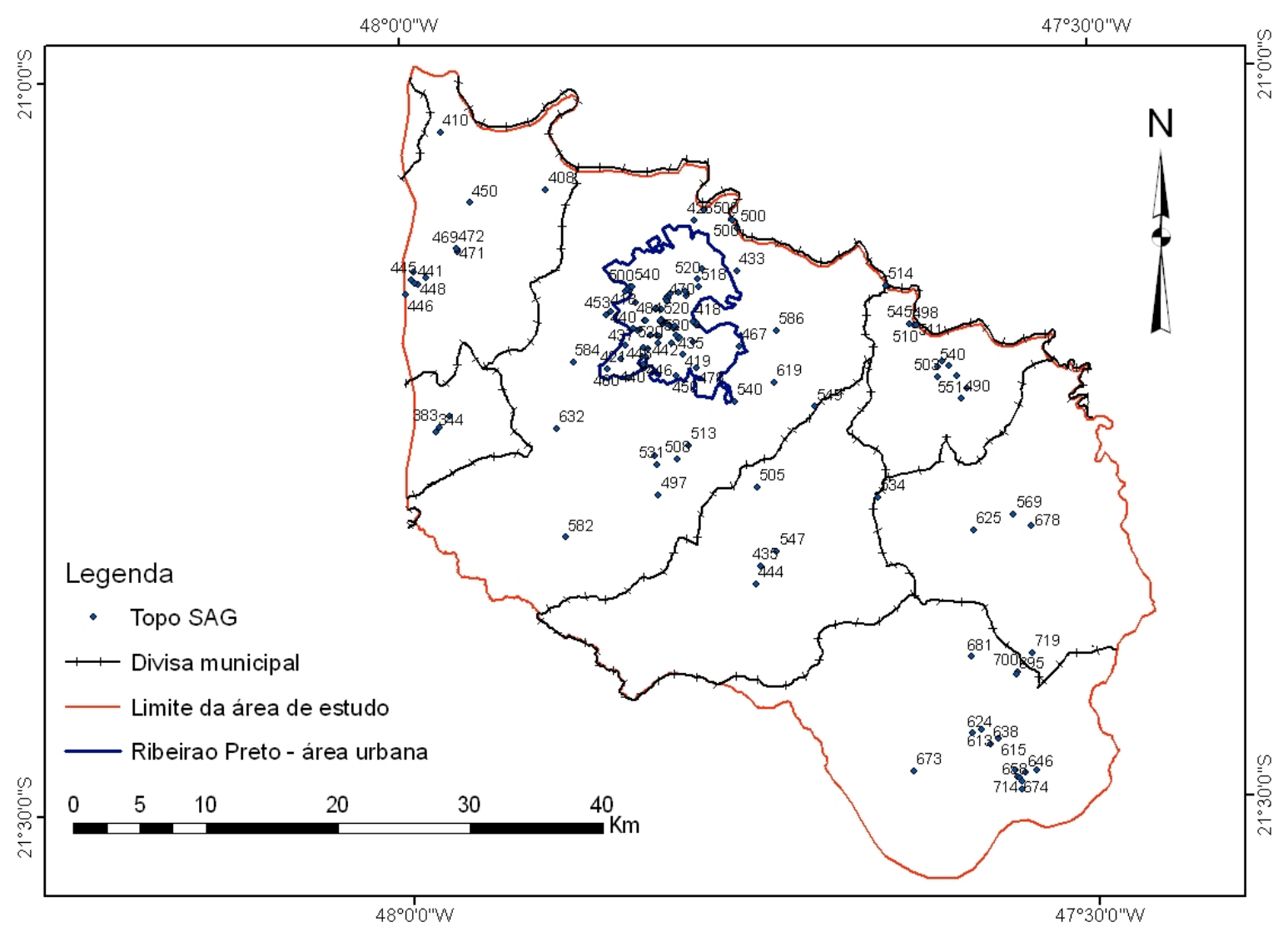

Figura 17: Poços contendo informações sobre topo do Aqüífero Guarani (m.s.n.m)

A partir desses pontos foi gerada uma superfície tipo raster do topo do Aqüífero Guarani. Esse arquivo raster foi transformado em uma shapefile do tipo ponto que, em seguida, foi transportada para o SPA. Essas informações foram utilizadas para definir a espessura do aqüífero. A superfície do tipo raster é apresentada na Figura 18.

A porção ao norte de Sertãozinho, onde há uma ausência de dados, foi preenchida manualmente. Já as regiões faltantes de Serra Azul e São Simão não foram preenchidas porque nelas o Guarani é aflorante, então a própria superfície do terreno constitui o topo do aqüífero. 


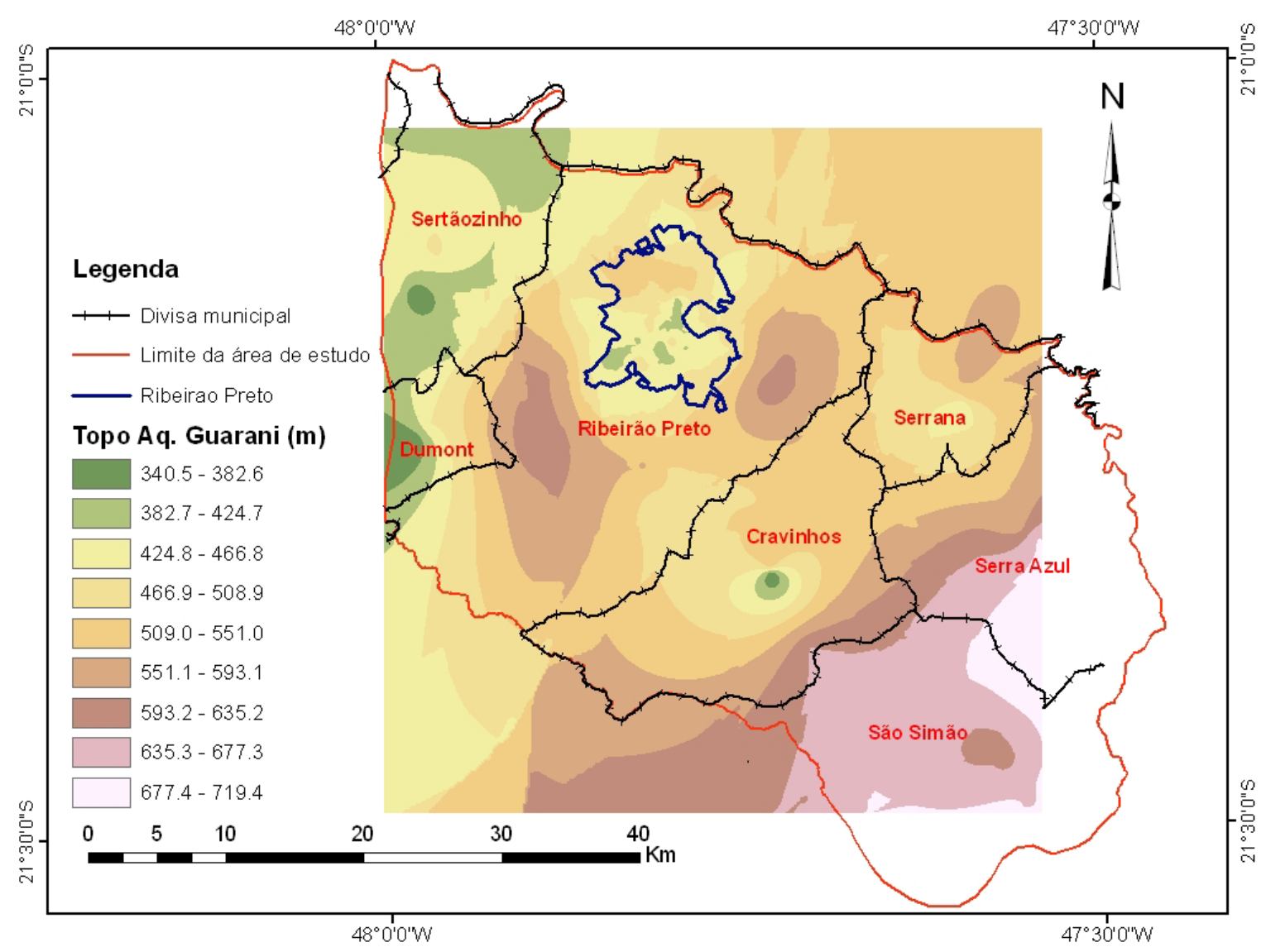

Figura 18: Superfície do topo do Aqüífero Guarani (m.s.n.m.)

Pela figura pode-se identificar um mergulho na direção de São Simão para Sertãozinho, ou seja, de Sudeste para Noroeste. As regiões em branco são devidas à insuficiência de dados nessas regiões e à uma limitação do processo de krigagem.

O topo do SAG implementado no SPA está apresentado na Figura 19. Os valores do parâmetro TOPO mostrados foram atribuídos às áreas confinadas pela Formação Serra Geral; na área de afloramento, foi atribuída a própria superfície do terreno. 


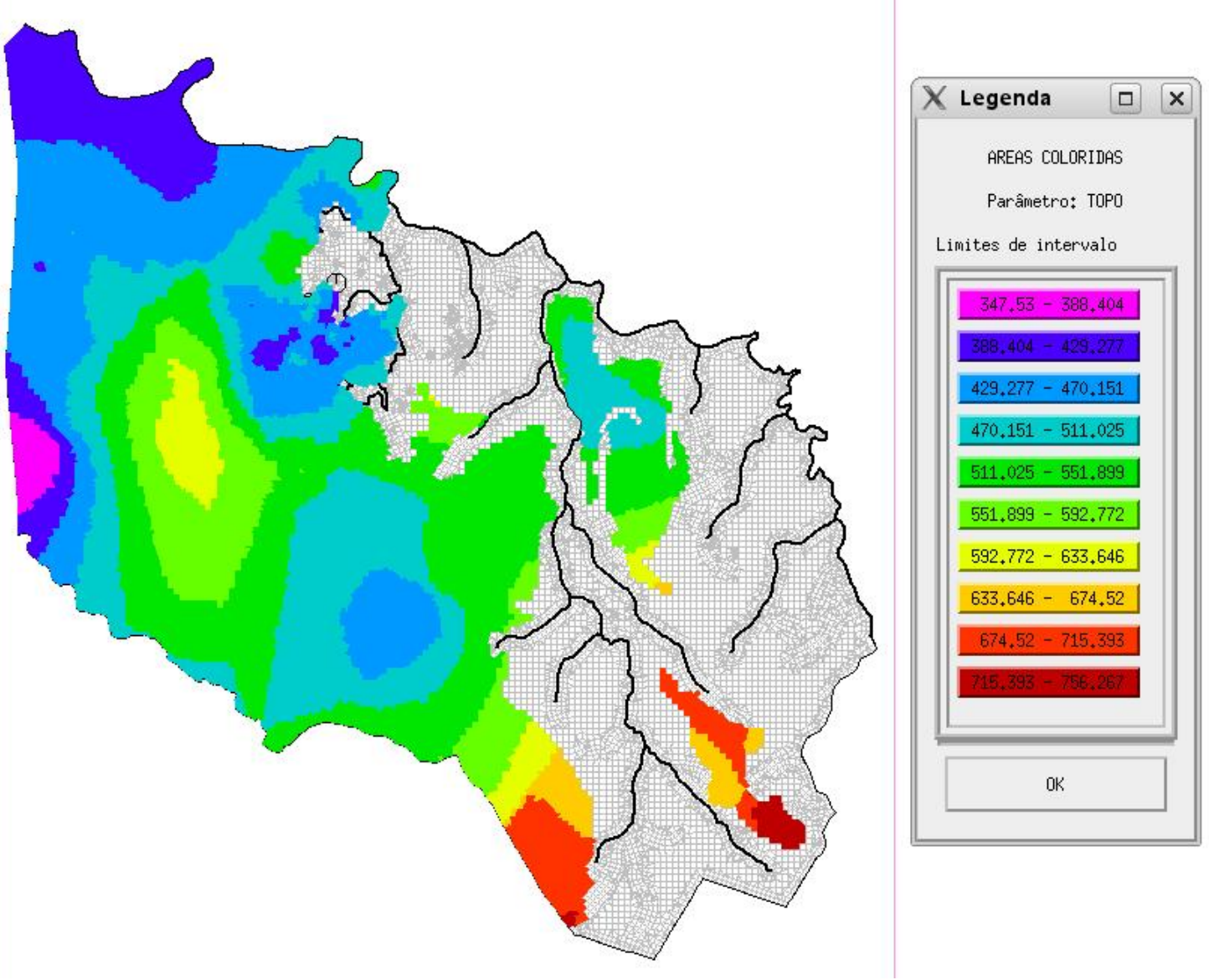

Figura 19: Topo do Aqüífero Guarani no SPA (m.s.n.m)

- Base do Aqüífero Guarani

Informações sobre a base da Formação Pirambóia são quase que inexistentes. A profundidade necessária de perfuração torna essa informação muito difícil de ser obtida, já que os custos aumentam bastante e a produção de água desejada é alcançada em profundidades menores na maioria dos casos.

Portanto, para obter as cotas de base do aqüífero foi utilizado um mapa regional de espessura do Aqüífero Guarani (Figura 20), em conjunto com dados de 19 poços (Figura 21) do SIAGAS (2006) que continham essa informação (interpretação de perfis geológicos). 


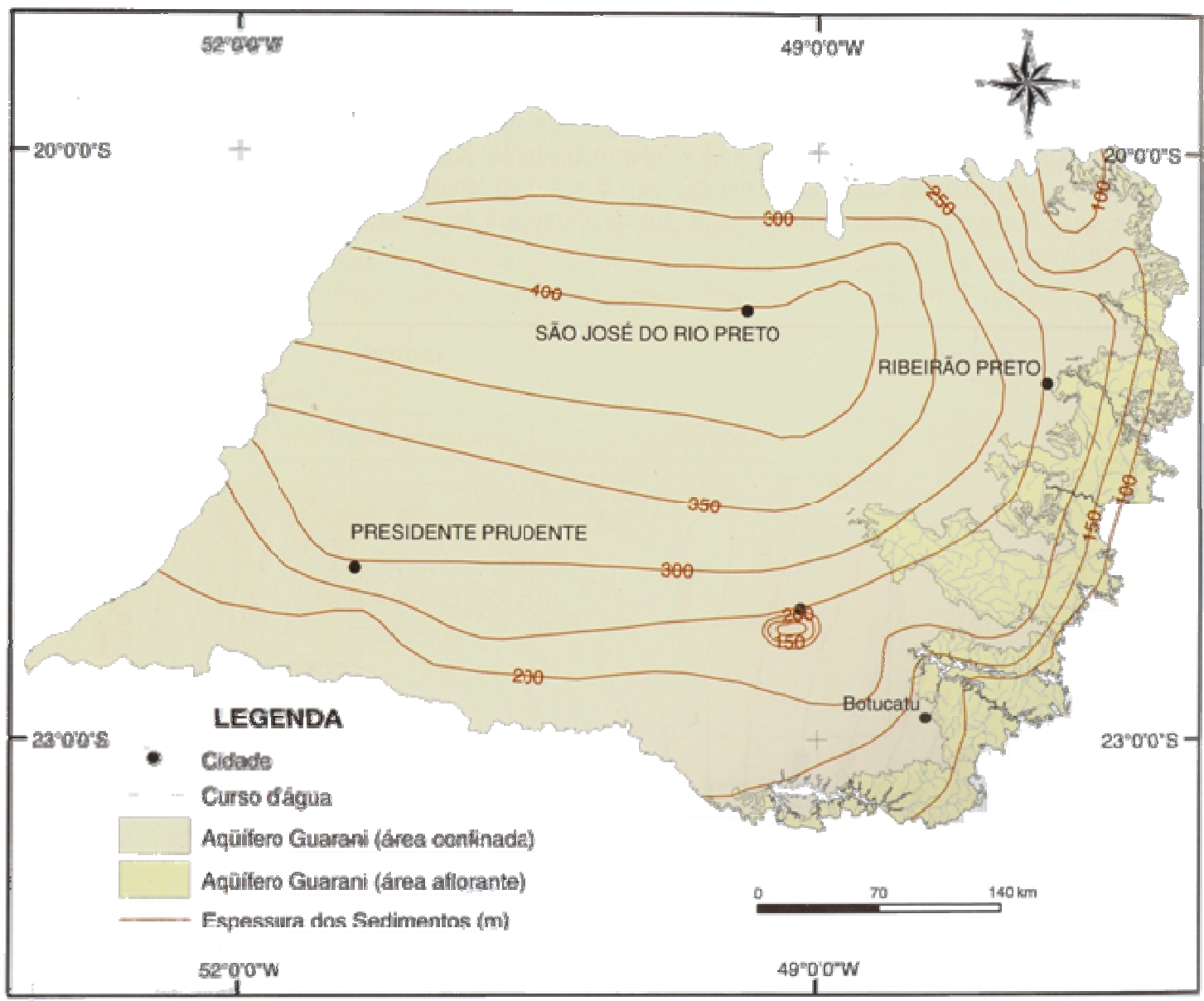

Figura 20: Isópacas dos sedimentos do Aqüífero Guarani (DAEE/IG/IPT/CPRM, 2005 ) 


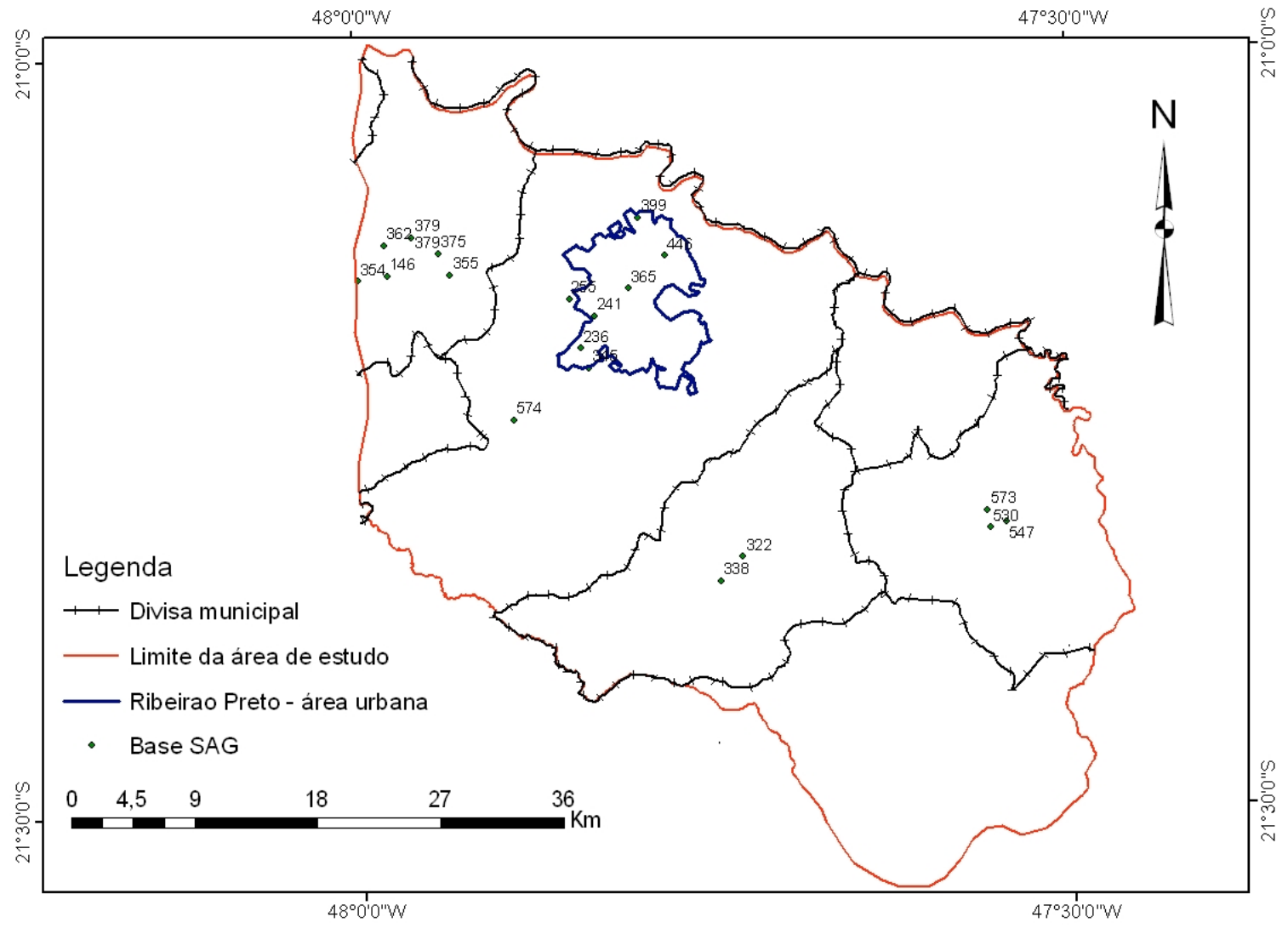

Figura 21: Pontos com dados de base da Formação Botucatu (m.s.n.m)

A Figura 22 ilustra a base do SAG considerada no modelo numérico, com as cotas em relação ao nível do mar. 


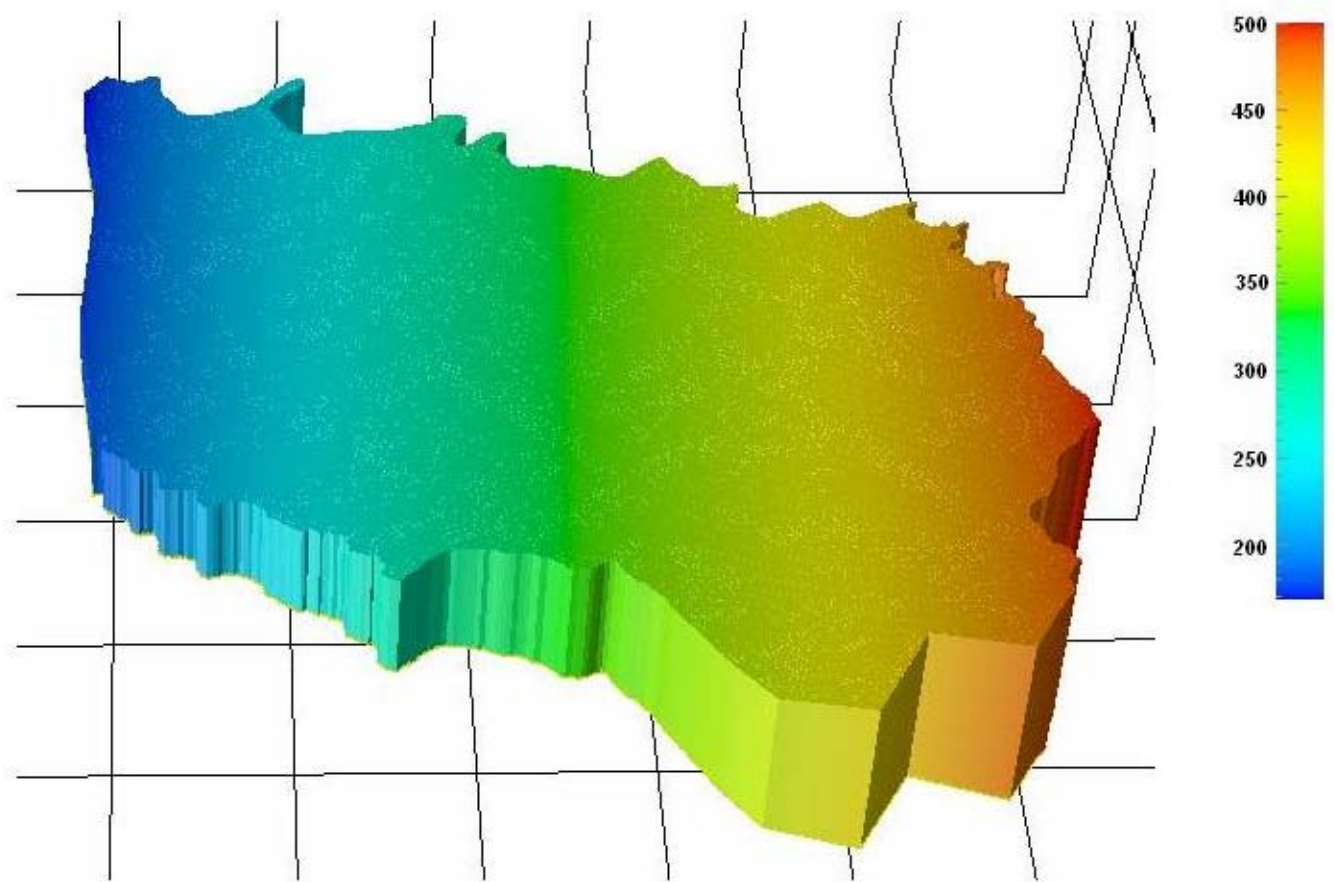

Figura 22: Base do Aqüífero Guarani (m.s.n.m) no SPA

\subsubsection{2 Área de afloramento}

Os afloramentos do Aqüífero Guarani correspondem a cerca de $40 \%$ da área de estudo. Foram consideradas como afloramentos as seguintes estruturas (Figura 23):

- Formação Botucatu;

- Formação Pirambóia;

- Sedimentos Aluvionares Modernos;

- Sedimentos Continentais Indiferenciados.

Nessas regiões, o SAG é considerado livre e em conexão hidráulica com os cursos d’água. 


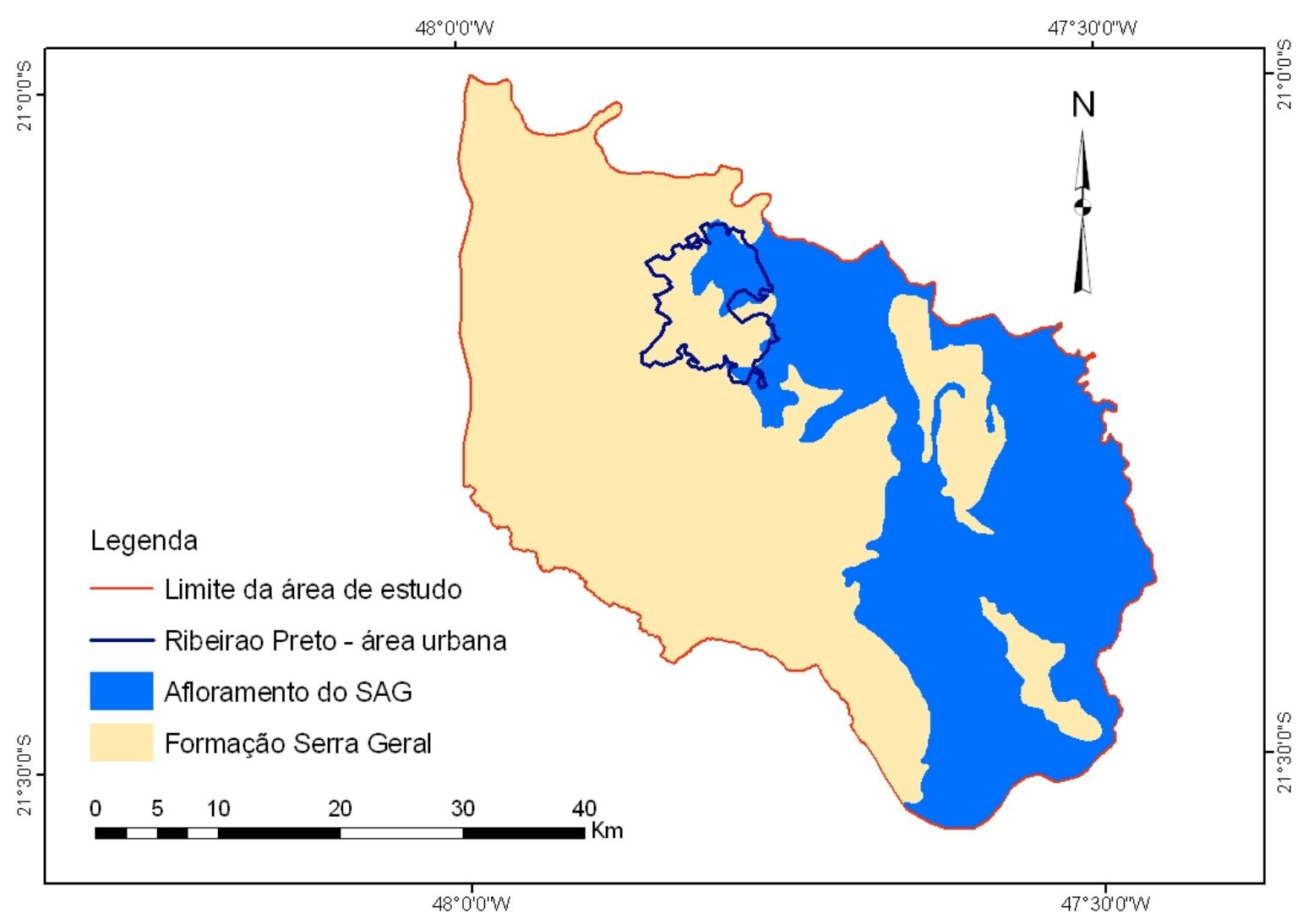

Figura 23: Área de afloramento do SAG

\subsubsection{Altimetria}

Os dados altimétricos foram obtidos a partir do mapa vetorial (citado na Seção 4.3.1.1) para o software AutoCAD, no qual as curvas de nível espaçadas de $20 \mathrm{~m}$ eram representadas por polylines. Para efetuar a interpolação pelo método da krigagem, essas polylines foram transformadas em pontos. Em seguida, esses pontos foram transportados para o software ArcView como uma shapefile. A partir daí foi construída uma superfície de triângulos interconectados (método TIN - Triangulated Irregular Network) para visualização da topografia da região.

Os valores de altimetria foram interpolados novamente no SPA para atribuição aos nós da malha do modelo numérico. 
A topografia da região de estudo é apresentada na Figura 24, juntamente com a hidrografia.

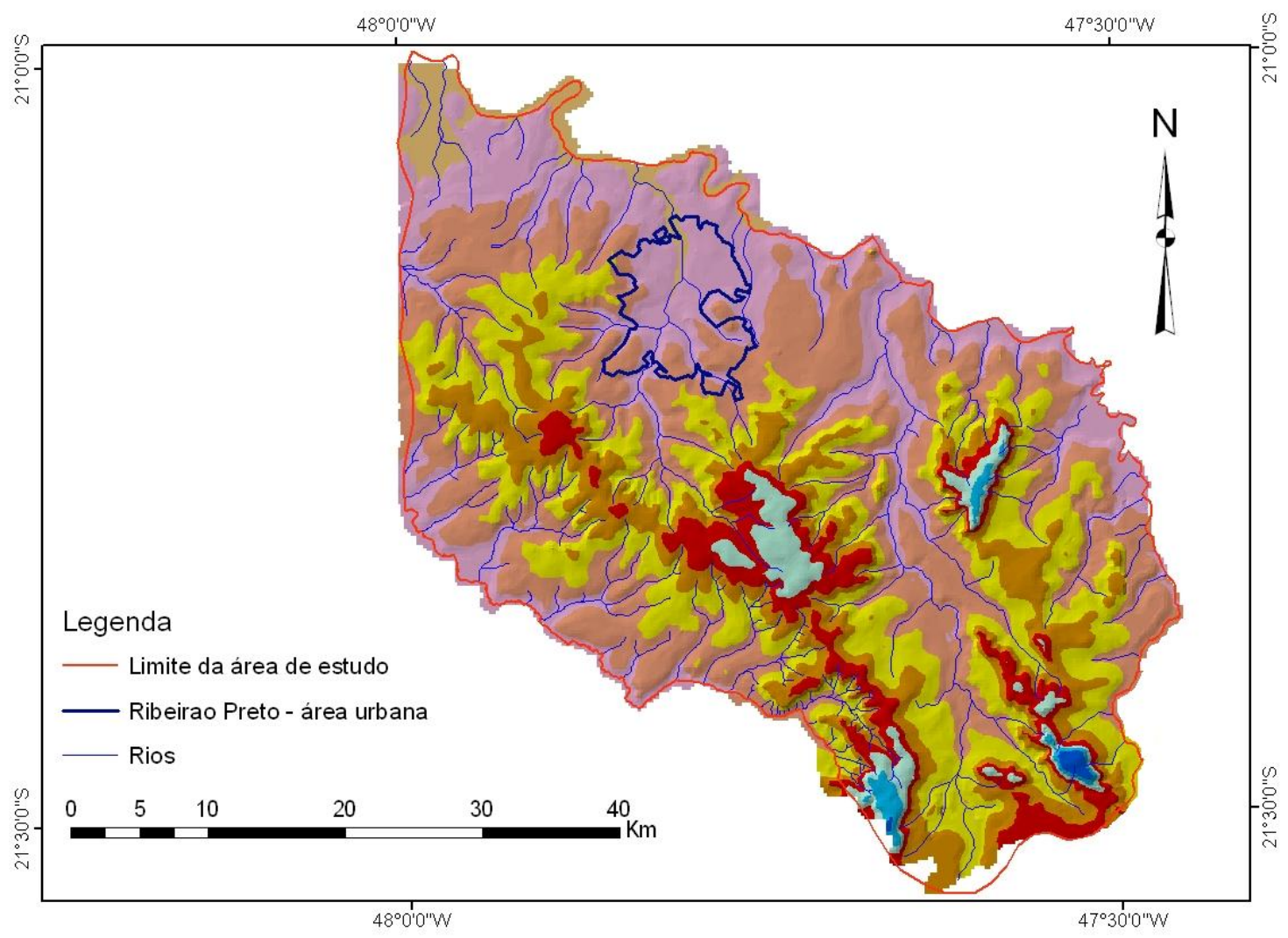

Figura 24: Topografia e hidrografia da região de estudo (m.s.n.m.)

Na Figura 25 é mostrada a superfície do terreno considerada no modelo numérico. 


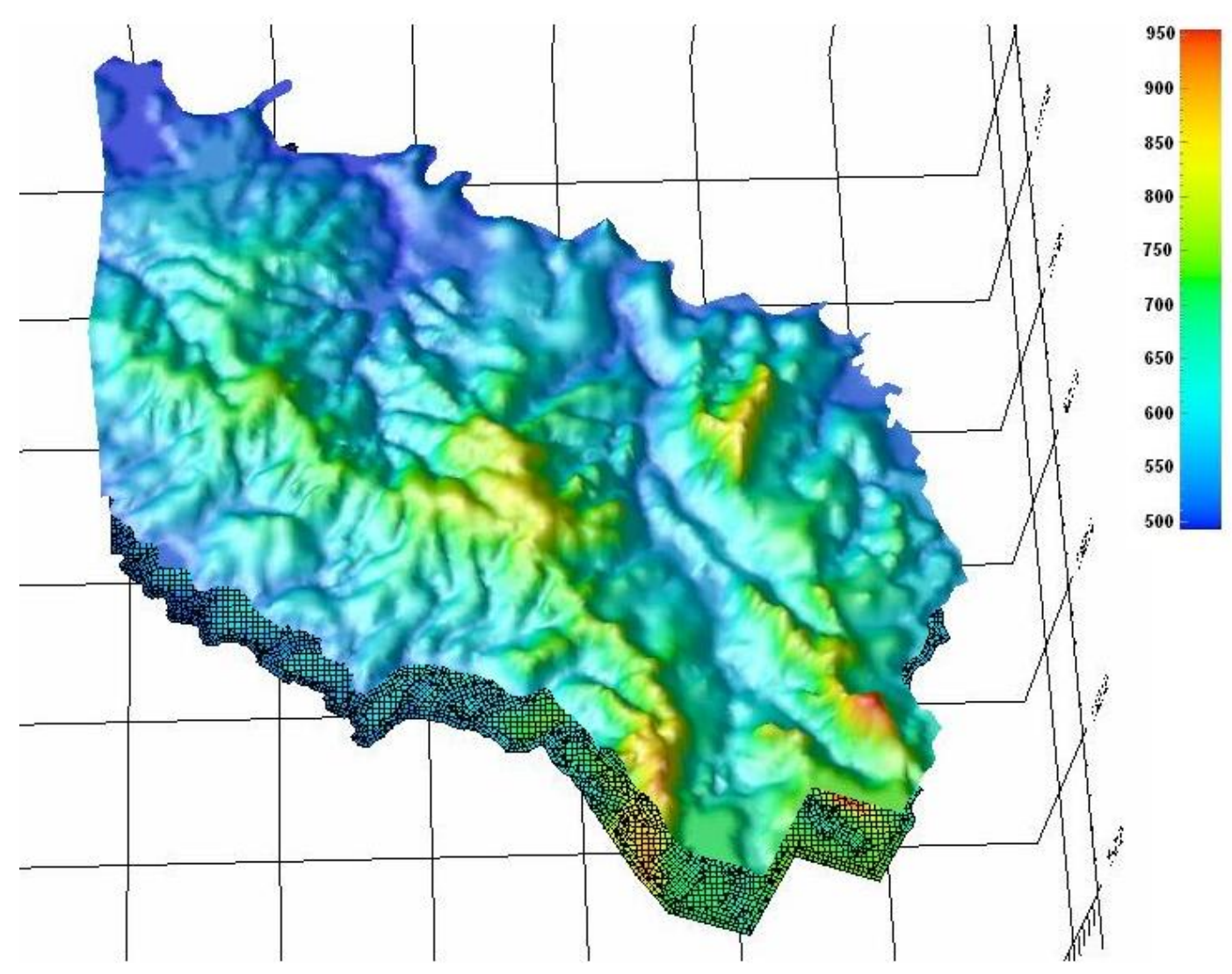

Figura 25: Altimetria no SPA (m.s.n.m)

\subsubsection{Hidrografia}

Na Figura 26 é mostrada a hidrografia da região de estudo. Os cursos d’água não-representativos (muito pequenos, baixa vazão) não foram apresentados.

O Rio Pardo é a principal drenagem da área de estudo, e recebe a contribuição de cerca de $80 \%$ dela (regiões Leste, Oeste, Norte e Central). Ao Sul destaca-se o Ribeirão da Onça, recebendo a contribuição dessa região (cerca de $20 \%$ ). 


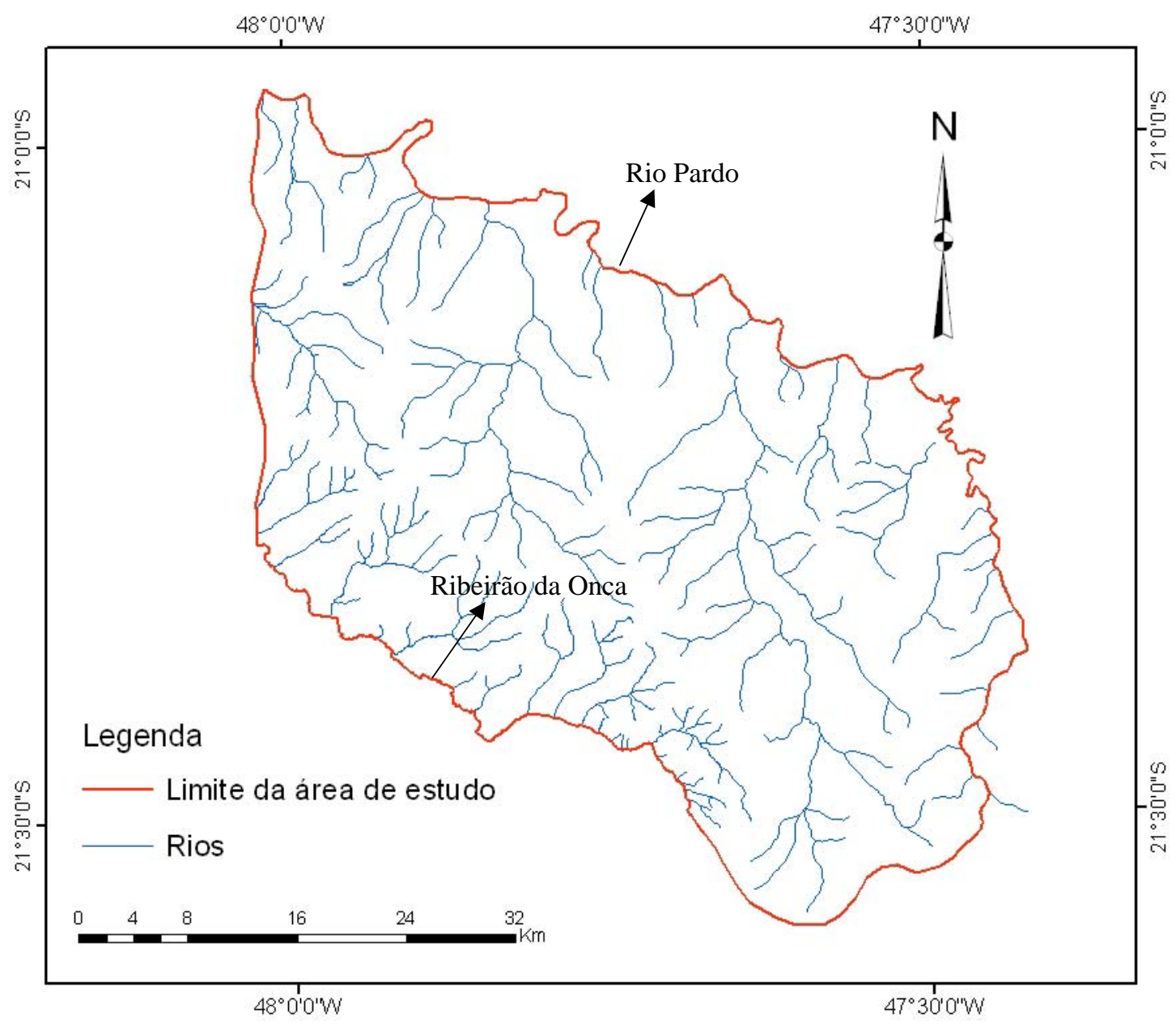

Figura 26: Hidrografia da área de estudo

Os cursos d’água que estão em suas áreas de afloramento foram considerados em contato hidráulico com o Aqüífero Guarani.

A cota da superfície livre em alguns pontos dos principais cursos d’água da região foi obtida das Cartas Topográficas do IBGE, em escala 1:10.000 (Figura 27). Os pontos localizam-se na região próxima ao Rio Pardo, que é a área abrangida pelas cartas disponíveis.

Para o restante da área, foram utilizadas informações de altimetria, em conjunto com Modelos Digitais de Elevação (DEM Digital Elevation Models) (CGIAR-CSI, 2007).

Em seguida, essas cotas pontuais foram usadas para interpolação para o restante do curso d’água no SPA. 


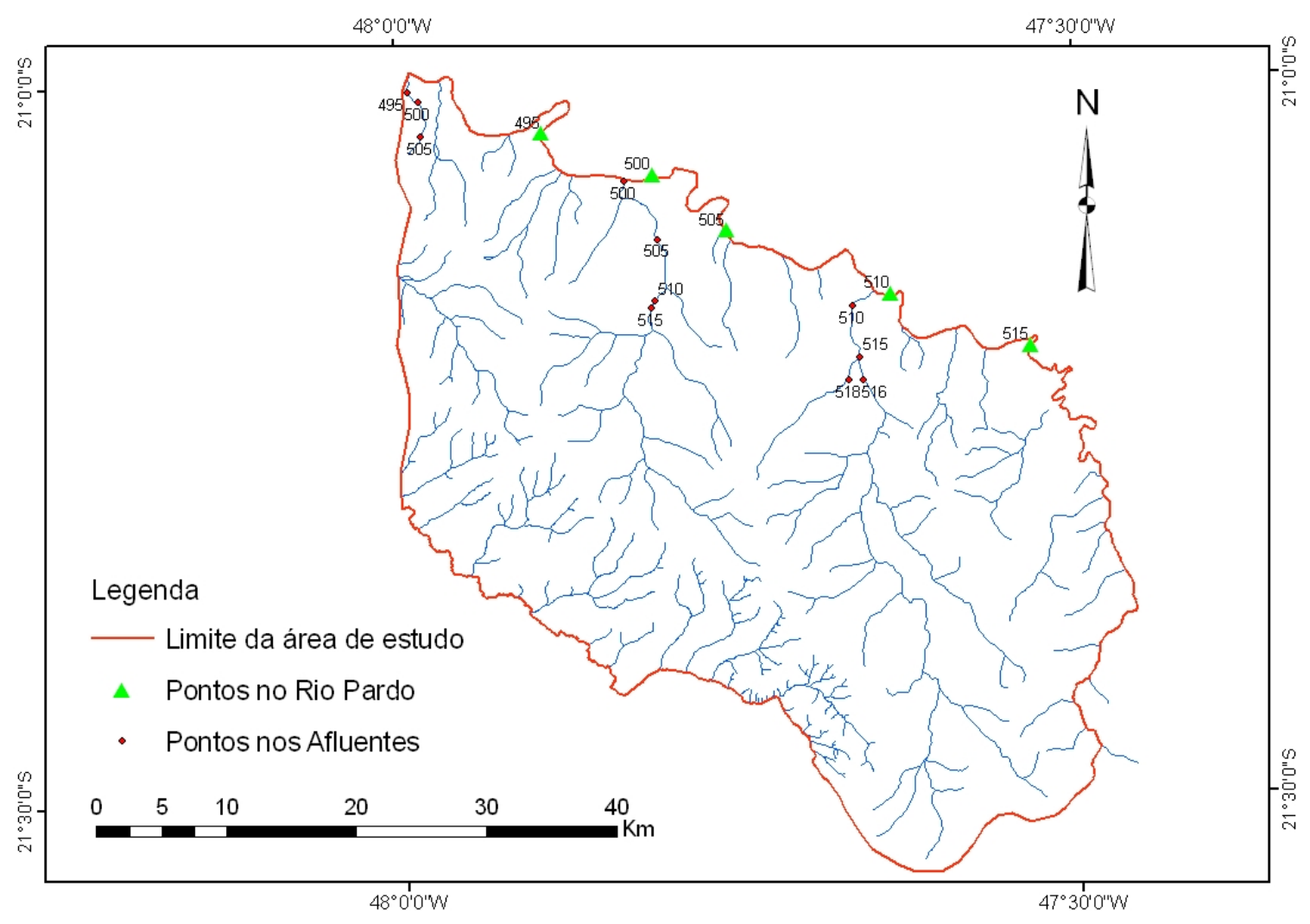

Figura 27: Pontos de carga hidráulica conhecida (m.s.n.m)

\subsubsection{Potenciometria}

Para determinar o nível estático do Aqüífero Guarani foram utilizados dados de poços, cotas nos rios onde há o contato hidráulico e a bibliografia disponível.

Visando a calibração do modelo, esses dados foram separados em décadas e associados à explotação dos poços correspondentes. A situação com pouca interferência (com poços em funcionamento até a década de 50) foi utilizada posteriormente para a calibração do modelo.

Para a região do município de Ribeirão Preto, o nível estático do Aqüífero Guarani para uma situação sem interferência (ou pouca explotação) foi definido a partir dos poços existentes nas décadas 
de 40 e 50. Para o restante da área, dado o grande espaçamento entre os poços, foram considerados também dados mais recentes (década de 90).

O conjunto de pontos com nível estático do SAG para uma situação de pouca interferência está apresentado na Figura 28.

Posteriormente esses dados foram interpolados e transportados para o SPA para se efetuar a calibração do modelo.

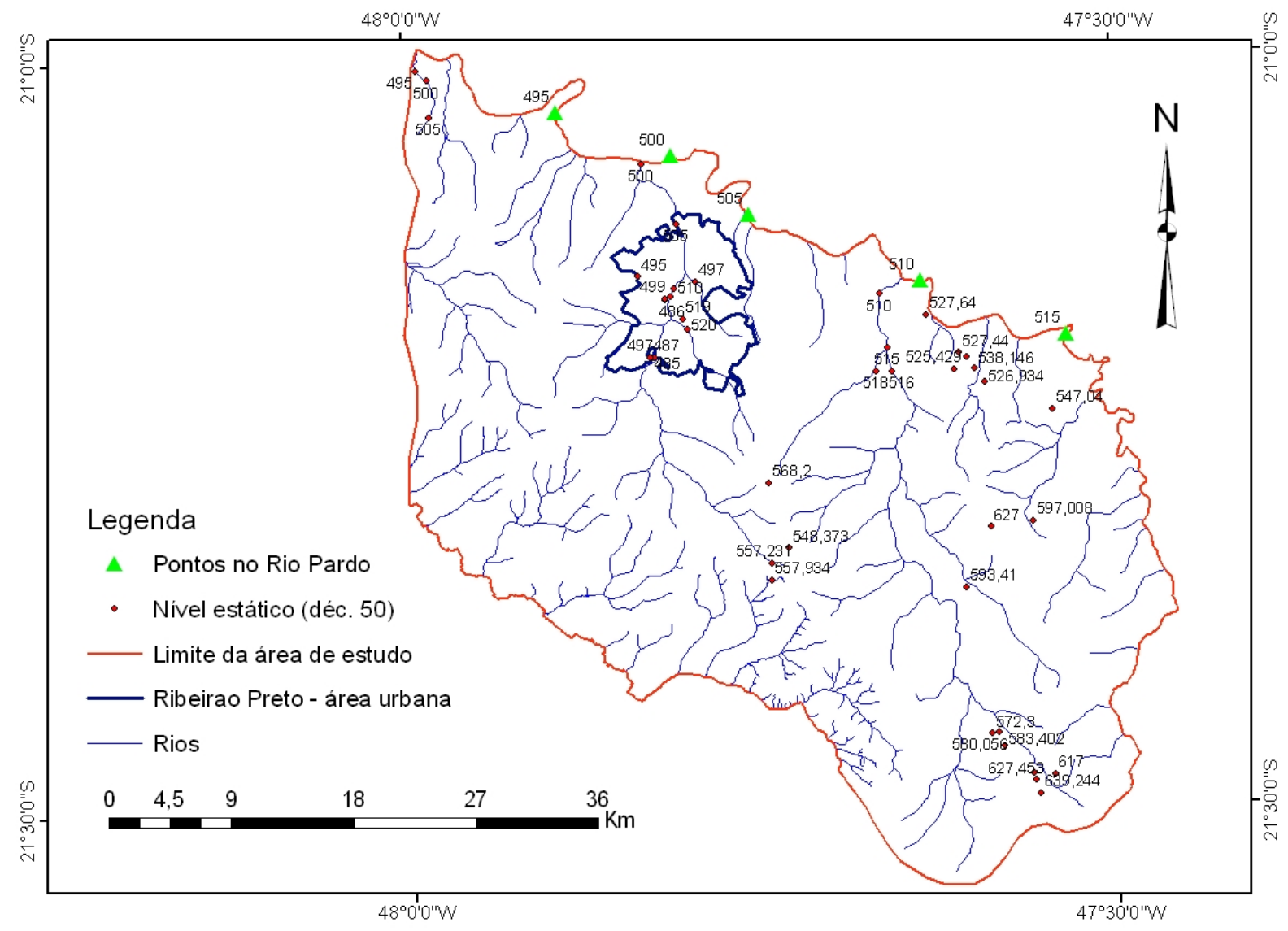

Figura 28: Potenciometria - poços até a década de 50 (m.s.n.m)

Para esses dados, foram construídas, manualmente, as equipotenciais do Aqüífero Guarani para a situação de exploração até a década de 50. Essas linhas estão apresentadas na Figura 29. 


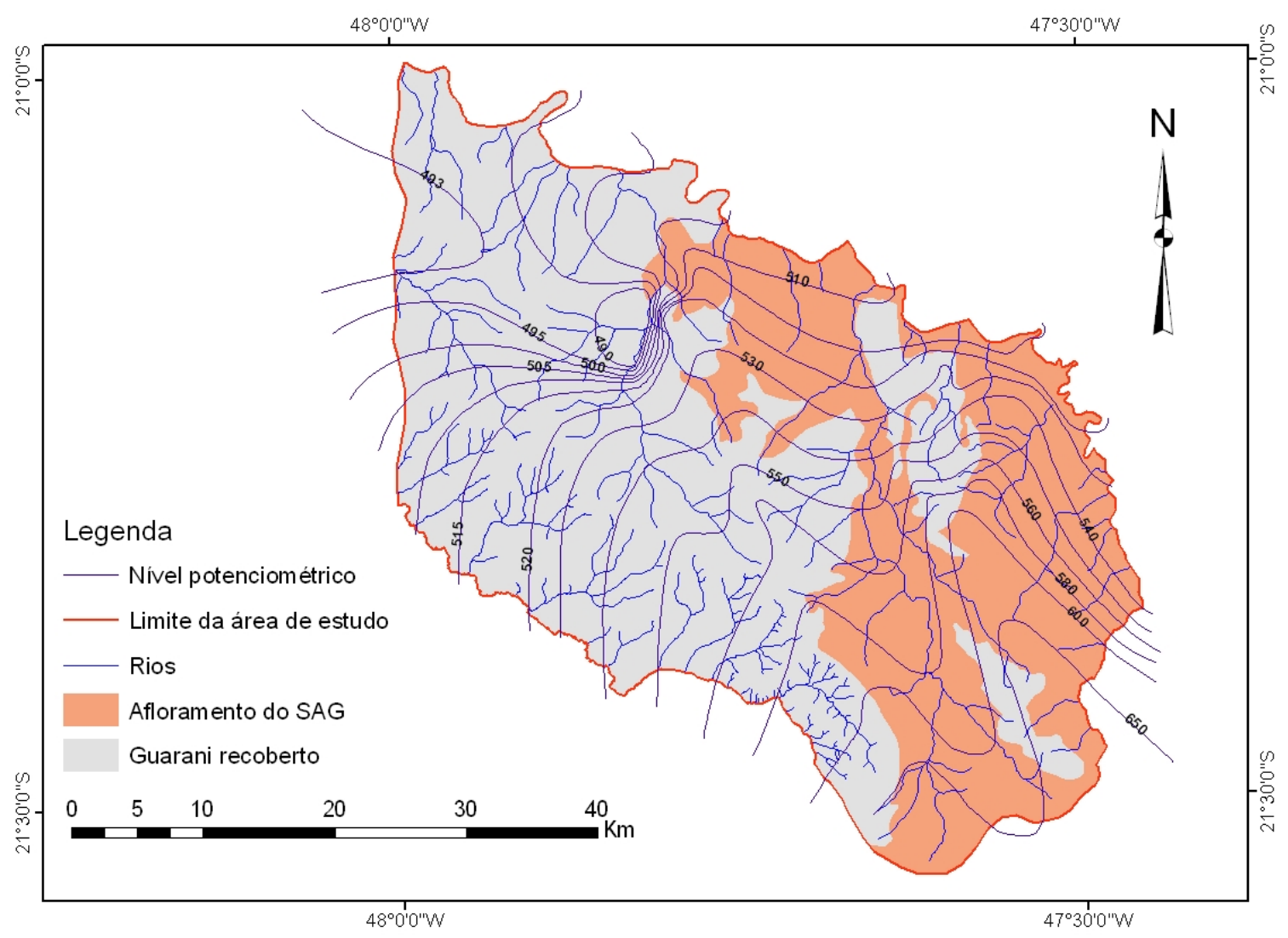

Figura 29: Isopotenciais do SAG, traçadas manualmente década de 50 (m.s.n.m)

\subsubsection{Poços em operação}

Atualmente existem 197 poços cadastrados no DAEE para a região do Projeto Piloto do Aqüífero Guarani, com 115 deles em operação. Os poços existentes na área de estudo que explotam água do Aqüífero Guarani estão concentrados no município de Ribeirão Preto, principalmente na zona urbana. Dos 115 poços em operação na área de estudo, 91 encontram-se nesse município.

Na Figura 30 pode-se ver a distribuição de poços por município e a densidade de poços existente na área de estudo. Os poços ilustrados nessa figura não contêm dados geológicos, apenas dados de vazão explotada. 
Informações sobre esses poços podem ser encontradas no ANEXO 4.

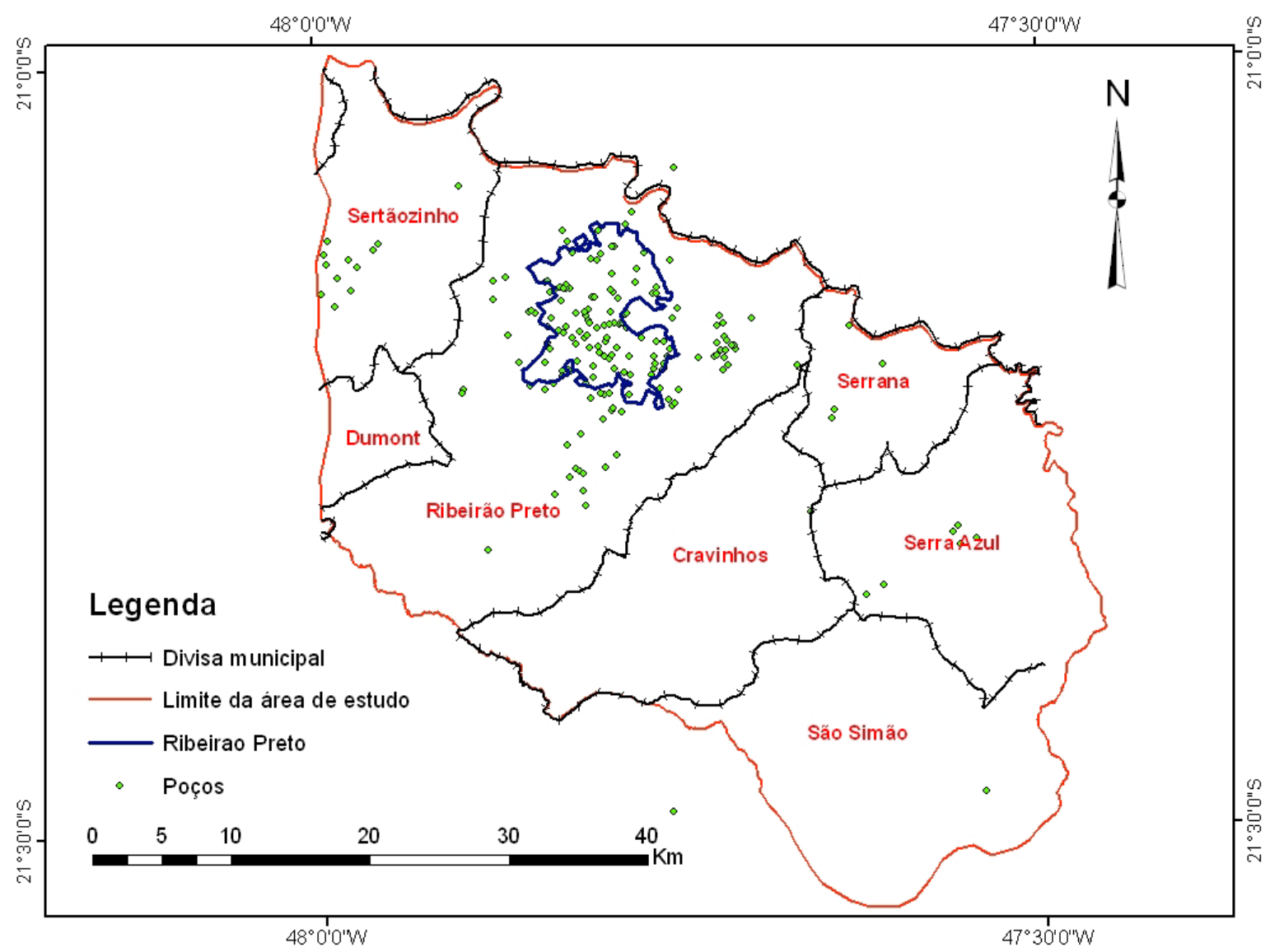

Figura 30: Municípios e distribuição dos poços em operação na área de estudo

\subsubsection{Perfis hidrogeológicos}

Foram traçados duas seções de perfis hidrogeológicos, A-B e C-D, na região do município de Ribeirão Preto, respectivamente orientados de Oeste para Leste e de Norte para Sul, e uma seção geral E-F, orientada de Noroeste para Sudeste. Esses perfis foram obtidos de interpolações das cotas altimétricas e topo e nível potenciométrico do SAG (Figura 31), a fim de se avaliar seus resultados. 


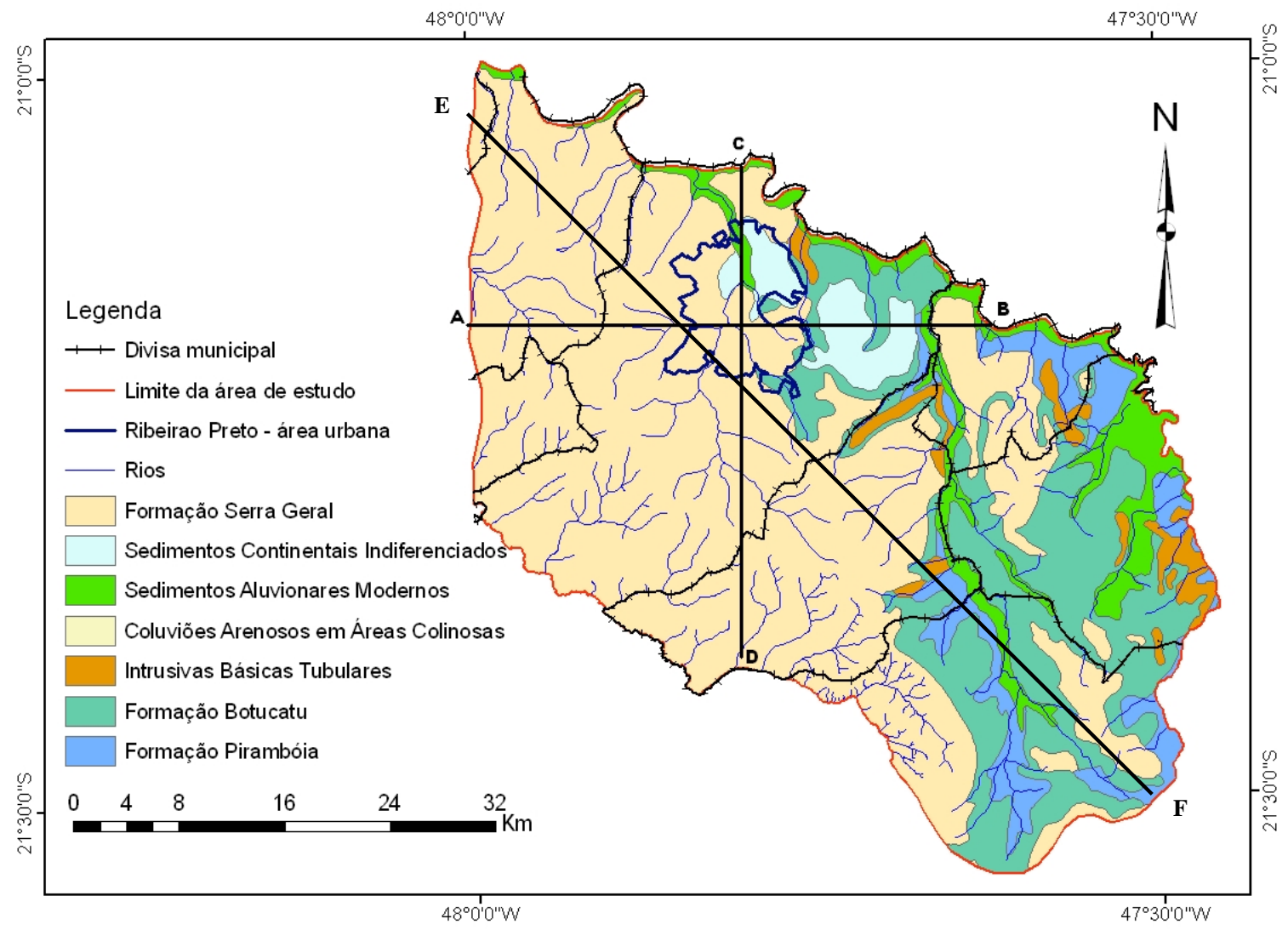

Figura 31: Seções Hidrogeológicas

Os perfis construídos estão mostrados na Figura 32, na Figura 33 e na Figura 34. Os valores de cotas estão expressos em metros sobre o nível do mar (m.s.n.m). 


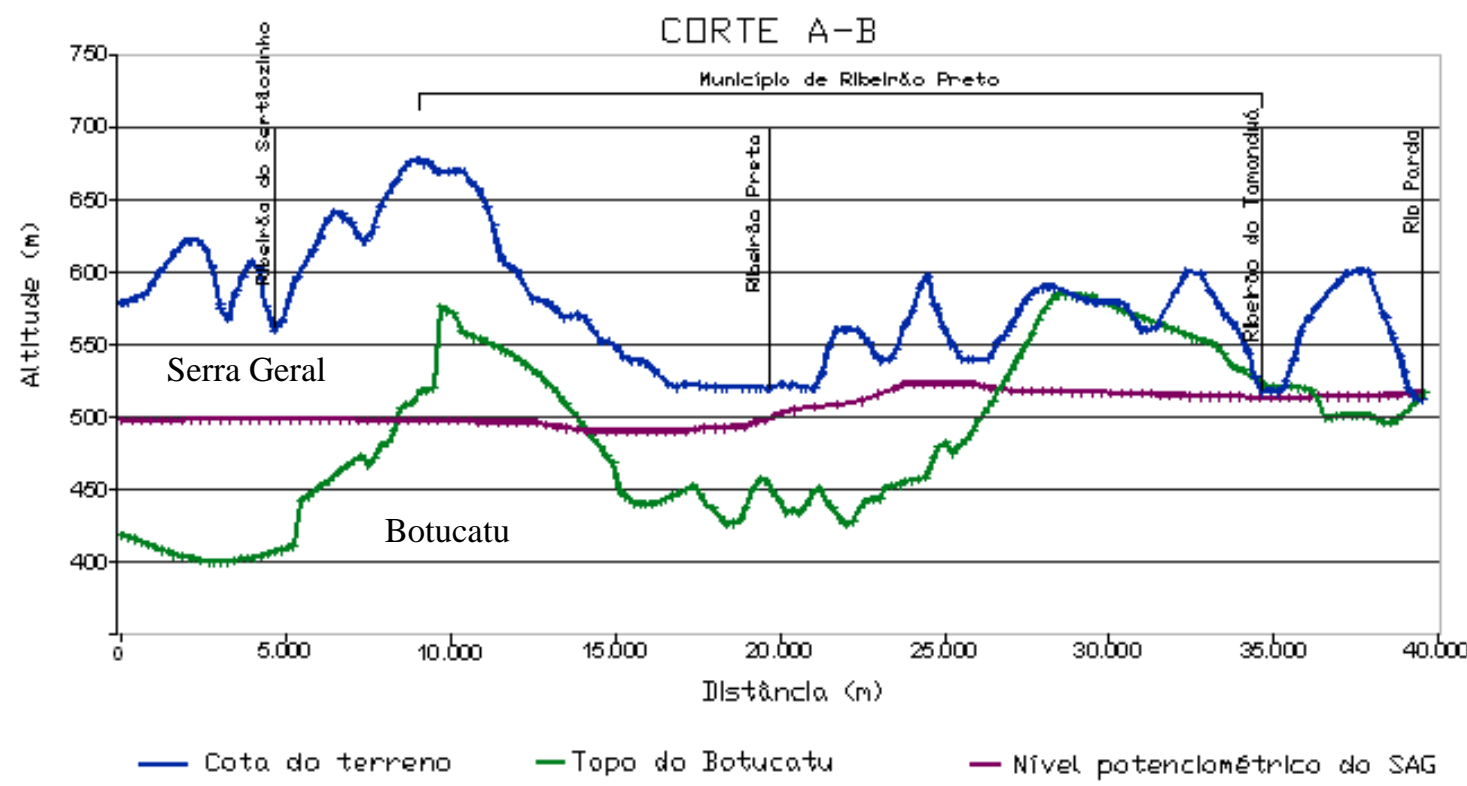

Figura 32: Perfil hidrogeológico do corte A-B

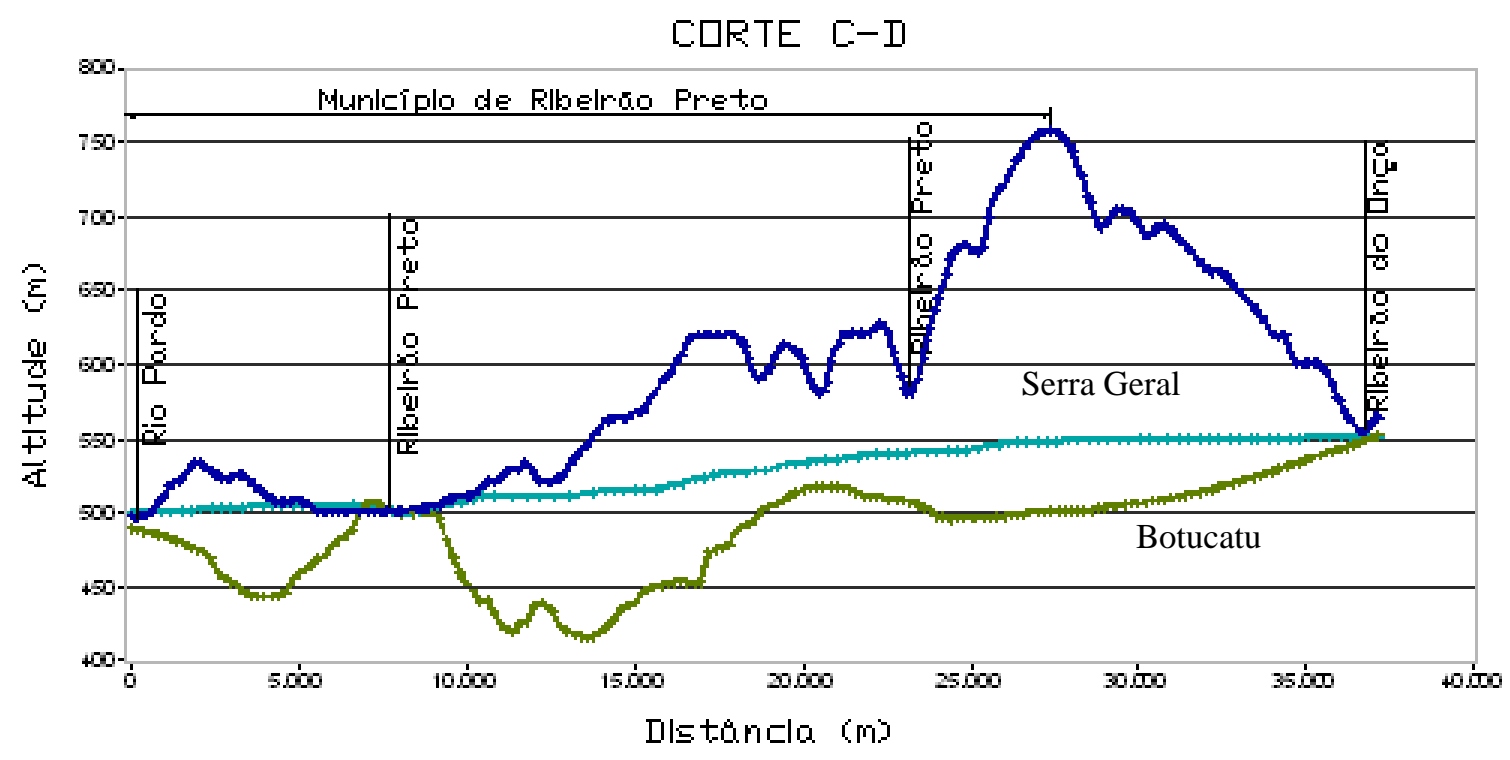

- Cota do Terreno -Topo do Botucatu - Nivel potenciométrico

Figura 33: Perfil hidrogeológico do corte C-D 


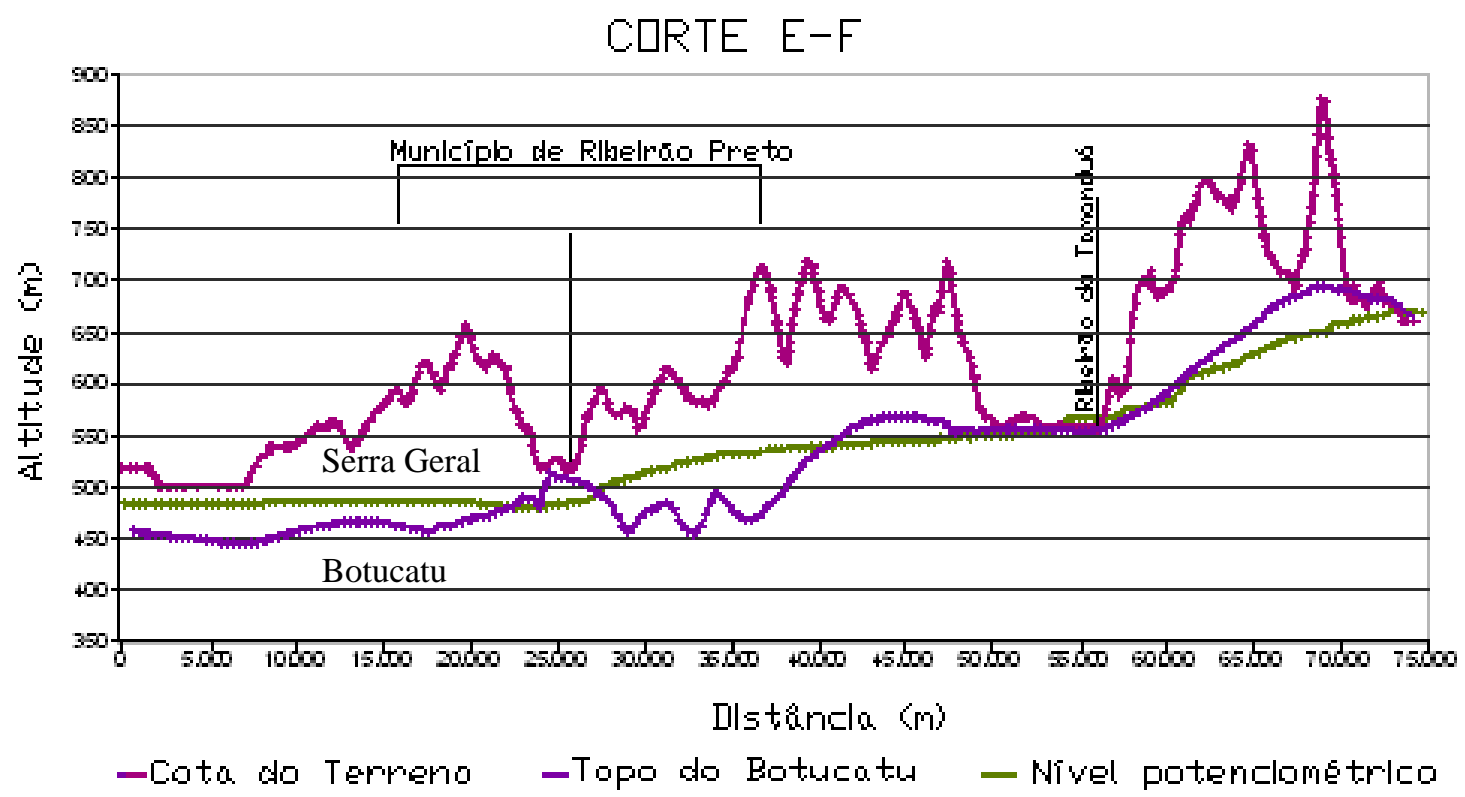

Figura 34: Perfil hidrogeológico do corte E-F

A análise dos dados dos perfis mostra que:

- A cobertura do Serra Geral na região do município de Ribeirão Preto varia entre 50 e $100 \mathrm{~m}$;

- A linha potenciométrica do SAG está acima da cota do terreno nos trechos do Rio Pardo, Ribeirão do Tamanduá, Ribeirão do Onça e Ribeirão Preto (porção que está na área de afloramento), indicando que o SAG alimenta esses corpos d’água;

- A interpolação do topo do SAG está coerente com os locais de afloramentos indicados no mapa geológico superficial.

Nota-se que as interpolações de dados de nível potenciométrico e topo do SAG foram feitas a partir de um pequeno número de dados, estando sujeita a eventuais imprecisões.

No modelo numérico, para as regiões de afloramento do Sistema Aqüífero Guarani, a própria superfície do terreno foi considerada como o topo do aqüífero. 


\subsection{MODELO NUMÉRICO}

Os dados levantados na elaboração do modelo conceitual foram implementados em um modelo numérico bidimensional horizontal, heterogêneo e isotrópico com recarga distribuída, aplicado sob condições de aqüífero livre e confinado.

As condições de contorno utilizadas inicialmente foram de carga conhecida (condição de $1^{\circ}$ tipo ou de Dirichlet) para o Rio Pardo e fluxo especificado (condição de $2^{\circ}$ tipo ou de Neumann) para as demais fronteiras do modelo.

A simulação foi feita utilizando-se o pacote SPA - Simulador de Processos em Aqüíferos (WENDLAND, 2003).

\subsubsection{FUNCIONAMENTO DO SPA}

O pacote SPA - Simulação de Processos em Aqüíferos foi desenvolvido no Laboratório de Hidráulica Computacional do Departamento de Hidráulica e Saneamento da Escola de Engenharia de São Carlos da Universidade de São Paulo (LHCSHS/EESC/USP), e funciona em sistemas operacionais Linux. O método numérico utilizado nos cálculos é o de Elementos Finitos (FEM); na geração da malha não-estruturada foi utilizado o método de Triangulação de Delaunay.

O SPA é composto de diversos módulos:

- CMA - Construtor de Modelos de Aqüíferos: responsável pela construção da malha de elementos finitos, e atribuição de parâmetros hidrogeológicos e geológicos; 
- VMA - Verificador de Modelos de Aqüíferos: responsável pela otimização e verificação de possíveis erros e defeitos na malha;

- FAS - Fluxo Águas Subterrâneas: responsável pela simulação de fluxo subterrâneo;

- VPA - Visualizador de Imagens de Aqüíferos: responsável pela geração de imagens 3D do modelo e resultados;

- GIA e XPLT: responsável pela geração de imagens 3D do modelo e resultados.

Na Figura 35 é apresentado o fluxo de dados no pacote SPA. $\mathrm{Na}$ parte de processamento principal, o módulo a ser utilizado depende do tipo de simulação que se pretenda fazer. No presente estudo foram utilizados os módulos CMA, VMA, FAS, GIA, XPLT e VPA.

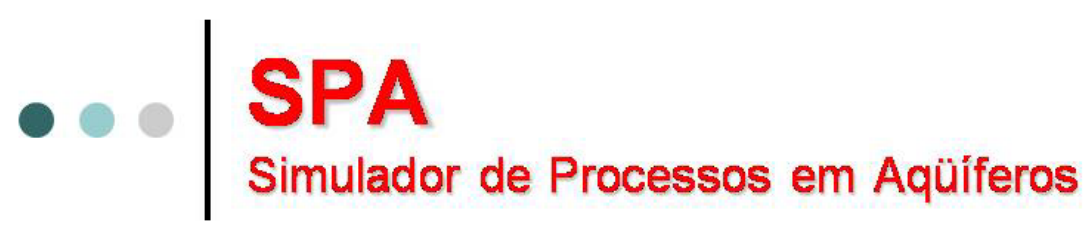

Pré-Processamento Processamento Principal Pós-Processamento

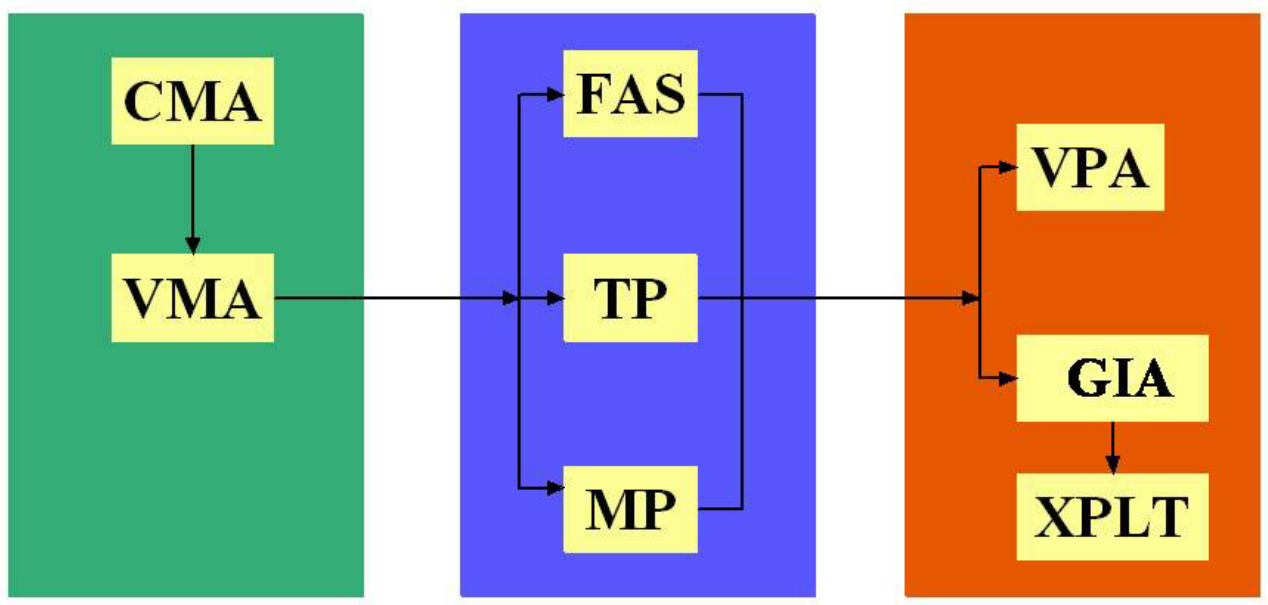

Figura 35: Fluxograma de dados através dos módulos do SPA 


\subsubsection{TIPOS DE DADOS}

Os dados georreferenciados em SIG foram convertidos para um arquivo tipo texto no formato de entrada de dados do CMA Construtor de Modelos de Aqüíferos (WENDLAND, 2003), que é o módulo responsável pela construção da malha de elementos finitos. Esses dados são representados por parâmetros designados de acordo com a sua representação no modelo (carga hidráulica, base e topo do aqüífero, explotação de poços etc.) e são reconhecidos por: numeração, coordenadas $\mathrm{X}$ e $\mathrm{Y}$ e valor do parâmetro designado Z (no formato $6 x, 10 x, 10 x, 10 x$ ). Os dados que foram interpolados por krigagem na ferramenta SIG necessitam ser atribuídos aos nós ou aos elementos da malha.

Os dados de entrada são classificados em estruturas e contornos (internos ou externos).

- Estruturas são os elementos hidrogeológicos existentes na natureza. Cada estrutura é atrelada a um parâmetro, cujo valor é posteriormente atribuído aos nós da malha.

- Contornos são as estruturas utilizadas na construção da malha, ou seja, elementos de definição da malha. Cada nó do contorno será um nó da malha de elementos finitos.

A formatação dos dados de entrada para o formato do CMA foi feita através de um aplicativo, elaborado para este fim por RABELO (2005). Seu código fonte, instruções de instalação e utilização na ferramenta SIG estão apresentados no ANEXO 6.

Na Tabela 3 são apresentados os dados de entrada do modelo, com sua classificação, programa no qual foi interpolado, parâmetro regente no SPA e o tipo de dado. 
Tabela 3: Dados utilizados no modelo numérico

\begin{tabular}{|c|c|c|c|c|c|}
\hline I N F ORM AÇÃO & ESTRUTURA & CONTORNO & $\begin{array}{l}\text { AMBIENTE DE } \\
\text { INTERPOLAÇÃO } \\
\end{array}$ & PARÂMETRO & TIPO \\
\hline $\begin{array}{c}\text { Limites da } \\
\text { área de } \\
\text { estudo }\end{array}$ & - & $x$ & - & - & $x, y$ \\
\hline Rios & - & $x$ & SPA & POTE & $x, y, h^{(1)}$ \\
\hline Poços & - & $x$ & - & POCO & $x, y, Q^{(2)}$ \\
\hline Altimetria & $x$ & - & SIG/SPA & SUPE & $x, y, h^{(3)}$ \\
\hline $\begin{array}{l}\text { Topo do } \\
\text { Guarani }\end{array}$ & $x$ & - & SIG/SPA & TOPO & $x, y, h^{(3)}$ \\
\hline $\begin{array}{l}\text { Base do } \\
\text { Guarani }\end{array}$ & $x$ & - & SPA & BASE & $x, y, h^{(3)}$ \\
\hline $\begin{array}{c}\text { Afloramento } \\
\text { do Guarani }\end{array}$ & $x$ & - & - & RECA & $x, y, r^{(4)}$ \\
\hline $\begin{array}{l}\text { Formação } \\
\text { Serra Geral }\end{array}$ & $x$ & - & - & RECA & $x, y, r^{(4)}$ \\
\hline $\begin{array}{c}\text { Nível } \\
\text { estático do } \\
\text { Aqüífero } \\
\text { Guarani }\end{array}$ & $x$ & - & SIG/SPA & CALI & $x, y, h^{(5)}$ \\
\hline \multicolumn{6}{|c|}{$\begin{array}{l}\text { (1) Carga hidráulica } \\
\text { (2) Vazão explotada } \\
\text { (3) Cota altimétrica } \\
\text { (4) Taxa de recarga } \\
\text { (5) Nível estático }\end{array}$} \\
\hline
\end{tabular}

\subsubsection{Estruturas}

As estruturas representam todas as estruturas hidrogeológicas que devem ser representadas no modelo numérico.

Foram implementados como estruturas:

- Corpos d’água, com parâmetro de carga hidráulica (POTE);

- Poços, com parâmetro de vazão explotada (POCO);

- Áreas de ocorrência de formações geológicas;

- Área de afloramento e confinamento do Aqüífero Guarani;

- Postos fluviométricos;

- Topo (TOPO) e Base (BASE) do Aqüífero Guarani;

- Altimetria (SUPE); 
- Nível estático do Aqüífero Guarani, com parâmetro para calibração do modelo (CALI);

- Taxa de recarga do Guarani livre e confinado (RECA);

- Condutividade Hidráulica (COND);

- Espessura do Aqüífero Guarani (ESPE).

\subsubsection{Contornos}

Os contornos são utilizados para a construção da malha de elementos finitos. Pontos da malha serão criados coincidentemente com os pontos do contorno de acordo com o especificado pelo usuário. Foi adotado um espaçamento de $300 \mathrm{~m}$ entre os pontos do contorno, considerando um nível de detalhamento suficiente para os objetivos propostos.

Os contornos externos do modelo foram definidos a partir da hidrografia da região. São eles:

- Norte: Rio Pardo;

- Sul: Ribeirão da Onça e Ribeirão do Pântano;

- Leste: Rio Pardo e Ribeirão da Prata;

- Oeste: Córrego do Tamboril e divisor de águas superficiais.

Os contornos internos são constituídos por:

- Rios e lagos;

- Poços em funcionamento.

Os contornos estão apresentados na Figura 36, sendo que os círculos representam os poços e as linhas representam os rios e divisores de águas superficiais. 


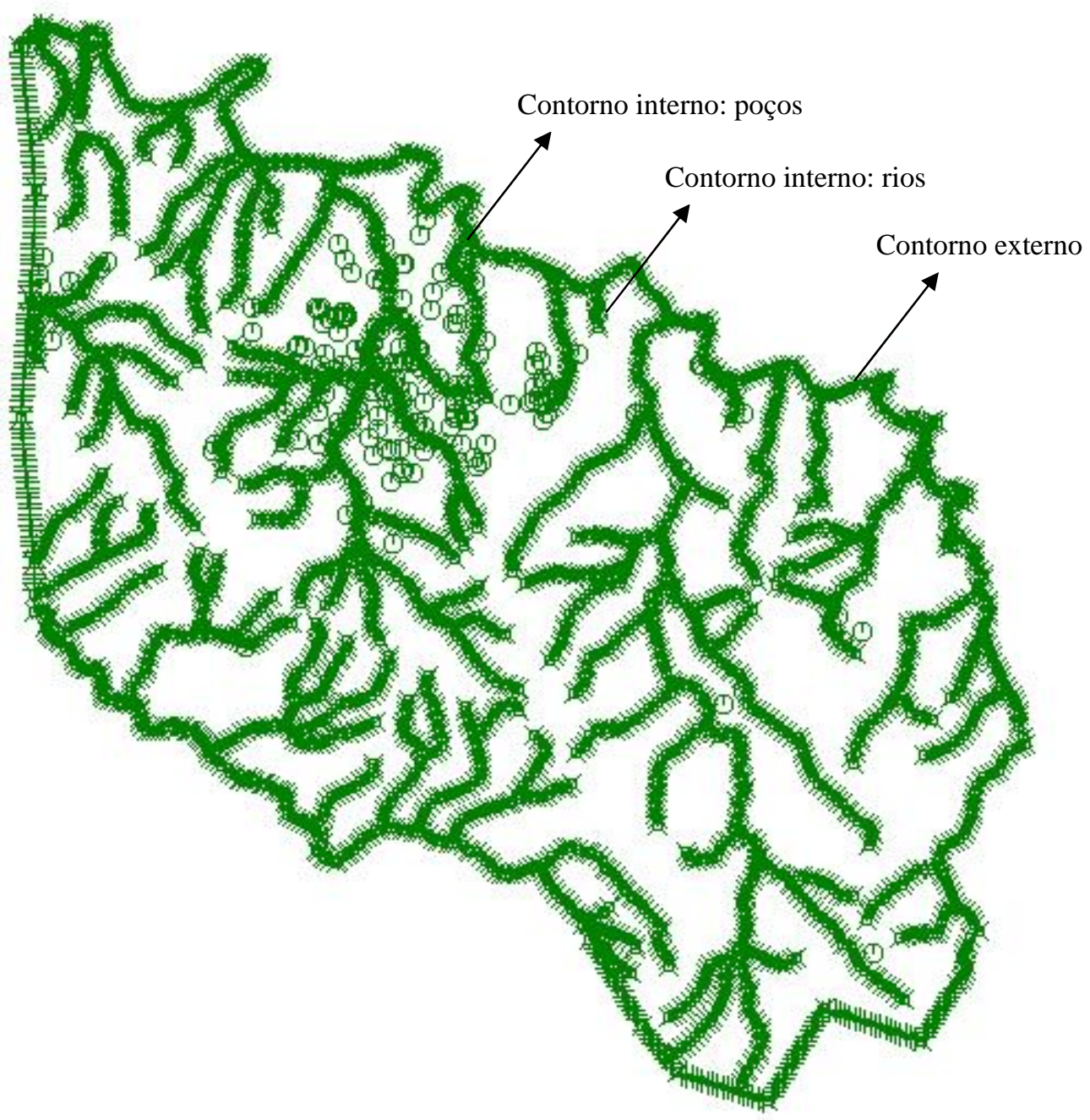

Figura 36: Contornos internos externo

Um detalhe do município de Ribeirão Preto está apresentado na Figura 37; pode-se observar a grande concentração de poços em funcionamento em sua área urbana. 


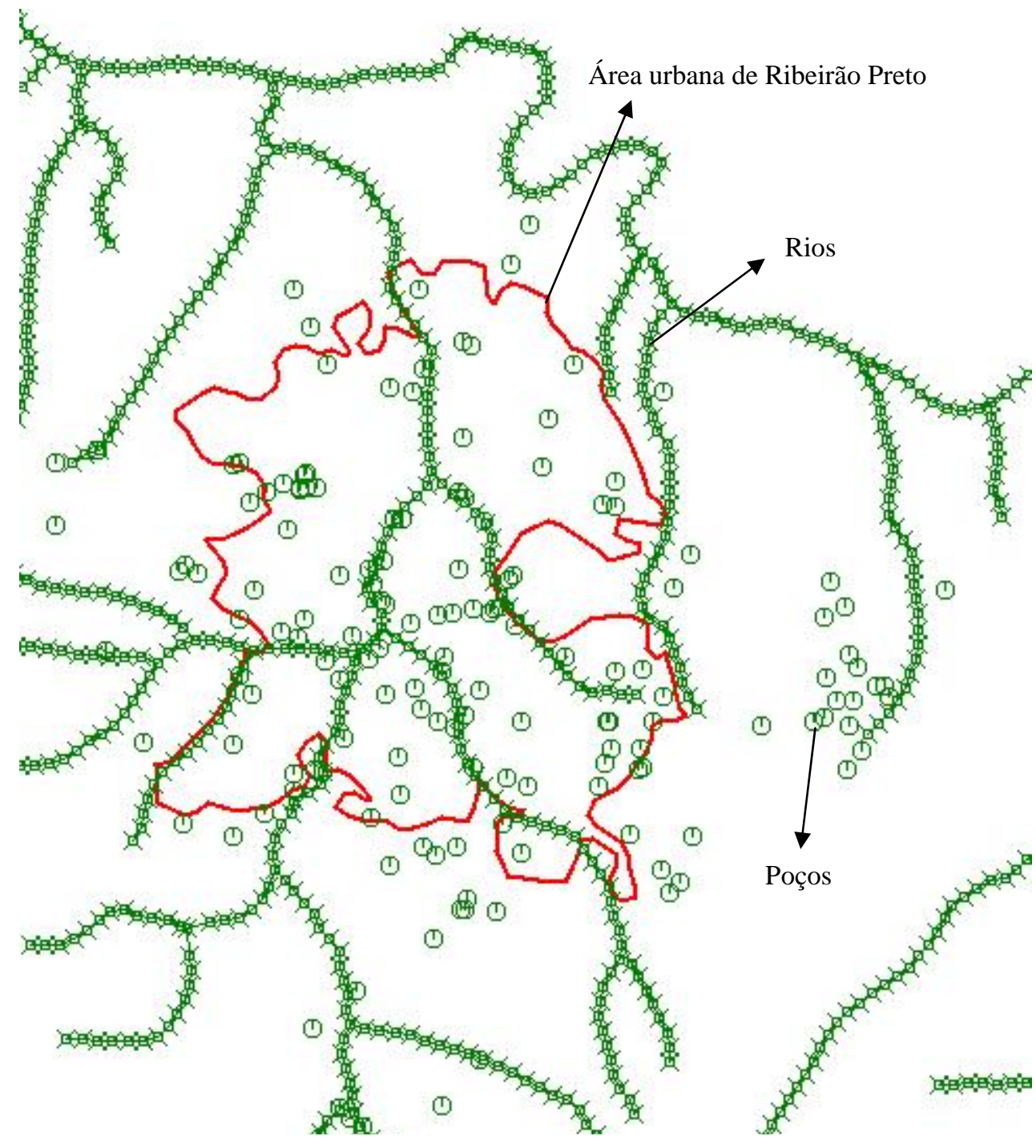

Figura 37: Detalhe dos contornos na área urbana de Ribeirão Preto

\subsubsection{MALHA DE ELEMENTOS FINITOS}

A qualidade de um modelo computacional baseado no Método dos Elementos Finitos está relacionada à qualidade da malha que representa o domínio estudado. Idealmente, triângulos eqüiláteros (e quadriláteros retângulos) são as melhores opções de elementos, admitindo variações graduais em seus tamanhos e formas. 
Para se chegar a formas próximas do ideal, a malha deve passar por uma análise visual seguida de ajustes manuais em alguns pontos. Isso se deve ao fato de que o programa não consegue otimizar todos os elementos próximos aos pontos fixos da malha em zonas de muitos contornos (poços próximos a rios, etc.).

Outro fator que deve ser levado em conta na construção da malha é o esforço computacional necessário aos cálculos e simulações que serão efetuadas no modelo numérico. Para reduzir esse esforço computacional, o programa avalia a malha e converte os triângulos que estão em regiões uniformes em quadriláteros.

Considerando-se esses fatores, foi definido um espaçamento inicial para os nós do contorno de $300 \mathrm{~m}$, havendo espaço suficiente para a possível inserção de refinamento sem sobrecarregar a memória do computador.

A malha construída para a região de estudo é apresentada na Figura 38, contando com 21035 nós e 25629 elementos. 


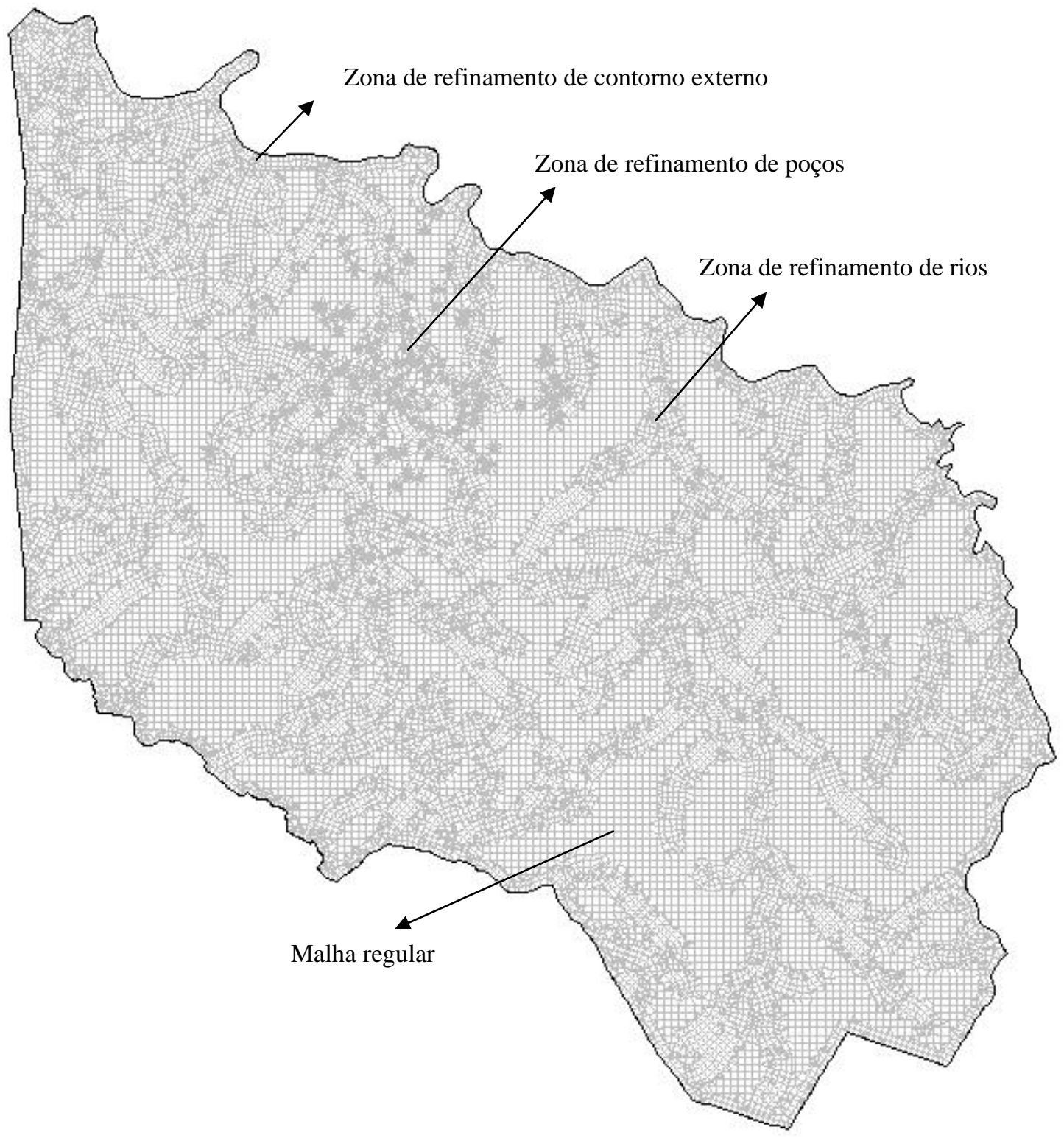

Figura 38: Malha de Elementos Finitos

Um detalhe da região de Ribeirão Preto é apresentado na Figura 39. 


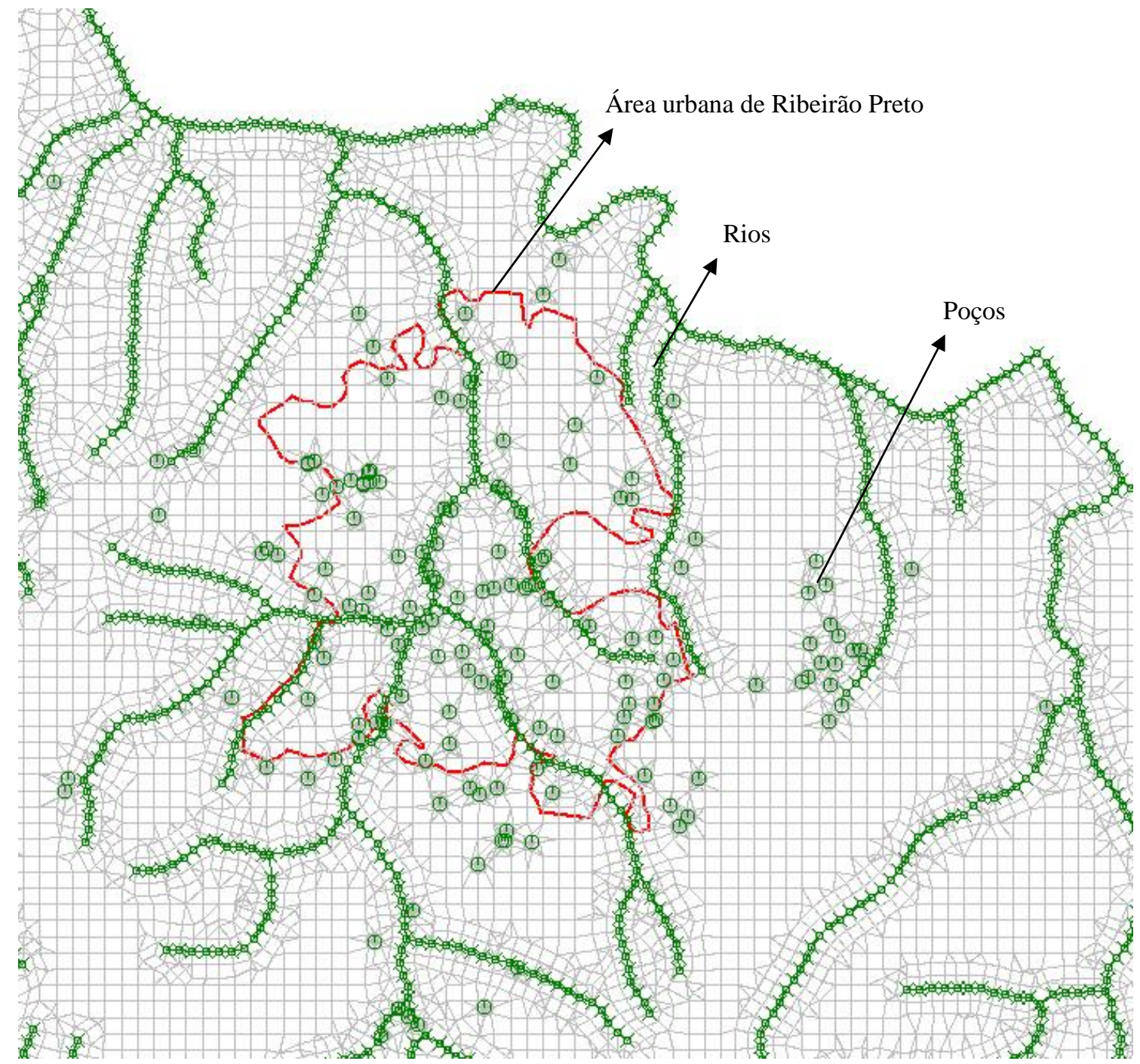

Figura 39: Detalhe da malha e contornos na área urbana de Ribeirão Preto

\subsubsection{PARÂMETROS HIDROGEOLÓGICOS}

Com base nos valores da Seção 4.1.6 (página 48), nas isópacas do mapa da Figura 20 e em dados de poços, foram definidos inicialmente para o Aqüífero Guarani na região do Projeto Piloto de Ribeirão Preto:

- Espessura média da porção confinada $\left(E_{c}\right)=250 \mathrm{~m}$ 
- Espessura média da porção livre $\left(E_{1}\right)=180 \mathrm{~m}$

- Espessura média total $(E)=220 \mathrm{~m}$

- Condutividade hidráulica $(K)=3,0.10^{-5} \mathrm{~m} / \mathrm{s}=2,6 \mathrm{~m} / \mathrm{d}$

Em seguida, foi calculada a transmissividade:

- Transmissividade da porção confinada $\left(T_{c}\right)$

$$
\mathrm{T}_{\mathrm{c}}=\mathrm{K} \cdot \mathrm{E}_{\mathrm{c}}=2,6.250=650 \mathrm{~m}^{2} / \mathrm{d}
$$

- Transmissividade da porção livre $\left(\mathrm{T}_{1}\right)$

$$
\mathrm{T}_{1}=\mathrm{K} \cdot \mathrm{E}_{\mathrm{l}}=2,6.180=468 \mathrm{~m}^{2} / \mathrm{d}
$$

\subsubsection{TAXA DE RECARGA E CONDIÇÕES DE CONTORNO}

As entradas e saídas de água da região, necessárias para se chegar ao balanço hídrico, são representadas pela recarga e pelas condições de contorno definidas para o modelo numérico.

A recarga, definida como entrada, foi distribuída aos elementos da malha de acordo com as características geológicas de cada um deles. A recarga considerada inicialmente (já considerando o escoamento básico) foi de $20 \mathrm{~mm} / a n o$ para as áreas confinadas e $400 \mathrm{~mm} / a n o$ para as zonas livres, baseando-se em valores médios da bibliografia e da pluviosidade da região $(1400 \mathrm{~mm} / \mathrm{ano}$ segundo DAEE, 1974).

A drenagem do aqüífero aos rios foi simulada por condição de contorno de Carga Especificada (condição de $1^{\circ}$ tipo ou de Dirichlet). Os valores dos pontos de carga conhecida foram atribuídos à malha, interpolados pelo CMA para os demais pontos 
e, em seguida, conferidos e corrigidos de acordo com a elevação do terreno. As vazões obtidas nesses pontos são uma reação do modelo à imposição da carga hidráulica. Foram utilizadas condições de $1^{0}$ tipo nos rios onde, supostamente, existe interação com o Sistema Aqüífero Guarani (escolhidos por análise de dados e complementados durante a calibração da malha) e no Rio Pardo. As cargas hidráulicas nos rios da área aflorante serão apresentadas no capítulo seguinte.

Os fluxos laterais foram simulados por condição de contorno de Fluxo Especificado (condição de $2^{\circ}$ tipo ou Neumann). A região de fluxo lateral foi estabelecida a partir da observação do nível piezométrico regional no entorno da bacia. Assim, foi definida uma zona de fluxo lateral a oeste da área de estudo, na direção do Rio Paraná. Os pontos onde são atribuídos os valores de fluxo especificado coincidem com os nós da malha no seu contorno externo. A descarga foi definida a partir do gradiente hidráulico no contorno sul da área de estudo, como segue:

$$
Q=-K \cdot i \cdot b \cdot l, \text { em que: }
$$

- $Q$ = descarga lateral saindo da área de estudo $\left(\mathrm{m}^{3} / \mathrm{s}\right)$;

- $K=$ condutividade hidráulica $=3,0.10^{-5} \mathrm{~m} / \mathrm{s}$;

- $i=$ gradiente hidráulico do $\mathrm{SAG}=-3 \mathrm{~m} / \mathrm{km}$;

- $b$ = espessura média do $\mathrm{SAG}=220 \mathrm{~m}$;

- $l$ = largura média da área $=30 \mathrm{~km}$.

Então tem-se:

$$
Q=3,0 \cdot 10^{-5} \cdot 0,003 \cdot 220 \cdot 30000=0,594 \mathrm{~m}^{3} / \mathrm{s}=1,87 \cdot 10^{7} \mathrm{~m}^{3} / a
$$


Essa vazão de saída foi distribuída ao longo de 97 nós na fronteira Oeste, resultando $1,92.10^{5} \mathrm{~m}^{3} / \mathrm{a}$ para cada nó, e foi utilizada no processo de ajuste do modelo. 


\section{RESULTADOS E DISCUSSÕES}

O principal resultado proposto nesse estudo é um modelo numérico do Sistema Aqüífero Guarani na região do Projeto Piloto de Ribeirão Preto, ferramenta muito útil para o gerenciamento de recursos hídricos subterrâneos na região.

\subsection{AJUSTE DO MODELO NUMÉRICO}

Para contornar a falta de informações verificadas em campo, foram testadas algumas configurações de funcionamento do fluxo subterrâneo e superficial, com os elementos hidrogeológicos sendo ativados seqüencialmente ao modelo numérico. Uma vantagem desse procedimento é a possibilidade de se analisar a sensibilidade do modelo e o impacto de cada componente do balanço hídrico.

Os elementos hidrogeológicos foram adicionados da seguinte forma:

1. Rio Pardo e o Ribeirão do Tamanduá, por se constituírem nos principais cursos d’água da parte aflorante;

2. Cursos d’água da parte aflorante e a descarga regional subterrânea de saída pela fronteira Oeste;

3. Poços em funcionamento no município de Ribeirão Preto até a década de 50 ;

4. Ribeirão da Onça e cursos d’água em Ribeirão Preto, que estão no afloramento da Formação Serra Geral.

Os resultados do ajuste para as diferentes configurações estão apresentadas a seguir, na seqüência em que foram implementadas. As taxas de recarga e a condutividade foram mantidas constantes nesta etapa, e são indicadas em cada configuração para facilidade de consulta. 


\subsubsection{RIO PARDO E RIBEIRÃO DO TAMANDUÁ}

O Rio Pardo e o Ribeirão do Tamanduá foram os primeiros cursos d’água a serem adicionados ao modelo por se constituírem nas principais drenagens da região aflorante. As cargas hidráulicas nesses rios são apresentadas na Figura $\mathbf{4 0}$.

Foram considerados os seguintes valores:

- Recarga na área aflorante: $400 \mathrm{~mm} / \mathrm{ano}$;

- Recarga na área confinada: $20 \mathrm{~mm} / a n o$;

- Condutividade hidráulica: $3,0.10^{-5} \mathrm{~m} / \mathrm{s}$.

Na Figura 41 é mostrada a diferença entre o nível do terreno e nível potenciométrico do SAG.
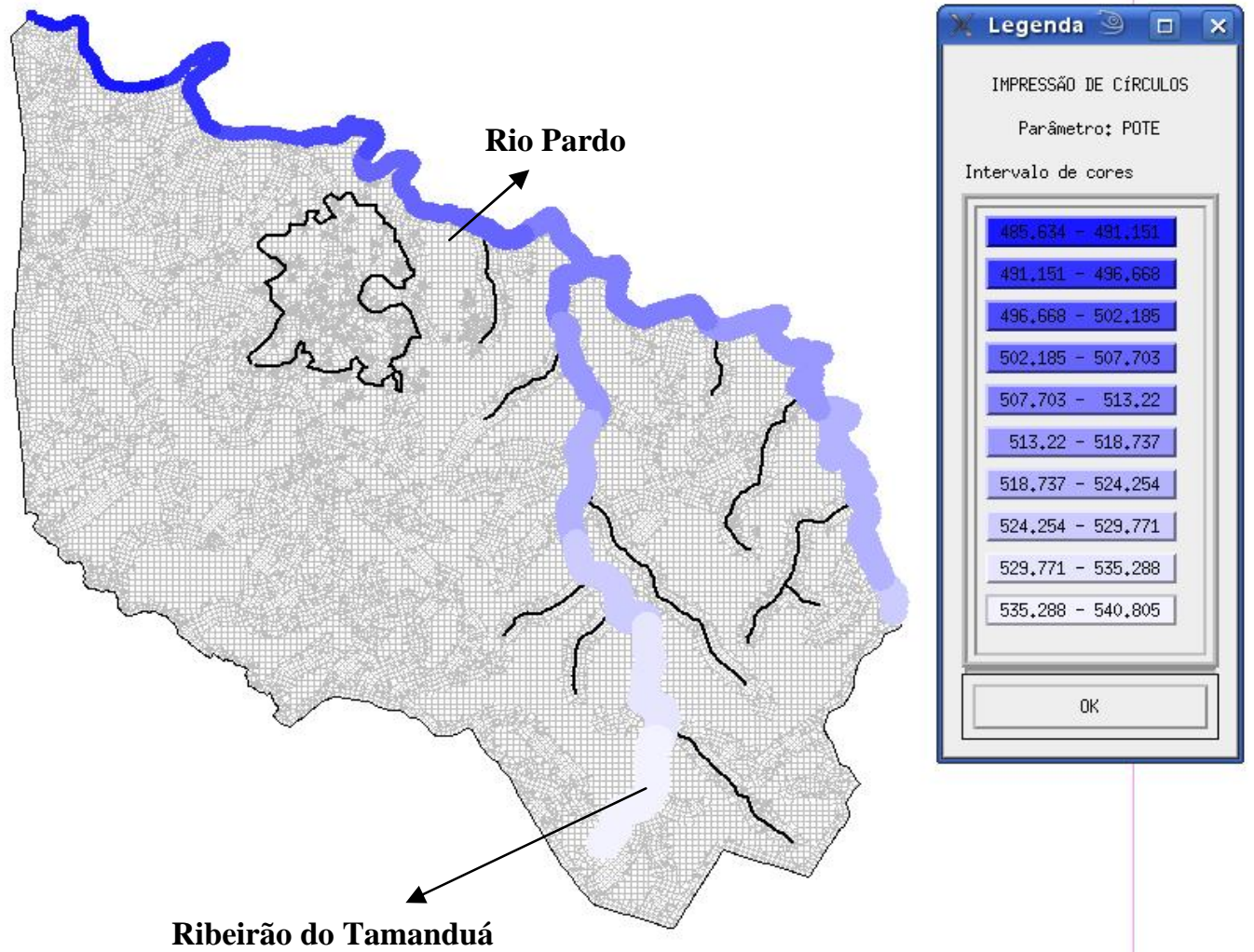

Figura 40: Cargas hidráulicas do Rio Pardo e do Ribeirão do Tamanduá (m.s.n.m) 
Pela análise da Figura 41 pode-se concluir que as entradas e saídas do sistema não estão balanceadas, ou seja, o modelo não está suficientemente drenado. Os valores negativos (regiões da figura em que a malha de elementos finitos é visível) indicam que a cota da superfície potenciométrica está acima da cota do terreno, havendo um excesso de água e, possivelmente, um ponto de descarga localizada não computado no modelo.

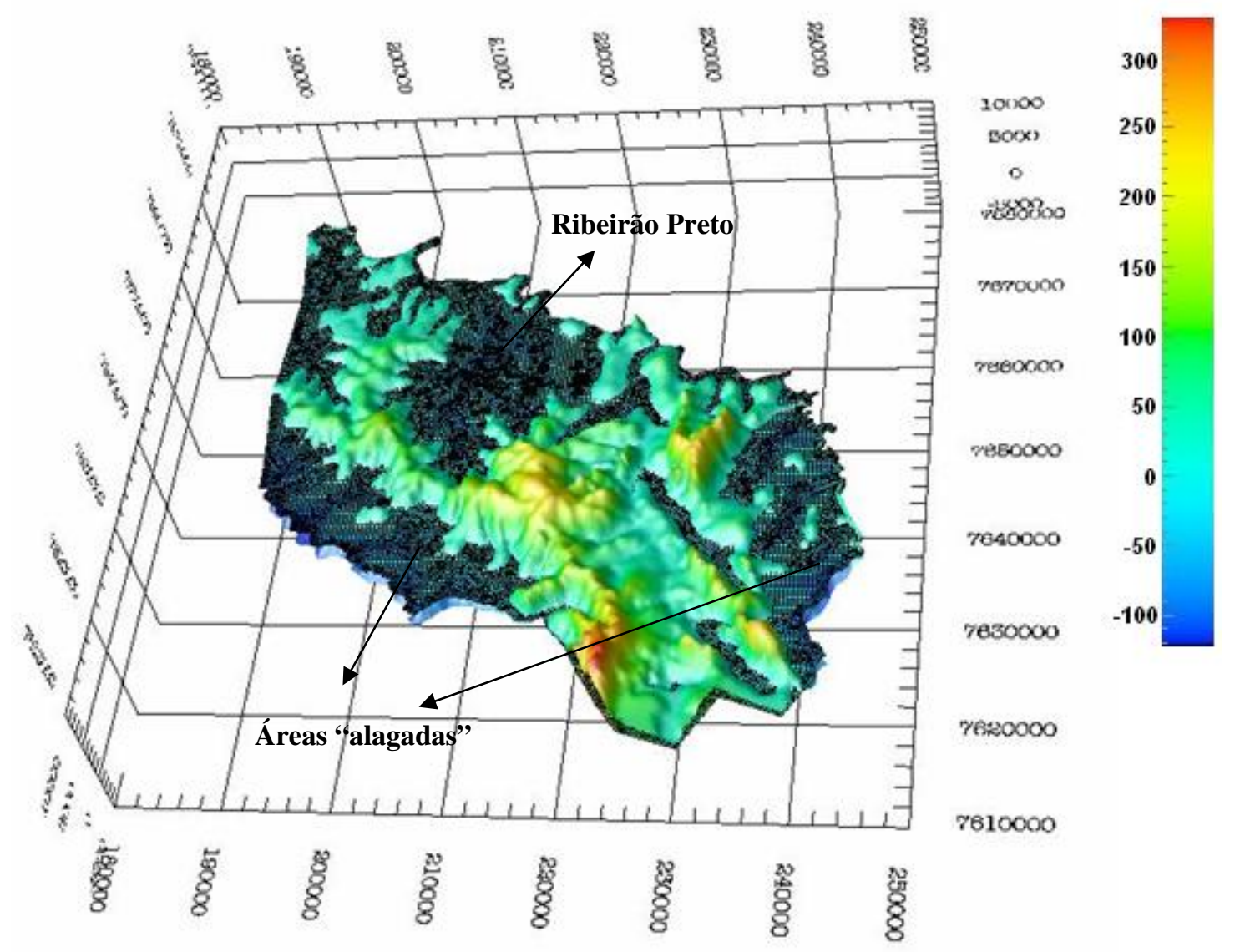

Figura 41: Diferença entre cota do terreno e nível potenciométrico do SAG (m) - configuração 1

\subsubsection{RIOS NO AFLORAMENTO E DESCARGA REGIONAL LATERAL}

Para a segunda configuração, optou-se por adicionar a descarga dos demais dos cursos d’água representativos da região 
aflorante e a descarga regional subterrânea lateral na fronteira Oeste, representando a tendência de fluxo regional na direção do Rio Paraná.

Na Figura 42 estão apresentadas as cargas hidráulicas dos rios da parte aflorante considerados como descargas do sistema e os nós utilizados para representar o fluxo de saída pela fronteira Oeste da área de estudo.

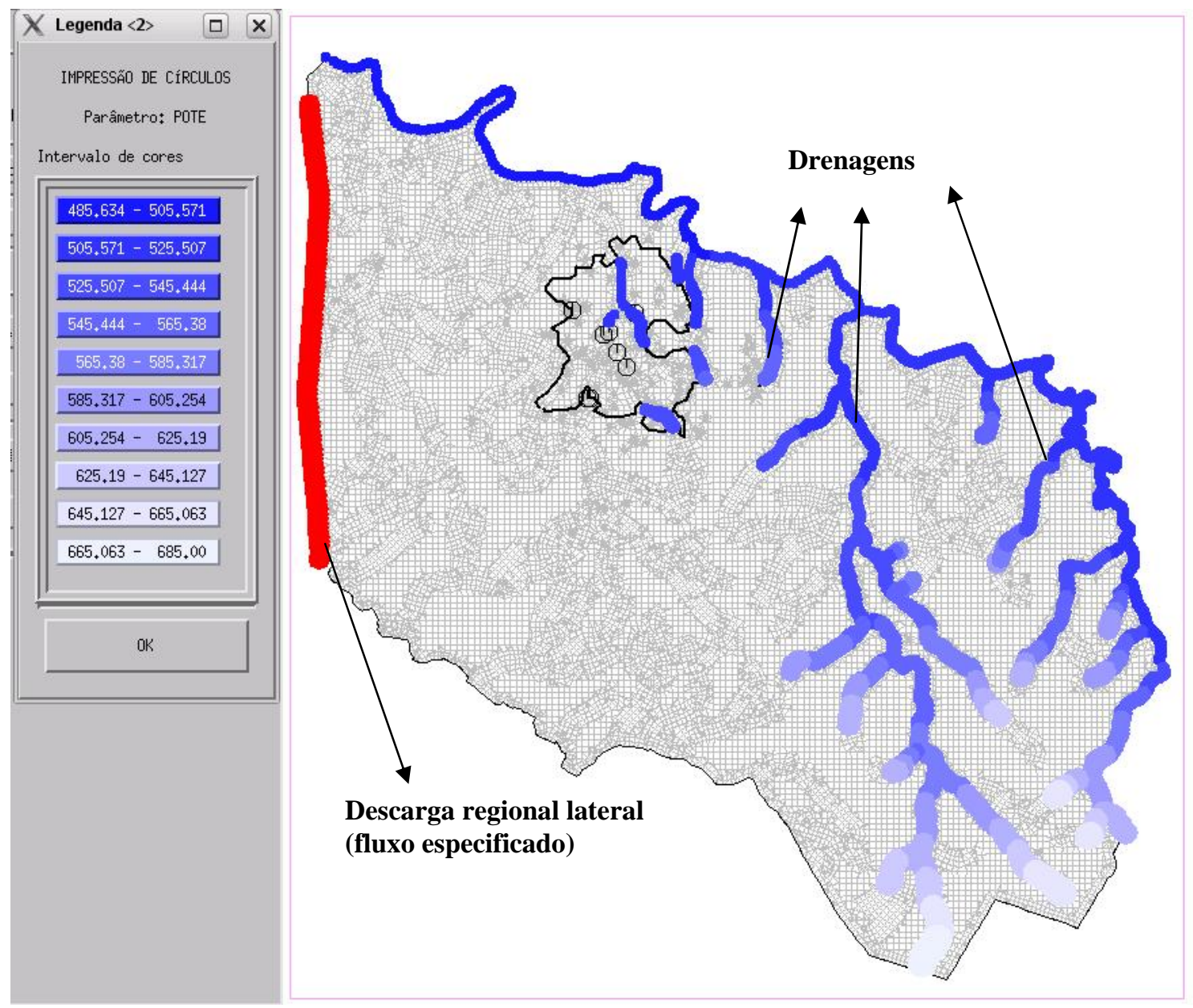

Figura 42: Carga hidráulica dos rios da região aflorante (m.s.n.m) e descarga regional lateral

Foram considerados os seguintes valores:

- Recarga na área aflorante: $400 \mathrm{~mm} / \mathrm{ano}$;

- Recarga na área confinada: $20 \mathrm{~mm} / \mathrm{ano}$; 
- Condutividade hidráulica: $3,0 \cdot 10^{-5} \mathrm{~m} / \mathrm{s}$;

- Descarga regional lateral em cada nó: $192000 \mathrm{~m}^{3} / a n o$.

Na Figura 43 é mostrada a diferença entre a cota do terreno e nível potenciométrico do SAG para a segunda configuração. Comparando-se com a Figura 41, verifica-se que a área em que o nível potenciométrico do SAG está acima da cota do terreno diminuiu, mas o modelo ainda não está devidamente ajustado.

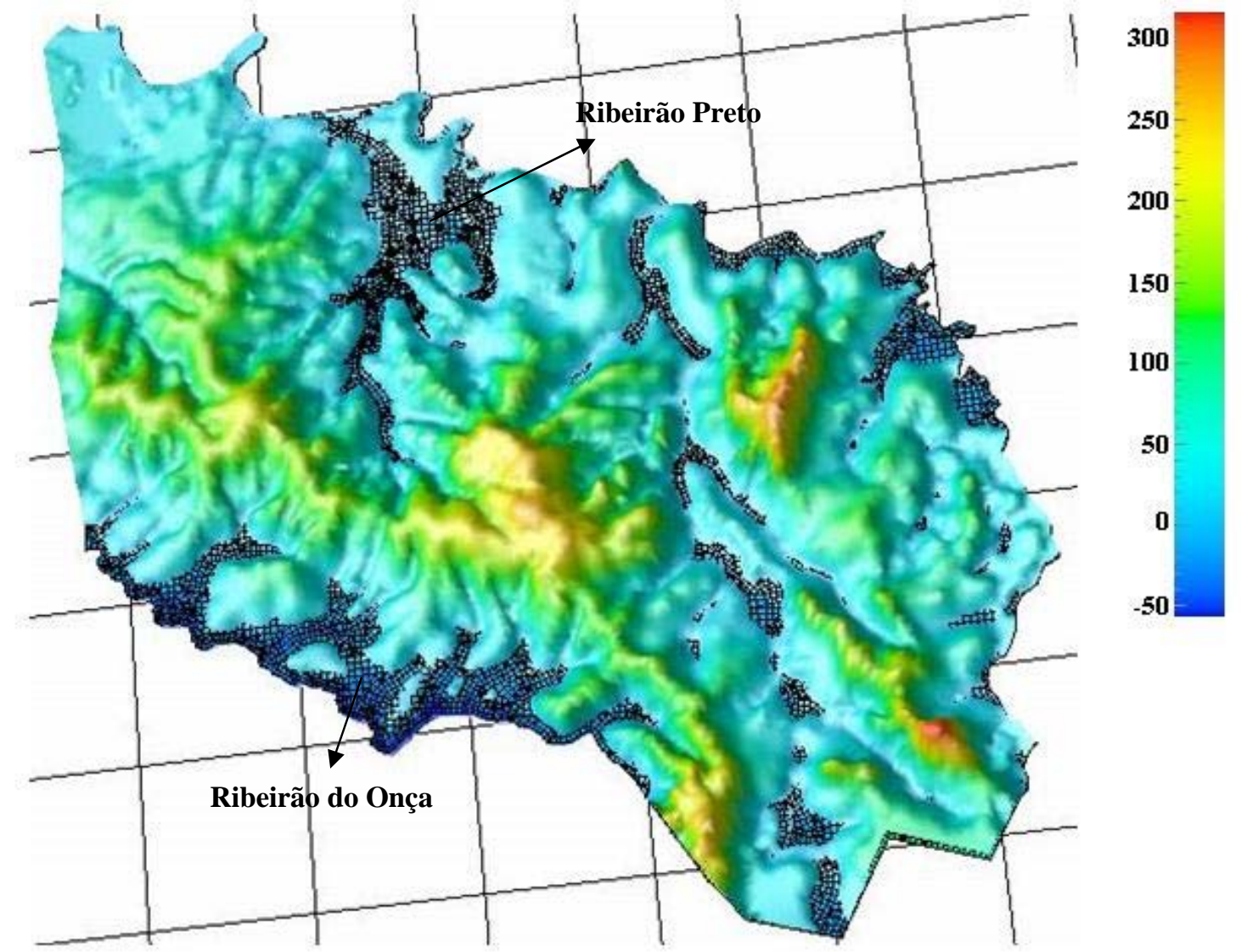

Figura 43: Diferença entre cota do terreno e nível potenciométrico SAG (m) - configuração 2

Verifica-se também na Figura 43 que, na região do município de Ribeirão Preto, bem como nas proximidades do Ribeirão do 
Onça, há um excesso de água proveniente do SAG, sugerindo a existência de drenagens nessas regiões não computadas no modelo.

\subsubsection{POÇOS EM RIBEIRÃO PRETO}

Para a terceira configuração, optou-se por adicionar os poços em funcionamento em Ribeirão Preto até a década de 50. Esses poços estão apresentados na Tabela 4.

Tabela 4: Poços em funcionamento em Ribeirão Preto até a década de 50 (adaptado de SIAGAS, 2006)

\begin{tabular}{|c|c|c|c|c|}
\hline Instalação & UTM-(N/S) & UTM-(L/O) & $\begin{array}{c}\text { Profundidade do } \\
\text { Nível Estático }(\mathbf{m})\end{array}$ & $\begin{array}{c}\text { Vazão Após } \\
\text { Estabilização }\left(\mathbf{m}^{\mathbf{3}} \mathbf{h}\right)\end{array}$ \\
\hline $01 / 01 / 1938$ & 7653100 & 206760 & 23 & 72 \\
\hline $01 / 01 / 1938$ & 7653100 & 206760 & 23 & 72 \\
\hline $01 / 01 / 1942$ & 7657370 & 207550 & 29 & 72 \\
\hline $01 / 01 / 1945$ & 7659050 & 205550 & 45 & 80 \\
\hline $01 / 01 / 1948$ & 7655160 & 209220 & 1 & 80 \\
\hline $01 / 01 / 1948$ & 7655900 & 208850 & 1 & 35 \\
\hline $01 / 01 / 1949$ & 7653100 & 206480 & 34 & 80 \\
\hline $01 / 01 / 1954$ & 7657420 & 207520 & 16 & 120 \\
\hline $01 / 01 / 1955$ & 7661450 & 234350 & 91 & 11,2 \\
\hline $01 / 01 / 1956$ & 7661880 & 192550 & 31 & 32,7 \\
\hline $01 / 01 / 1956$ & 7658650 & 209800 & 15 & 33 \\
\hline $01 / 01 / 1957$ & 7662000 & 192420 & 61,5 & 36 \\
\hline
\end{tabular}

Foram considerados os seguintes valores:

- Recarga na área aflorante: $400 \mathrm{~mm} / \mathrm{ano}$;

- Recarga na área confinada: $20 \mathrm{~mm} / \mathrm{ano}$;

- Condutividade hidráulica: $3,0.10^{-5} \mathrm{~m} / \mathrm{s}$;

- Descarga regional lateral em cada nó: $192000 \mathrm{~m}^{3} / \mathrm{ano}$.

Na Figura 44 estão apresentadas as cargas hidráulicas dos rios da parte aflorante considerados como descargas do sistema, os 
nós utilizados para representar descarga regional lateral pela fronteira Oeste da área de estudo e os poços em funcionamento em Ribeirão Preto até a década de 50.

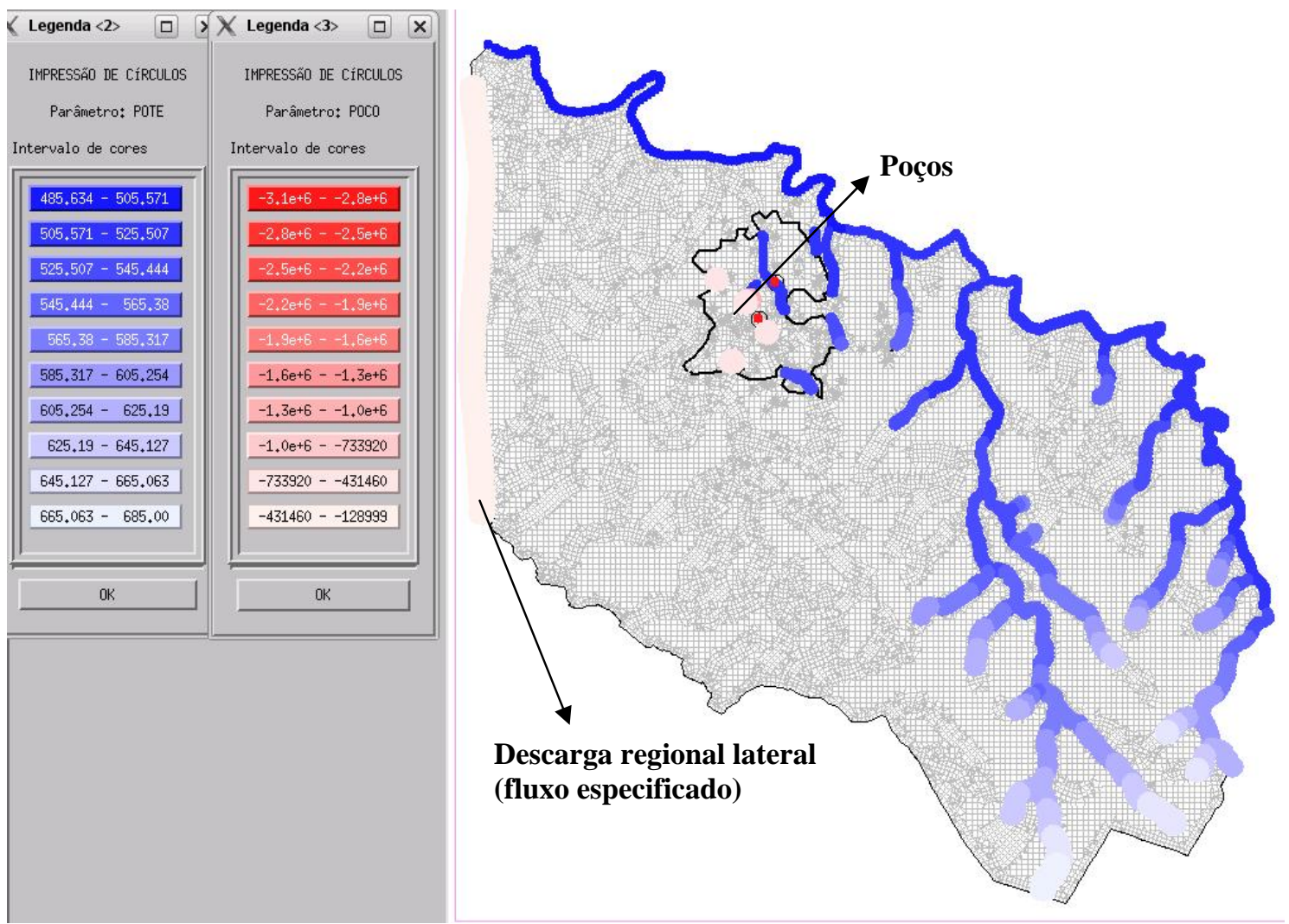

Figura 44: Carga hidráulica dos rios da região aflorante (m.s.n.m), descarga regional lateral e poços $\left(\mathrm{m}^{3} / \mathrm{ano}\right)$ em Ribeirão Preto até a década de 50

Na Figura 45 é mostrada a diferença entre a cota do terreno e o nível potenciométrico do SAG para a terceira configuração. Notase que a alteração é imperceptível, indicando que a vazão extraída pelos poços em Ribeirão Preto até a década de 50 tinha pequeno impacto no sistema de fluxo. Isso vai de encontro às constatações de DAEE (1974), que verifica esse fato até a década de 70 pelo menos. 
Portanto, mesmo com a adição desses poços, a região de Ribeirão Preto ainda não está totalmente drenada, e o modelo ainda não está devidamente ajustado.

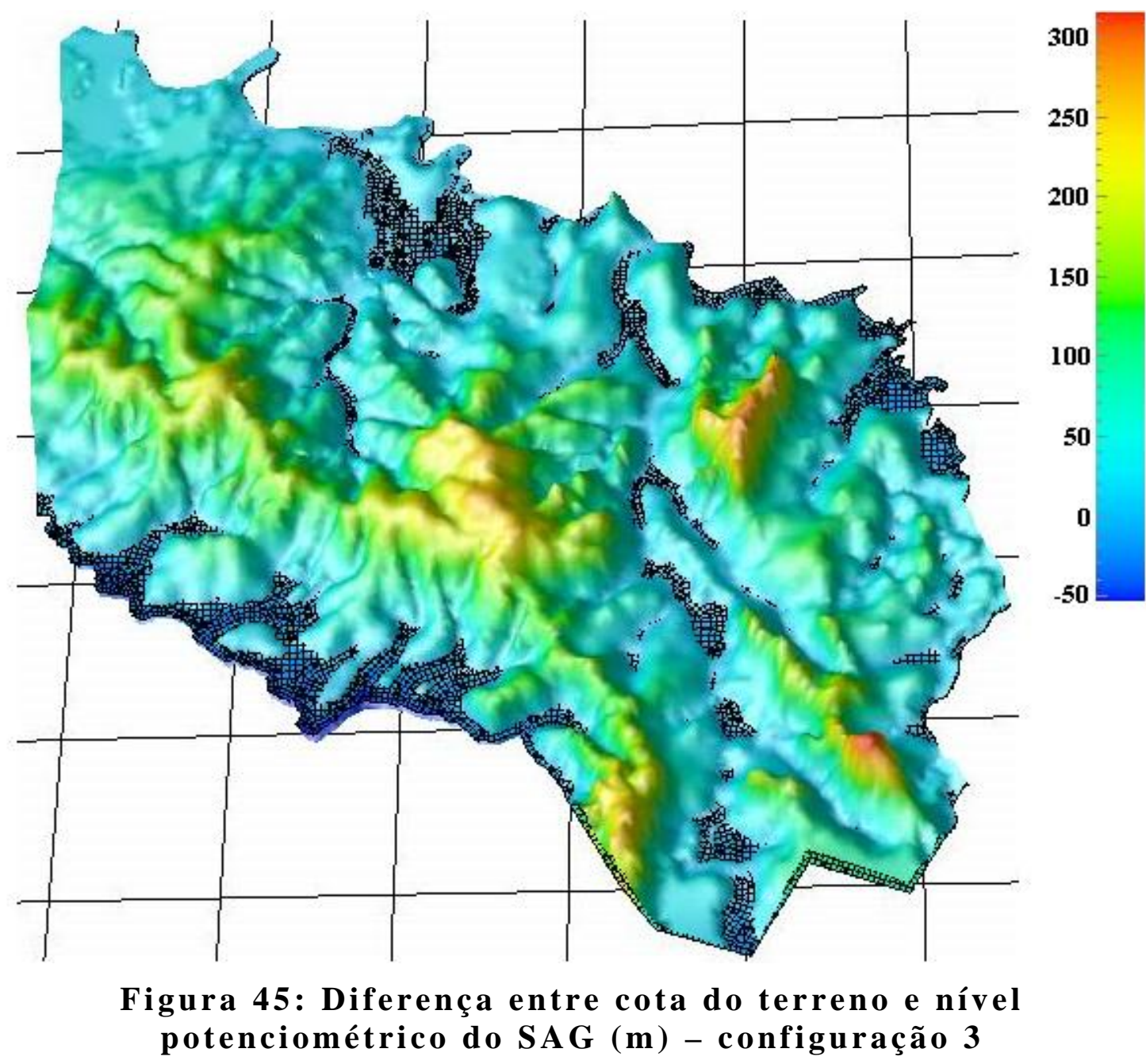

\subsubsection{RIBEIRÃO DO ONÇA E TRECHOS DE RIOS EM RIBEIRÃO PRETO}

A quarta configuração de dados para ajuste do modelo levou em conta a possibilidade do contato hidráulico entre o SAG e alguns cursos d’água que possam estar localizados em lineamentos da Formação Serra Geral. 
A suposição é que esse contato exista com o Ribeirão do Onça e com os afluentes do Ribeirão Preto que estão nas proximidades da zona de afloramento da Formação Botucatu na área urbana de Ribeirão Preto. As cargas hidráulicas desses rios, a descarga regional lateral pela fronteira Oeste da área de estudo e os poços em funcionamento em Ribeirão Preto até a década de 50 são mostrados na Figura 46.
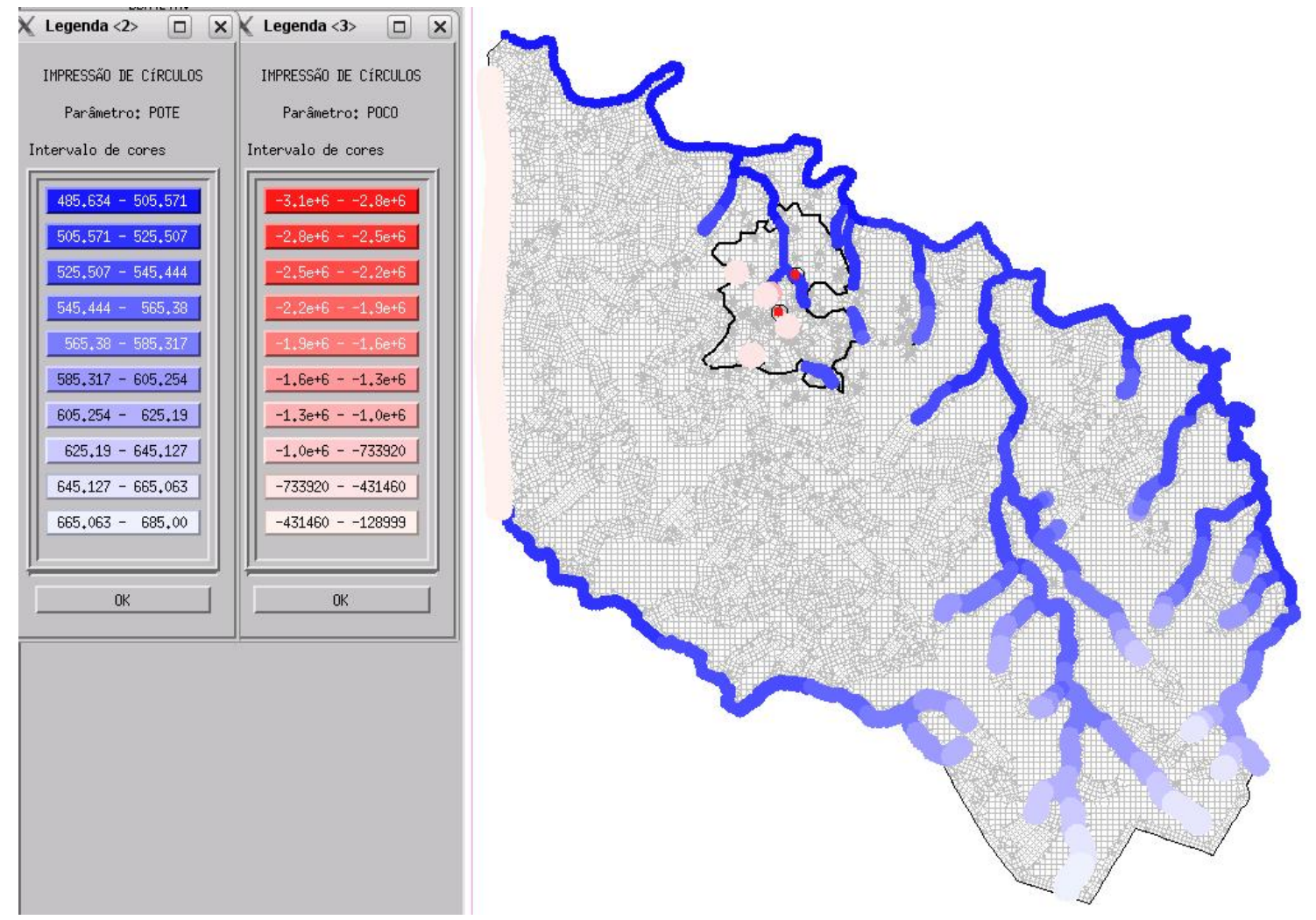

Figura 46: Carga hidráulica dos rios (m.s.n.m), descarga regional lateral e vazão em poços $\left(\mathrm{m}^{3} / \mathrm{ano}\right)$ em Ribeirão Preto

Foram considerados os seguintes valores:

- Recarga na área aflorante: $400 \mathrm{~mm} / \mathrm{ano}$;

- Recarga na área confinada: $20 \mathrm{~mm} / \mathrm{ano}$;

- Condutividade hidráulica: $3,0.10^{-5} \mathrm{~m} / \mathrm{s}$;

- Descarga regional lateral em cada nó: $192000 \mathrm{~m}^{3} / a n o$. 
Na Figura 47 é apresentada a diferença entre a cota do terreno e o nível potenciométrico do SAG para a quarta configuração.

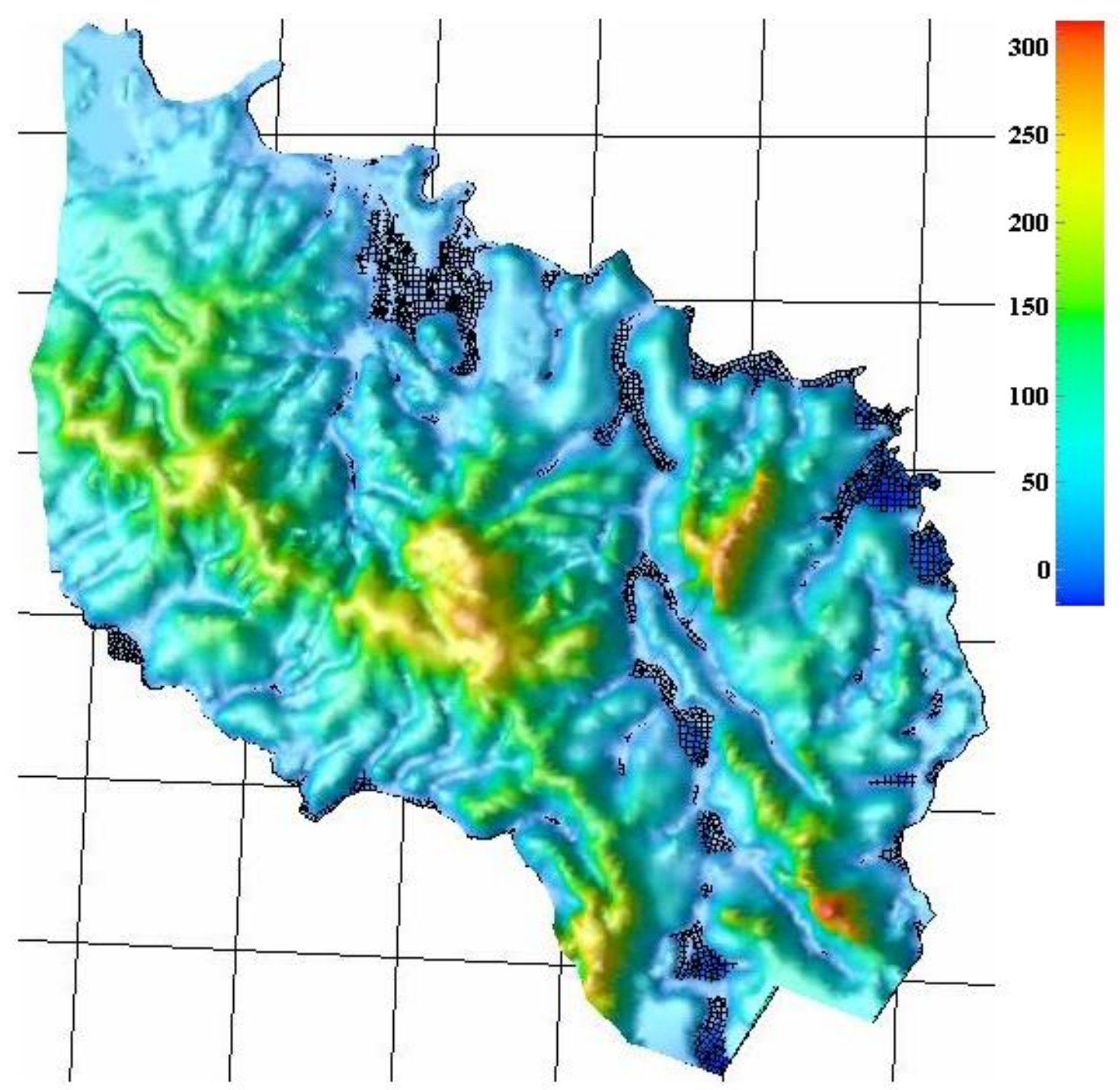

Figura 47: Diferença entre cota do terreno e nível potenciométrico do SAG (m) - configuração 4

Pela análise da Figura 47, vê-se que a inserção da descarga do Ribeirão do Onça resolveu a inconsistência do excesso de água na região Sul do modelo.

Aparentemente o problema de Ribeirão Preto ainda não está solucionado, mas o que ocorre é um problema de escala, já que a 
cota do terreno e o nível potenciométrico do SAG estão muito próximos nessa região. Então, para melhor visualizar essa área, foi elabora o detalhe apresentado na Figura 48.

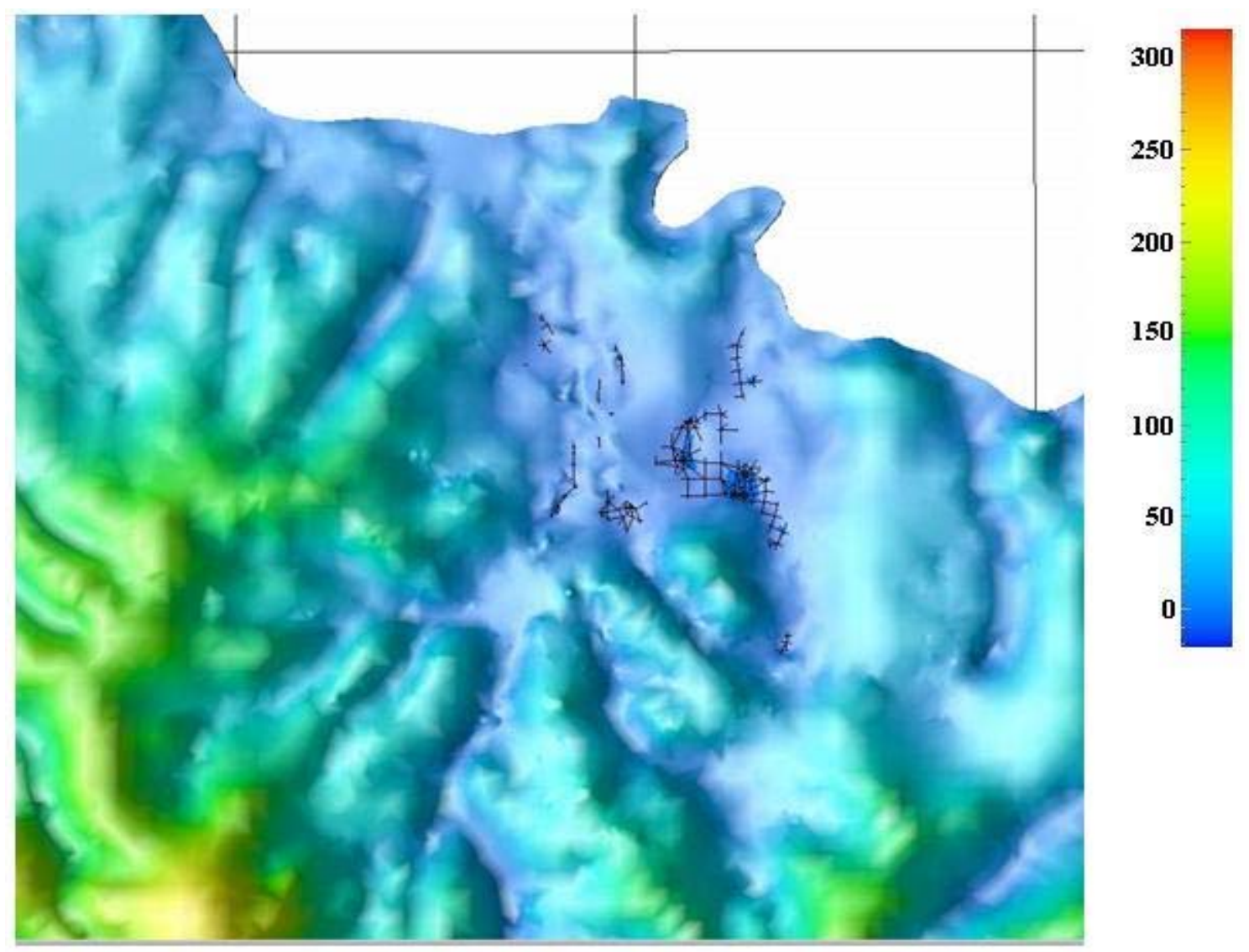

Figura 48: Diferença entre cota do terreno e nível potenciométrico do SAG (m) para a região de Ribeirão Pretoconfiguração 4

Pela análise da Figura 48, pode-se concluir que a inserção de cursos d’água na região de afloramento da Formação Serra Geral resolveu a inconsistência na região de Ribeirão Preto (as falhas remanescentes são devidas à imprecisão do modelo digital do terreno; geralmente essa imprecisão não é perceptível, mas como nesse caso os valores são baixos, ela se torna representativa). 
Esse fato é bastante representativo, já que indica que, para essa região, os cursos d'água que estão sobre os basaltos da Formação Serra Geral drenam o Aqüífero Guarani, ao invés de o recarregarem.

\subsection{RESULTADOS}

Depois de definido o sistema de fluxo da região (modelo conceitual) na seção anterior, foram gerados resultados para a verificação da consistência do modelo numérico.

Os parâmetros utilizados são os mesmos da seção anterior:

- Recarga na área aflorante: $400 \mathrm{~mm} / \mathrm{ano}$;

- Recarga na área confinada: $20 \mathrm{~mm} / a n o$;

- Condutividade hidráulica: $3,0.10^{-5} \mathrm{~m} / \mathrm{s}$;

- Descarga regional lateral em cada nó: $192000 \mathrm{~m}^{3} / a n o$.

A recarga total calculada a partir dessas taxas de recarga foi de $327,3 \cdot 10^{6} \mathrm{~m}^{3} / \mathrm{a}$.

O primeiro deles ilustra as reações de positivas e negativas dos cursos d'água no Aqüífero Guarani (Figura 49). Se a reação é positiva, o curso d'água está recarregando o SAG (Reação de Recarga); se ela for negativa, o SAG está recarregando o curso d’água (Reação de Descarga). Estes escoamentos são respostas à especificação de carga hidráulica no ponto. 


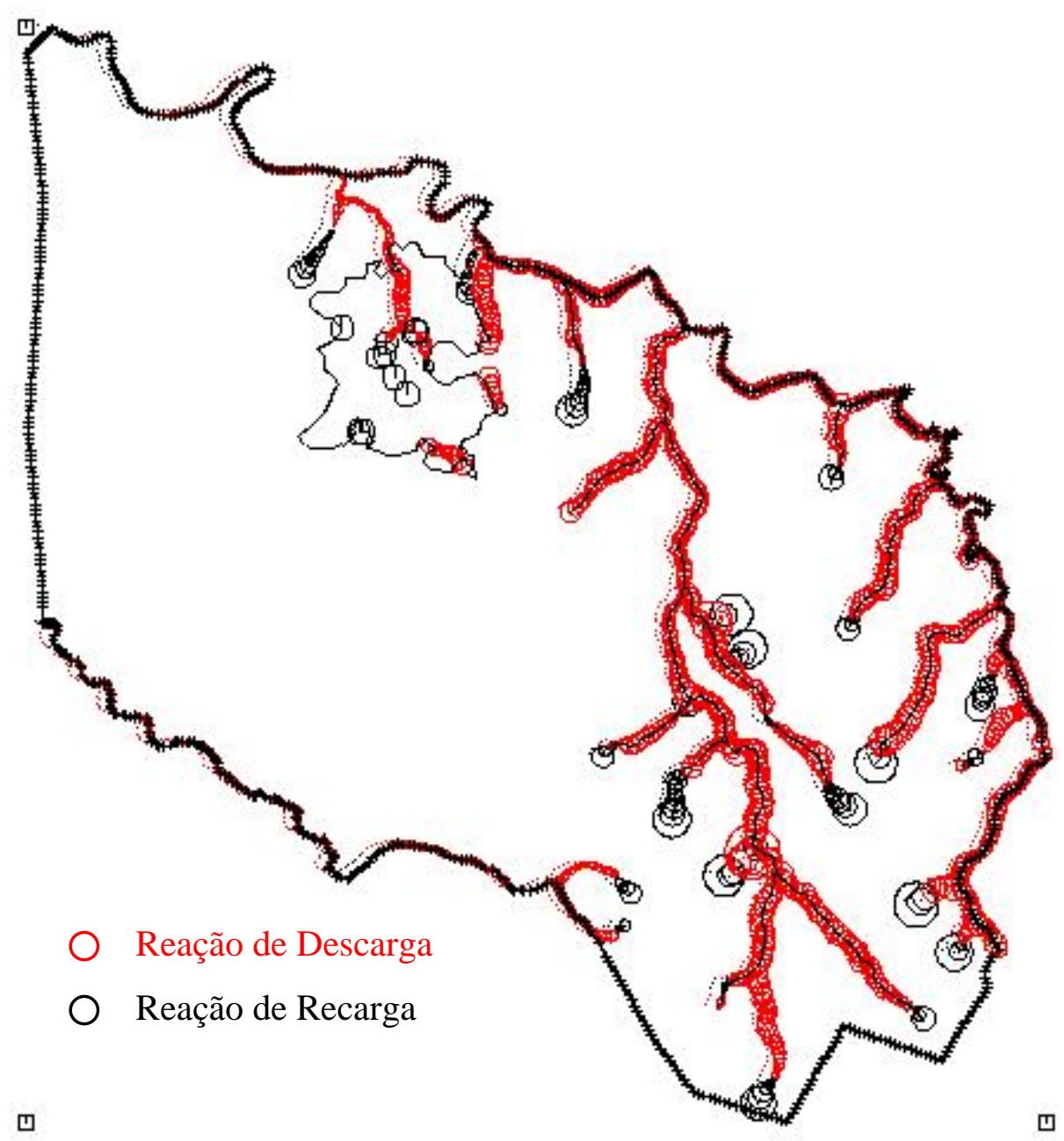

Figura 49: Reações nos rios

Pela análise da Figura 49 pode-se ver que a maioria dos cursos d’água no afloramento do Serra Geral, nos arredores do município de Ribeirão Preto apresenta reação negativa, ou seja, estão drenando o SAG. Isto vai de encontro ao proposto na seção anterior, ao se considerar esses rios em conexão hidráulica com o SAG, e drenando-o.

O segundo resultado gerado foi o mapa de isolinhas de potenciometria do SAG, para a década de 50. Esse mapa de isolinhas pode ser comparado àquele gerado manualmente (Figura 29) 


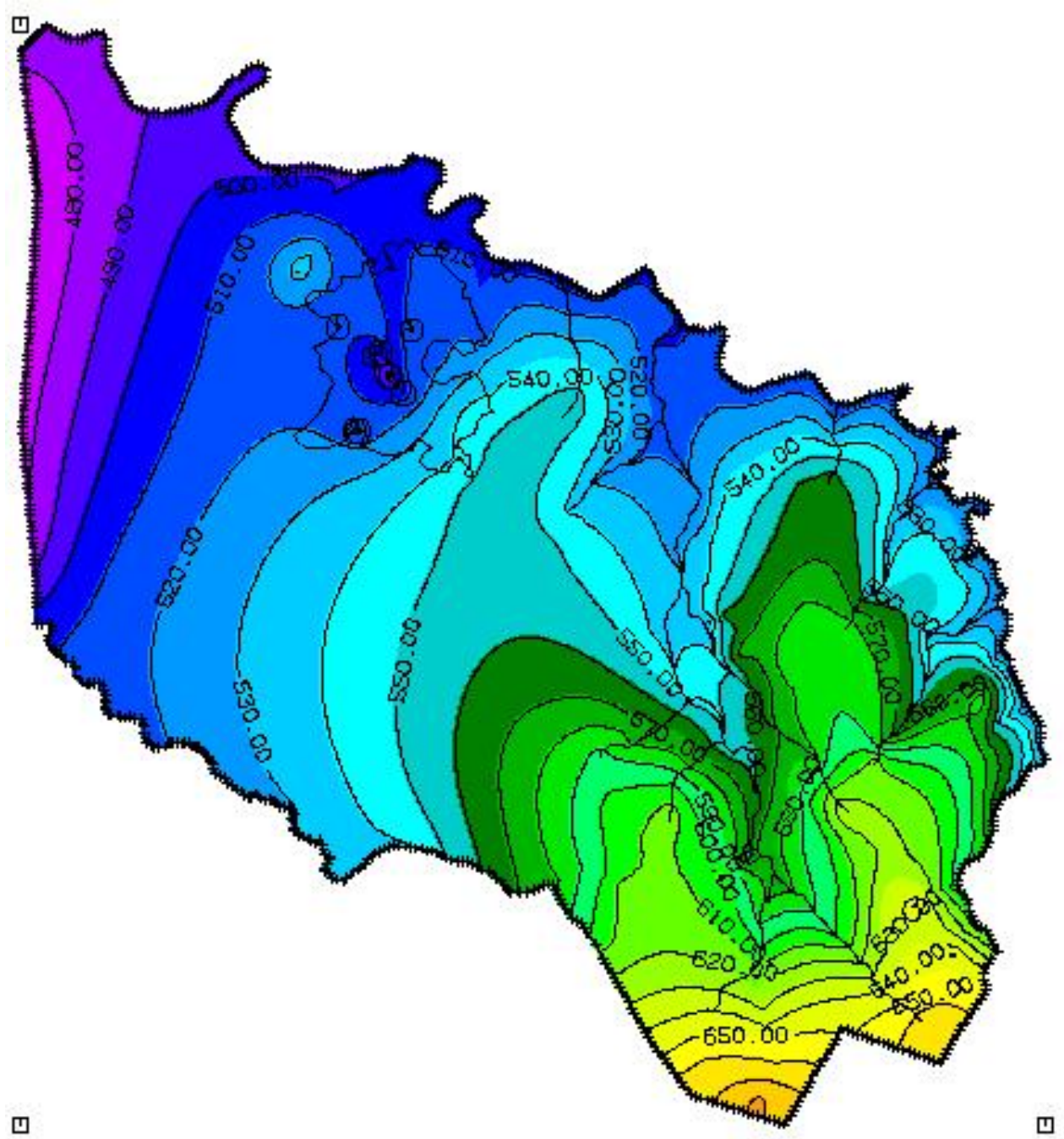

Figura 50: Isolinhas de potenciometria do SAG (m.s.n.m).

Juntamente às isolinhas é apresentada a superfície potenciométrica do SAG para a região de estudo, que é gerada a partir do balanço de entradas e saídas implementadas no modelo numérico. A superfície potenciométrica (exagerada verticalmente na proporção de $10 \mathrm{~V}: 1 \mathrm{H})$ para a década de 50 está apresentada na Figura 51. 


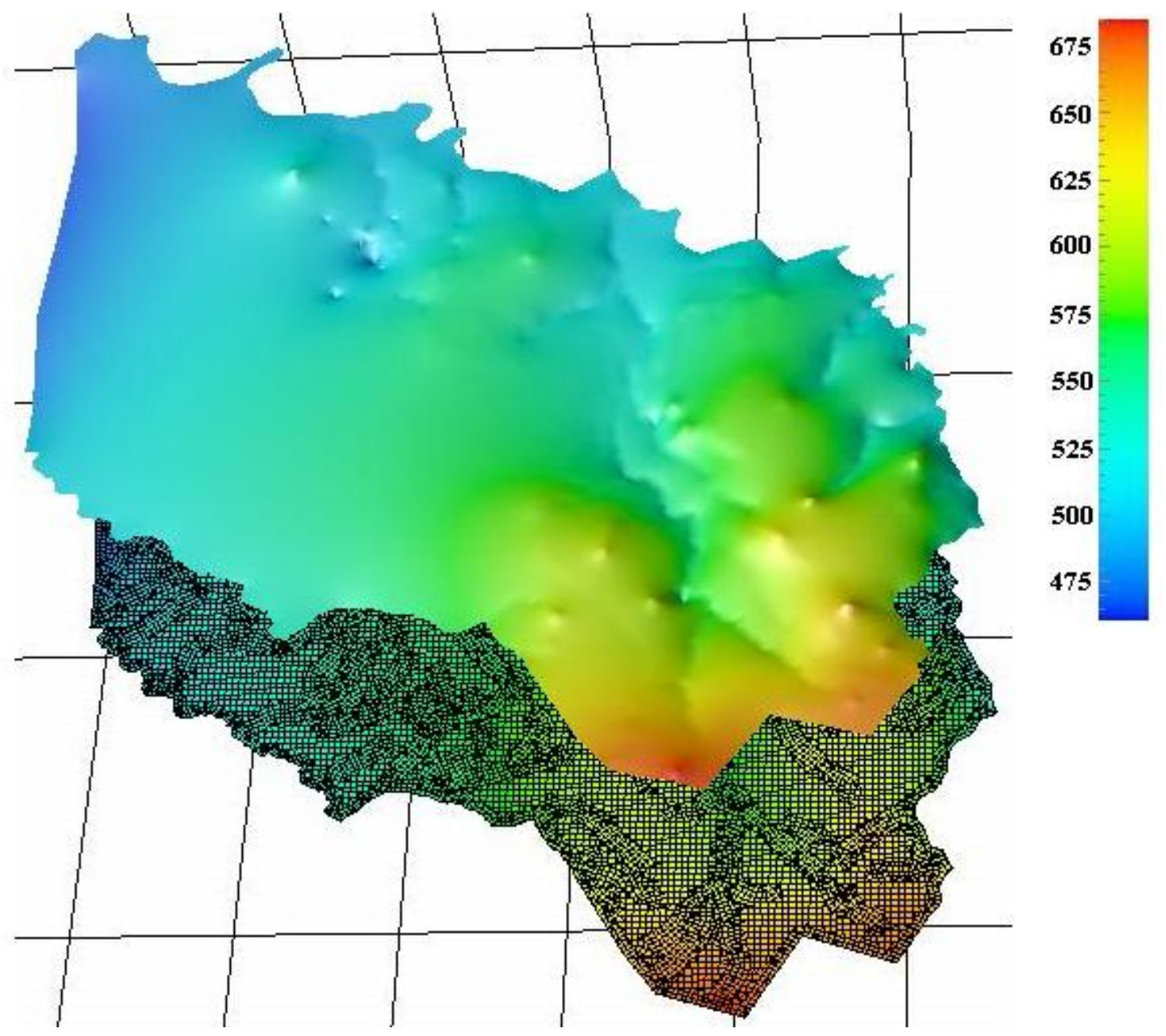

Figura 51: Superfície potenciométrica (m.s.n.m.).

Os picos existentes na superfície potenciométrica gerada nessa simulação são inconsistências do modelo numérico, já que essa superfície tende a ser mais plana para uma situação de baixa exploração. Observa-se que os valores nos picos são fixados pelo valor da carga hidráulica definida para aquele ponto do curso d’água.

Esses picos são resultado, provavelmente, de um dos seguintes fatores:

- Incerteza nos valores das cargas hidráulicas dos rios: as cotas nos cursos d’água foram tomadas a partir de um modelo 
digital de terreno, que possui relativa imprecisão. Há a necessidade de verificar esses valores em campo, se possível.

- Baixo valor de recarga: se a recarga for aumentada ocorre uma elevação global do nível potenciométrico, reduzindo os picos. Para testar essa hipótese, a recarga direta foi aumentada para $425 \mathrm{~mm} / \mathrm{a}$ (RABELO, 2005). Os resultados estão apresentados a seguir.

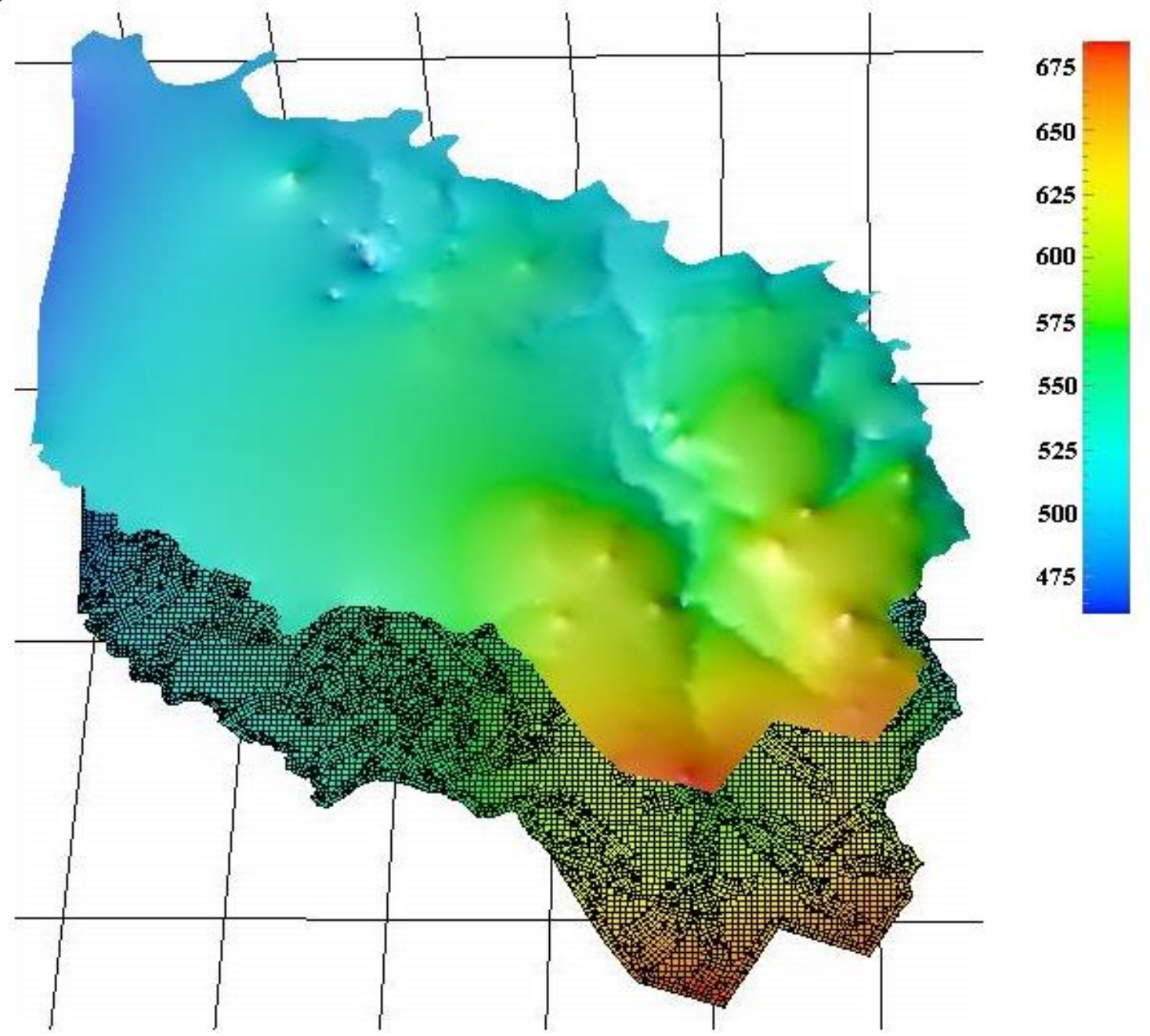

Figura 52: Superfície potenciométrica para valores de $425 \mathrm{~mm} / \mathrm{a}$ de recarga direta e $20 \mathrm{~mm} / a$ para recarga indireta (m.s.n.m.).

Percebe-se uma leve melhora, mas ainda assim não resolve a inconsistência dos picos. 
- Recarga localizada: pode estar ocorrendo uma recarga localizada através da Formação Serra Geral, ou de algum solo retentor de água, de acordo com o esquema mostrado na Figura 53. Nela, é mostrada uma hipótese onde o escoamento de base sobre o basalto provoca uma recarga localizada no Aqüífero Guarani, que depois é estabilizada por um ponto a jusante no curso d’água, gerando um pico na superfície potenciométrica. A maioria desses picos ocorre nos rios que nascem em regiões de confinamento pela Formação Serra Geral, e são mostrados na Figura 54. Esse esquema deve ser verificado fazendo-se a somatória das entradas e saídas do trecho. O mapa de reações (Figura 49) reforça essa teoria, já que as reações nas nascentes dos cursos d’água são, na maioria das vezes, positivas (recarregam o SAG).

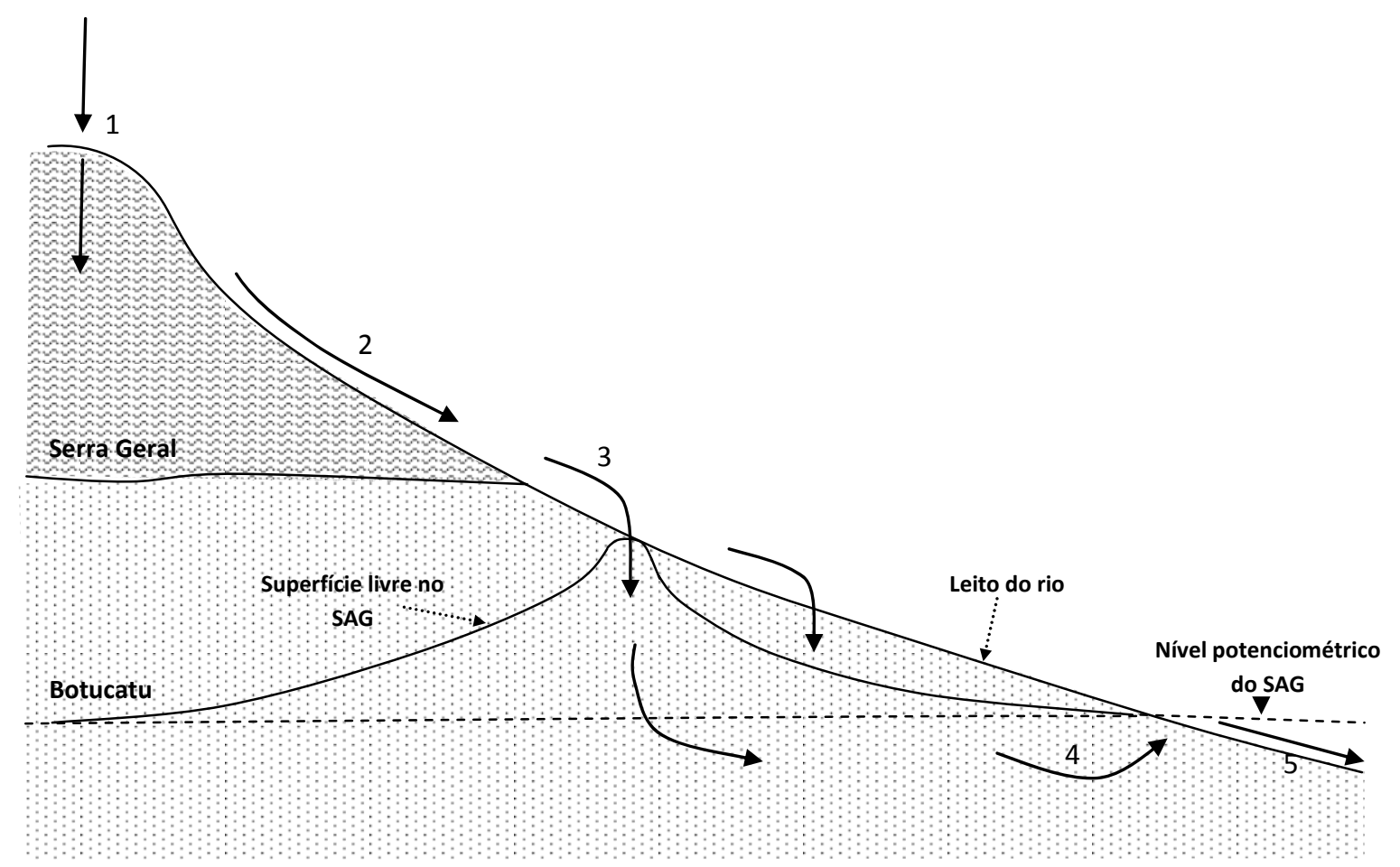

Figura 53: Esquema de fluxo em zonas de transição entre a Formação Serra Geral e a Formação Botucatu (corte longitudinal no leito do rio) 
Em que:

1 - Nascente: drenagem de solos residuais de basalto (latossolos);

2 - Vazão de base escoando sobre o basalto;

3 - Recarga localizada no Aqüífero Guarani através do leito do rio (influente);

4 - Drenagem do Aqüífero Guarani através do leito do rio (efluente);

5 - Vazão de base escoando sobre o Arenito Botucatu.

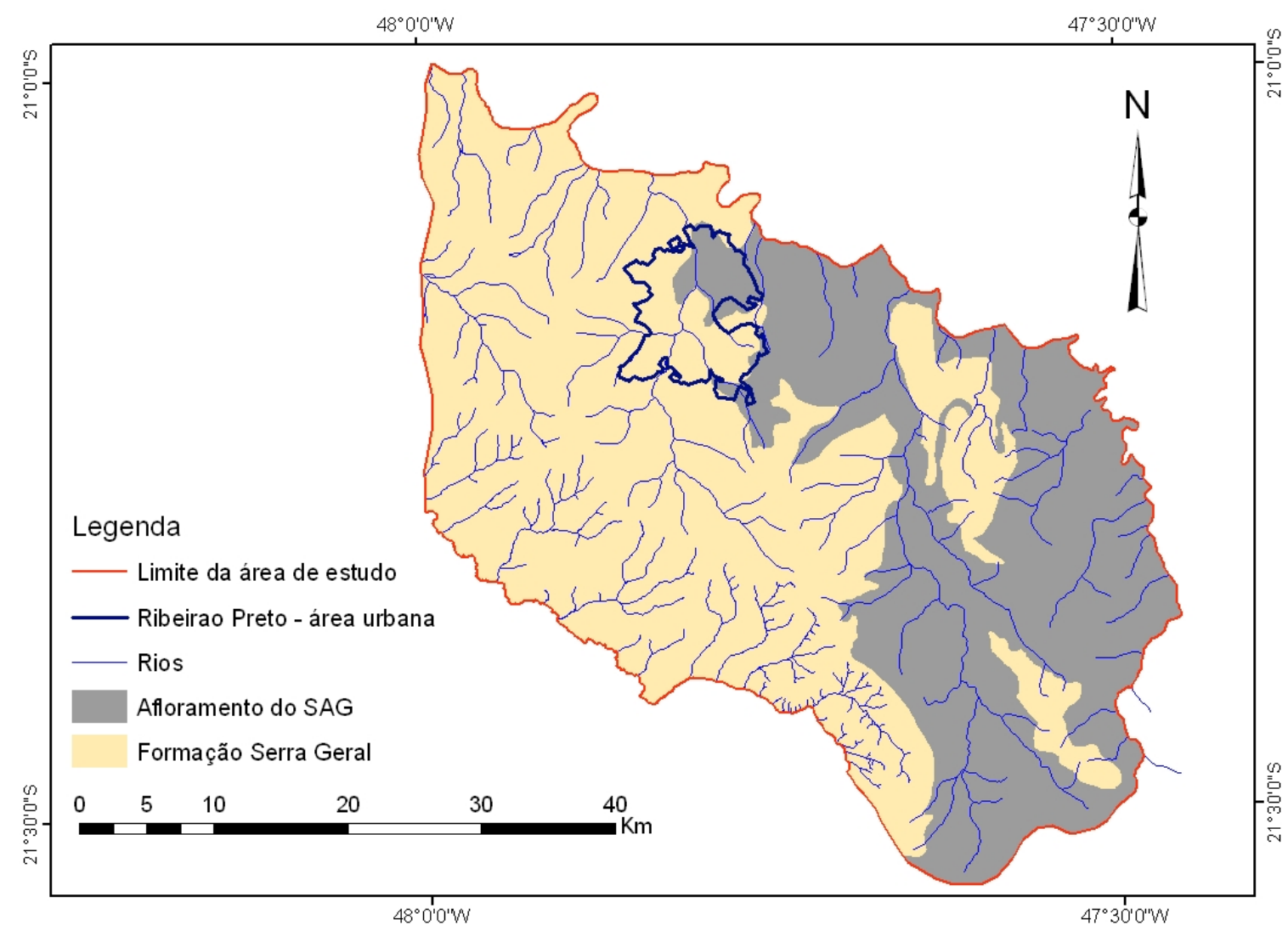

Figura 54: Afloramento do Aqüífero Guarani e cursos d’água

Para verificar a sensibilidade do modelo à recarga indireta pela Formação Serra Geral, optou-se por elaborar um mapa de reações e um de isolinhas de potenciometria para uma taxa de 
110

recarga indireta de $0,1 \mathrm{~mm} / \mathrm{a}$, ou seja, uma situação onde o Aqüífero Serra Geral praticamente não recarrega o Guarani.

As reações nos cursos d’água estão apresentadas na Figura 55.

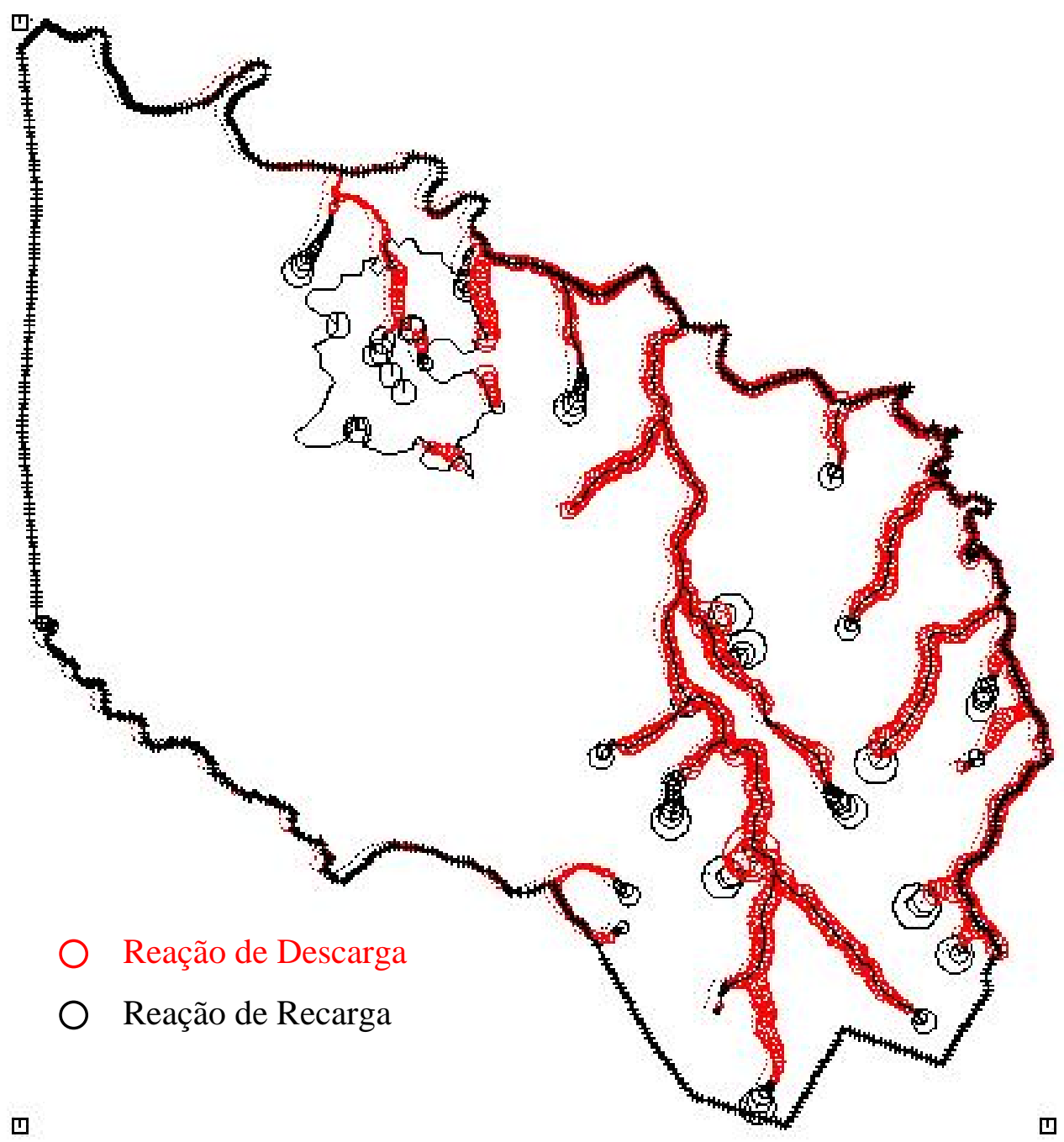

Figura 55: Reações nos cursos d'água, para uma taxa de recarga indireta de $0,1 \mathrm{~mm} / \mathrm{a}$.

As isolinhas de potenciometria estão apresentadas na Figura

56. 


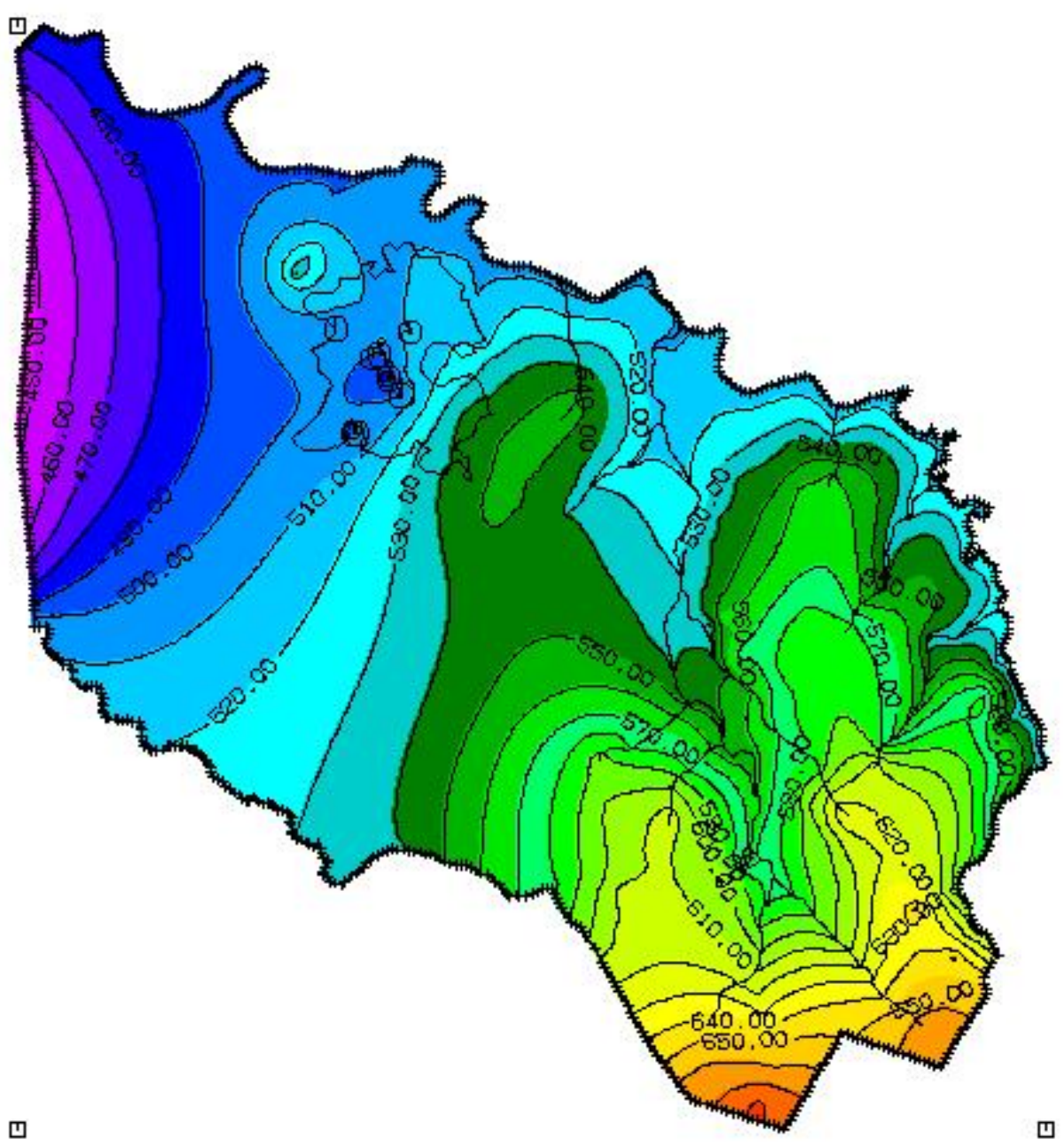

Figura 56: Isolinhas para recarga indireta do $S A G$ de $0,1 \mathrm{~mm} / \mathrm{a}$.

Pode-se perceber que ocorreram pequenas mudanças nas reações e na disposição das linhas, mas sem interferir significativamente no resultado do modelo. Nesses índices, o modelo é pouco sensível a alterações na taxa de recarga indireta. 


\section{CONCLUSÃO}

Neste trabalho objetivou-se a construção de um modelo numérico bi-dimensional, heterogêneo e estacionário do Sistema Aqüífero Guarani na região do Projeto Piloto de Ribeirão Preto. Para tal, foi realizado um extenso levantamento de dados com suporte SIG e elaborado um modelo conceitual do sistema de fluxo na região.

A construção de um modelo numérico desse porte exige uma grande quantidade de dados de entrada. Na região do município de Ribeirão Preto essa necessidade é suprida, dada a existência de uma grade quantidade de poços perfurados. Nos municípios circunvizinhos essa situação não se repete; não existe uma quantidade suficiente de dados para construir um modelo numérico preciso, sendo que a maior parte deles teve que ser inferida ou sua interpolação produziu resultados poucos precisos. No decorrer do projeto chegou-se a um banco de dados bastante representativo para a área de estudo, todos catalogados em ferramenta SIG.

A estratégia adotada para elaboração do modelo conceitual foi a de uma análise de sensibilidade a diferentes elementos hidrológicos da área de estudo. A partir dessas análises, chegou-se às seguintes conclusões .

- O modelo numérico foi construído levando-se em conta os seguintes valores de parâmetros hidrodinâmicos: Recarga direta = $400 \mathrm{~mm} / \mathrm{a}$; Recarga indireta $=20 \mathrm{~mm} / \mathrm{a}$; Condutividade $=3,0.10^{-5}$ $\mathrm{m} / \mathrm{s}$; Fluxo subterrâneo em direção ao Rio Paraná $=1,87.10^{7} \mathrm{~m}^{3} / \mathrm{a}$;

- Até a década de 50, o Aqüífero Guarani não sofria de superexplotação no município de Ribeirão Preto;

- Há a possibilidade de que os cursos d’água localizados em lineamentos da Formação Serra Geral, no município de Ribeirão Preto, estejam descarregando o SAG; 
- Verificações em campo são necessárias para se evitar que certas imprecisões do modelo digital do terreno afetem os resultados do modelo numérico;

- Há evidência de recarga localizada nas zonas de transição entre a Formação Serra Geral e a Formação Botucatu.

O modelo gerado neste trabalho apresentou um bom resultado, porém é uma versão preliminar do modelo final. A construção de um modelo numérico é um processo iterativo, de constante aperfeiçoamento. Tendo isto em mente, como continuidade desse projeto, sugere-se verificar em campo dados, simplificações e hipóteses assumidas neste trabalho. Alguns fatores que devem ser incrementados e estudados com mais cuidado são:

- Verificação em campo de cargas hidráulicas dos cursos d’água em áreas aflorantes;

- Contato hidráulico entre o Ribeirão da Onça e o SAG;

- Contato hidráulico entre os cursos d’água em zonas de afloramento da Formação Serra Geral, no município de Ribeirão Preto;

- Taxa de recarga indireta pelo Aqüífero Serra Geral;

- Taxa de recarga direta pelos afloramentos;

- Variação dos valores do fluxo lateral em direção ao Rio Paraná, acompanhada de análise de sensibilidade.

É importante salientar que este modelo numérico não está terminado. Com dados mais consistentes e verificados em campo, pode-se aumentar sua precisão e fidelidade na representação dos processos de fluxo subterrâneo para o Aqüífero Guarani, e ficam como proposta para a continuidade e término desse modelo computacional. 


\section{REFERÊNCIAS}

ARAÚJO, L. M.; FRANÇA, A. B. E POTTER, P. E., 1999. Hydrogeology of the Mercosul Aquifer System in the Chaco-Paraná Basins, South America, an comparison with de Navajo-Nugget Aquifer System, USA. Hydrogeology Journal, nº 7, p. 317-336.

BORGHETti, N. R. B; BORGhetTi, J. R. E ROSA Filho, E. F., 2004. Aqüífero Guarani - A verdadeira integração dos países do Mercosul. Curitiba - PR.

CAETANO-CHANG, M. R. E WU, F. T., 1992. Bacia do Paraná: Formações Pirambóia e Botucatu. Em: Congresso Brasileiro de Geologia, 37, São Paulo. Roteiro de Excursão. São Paulo: SBG, 1992, v.2, 19p.

CALCAGNO, A, 2001. Actividad 09 - Identificación de areas para a ejecución de programas y acciones piloto y definición de terminos de referencia. Preparación del proyecto para la protección ambiental y desarrollo sostenible del Sistema Acuífero Guaraní. Anexos. GEF - BIRF - OEA.

CAMPOS, H. C. N. S., 1999. Modelación conceptual y matamática del Acuífero Guaraní, Cono Sur. Mapa Hidrogeológico do Aqüífero Guarani. Acta Geológica Leopoldensia v. 23(4), p. 3-50.

CETESB - Companhia De Tecnologia De Saneamento Ambiental, 1997. Uso das águas subterrâneas para abastecimento público no Estado de São Paulo. CETESB, São Paulo. 48 p. 
CGIAR-CSI - Consultative Group on International Agricultural Rsearch-Consortium for Spacial Information. Disponível em: <srtm.csi.cgiar.org>. Acesso em: 2007.

CHANG, H. K., 2001. Uso atual e potencial do Aqüífero Guarani Brasil. Atividade $3 b$ do Projeto Aqüífero Guarani: Proteção Ambiental e Gerenciamento Sustentável Integrado do Aqüífero Guarani - Agência Nacional de Águas. Disponível em www.ana.gov.br/guarani/gestao/gest_cbasico.htm.

DAEE - Departamento de Águas e Energia Elétrica, 1974. Estudo de Águas Subterrâneas: Região Administrativa $n^{\circ} 6$, Ribeirão Preto. São Paulo: v. 4.

DAEE - Departamento de Águas e Energia Elétrica, 1984. Caracterização dos recursos hídricos no Estado de São Paulo. São Paulo. 175 p.

DAEE - Departamento de Águas e Energia Elétrica; IG - Instituto Geológico; IPT - Instituto de Pesquisas Tecnológicas do Estado de São Paulo e CPRM - Serviço Geológico do Brasil, 2005. Mapa de Águas Subterrâneas do Estado de São Paulo. Escala 1:1.000.000.

DNM - Departamento Nacional de Meteorologia - Ministério da Agricultura e Reforma Agrária, Secretaria Nacional de Irrigação, 1992. Normas climatológicas, 1961-1990, Brasília, p. 1-84.

ESRI, 2002. Software ArcView. Versão. 8.3. CA, USA. Manual Arcmap, 229 p.

FERNANDES, A. J.; MALDANER, C.; WAHNFRIED, I.; FERREIRA, L. M. R.; PRESSINOTTI, M. M. N.; VARNIER, C.; 
IRITANI, M. A. E HIRATA, R., 2006. Modelo conceitual preliminar de circulação de água subterrânea no Aqüífero Serra Geral, Ribeirão Preto, SP. Artigo no XIV Congresso Brasileiro de Águas Subterrâneas. Curitiba - PR.

FILI, M.; ROSA FILHO, E. F.; AUGE, M.; MONTAÑO XAVIER, J. E TUJCHNEIDER, O., 1998. El Acuífero Guarani: um recurso compartido por Argentina, Brasil, Paraguay y Uruguai (América Del Sur). Boletin Geológico y Minero, v. 109, $\mathrm{n}^{\circ}$ 4, p. 389-394, julho/agosto.

FIPAI, 1996. Relatório técnico do Projeto de Gestão da Quantidade de Águas Subterrâneas. Ribeirão Preto, SP, 43 p.

FRANTZ, L. C., 2005. Avaliação do Índice de Vulnerabilidade do Aqüífero Guarani no perímetro urbano da cidade de Sant'ana Do Livramento - RS. Dissertação de Mestrado. Universidade Federal de Santa Maria - Centro de Tecnologia, Santa Maria, RS - Brasil.

GILBOA, Y.; MERO, F. E MARIANO, I. B., 1976. The Botucatu Aquifer of South America. Model of an untapped continental aquifer. Journal of Hydrology, New York: v. 29, p. 165-179.

GUIDO, B., 2004. Grundwasserbewirtschaftung mittels eines dreidimensionalen numerischen Strömungsmodels im Raum Ribeirão Preto - São Paulo - Brasilien. Diplomarbeit am Institut für Bauningenieurswesen und Angewandte Geowissenschaften Technischen Universität Berlin.

IBGE - Instituto Brasileiro de Geografia e Estatística, Superintendência de Cartografia, 1971. Carta do Brasil. Escala 
1:50.000, reimpressão. Digitalizado por SMA - Secretaria do Meio Ambiente/CPLA - Coordenadoria de Planejamento Ambiental.

IG - Instituto Geológico/CETESB - Companhia De Tecnologia De Saneamento Ambiental/DAEE - Departamento De Águas E Energia Elétrica, 1997. Mapeamento da vulnerabilidade e risco de poluição das águas subterrâneas no Estado de São Paulo. São Paulo, 2 volumes.

IPT - Instituto de Pesquisas Tecnológicas do Estado de São Paulo, 2000. Diagnóstico da situação atual dos recursos hídricos e estabelecimento de diretrizes técnicas para a elaboração do Plano da Bacia Hidrográfica do Pardo - Relatório Zero. Relatório elaborado para o Comitê da Bacia Hidrográfica do Pardo - CBHPARDO.

KRESIC, N., 1997. Quantitative solutions in Hydrogeology and Groundwater Modeling. Lewis Publishers, cap. 11.

MALDANER, C.; FERNANDES, A. J.; WAHNFRIED, I.; FERREIRA，L. M. R.; PRESSINOTI，M. M. N.; VARNIER， C; IRITANI, M. A. E HIRATA, R., 2005. Representação tridimensional do Aqüífero Serra Geral na região de Ribeirão Preto, $S P$ (enviado ao $43^{\circ}$ Congresso Brasileiro de Geologia).

MONTEIRO, R. C., 2003. Estimativa espaço temporal da superfície potenciométrica do Sistema Aqüífero Guarani na cidade de Ribeirão Preto (SP), Brasil. Tese de Doutorado. Universidade Estadual Paulista - Instituto de Geociências e Ciências Exatas, Rio Claro, SP - Brasil. 
MOntenegro, A. A.; Righetto, A. M. E Sinelli, O., 1988. Modelação do manancial subterrâneo de Ribeirão Preto. Anais $5^{\circ}$ Congresso Brasileiro de Águas Subterrâneas, ABAS, São Paulo. P $32-41$.

MONTENEGRO, A. A., 1990. Modelação matemática do manancial subterrâneo de Ribeirão Preto - SP. Dissertação de Mestrado. Escola de Engenharia de São Carlos, Universidade de São Paulo, São Carlos, SP - Brasil.

PIUCI, J. E DINIZ, H. N., 1985. Conhecimento do Aqüífero Botucatu na Cidade de Araraquara - SP. Revista do Instituto Geológico. v. 6, p. 23-44.

RABELO, J., 2005. Desenvolvimento de modelo numérico para avaliar a recarga do Aqüífero Guarani na sua região de afloramento no Estado de São Paulo. Relatório Científico para a FAPESP. Processo n ${ }^{\circ} 02 / 12836-1$.

REBOUÇAS, A. C. 1976. Recursos hídricos subterrâneos da Bacia do Paraná - análise de pré-viabilidade. Tese de Livre Docência apresentada a Instituto de Geociências - USP. São Paulo. 143p.

REBOUÇAS. A. C. 1994. Sistema Aqüífero Botucatu no Brasil. Em: ABAS - Congresso Brasileiro de Águas Subterrâneas, 8, Recife. Anais. P. 500-509.

ROCHA, G., 1997. O grande manancial do Cone Sul. Estudos Avançados, Universidade de São Paulo, São Paulo. v. 30, p. 191213. 
ROSA FILHO, E. F.; Hindi, E. C.; GIUSTI, D. A.; ROSTIROLA, S. P.; FERREIRA, F. J. F. E BitTEnCOURT, A. V. L., 2003. Sistema Aqüífero Guarani - Considerações preliminares sobre a influência do Arco de Ponta Grossa no fluxo das águas subterrâneas. Águas Subterrâneas, São Paulo. V. 17, v. 91-111.

SG-SAG - Secretaria Geral do Projeto Sistema Aqüífero Guarani. Disponível em:

<www.sg-guarani.org/index/site/sistema_acuifero/sa001.php > . A c es s o em: 2006.

SG-SAG - Secretaria Geral do Projeto Sistema Aqüífero Guarani. Disponível em: <www.sg-guarani.org>. Acesso em: 2007.

SIAGAS - Sistema de Informação de Águas Subterrâneas. Disponível em:

<http://siagas.cprm.gov.br/wellshow/indice.asp?w $=800 \& \mathrm{~h}=600>$. Acesso em: 2006.

SILVA, R. B. G., 1983. Estudo Hidroquímico e Isotópico das Águas Subterrâneas do Aqüífero Botucatu no Estado de São Paulo. Tese de Doutorado. Instituto de Geociências - Universidade de São Paulo, São Paulo.

SINELLI, O. E WERNICK, E., 1970. Análise estrutural geomorfológica. Notícias Geomorfológicas. Campinas - SP, 10 (20). P $39-54$.

SMA - Secretaria do Estado do Meio Ambiente, 2004. Gerenciamento de aqüíferos - Um exemplo de solução integrada para a criação de áreas de abastecimento público com uso de modelos de sustentabilidade e sistemas avançados de suporte de tecnologia de informação. Relatório 11.04.04, 40p. São Paulo, SP. 
SMA/São Paulo \& StMUGV/Baviera, 2004. Sistema de informação para o gerenciamento ambiental dos recursos hídricos subterrâneos na área de afloramento do Aqüífero Guarani no Estado de São Paulo. Projeto em cooperação com Secretaria de Meio Ambiente, Saúde Pública e Proteção ao Consumidor do Estado da Baviera (Alemanha). São Paulo.

WENDLAND, E., 2003. Desenvolvimento do pacote computacional SPA - Simulação de Processos em Aqüíferos. Relatório de Pesquisa, Processo FAPESP 02/09696-3, Departamento de Hidráulica e Saneamento, Escola de Engenharia de São Carlos, Universidade de São Paulo, 78 p.

ZALÁN, P.; WOLFF, S.; CONCEIÇAO, J.; MARQUES, A.; ASTOLFI, M.; VIEIRA, I.; APPI, V. E ZANOTTO Y. O., 1990. Bacia Do Paraná. Em: Pederneiras Raja Gabaglia, G. Y E. Milani (Ed.) Origem e Evolução de Bacias Sedimentares. Petróleo Brasileiro S. A., 415 Pág., Rio De Janeiro. P 135-168. 
APÊNDICE A - Roteiro de utilização integrada e transporte de dados entre os softwares utilizados nesse projeto 


\section{ROTEIRO DE UTILIZAÇÃO INTEGRADA E TRANSPORTE DE \\ DADOS ENTRE OS SOFTWARES UTILIZADOS NESSE PROJETO}

Muitas vezes, características de uma determinada região, cidade etc. encontram-se armazenadas em meio digital na forma de mapas do AutoCAD, ou seja, arquivos de extensão dxf e dwg.

Neste projeto houve a necessidade de se tranportar os dados do AutoCAD para a ferramenta GIS, por motivos de organização e processamento dos dados. Essa operação é facilitada pelo certo grau de integração existente entre o ArcGIS e o AutoCAD.

Para isso, foram executados os seguintes passos:

1. Separação de conjuntos de dados por layers no AutoCAD: para facilitar a operação de transporte de dados entre esses dois softwares, os dados do mesmo tipo (polyline, por exemplo) que representem diferentes estruturas (por exemplo, estradas, rios e ferrovias) podem ser separados em diferentes layers (ver Figura $57)$. 


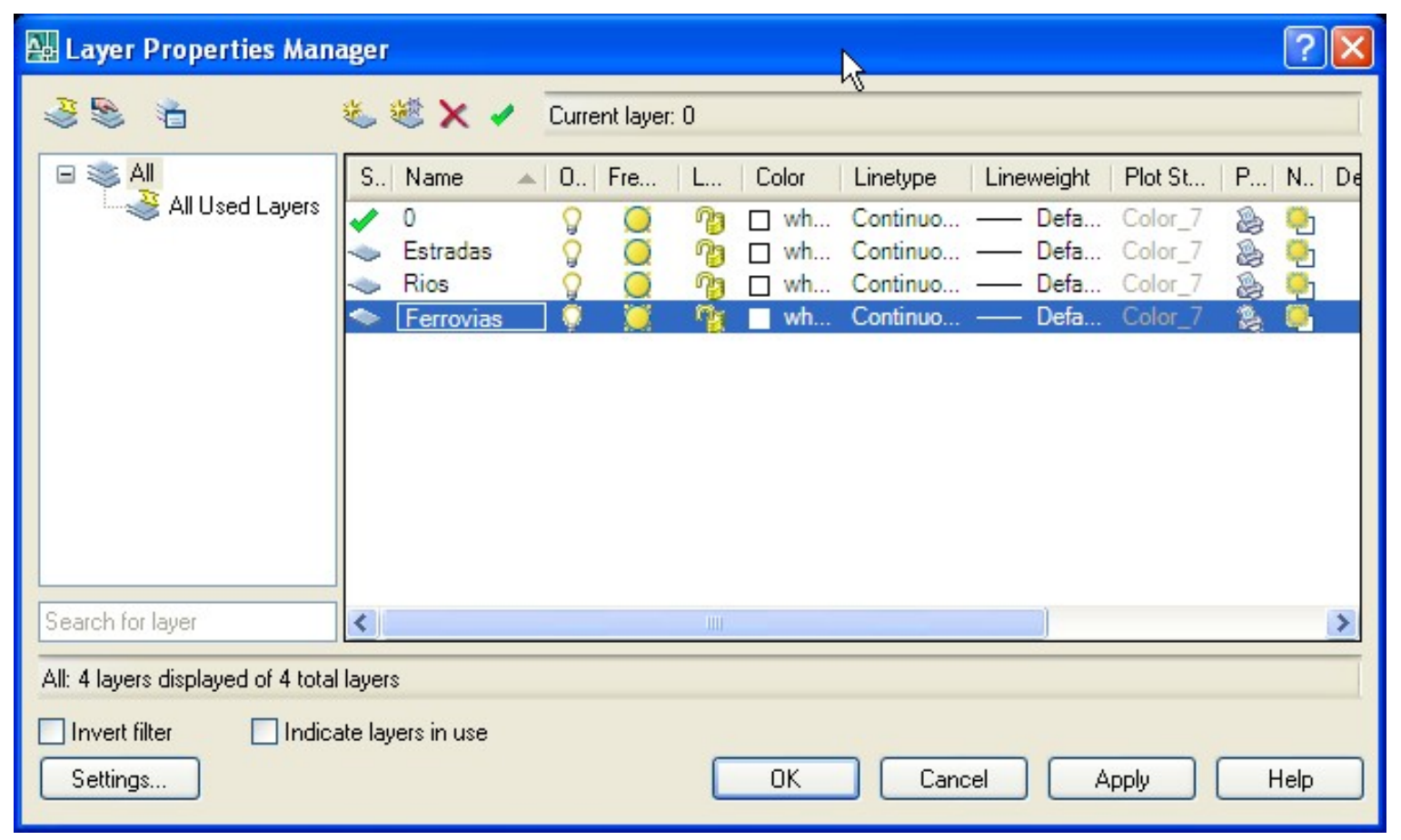

Figura 57: Separação em layers

2. Importação de dados do AutoCAD pelo Arcmap: no ArcMap, File $\rightarrow$ Add Data. Procurar o arquivo vetorial (.dxf ou .dwg) desejado (como exemplo, projeto1.dwg) dar duplo clique com o botão direito do mouse. O arquivo será aberto em cinco outros arquivos (Annotation, MultiPatch, Point, Polygon e Polyline), cada um representando um tipo de dado ou informação do AutoCAD (ver Figura 58). Selecionar aquele que se deseja transportar (como exemplo, polyline) $\rightarrow$ Add. Todos os dados do tipo polyline serão adicionados como nome_do_arquivo.dwg Tipo_de_dado (temos, no caso do exemplo, Exemplo.dwg Polyline), e esse arquivo deve ser separado nas diferentes estruturas que o compõe. 


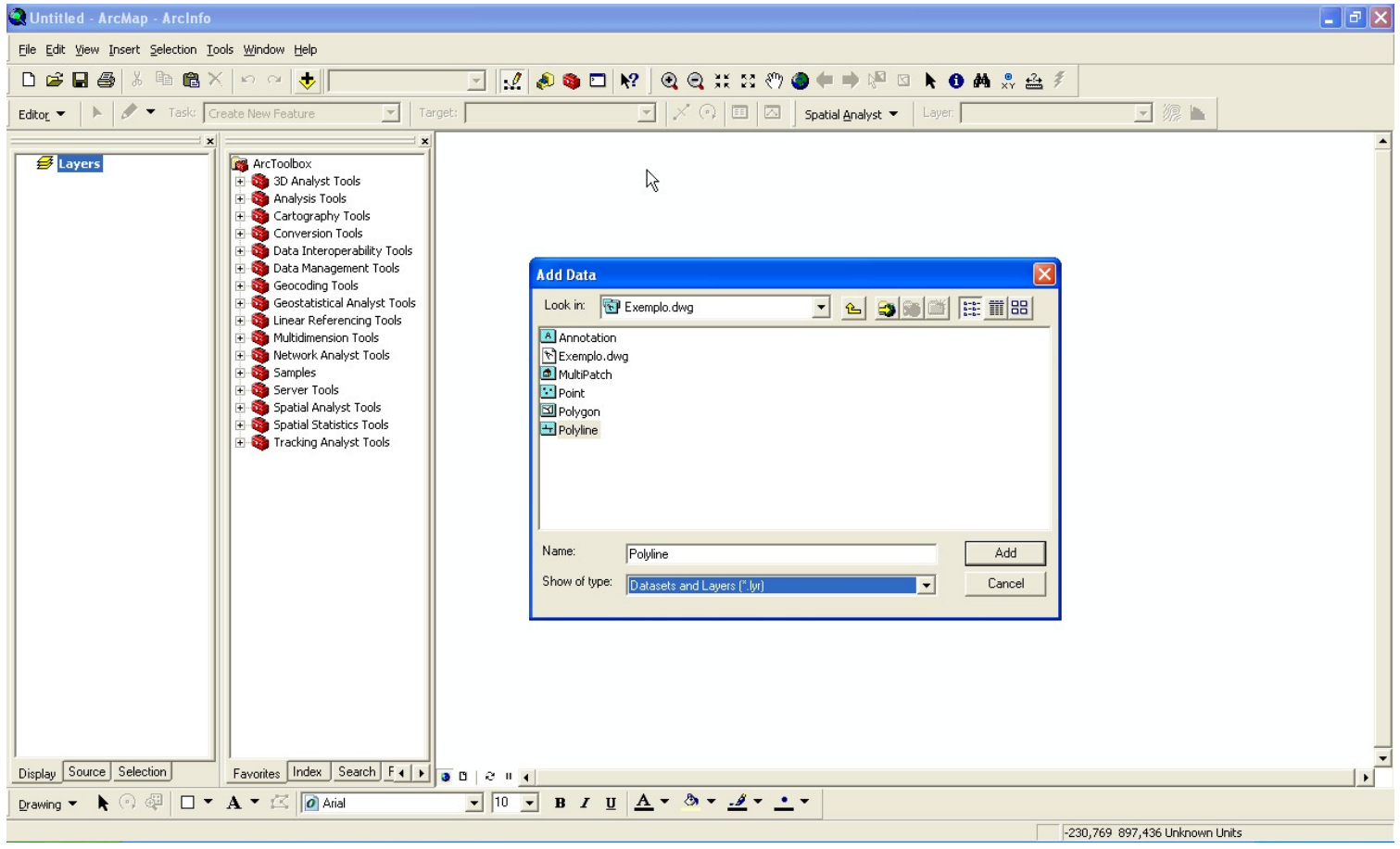

Figura 58: Adicionando dados do AutoCAD

\section{Separando as estruturas (layers) de um arquivo vetorial no}

ArcMap: no ArcMap $\rightarrow$ Selection $\rightarrow$ Select by Attributes. Na janela que será aberta: em Layer, selecionar o arquivo do AutoCAD recém importado pelo ArcMap (no caso do exemplo, Exemplo.dwg Polyline); em Method, selecionar Create a New Selection; em Fields, selecionar “Layer"; clicar em Get Unique Values para que as layers definidas no AutoCAD apareçam no campo Unique Values (no caso do exemplo, estradas, rios e ferrovias). Para cada estrutura que se deseja entrar no ArcMap, montar a equação "Layer" = estrutura (no caso do exemplo, a operação seria repetida três vezes: "Layer" = estradas, "Layer" $=$ rios e "Layer" = ferrovias $\rightarrow$ APPLY. A estrutura selecionada aparecerá em destaque. 


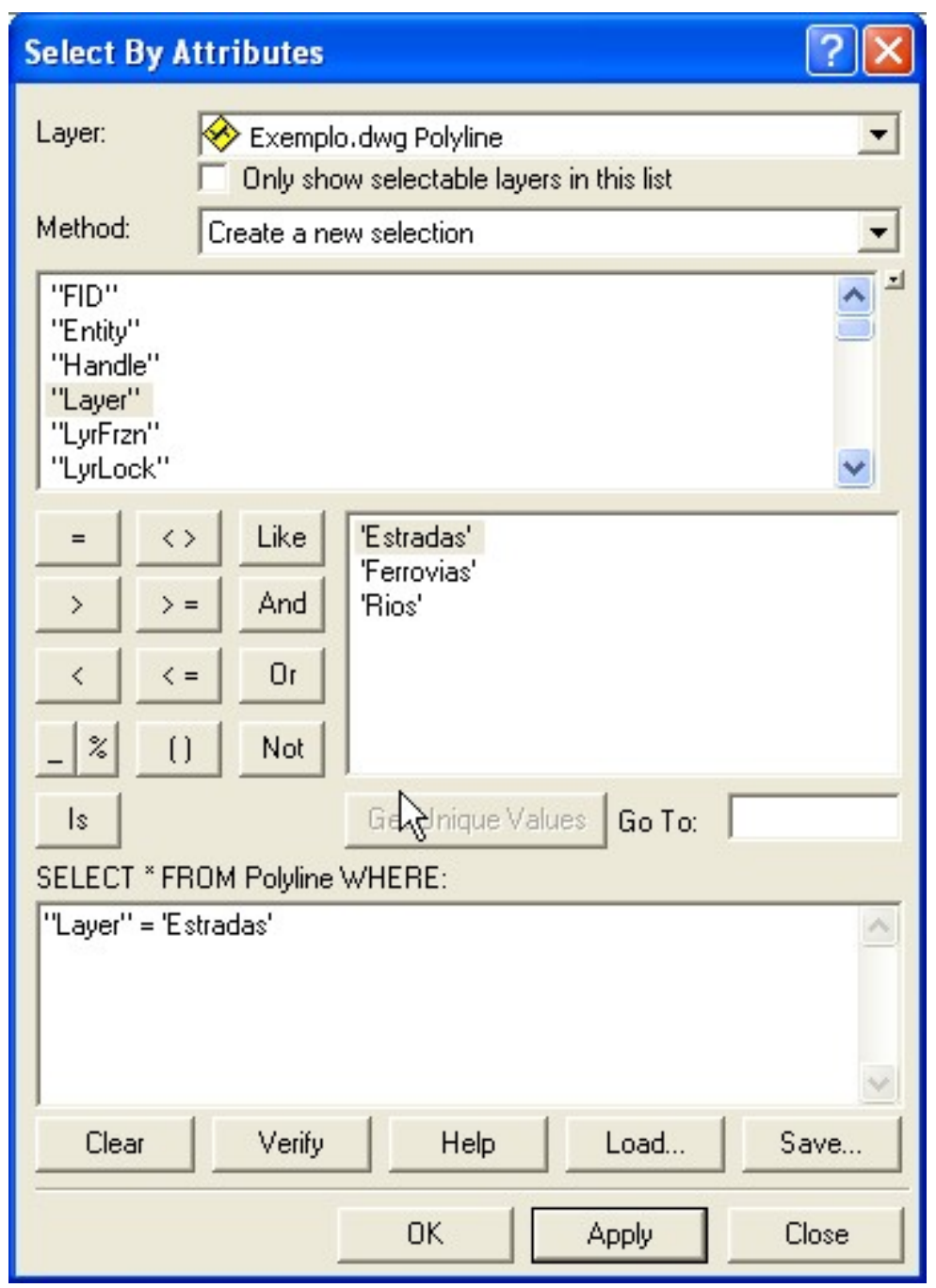

Figura 59: Separação das estruturas

4. Transformação de arquivo vetorial em shapefiles: com a estrutura selecionada, clicar com o botão direito do mouse no arquivo vetorial de entrada (no caso, Exemplo.dwg Polyline) $\rightarrow$ Data $\rightarrow$ Export Data. Na janela aberta, em Export, selecionar Selected Features; marcar a opção de sistema de coordenadas mais adequada ao projeto; em Output shapefile or feature class, definir um nome para a nova shapefile $\rightarrow$ OK (ver Figura 60). Terminada a transformação: Do you want to add the exported data to the map as a layer? $\rightarrow$ Sim. 


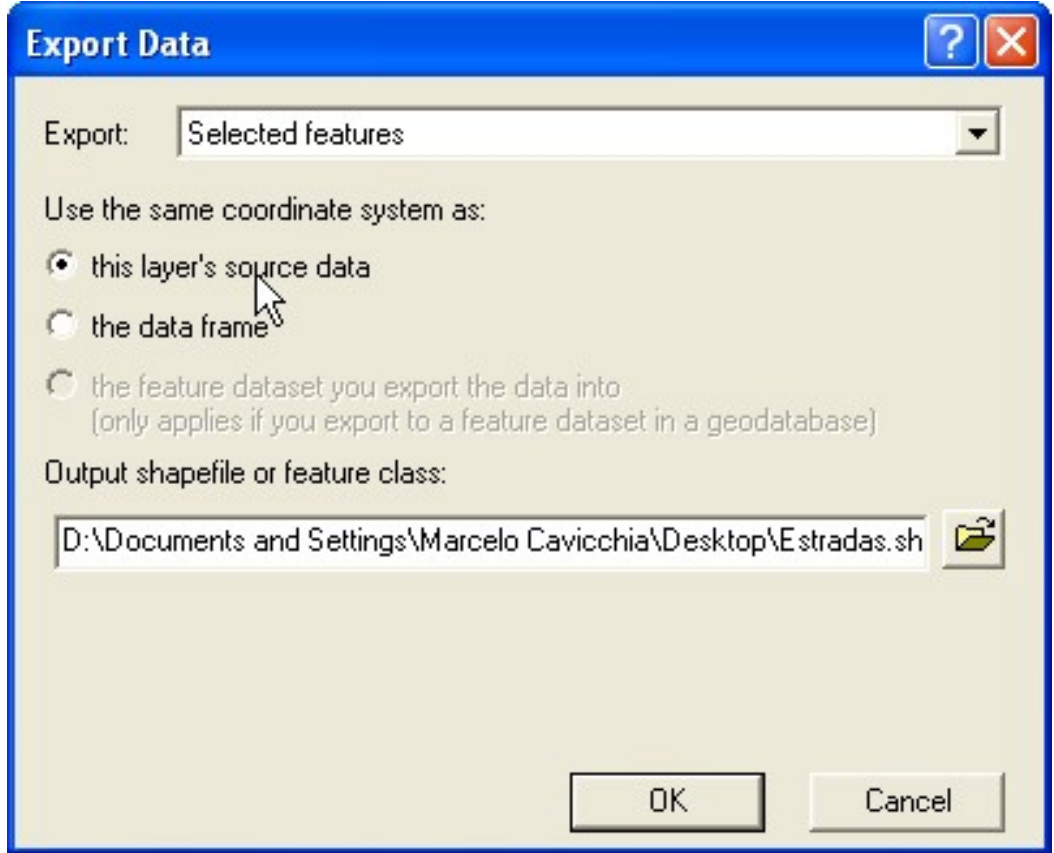

Figura 60: Exportação de dados vetoriais para shapefiles

Terminado o processo, cada estrutura da região (estradas, ferrovias, cursos d’água, poços, lagos etc) originará uma shapefile na ferramenta SIG. O arquivo de entrada inicial do AutoCAD pode ser removido do projeto (clique do botão direito do mouse $\rightarrow$ Remove), deixando-se apenas as shapefiles. Na Figura 61, pode-se observar o processo finalizado com as estruturas fictícias do exemplo. 


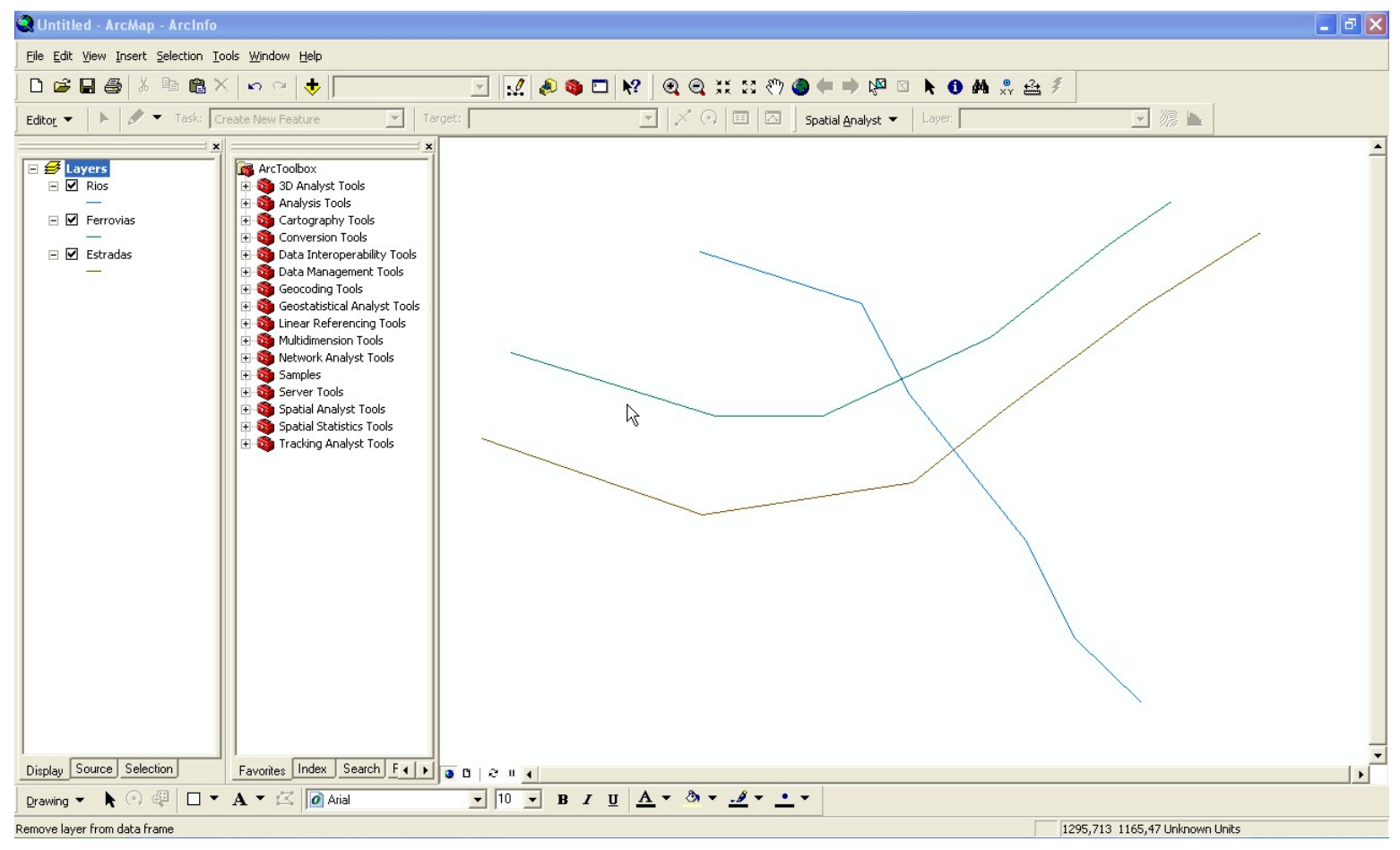

Figura 61: Estruturas passadas do AutoCAD para ArcMap

\section{ETAPAS PARA INTERPOLAÇÃO DE DADOS EM FERRAMENTA SIG (ARCMAP)}

A interpolação por krigagem de um conjunto de pontos gera uma superficie do tipo raster. Para que os valores desse raster sejam transportados para o CMA, cada pixel do raster deve ser transformado em um ponto, que será alocado no centro do pixel.

Essa transformação de raster em pontos pode ser feita de forma direto caso os valores do raster sejam valores inteiros (se existirem valores decimais, uma mensagem de erro é exibida, encerrando o processo). Como essa é uma situação difícil de acontecer, primeiramente tem-se que transformar os valores do raster em valores inteiros (assim, cada faixa de valores será representada por um algarismo) para, a seguir, transformá-los em pontos e re-atribuir os valores do raster original.

Para isso, foram executados os seguintes passos: 
1. Interpolação por Krigagem: na barra de ferramentas Spatial Analyst $\rightarrow$ Interpolate to Raster $\rightarrow$ Kriging. Na janela Kriging (ver Figura 62): em Input points, selecionar a shapefile pontos que se deseja interpolar; em $\mathrm{Z}$ value field, colocar o campo que representa os valores que se deseja interpolar; nos demais itens, colocar a opção que melhor se adapta à situação; em Output raster, definir um nome para o raster que será gerado (como exemplo, nomeado raster1). Essa etapa resultará em uma superfície do tipo raster, com valores decimais interpolados (variável tipo Float).

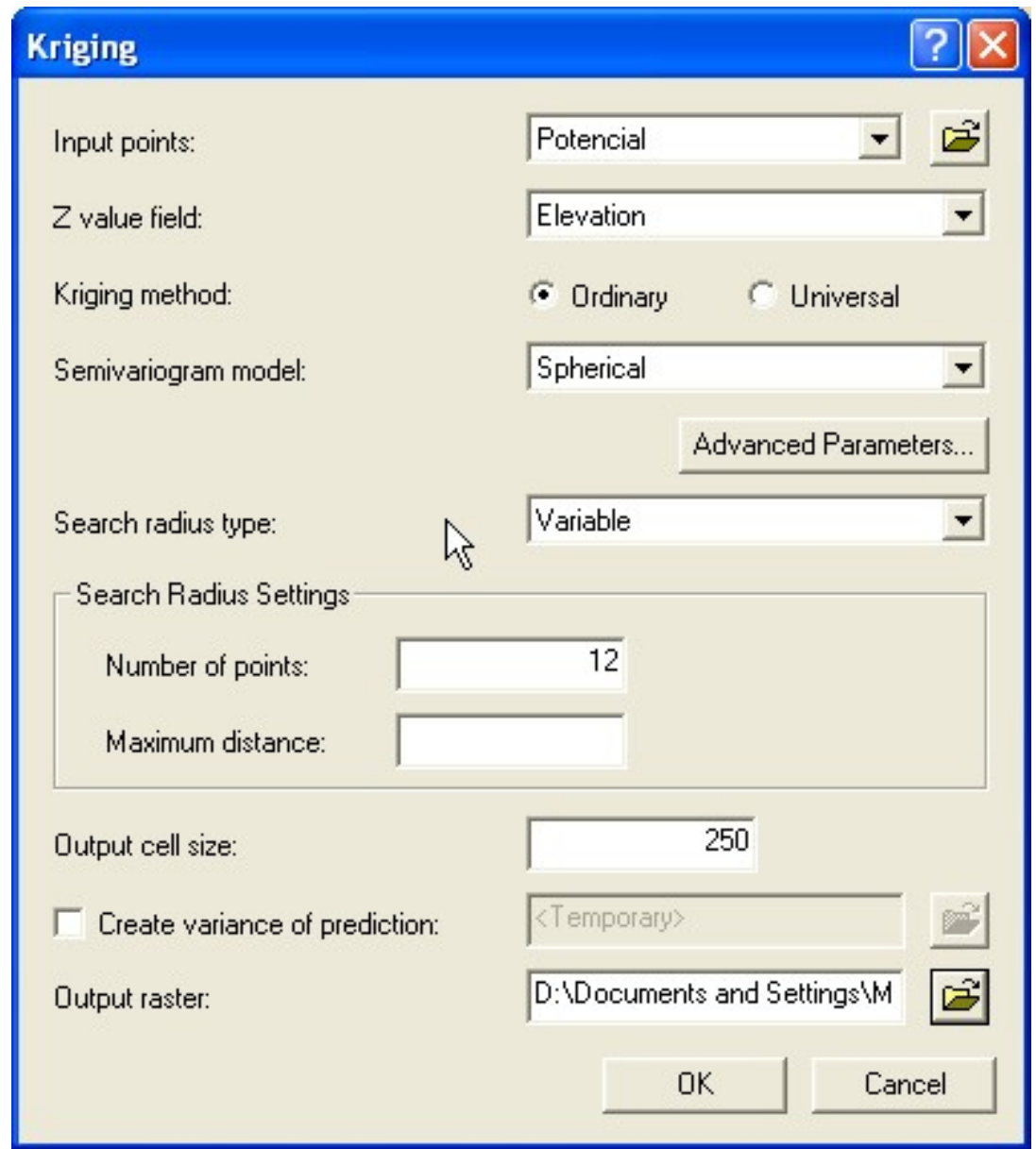

Figura 62: Informações para interpolação 


\section{Transformação dos valores do raster de Float para Integer: na} barra de ferramentas Spatial Analyst $\rightarrow$ Reclassify. Na janela Reclassify (ver Figura 63): em Input Raster, selecionar o raster gerado na etapa anterior (raster1); em Set values to reclassify, observar os valores inteiros que serão atribuídos às faixas de valores; em Output raster, definir um nome para o novo raster que será gerado (como exemplo, será utilizado o nome raster1rc).

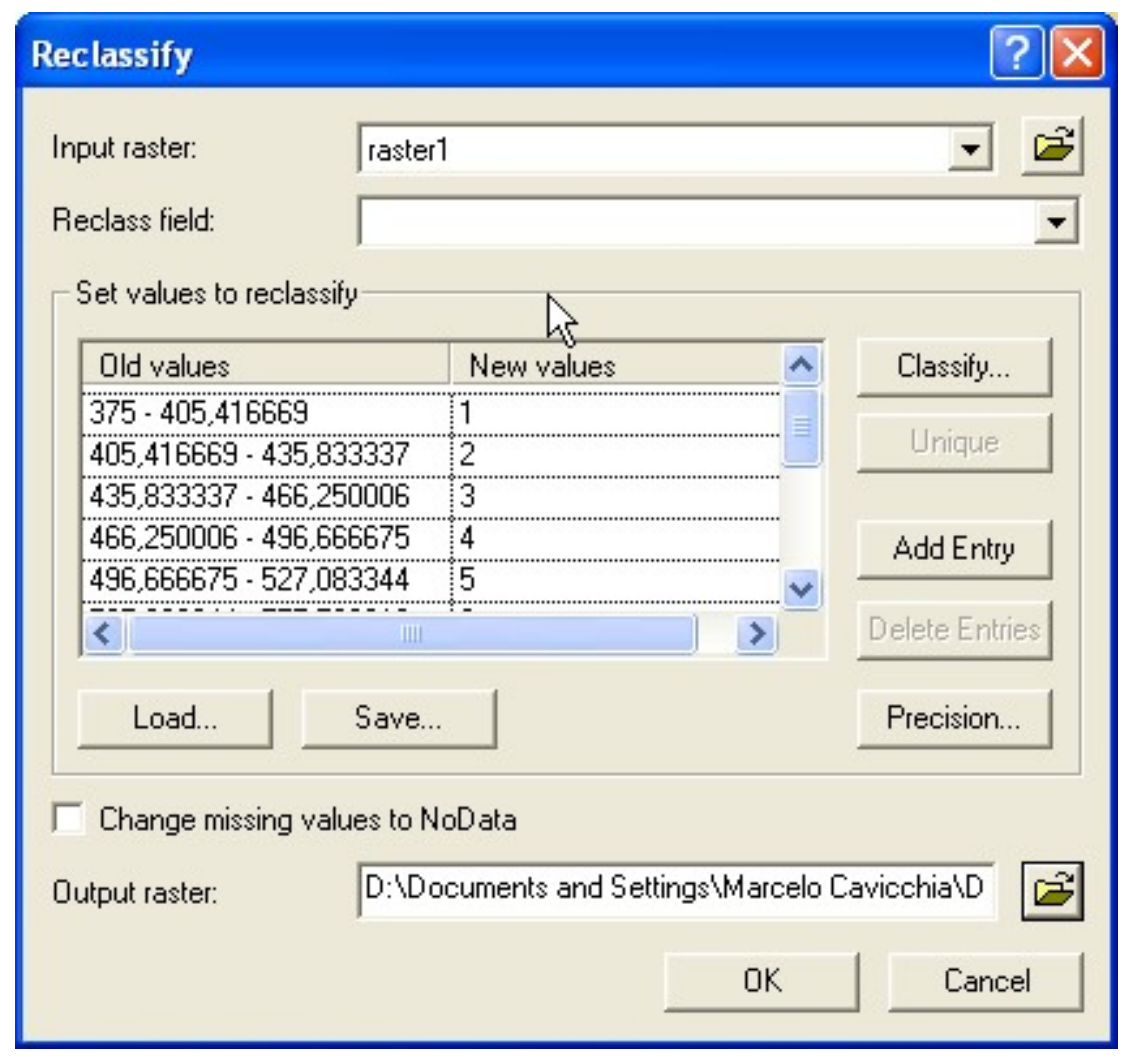

Figura 63: Janela Reclassify

\section{Transformação do raster com valores inteiros (raster1-rc)} para uma shapefile pontos: no ArcToolbox $\rightarrow$ Conversion Tools $\rightarrow$ From Raster $\rightarrow$ Raster to Point (ver Figura 64). Em Input Raster, selecionar o raster gerado na etapa anterior (raster1-rc); em Output point features, definir um nome para a shapefile pontos resultante da transformação (como exemplo, 
nomeada shap1). Assim, cada pixel do raster será transformado em um ponto concêntrico.

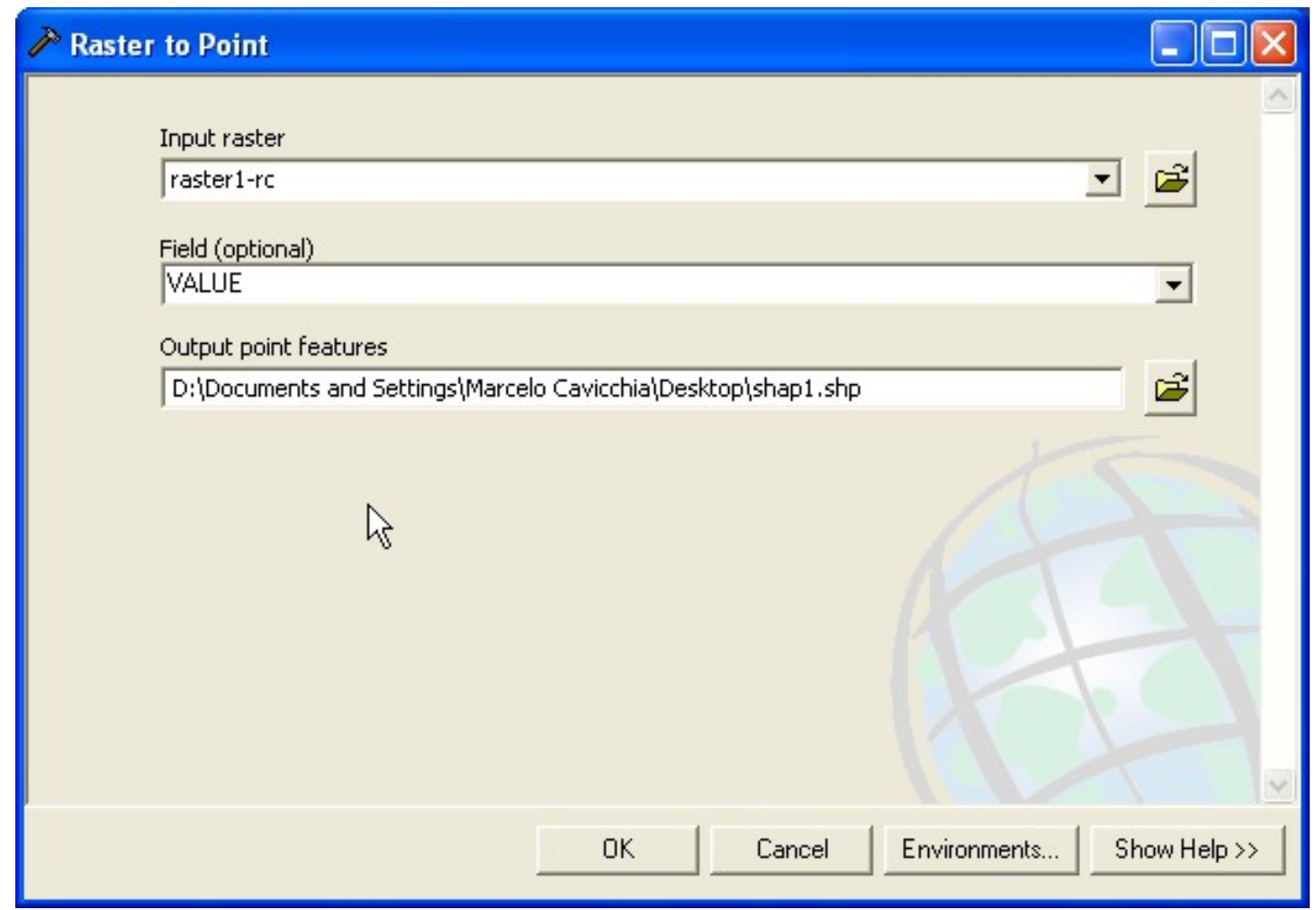

Figura 64: Raster para Pontos

4. Atribuição dos valores do raster original (raster1) para a shapefile pontos criada (shap1): no ArcToolbox $\rightarrow$ Spatial Analyst Tools $\rightarrow$ Extraction $\rightarrow$ Extract Values to Points. Em Input point features, selecionar a shapefile pontos à qual se deseja extrair os valores da superfície raster, ou seja, aquela gerada na etapa anterior (shap1); em Input raster, selecionar o raster com os valores originais (raster1); em Output point features, definir o nome da shapefile pontos que será gerada (como exemplo, shap-pontos). 
Extract Values to Points

Input point features

D:',Documents and Settings',Marcelo Cavicchia',Desktop',shap1.shp

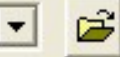

Input raster

D:',Documents and Settings'i|Marcelo Cavicchia'Desktop'íraster 1

Output point features

is

S:',Documents and Settings'Marcelo Cavicchia',Desktop'shap-pontos,shp

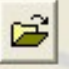

$\Gamma$ Interpolate values at the point locations

$\Gamma$ Append all the input raster attributes to the output point features

$<$

Figura 65: Janela para extração de valores do raster para a shapefile pontos

Executados esses passos, temos uma shapefile do tipo pontos, e cada ponto possui um valor interpolado decimal do pixel que o gerou, já que cada ponto representa o centro de um pixel do raster. Esses dados distribídos em pontos já podem ser transportados para o CMA, e integrados à malha de Elementos Finitos.

\section{TRANSPORTE DE DADOS DA FERRAMENTA SIG (ARCGIS) PARA O CMA}

Para se converter os dados de uma dada estrutura do ArcMap para um arquivo tipo texto simples, são necessárias a separação por trechos (importante quando se tem diversos segmentos do mesmo tipo, por exemplo no caso de cursos d’água), a coordenada $X$, a coordenada Y e os valores para cada ponto. Esses campos são 
utilizados pela rotina de conversão que, em sua ausência, não funciona. Posteriormente, esse arquivo de texto simples formatado adequadamente (.txt) consiste no arquivo de entrada do CMA.

Nessa etapa, foram executados os seguintes passos:

1. Separação por trechos: na Table os Contents (coluna da esquerda na área de trabalho do ArcMap), clicar com o botão direito do mouse no arquivo que se deseja transportar $\rightarrow$ Open Attribute Table. Na tabela que será aberta $\rightarrow$ Options $\rightarrow$ Add Field. Em Name, colocar Trecho; em Type, selecionar Short Integer $\rightarrow$ OK (ver Figura 66). Se a separação por segmentos for importante para o conjunto de dados, identificar os pontos de início do segmento e identificá-los na tabela, numerando-os.

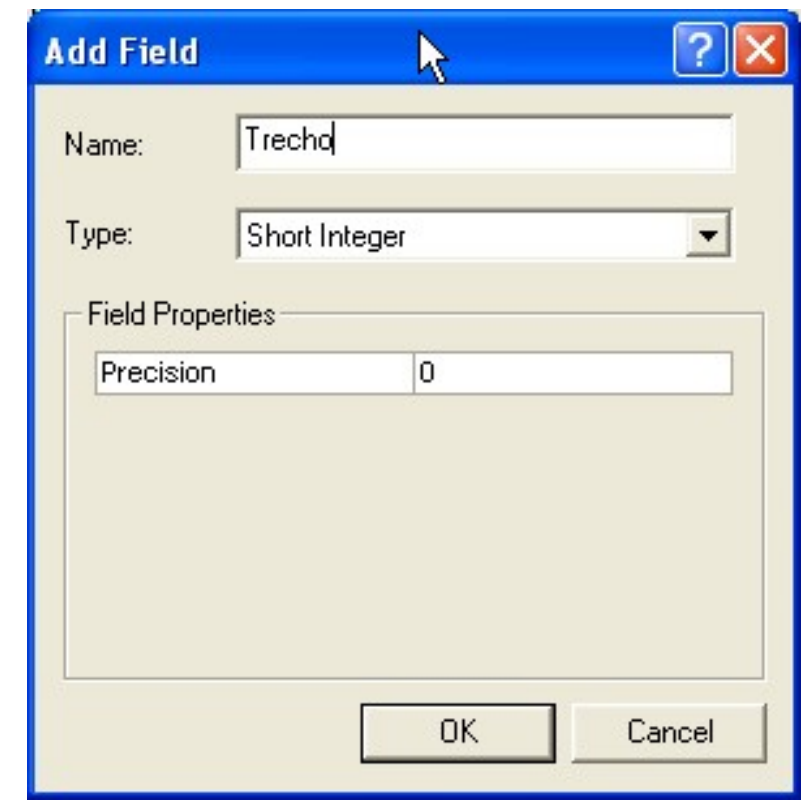

Figura 66: Janela para adição de campos

2. Obtenção das coordenadas $\mathbf{X}$ : na Table os Contents (coluna da esquerda na área de trabalho do ArcMap), clicar com o botão direito do mouse no arquivo que se deseja transportar $\rightarrow$ Open Attribute Table. Na tabela que será aberta $\rightarrow$ Options $\rightarrow$ Add 
Field. Em Name, colocar Coord_X; em Type, selecionar Long Integer $\rightarrow$ OK (analogamente ao passo 1, ver Figura 66). Em seguida, clicar com o botão direito do mouse no campo recém criado $\rightarrow$ Calculate Values. $\mathrm{Na}$ janela Field Calculator $\rightarrow$ marcar a caixa Advanced $\rightarrow$ Help. No Help, procurar a opção To add the $x$ coordinate of points e copiar as três primeiras linhas da rotina que se segue para o campo Pre-Logig VBA Script Code; o que se segue ao Output (pPoint.X), colar na última linha do Field Calculator $\rightarrow$ OK (ver Figura 67).
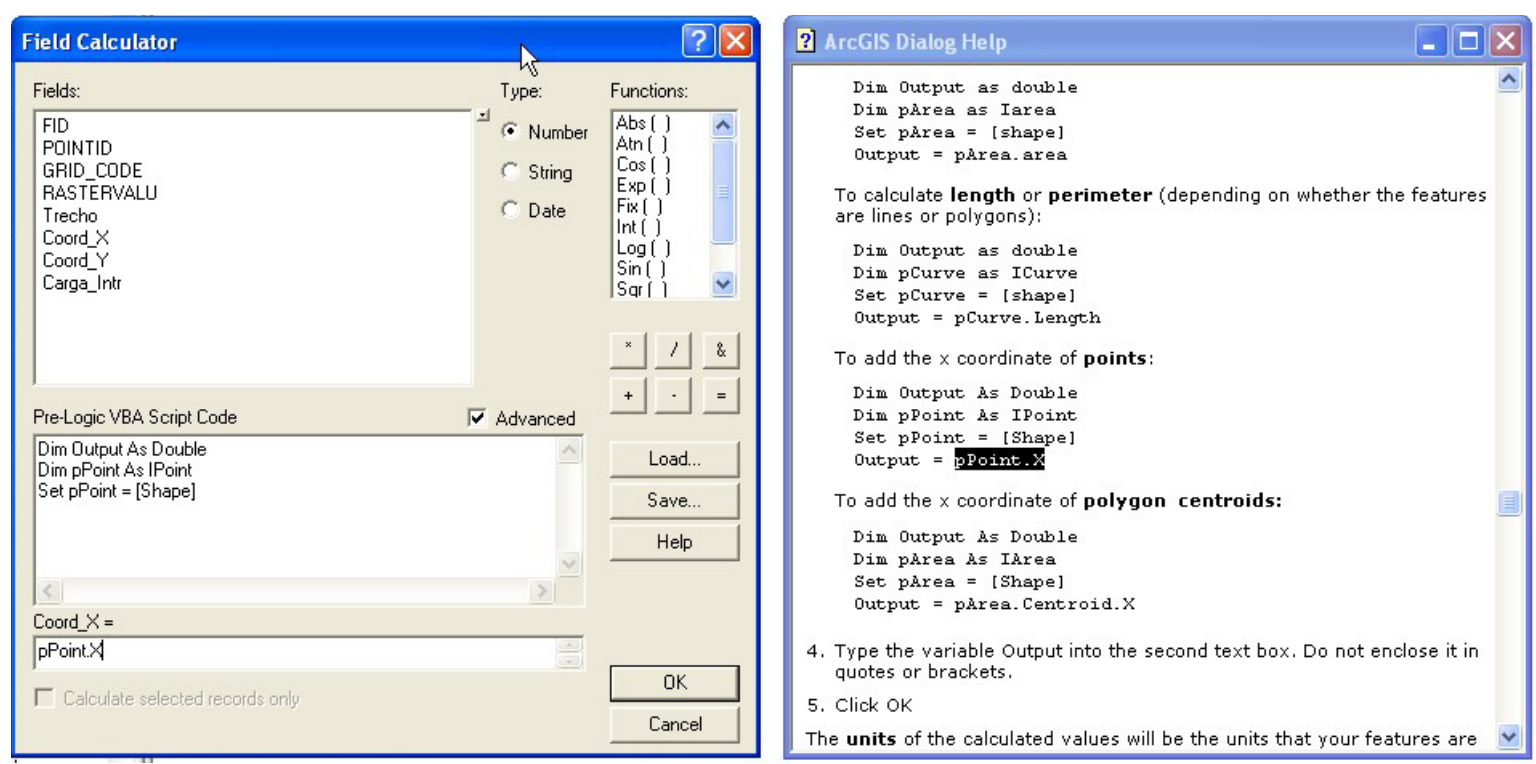

Figura 67: Cálculo das coordenadas X e Help

3. Obtenção das coordenadas Y: na Table os Contents (coluna da esquerda na área de trabalho do ArcMap), clicar com o botão direito do mouse no arquivo que se deseja transportar $\rightarrow$ Open Attribute Table. Na tabela que será aberta $\rightarrow$ Options $\rightarrow$ Add Field. Em Name, colocar Coord_Y; em Type, selecionar Long Integer $\rightarrow$ OK (analogamente ao passo 1, ver Figura 66). Em seguida, clicar com o botão direito do mouse no campo recém criado $\rightarrow$ Calculate Values. Na janela Field Calculator $\rightarrow$ 
marcar a caixa Advanced $\rightarrow$ Help. No Help, procurar a opção To add the $x$ coordinate of points e copiar as três primeiras linhas da rotina que se segue para o campo Pre-Logig VBA Script Code; no campo “Coord_Y =" colocar pPoint.Y $\rightarrow$ OK (ver Figura 68).

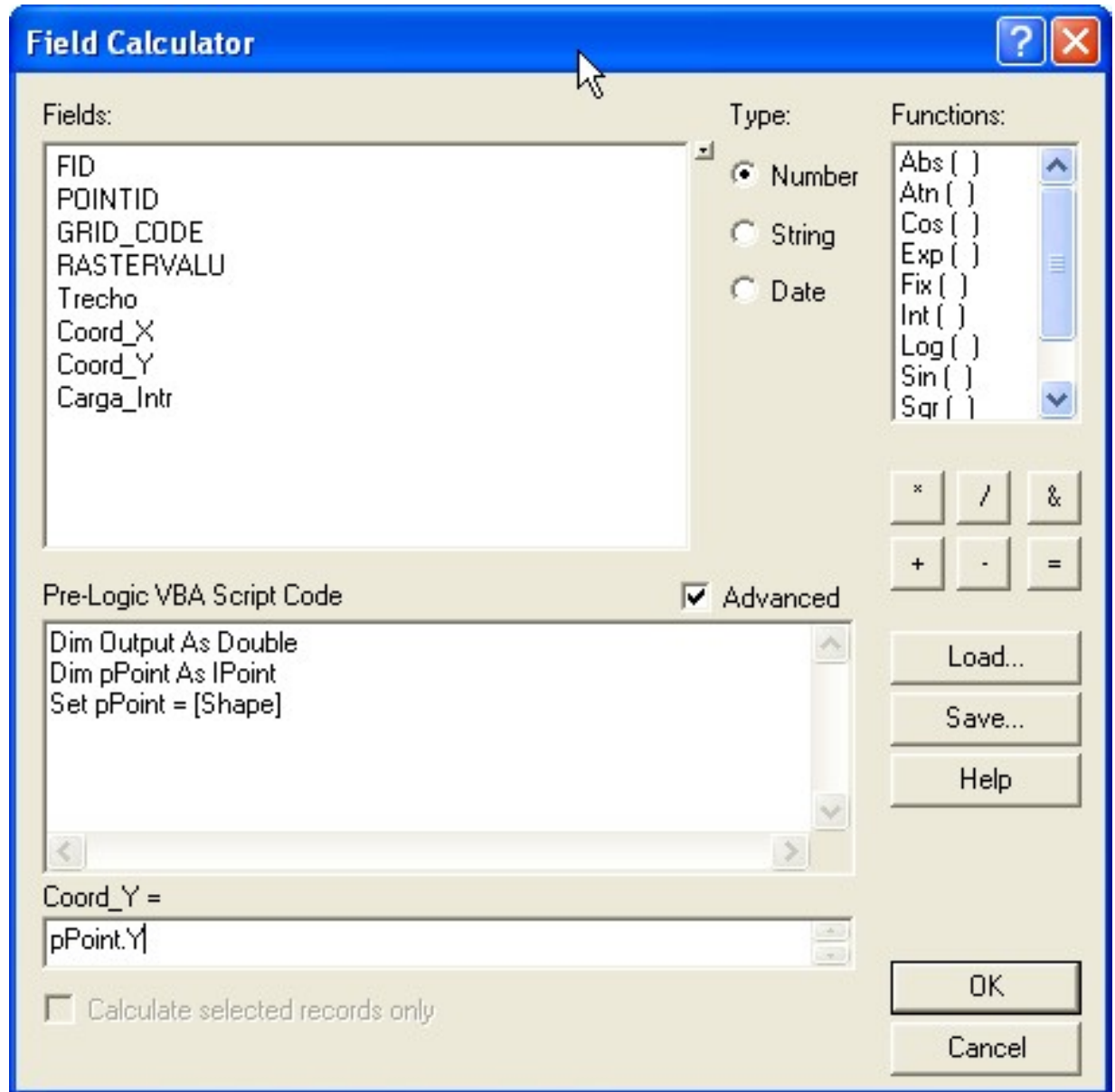

Figura 68: Cálculo das coordenadas $Y$

4. Valores para cada ponto: na Table os Contents (coluna da esquerda na área de trabalho do ArcMap), clicar com o botão direito do mouse no arquivo que se deseja transportar $\rightarrow$ Open Attribute Table. Na tabela que será aberta $\rightarrow$ Options $\rightarrow$ Add Field. Em Name, colocar Carga_Intr; em Type, selecionar Float $\rightarrow$ OK. Em seguida, clicar com o botão direito do mouse no campo recém criado $\rightarrow$ Calculate Values. Na janela Field 
Calculator $\rightarrow$ campo Fields $\rightarrow$ duplo clique no campo que contém os valores $\rightarrow$ OK (ver Figura 69).

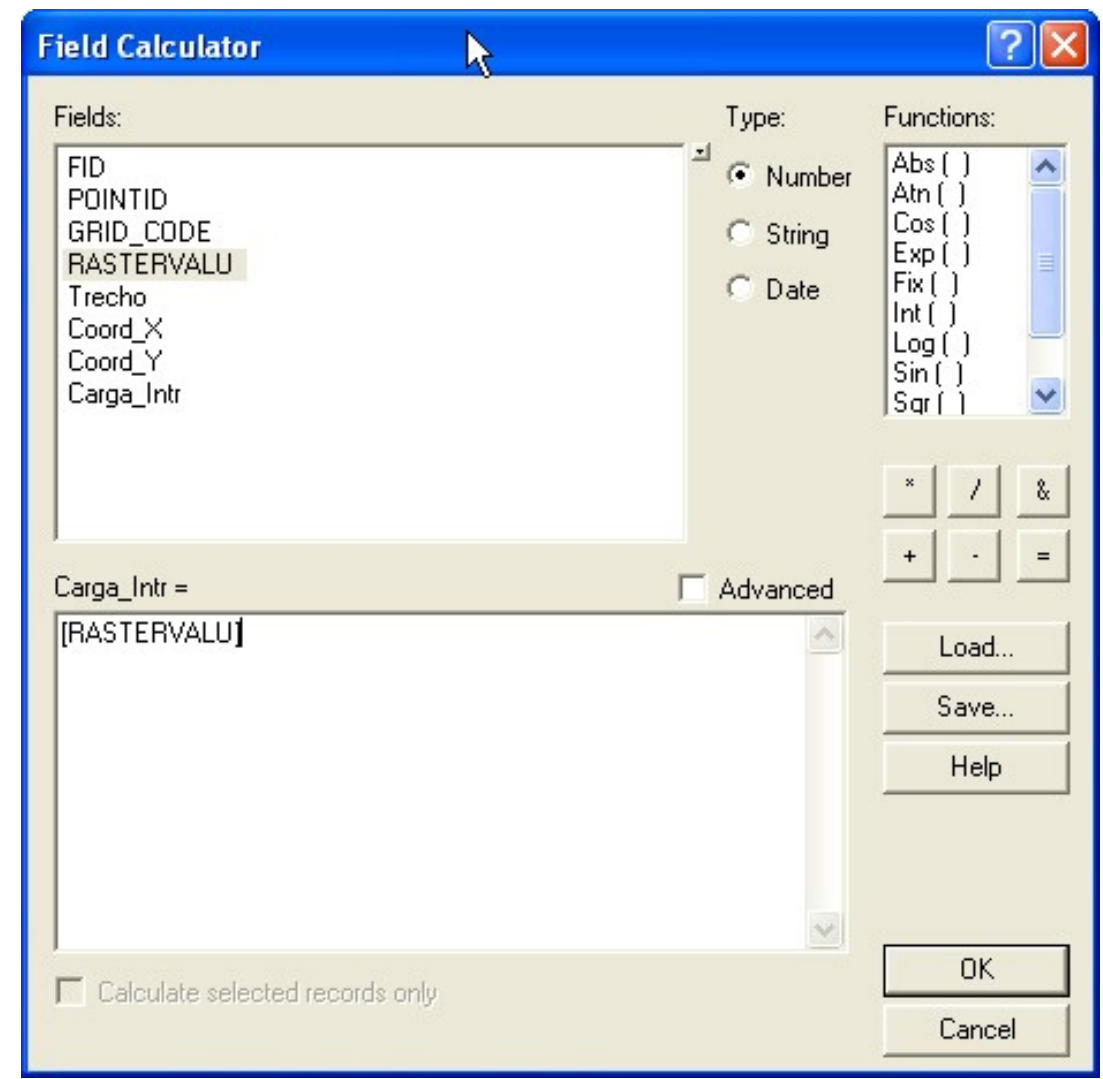

Figura 69: Inserção dos valores para cada ponto

Terminado esse processo, a tabela de atributos (Attribute Table) da shapefile deve ficar como pode ser visto na Figura 70. Nesse formato, a rotina de transporte de shapefiles para um arquivo de texto simples funciona adequadamente. 
圈 Attributes fo shap-pontos

\begin{tabular}{|c|c|c|c|c|c|c|c|c|c|c|c|c|}
\hline FID & \multicolumn{2}{|c|}{ Shape * } & POIIIID & & RID & CODE & RASTERVALU & Trecho & Coord $X$ & Coord Y & Carga Intr & $\wedge$ \\
\hline 2438 & \multicolumn{2}{|c|}{ Point } & 2439 & & & 4 & 495,5 & 0 & 201823 & 7670943 & 495,5 & \\
\hline 2439 & \multicolumn{2}{|l|}{ Point } & 2440 & & & 4 & 495,666656 & 0 & 202073 & 7670943 & 495,66699 & \\
\hline 2440 & \multicolumn{2}{|l|}{ Point } & 2441 & & & 4 & 495,833344 & 0 & 202323 & 7670943 & 495,83301 & \\
\hline 2441 & \multicolumn{2}{|l|}{ Point } & 2442 & & & 4 & 495,833344 & 0 & 202573 & 7670943 & 495,83301 & = \\
\hline 2442 & \multicolumn{2}{|l|}{ Point } & 2443 & & & 4 & 495,833344 & 0 & 202823 & 7670943 & 495,83301 & \\
\hline 2443 & \multicolumn{2}{|l|}{ Point } & 2444 & & & 4 & 496 & 0 & 203073 & 7670943 & 496 & \\
\hline 2444 & \multicolumn{2}{|l|}{ Point } & 2445 & & & 4 & 496 & 0 & 203323 & 7670943 & 496 & \\
\hline 2445 & \multicolumn{2}{|l|}{ Point } & 2446 & & & 4 & 496,25 & 0 & 203573 & 7670943 & 496,25 & \\
\hline 2446 & \multicolumn{2}{|l|}{ Point } & 2447 & & & 4 & 496,666656 & 0 & 203823 & 7670943 & 496,66699 & \\
\hline 2447 & \multicolumn{2}{|l|}{ Point } & 2448 & & & 4 & 496,666656 & 0 & 204073 & 7670943 & 496,66699 & \\
\hline 2448 & \multicolumn{2}{|l|}{ Point } & 2449 & & & 5 & 497,083344 & 0 & 204323 & 7670943 & 497,08301 & \\
\hline 2449 & \multicolumn{2}{|l|}{ Point } & 2450 & & & 5 & 497,083344 & 0 & 204573 & 7670943 & 497,08301 & \\
\hline 2450 & \multicolumn{2}{|l|}{ Point } & 2451 & & & 5 & 497,5 & 0 & 204823 & 7670943 & 497,5 & \\
\hline 2451 & \multicolumn{2}{|l|}{ Point } & 2452 & & & 5 & 497,5 & 0 & 205073 & 7670943 & 497,5 & \\
\hline 2452 & \multicolumn{2}{|l|}{ Point } & 2453 & & & 5 & 497,916656 & 0 & 205323 & 7670943 & 497,91699 & \\
\hline 2453 & \multicolumn{2}{|l|}{ Point } & 2454 & & & 5 & 499 & 0 & 205573 & 7670943 & 499 & \\
\hline 2454 & \multicolumn{2}{|l|}{ Point } & 2455 & & & 5 & 499 & 0 & 205823 & 7670943 & 499 & \\
\hline 2455 & \multicolumn{2}{|l|}{ Point } & 2456 & & & 5 & 499 & 0 & 206073 & 7670943 & 499 & \\
\hline 2456 & \multicolumn{2}{|l|}{ Point } & 2457 & & & 5 & 499 & 0 & 206323 & 7670943 & 499 & \\
\hline 2457 & \multicolumn{2}{|l|}{ Point } & 2458 & & & 5 & 499 & 0 & 206573 & 7670943 & 499 & \\
\hline 2458 & \multicolumn{2}{|l|}{ Point } & 2459 & & & 5 & 499,25 & 0 & 206823 & 7670943 & 499,25 & \\
\hline 2459 & \multicolumn{2}{|l|}{ Point } & 2460 & & & 5 & 499,25 & 0 & 207073 & 7670943 & 499,25 & \\
\hline 2460 & \multicolumn{2}{|l|}{ Point } & 2461 & & & 5 & 499,25 & 0 & 207323 & 7670943 & 499,25 & \\
\hline 2461 & Point & & 2462 & & & 5 & 499,25 & 0 & 207573 & 7670943 & 499,25 & \\
\hline 2462 & Point & & 2463 & & & 5 & 499,5 & 0 & 207823 & 7670943 & 499,5 & \\
\hline 2463 & Point & & 2464 & & & 5 & 499,75 & 0 & 208073 & 7670943 & 499,75 & \\
\hline 2464 & Point & & 2465 & & & 5 & 499,75 & 0 & 208323 & 7670943 & 499,75 & \\
\hline 2465 & Point & & 2466 & & & 5 & 499,75 & 0 & 208573 & 7670943 & 499,75 & \\
\hline 2466 & Point & & 2467 & & & 5 & 500,25 & 0 & 208823 & 7670943 & 500,25 & \\
\hline 2467 & Point & & 2468 & & & 5 & 500,25 & 0 & 209073 & 7670943 & 500,25 & \\
\hline 2468 & Point & & 2469 & & & 5 & 500,25 & 0 & 209323 & 7670943 & 500,25 & \\
\hline 2469 & Point & & 2470 & & & 5 & 500,5 & 0 & 209573 & 7670943 & 500,5 & \\
\hline 2470 & Point & & 2471 & & & 5 & 500,5 & 0 & 209823 & 7670943 & 500,5 & \\
\hline 2471 & Point & & 2472 & & & 5 & 500,5 & 0 & 210073 & 7670943 & 500,5 & \\
\hline 2472 & Point & & 2473 & & & 5 & 500,5 & 0 & 210323 & 7670943 & 500,5 & $v$ \\
\hline $\operatorname{Re}$ & cord: 14 & 4 & 1 & 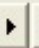 & 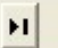 & Sho & Selecte & & & - & & ons \\
\hline
\end{tabular}

Figura 70: Formato final da tabela de atributos 
APÊNDICE B - Relatório de visita ao instituto geológico 


\section{RELATÓRIO DE VISITA AO INSTITUTO GEOLÓGICO -}

$06 / 02 / 2007$

A reunião no Instituto Geológico contou com as pesquisadoras Mara Akie Iritani, Amélia João Fernandes e Márcia Maria Nogueira Pressinotti, profundas conhecedoras da área de estudo.

As pesquisadoras indicaram fatores complicadores do processo de construção de um modelo computacional, bem como temas relacionados à área em geral. Todas as sugestões foram aproveitadas e estudadas, sendo de muita importância no desenvolvimento do projeto.

Cabe salientar que diversas das dificuldades aqui apresentadas foram solucionadas com o conjunto de dados fornecidos pelo Grupo Coordenador do Projeto Piloto de Ribeirão Preto, em 16/03/2007.

As áreas abordadas foram:

\section{Geologia:}

- Topo do Botucatu: foi recomendado q o candidato preenchesse os vazios de dados nas regiões a Sul e Leste da área urbana de Ribeirão Preto. Para tal, foi recomendada uma visita ao banco de dados físico do DAEE em São Paulo e uma consulta ao banco de dados SIDAS.

- Base do Botucatu: esse é um parâmetro de difícil obtenção, segundo as pesquisadoras, por causa da pouca profundidade dos poços perfurados, que não chegam até o cristalino. O número de poços com essa informação foi maior do que o esperado por elas. Essa informação deve ser adaptada de um mapa regional. 
- Basalto Serra Geral: estudos sobre a interação da camada de basalto confinante e o aqüífero são poucos na área de estudo, se restringindo a uma pequena parcela à sudeste da região urbanizada de Ribeirão Preto. Foi indicado o artigo Modelo conceitual preliminar de circulação de água subterrânea no Aqüífero Serra Geral, Ribeirão Preto, S.P. para consulta. Ficou entendido que a infiltração do basalto para o arenito é baixa e ocorre, principalmente, por fraturas sub-horizontais.

- Pirambóia: como as regiões de afloramento da Formação Pirambóia são representativas, as pesquisadoras sugeriram um estudo mais detalhado dessa formação.

- Perfis: as pesquisadoras recomendaram a elaboração de diversos perfis geológicos da área, a fim de facilitar a compreensão de sua geologia.

- Espessura: Com os perfis prontos, pode-se fazer uma comparação entre eles e o mapa regional de espessura do Aqüífero Guarani, com o objetivo de conferência.

\section{Calibração}

- Estações Fluviométricas: foi recomendada a procura de um segundo posto fluviométrico na região do Agrishow, em Ribeirão Preto (o primeiro está no Clube de Regatas, também em Ribeirão Preto). Essa estação pertencia ao Instituto Agronômico de Campinas (IAC) e talvez tenha informações dessa natureza. 


\section{Condições de Contorno}

- Contorno Oeste: foi sugerida a utilização de uma condição de contorno que leve em conta a tendência de fluxo regional da área, para Oeste. Para essa porção, também se discutiu uma possível interferência do cone de depressão centralizado na zona urbana de Ribeirão Preto no contorno do modelo. Se essa interferência de fato ocorrer, o limite terá que ser afastado dessa zona central.

- Contorno Norte: foi discutido a forma de abordagem do Rio Pardo no modelo, e se uma condição de carga hidráulica constante nesse rio não estaria forçando demais a “subida” da água do Aqüífero Guarani através do basalto. 
APÊNDICE C - Instruções de instalação e utilização de aplicativo da ferramenta SIG 
Instruções para instalação e utilização do aplicativo de interpolação de cargas hidráulicas exportação de dados para arquivo ASCII, em ambiente ArcGis (compatível com versões 8x e 9x)

O aplicativo elaborado em linguagem Visual Basic é composto de dois módulos: um de interpolação dos valores de carga e outro que permite exportar os dados de um arquivo shapefile (de pontos $\mathrm{x}, \mathrm{y}, \mathrm{z})$ para um arquivo texto, segundo formatação específica.

\section{Módulo de Interpolação}

$\mathrm{Na}$ tabela de atributos da layer (formato shapefile) que contém os pontos a terem suas cargas interpoladas, devem ser criados quatro campos (ou colunas) com os seguintes nomes: “Coord_X”, “Coord_Y”, “Trecho” e “Carga”. O uso de caixa-alta, ordem e posição em que os campos se encontram na tabela são indiferentes. Abaixo, segue a formatação e conteúdo necessários a cada campo:

1. Os campos “Coord_X” e “Coord_Y” (formato numérico inteiro) devem conter respectivamente as coordenadas (UTM) de cada ponto. Todos os pontos devem possuir coordenadas.

2. “Trecho” (formato numérico inteiro) deve conter as identificações de início de cada trecho; essa identificação deve constar apenas no primeiro ponto de cada trecho, a identificação pode ser um numero qualquer (\# 0$)$, compatível com a característica do campo. Um trecho é definido como um conjunto de pontos que possui necessariamente cargas conhecidas nos pontos extremos, entre esses, pode possuir quaisquer outros pontos com ou sem valor de carga conhecido. 
3. “Carga” (formato string) deve conter os valores de carga, atribuídos de modo crescente ou constante (do alto para baixo da tabela), representando o sentido jusante para montante das cargas nos rios. Os pontos de carga desconhecida (a interpolar) devem permanecer em branco. O caracter utilizado para separação decimal deve ser o mesmo configurado para o computador. Caso necessário, pode-se utilizar o recurso localizer \& trocar (em opções da tabela de atributos) para automatizar possíveis conversões de ponto para vírgula ou vice-versa. A geração dos campos deve parecer como na tabela abaixo.

No ArcMap, antes de executar o módulo, a layer contendo os dados a interpolar deve ocupar a primeira posição na área de dados (data frame).

Depois de iniciado, o módulo faz a leitura dos dados e verifica sua consistência segundo as definições acima. Assim, cada trecho é verificado quanto a possuir:

a) existência de coordenadas em todos os pontos;

b) uma identificação (apenas no respectivo primeiro ponto, na coluna “Trecho”);

c) cargas conhecidas necessariamente nos pontos extremos;

d) cargas crescentes (ou constantes), condição exigida apenas ao longo de cada trecho e não intertrechos.

Garantida a consistência dos dados, a interpolação linear (em cada trecho) é realizada entre cada par de cargas conhecidas (subtrechos). Os valores de carga (calculados e conhecidos) são dispostos no campo “Carga_Intr”. 


\begin{tabular}{|c|c|c|c|c|c|c|c|c|}
\hline \multicolumn{7}{|c|}{ 囲 Attributes of Riosjg_SPA } & \multicolumn{2}{|l|}{$\square \square$} \\
\hline & FID & Shape ${ }^{x}$ & Coord_X & Coord_Y & Trecho & Carga & Carga_Intr & A \\
\hline & 497 & Point & 766087 & 7582883 & 11300 & 497 & 497 & \\
\hline & 498 & Point & 765772 & 7583226 & 0 & & 500,528466 & \\
\hline & 499 & Point & 765702 & 7583812 & 0 & 505 & 505 & \\
\hline & 500 & Point & 766584 & 7582842 & 11400 & 497,2 & 497,2 & \\
\hline & 501 & Point & 766930 & 7583043 & 0 & & 498,509888 & \\
\hline & 502 & Point & 767305 & 7583394 & 0 & & 500,191300 & \\
\hline & 503 & Point & 767617 & 7583762 & 0 & & 501,770644 & \\
\hline & 504 & Point & 767946 & 7584216 & 0 & & 503,606028 & \\
\hline & 505 & Point & 768181 & 7584732 & 0 & & 505,462092 & \\
\hline & 506 & Point & 768298 & 7585187 & 0 & 507 & 507 & \\
\hline & 507 & Point & 768216 & 7585541 & 0 & & 515,141905 & \\
\hline & 508 & Point & 767935 & 7585928 & 0 & & 525,857958 & \\
\hline & 509 & Point & 767700 & 7586336 & 0 & & 536,407785 & \\
\hline & 510 & Point & 767535 & 7586779 & 0 & 547 & 547 & \\
\hline & 511 & Point & 768298 & 7585187 & 11401 & 507 & 507 & \\
\hline & 512 & Point & 768654 & 7585390 & 0 & & 516,997546 & \\
\hline & 513 & Point & 768959 & 7585836 & 0 & & 530,178821 & \\
\hline & 514 & Point & 769217 & 7586431 & & 546 & 546 & $5 \%$ \\
\hline$<$ & & & & & IIIII & & $\geq$ & \\
\hline & id: 114 & & - 11 & ow: All & elected & ecords 10 & of 1840 Selecte & ted.] \\
\hline
\end{tabular}

Tabela de atributos contendo valores interpolados de carga hidráulica, obtidos pelo aplicativo.

A instalação do módulo de interpolação no ambiente ArcGis é feita a partir do ArcMap seguindo os passos abaixo; os módulos devem ser instalados separadamente, um por vez :

- na barra de ferramenta Tools -> Customize...;

- na janela “Customize”, abrir a paleta “Toolbars” -> New..

- em “Toolbar Name” atribuir um nome para uma nova ferramenta e em “Save in”, selecionar o próprio arquivo .mxd onde estão os dados;

- na paleta Comands, escolher a categoria UIControls -> New UIControl...;

- na janela “New UIControl “ (opção UIBittonControl) -> Create;

- em Comands, alterar o nome do botão Project.

UIBittonContro11 (clik sobre ele e editar um nome qualquer desejado - Project. nome do botão; 
- arrastar o botão criado, de Comands para a ferramenta criada, nesta, clik-D -> Image and Text; fechar a janela "Customize";

- sobre a ferramenta criada, clik-D -> View Source; no

ambiente visual basic, inserir o código do módulo entre as duas linhas de comando: Private Sub nome do botão_Click() e End Sub. Com isso, não se deve deixar duplicado os comandos Private... (acima) nem o End Sub (abaixo).

\section{Módulo de exportação de dados}

A exportação de arquivos shapfile para arquivos de texto (ASCII), seguindo formatação específica (formato utilizado pelo simulador de processos em aqüíferos - SPA), a partir do ArcMap, necessita que na tabela de atributos do respectivo arquivo shapefile (de pontos) sejam adicionados os seguintes campos: “Coord_X”, “Coord_Y”, “Trecho” e “Carga_Intr”. As características dos campos são as mesmas, como referido no módulo de interpolação, e o campo “Carga_Intr” pode ser do tipo numérico ou string (valendo as mesmas observações em relação à colocação dos dados em campos desses tipos). Diferentemente do módulo de interpolação, agora o campo “Trecho” não possui qualquer tipo de restrição para preenchimento, podendo inclusive não possuir qualquer registro de identificação de trechos, apesar disso o campo é necessário. Alem da existência dos campos com os referidos nomes, este módulo checa apenas a condição de todos os pontos possuírem coordenadas.

O módulo permite gerar os dados também em ordem inversa a da tabela de atributos, bem como, com diferentes números de casas decimais para o valor de cargas. A formatação com que os dados são listados em arquivo texto pode ser facilmente alterada a partir do código-fonte do referido módulo. 
A instalação deste módulo segue os mesmos passos descritos na instalação do módulo anterior. 
ANEXO A: Poços do SIAGAS na área de estudo, com dados geológicos 


\begin{tabular}{|c|c|c|c|c|c|c|c|c|c|c|c|c|c|}
\hline \multirow{4}{*}{ Instalacão } & \multirow[b]{4}{*}{ Uso } & \multirow[b]{4}{*}{$\begin{array}{l}\text { UTM- } \\
\text { (N/S) }\end{array}$} & \multirow[b]{4}{*}{$\begin{array}{l}\text { UTM- } \\
\text { (L/O) }\end{array}$} & \multirow{2}{*}{\multicolumn{6}{|c|}{ Geológicos }} & & & & \\
\hline & & & & & & & & & & & & & \\
\hline & & & & \multicolumn{2}{|c|}{ S. Geral (m) } & \multicolumn{2}{|c|}{ Botucatu (m) } & \multicolumn{2}{|c|}{ Pirambóia (m) } & \multicolumn{4}{|c|}{ Hidrogeológicos } \\
\hline & & & & INI. & FIM & INI. & FIM & INI. & FIM & Aquífero & Topo(m) & Base(m) & Condicão \\
\hline $1 / 1 / 1966$ & Urbano & 7664850 & 211150 & & & & & & & Botucatu & 0 & 96 & \\
\hline 1/1/1973 & & 7664100 & 210450 & 0 & 114 & 114 & 145 & & & Botucatu & 114 & 145 & Semi-Confinado \\
\hline 1/1/1973 & Industrial & 7663150 & 209050 & & & 0 & 110 & 110 & 200 & Botucatu & & & Confinado \\
\hline 1/1/1979 & & 7662050 & 209700 & & & & & & & & & & \\
\hline 1/1/1958 & Outros & 7664200 & 213280 & & & & & & & Botucatu & 0 & 90 & \\
\hline 1/1/1961 & Urbano & 7664120 & 213300 & & & & & & & Botucatu & 0 & 100 & \\
\hline \multirow[t]{2}{*}{$1 / 1 / 1967$} & & 7663550 & 213680 & & & 0 & 70 & & & Botucatu & 0 & 70 & Confinado \\
\hline & Urbano & 7662660 & 214080 & & & & & & & Botucatu & & & Confinado \\
\hline $1 / 1 / 1973$ & & 7660250 & 213650 & 0 & 87 & 87 & 150 & & & Botucatu & 87 & 150 & Confinado \\
\hline $1 / 1 / 1971$ & Industrial & 7660400 & 211000 & & & 0 & 74 & & & Botucatu & 0 & 74 & Semi-Confinado \\
\hline \multirow[t]{4}{*}{ 1/1/1976 } & & 7660220 & 211000 & & & & & & & & & & \\
\hline & Urbano & 7659650 & 210670 & & & & & & & Botucatu & 0 & 120 & \\
\hline & & 7659100 & 210750 & & & & & & & Botucatu & 0 & 175 & \\
\hline & Urbano & 7657100 & 210870 & 0 & 90 & 90 & 120 & & & Serra geral & & & Livre \\
\hline $1 / 1 / 1970$ & Urbano & 7658430 & 209850 & 0 & 107,1 & 107,1 & 109.6 & & & Botucatu & 107.1 & 109.6 & \\
\hline $1 / 1 / 1956$ & Urbano & 7658650 & 209800 & 0 & 34 & 34 & 68 & & & Botucatu & 34 & 68 & Semi-Confinado \\
\hline 1/1/1965 & Urbano & 7658730 & 209700 & 0 & 30 & 30 & 76,1 & & & Botucatu & 30 & 76.1 & Semi-Confinado \\
\hline \multirow[t]{2}{*}{$1 / 1 / 1970$} & & 7658650 & 209260 & & & & & & & Botucatu & 0 & 162 & \\
\hline & & 7658530 & 208600 & 0 & 25 & 25 & 85 & & & Botucatu & 25 & 85 & Confinado \\
\hline $1 / 1 / 1965$ & & 7658310 & 208410 & 0 & 39 & 39 & 62 & & & Botucatu & 39 & 62 & Semi-Confinado \\
\hline $1 / 1 / 1962$ & Urbano & 7658250 & 208420 & 0 & 40 & 40 & 96 & & & Botucatu & 40 & 96 & Semi-Confinado \\
\hline \multirow[t]{3}{*}{ 1/1/1962 } & Urbano & 7658190 & 208500 & 0 & 35 & 35 & 81,5 & & & Botucatu & 35 & 81.5 & Semi-Confinado \\
\hline & Industrial & 7658100 & 208250 & & & & & & & Botucatu & 0 & 110 & \\
\hline & Industrial & 7658000 & 208350 & 0 & 30 & 30 & 135 & 135 & 205 & Botucatu & 30 & 205 & Confinado \\
\hline \multirow[t]{2}{*}{ 1/1/1948 } & Industrial & 7657900 & 208230 & & & & & & & & & & Confinado \\
\hline & & 7657750 & 208260 & & & & & & & & & & Confinado \\
\hline 1/1/1945 & Urbano & 7657340 & 207950 & 0 & 34 & 34 & 67 & & & & 34 & 67 & Confinado \\
\hline $1 / 1 / 1954$ & Urbano & 7657390 & 207530 & 0 & 35 & 35 & 102 & & & Botucatu & 35 & 102 & Confinado \\
\hline
\end{tabular}




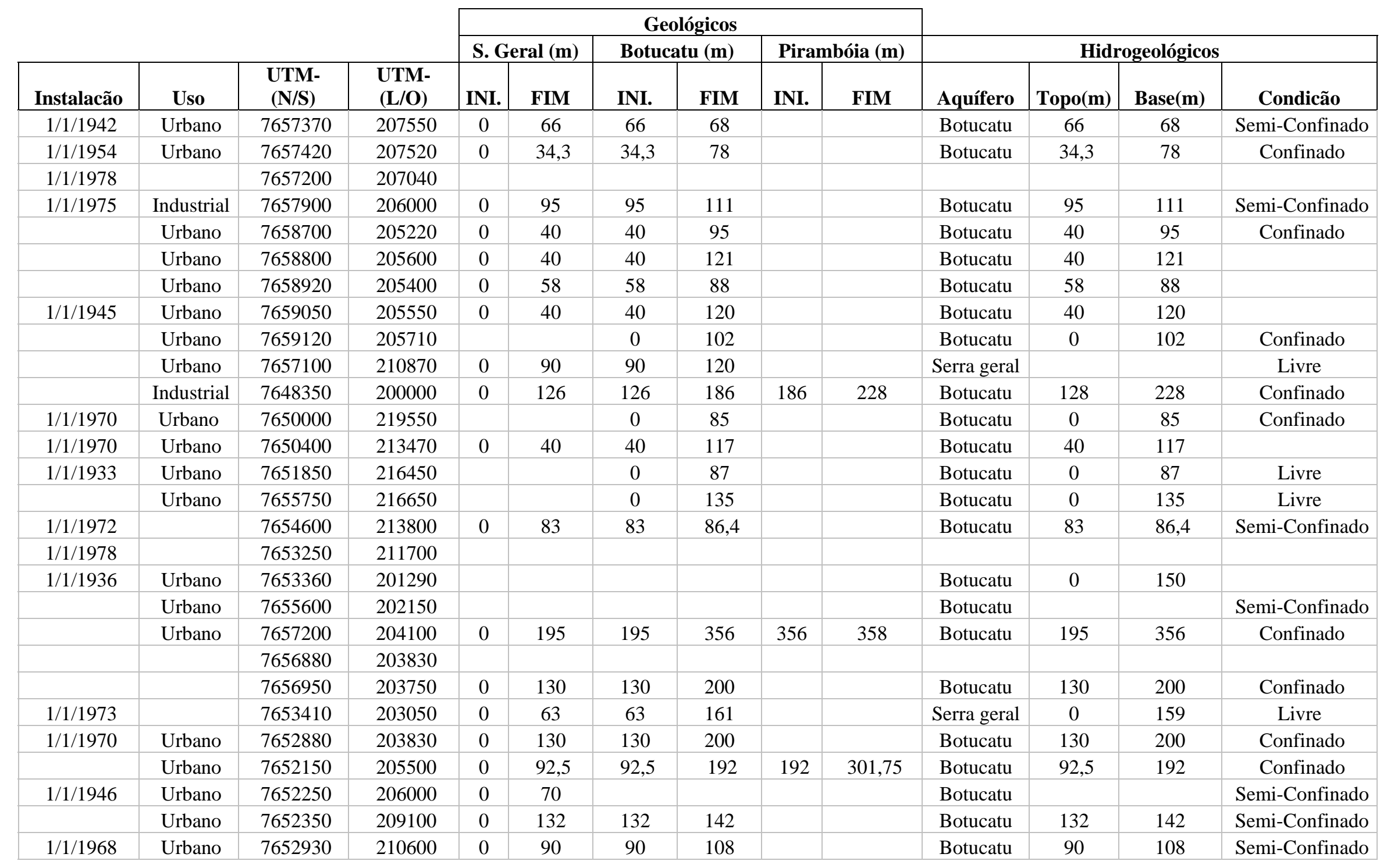




\begin{tabular}{|c|c|c|c|c|c|c|c|c|c|c|c|c|c|}
\hline \multirow[b]{3}{*}{ Instalacão } & \multirow[b]{3}{*}{ Uso } & \multirow[b]{3}{*}{$\begin{array}{l}\text { UTM- } \\
\text { (N/S) }\end{array}$} & \multirow[b]{3}{*}{$\begin{array}{l}\text { UTM- } \\
\text { (L/O) }\end{array}$} & \multicolumn{6}{|c|}{ Geológicos } & & & & \\
\hline & & & & \multicolumn{2}{|c|}{ S. Geral (m) } & \multicolumn{2}{|c|}{ Botucatu (m) } & \multicolumn{2}{|c|}{ Pirambóia (m) } & \multicolumn{4}{|c|}{ Hidrogeológicos } \\
\hline & & & & INI. & FIM & INI. & FIM & INI. & FIM & Aquífero & Tоро(m) & Base(m) & Condicão \\
\hline $1 / 1 / 1977$ & & 7656400 & 203850 & & & & & & & & & & \\
\hline \multirow[t]{6}{*}{ 1/1/1987 } & & 7656230 & 203950 & & & & & & & & & & \\
\hline & & 7655600 & 203550 & 0 & 108 & & & & & Serra geral & 0 & 108 & Livre \\
\hline & Urbano & 7653630 & 204860 & 0 & 168 & 168 & 344 & 344 & 385 & Botucatu & 168 & 385 & Confinado \\
\hline & Urbano & 7654650 & 205250 & 0 & 159 & 159 & 390 & & & Botucatu & 159 & 390 & \\
\hline & Urbano & 7652150 & 205500 & 0 & 92,5 & 92,5 & 192 & 192 & 301,75 & Botucatu & 92,5 & 192 & Confinado \\
\hline & & 7655950 & 205850 & 0 & 74 & 74 & 282 & 282 & 286 & Botucatu & 70 & 282 & Confinado \\
\hline \multirow[t]{2}{*}{ 1/1/1966 } & Urbano & 7655750 & 206160 & 0 & 83 & 83 & 122 & & & Botucatu & 83 & 122 & Semi-Confinado \\
\hline & Urbano & 7655800 & 206050 & & & & & & & & & & Semi-Confinado \\
\hline 1/1/1972 & & 7655850 & 206340 & 0 & 80,3 & 80,3 & 132,7 & & & Botucatu & 80,3 & 132,7 & Semi-Confinado \\
\hline \multirow[t]{2}{*}{ 1/1/1973 } & & 7653800 & 206500 & 0 & 94,6 & 94,6 & 106 & & & Botucatu & 94,6 & 106 & Semi-Confinado \\
\hline & Industrial & 7653820 & 206750 & & & & & & & Botucatu & 0 & 105 & \\
\hline 1/1/1966 & Urbano & 7655250 & 207080 & & & & & & & & & & Semi-Confinado \\
\hline $1 / 1 / 1963$ & Urbano & 7655420 & 207100 & 0 & 101 & 101 & 107 & & & Botucatu & 101 & 107 & Semi-Confinado \\
\hline $1 / 1 / 1961$ & Urbano & 7656550 & 206670 & 0 & 94 & 94 & 101 & & & Botucatu & 94 & 101 & Semi-Confinado \\
\hline $1 / 1 / 1961$ & Urbano & 7656520 & 206720 & 0 & 94,7 & 94,7 & 100,1 & & & Botucatu & 94.7 & 100,1 & Semi-Confinado \\
\hline $1 / 1 / 1960$ & Urbano & 7654500 & 206620 & 0 & 98 & 98 & 100 & & & Botucatu & 98 & 100 & \\
\hline $1 / 1 / 1966$ & Urbano & 7654450 & 206600 & 0 & 107 & 107 & 183 & & & Botucatu & 107 & 183 & \\
\hline \multirow[t]{2}{*}{$1 / 1 / 1970$} & & 7654400 & 206950 & 0 & 69,1 & 69,1 & 75,1 & & & Botucatu & 69,1 & 75,1 & Semi-Confinado \\
\hline & Urbano & 7652940 & 206650 & 0 & 83 & 83 & 87 & & & Botucatu & 83 & 87 & Semi-Confinado \\
\hline 1/1/1938 & Urbano & 7653100 & 206760 & 0 & 83,5 & 83,5 & 87 & & & Botucatu & 83.5 & 87 & Confinado \\
\hline 1/1/1965 & Urbano & 7653060 & 206570 & 0 & 80 & 80 & 86 & & & Botucatu & 80 & 86 & Semi-Confinado \\
\hline 1/1/1930 & & 7653050 & 206550 & 0 & 76 & 76 & 82 & & & Botucatu & 76 & 82 & Confinado \\
\hline $1 / 1 / 1938$ & Urbano & 7653100 & 206760 & 0 & 83,5 & 83,5 & 87 & & & Botucatu & 83.5 & 87 & Confinado \\
\hline \multirow[t]{2}{*}{$1 / 1 / 1949$} & Urbano & 7653100 & 206480 & 0 & 81 & 81 & 83 & & & Botucatu & 81 & 83 & Semi-Confinado \\
\hline & & 7653120 & 206610 & 0 & 74,5 & 74,5 & 80 & & & Botucatu & 74,5 & 80 & Confinado \\
\hline $1 / 1 / 1966$ & Urbano & 7653160 & 206550 & 0 & 73 & 73 & 81 & & & Botucatu & 73 & 81 & Semi-Confinado \\
\hline 1/1/1971 & Urbano & 7655380 & 207620 & 0 & 92,8 & 92,8 & 95.2 & & & Botucatu & 92,8 & 95.2 & Semi-Confinado \\
\hline
\end{tabular}




\begin{tabular}{|c|c|c|c|c|c|c|c|c|c|c|c|c|c|}
\hline & & & & & & & & & & & & & \\
\hline \multirow{3}{*}{ Instalacão } & \multirow[b]{3}{*}{ Uso } & \multirow[b]{3}{*}{$\begin{array}{l}\text { UTM- } \\
\text { (N/S) }\end{array}$} & \multirow[b]{3}{*}{$\begin{array}{l}\text { UTM- } \\
\text { (L/O) }\end{array}$} & \multicolumn{6}{|c|}{ Geológicos } & & & & \\
\hline & & & & \multicolumn{2}{|c|}{ S. Geral (m) } & \multicolumn{2}{|c|}{ Botucatu (m) } & \multicolumn{2}{|c|}{ Pirambóia (m) } & \multicolumn{4}{|c|}{ Hidrogeológicos } \\
\hline & & & & INI. & FIM & INI. & FIM & INI. & FIM & Aquífero & Topo(m) & Base(m) & Condicão \\
\hline 1/1/1969 & & 7654830 & 207670 & 0 & 95 & 95 & 120 & & & Botucatu & 95 & 120 & Semi-Confinado \\
\hline 1/1/1968 & Urbano & 7655300 & 207820 & 0 & 90 & 90 & 110 & & & Botucatu & 90 & 110 & Semi-Confinado \\
\hline 1/1/1970 & Urbano & 7653950 & 209550 & 0 & 110 & 110 & 150 & & & Botucatu & 110 & 150 & Semi-Confinado \\
\hline 1/1/1959 & & 7654850 & 208700 & 0 & 142,3 & 142,3 & 146,5 & & & Botucatu & 142,3 & 146,5 & Semi-Confinado \\
\hline 1/1/1963 & Urbano & 7654900 & 210370 & 0 & 145 & 145 & 205 & & & Botucatu & 145 & 205 & Semi-Confinado \\
\hline \multirow{2}{*}{$1 / 1 / 1948$} & Urbano & 7655160 & 209220 & 0 & 80 & 80 & 125 & & & Botucatu & 80 & 125 & Semi-Confinado \\
\hline & Industrial & 7655250 & 209320 & & & & & & & Botucatu & 0 & 160 & \\
\hline 1/1/1970 & & 7656100 & 210750 & & & & & & & Botucatu & & & Semi-Confinado \\
\hline 1/1/1961 & Urbano & 7656150 & 210650 & 0 & 82 & 82 & 96,5 & & & Botucatu & 82 & 96,5 & Confinado \\
\hline 1/1/1966 & Urbano & 7656150 & 210600 & 0 & 131,7 & 131,7 & 137,7 & & & Botucatu & 131,7 & 137,7 & Semi-Confinado \\
\hline $1 / 1 / 1964$ & Urbano & 7656220 & 210570 & 0 & 81 & 81 & 105 & & & Botucatu & 81 & 105 & \\
\hline $1 / 1 / 1966$ & Urbano & 7656350 & 210600 & 0 & 72 & 72 & 78 & & & Botucatu & 72 & 78 & Semi-Confinado \\
\hline \multirow[t]{2}{*}{$1 / 1 / 1971$} & Urbano & 7656470 & 210310 & 0 & 113,6 & 113,6 & 172,6 & & & Botucatu & 113,6 & 172,6 & \\
\hline & Urbano & 7655450 & 209050 & 0 & 85 & 85 & 96 & & & Botucatu & 85 & 96 & Semi-Confinado \\
\hline \multirow[t]{2}{*}{ 1/1/1948 } & Urbano & 7655900 & 208850 & 0 & 80 & 80 & 91 & & & Botucatu & 80 & 91 & Semi-Confinado \\
\hline & Urbano & 7656050 & 209070 & 0 & 112 & 112 & 122 & & & Botucatu & 112 & 122 & \\
\hline 1/1/1970 & Urbano & 7656070 & 209000 & 0 & 92 & 92 & 150 & & & Botucatu & 90 & 150 & Semi-Confinado \\
\hline $1 / 1 / 1970$ & Urbano & 7656150 & 208550 & 0 & 100 & 100 & 195 & & & Botucatu & 100 & 195 & Semi-Confinado \\
\hline $1 / 1 / 1960$ & Urbano & 7656270 & 208370 & 0 & 93 & 93 & 96 & & & Botucatu & 93 & 96 & Semi-Confinado \\
\hline $1 / 1 / 1963$ & Industrial & 7656230 & 208070 & 0 & 30 & 30 & 75 & & & Botucatu & 30 & 75 & Semi-Confinado \\
\hline $1 / 1 / 1953$ & Industrial & 7656360 & 207960 & 0 & 43 & 43 & 81,2 & & & Botucatu & 43 & 81,2 & Semi-Confinado \\
\hline 1/1/1953 & Industrial & 7656450 & 207850 & 0 & 50 & 50 & 71 & & & Botucatu & 50 & 71 & Semi-Confinado \\
\hline \multirow[t]{4}{*}{$1 / 1 / 1958$} & Industrial & 7656480 & 208000 & 0 & 32 & 32 & 100 & & & Botucatu & 32 & 100 & \\
\hline & Industrial & 7656510 & 207960 & & & & & & & Botucatu & 0 & 72 & \\
\hline & Industrial & 7656530 & 207920 & & & & & & & Botucatu & 0 & 90 & \\
\hline & & 7656570 & 207940 & 0 & 36,5 & 36,5 & 119 & & & Botucatu & 36,5 & 119 & Semi-Confinado \\
\hline \multirow[t]{2}{*}{$1 / 1 / 1961$} & Industrial & 7656540 & 207880 & & & & & & & Botucatu & 0 & 90 & \\
\hline & & 7653000 & 228850 & 0 & 30 & 30 & 153 & & & Botucatu & 30 & 153 & \\
\hline
\end{tabular}




\begin{tabular}{|c|c|c|c|c|c|c|c|c|c|c|c|c|c|}
\hline \multirow{4}{*}{ Instalacão } & \multirow[b]{4}{*}{ Uso } & \multirow[b]{4}{*}{$\begin{array}{l}\text { UTM- } \\
\text { (N/S) }\end{array}$} & \multirow[b]{4}{*}{$\begin{array}{l}\text { UTM- } \\
\text { (L/O) }\end{array}$} & \multirow{2}{*}{\multicolumn{6}{|c|}{ Geológicos }} & & & & \\
\hline & & & & & & & & & & & & & \\
\hline & & & & \multicolumn{2}{|c|}{ S. Geral (m) } & \multicolumn{2}{|c|}{ Botucatu (m) } & \multicolumn{2}{|c|}{ Pirambóia (m) } & \multicolumn{4}{|c|}{ Hidrogeológicos } \\
\hline & & & & INI. & FIM & INI. & FIM & INI. & FIM & Aquífero & Topo(m) & Base(m) & Condicão \\
\hline & & 7653176 & 229628 & & & & & & & & & & \\
\hline 1/1/1972 & & 7655600 & 236950 & & & 0 & 100 & & & Botucatu & 0 & 100 & Confinado \\
\hline \multirow[t]{7}{*}{ 1/1/1955 } & Urbano & 7661450 & 234350 & & & 0 & 172,8 & & & Botucatu & 0 & 172,8 & Livre \\
\hline & & 7636500 & 215100 & 0 & 282 & 282 & 451 & & & & & & \\
\hline & Urbano & 7636600 & 215100 & 0 & 282 & 282 & 367 & 367 & 451 & Botucatu & 282 & 367 & Confinado \\
\hline & Urbano & 7637170 & 216020 & & & & & & & & & & \\
\hline & & 7638400 & 216800 & & & & & & & & & & \\
\hline & & 7638400 & 216750 & 0 & 394 & 394 & 496 & 496 & 613,62 & Botucatu & 496 & 613,62 & Confinado \\
\hline & Urbano & 7649300 & 191910 & & & & & & & Botucatu & 171 & 271 & \\
\hline 1/1/1969 & Urbano & 7648440 & 191180 & 0 & 196 & 196 & 204 & & & Botucatu & 196 & 204 & Semi-Confinado \\
\hline \multirow[t]{2}{*}{ 1/1/1981 } & Urbano & 7648250 & 191350 & & & & & & & & & & \\
\hline & Urbano & 7648100 & 190900 & 0 & 230 & 230 & 359 & & & Botucatu & 230 & 359 & Confinado \\
\hline 1/1/1981 & & 7647900 & 190900 & & & & & & & & & & \\
\hline \multirow[t]{3}{*}{ 1/1/1962 } & & 7675550 & 223550 & 0 & 235 & 235 & 261 & & & Botucatu & 235 & 261 & \\
\hline & & 7678900 & 224400 & & & & & & & Botucatu & 290 & 565 & \\
\hline & Urbano & 7677250 & 225750 & 0 & 12 & 12 & 216 & 216 & 220 & Botucatu & 216 & 220 & Confinado \\
\hline 18/01/1986 & Urbano & 7677250 & 226000 & 0 & 251 & 251 & 365 & 365 & 450 & Botucatu & 251 & 450 & Confinado \\
\hline $1 / 1 / 1986$ & & 7677450 & 225970 & & & & & & & Botucatu & 320 & 450 & \\
\hline \multirow[t]{2}{*}{ 1/1/1973 } & Urbano & 7677770 & 225730 & 0 & 218 & 218 & 220 & & & Botucatu & 218 & 220 & \\
\hline & & 7677950 & 225750 & 0 & 75 & & & & & Serra geral & 9 & 75 & \\
\hline 1/1/1972 & & 7665400 & 214400 & & & & & & & Botucatu & & & Semi-Confinado \\
\hline $1 / 1 / 1964$ & Urbano & 7664980 & 215650 & 0 & 178 & 178 & 180 & & & Botucatu & 178 & 180 & Semi-Confinado \\
\hline \multirow[t]{3}{*}{ 1/1/1979 } & & 7665400 & 216700 & & & & & & & & & & \\
\hline & Urbano & 7668443 & 215055 & & & & & & & & & & \\
\hline & & 7673763 & 212136 & 0 & 110 & 110 & 280 & & & Botucatu & 110 & 280 & Confinado \\
\hline \multirow[t]{3}{*}{$1 / 1 / 1970$} & Pecuária & 7681150 & 203550 & 0 & 100 & 100 & 103 & & & Botucatu & & & \\
\hline & Urbano & 7670750 & 191220 & 0 & 90 & 90 & 114 & & & Botucatu & 90 & 114 & \\
\hline & & 7666430 & 199200 & 0 & 130 & 130 & 141 & & & Botucatu & 130 & 141 & Semi-Confinado \\
\hline
\end{tabular}




\begin{tabular}{|c|c|c|c|c|c|c|c|c|c|c|c|c|c|}
\hline \multirow[b]{3}{*}{ Instalacão } & \multirow[b]{3}{*}{ Uso } & \multirow[b]{3}{*}{$\begin{array}{c}\text { UTM- } \\
\text { (N/S) }\end{array}$} & \multirow[b]{3}{*}{$\begin{array}{l}\text { UTM- } \\
\text { (L/O) }\end{array}$} & \multicolumn{6}{|c|}{ Geológicos } & & & & \\
\hline & & & & \multicolumn{2}{|c|}{ S. Geral (m) } & \multicolumn{2}{|c|}{ Botucatu (m) } & \multicolumn{2}{|c|}{ Pirambóia (m) } & \multicolumn{4}{|c|}{ Hidrogeológicos } \\
\hline & & & & INI. & FIM & INI. & FIM & INI. & FIM & Aquífero & Topo(m) & Base(m) & Condicão \\
\hline & & 7665450 & 193450 & 0 & 90 & 90 & 166 & & & Botucatu & 90 & 166 & \\
\hline & Industrial & 7666250 & 810450 & & & & & & & & & & \\
\hline & Industrial & 7661700 & 192500 & 0 & 109 & 109 & 200 & 200 & 311 & Botucatu & 109 & 311 & Confinado \\
\hline & & 7657300 & 189800 & & & & & & & & & & \\
\hline & & 7658500 & 188600 & 0 & 102,5 & 102,5 & 198 & 198 & 337,5 & Botucatu & 102.5 & 337,5 & Confinado \\
\hline & Urbano & 7658850 & 190750 & 0 & 191 & 191 & 402 & 402 & 408 & Botucatu & 191 & 408 & Confinado \\
\hline & Urbano & 7659050 & 810350 & 0 & 190 & & & & & Serra geral & 0 & 190 & Livre \\
\hline & Urbano & 7659700 & 811100 & 0 & 141 & 141 & 247 & 247 & 302 & Botucatu & 141 & 302 & Confinado \\
\hline 1/1/1979 & & 7659600 & 810600 & 0 & 222 & & & & & & & & \\
\hline \multirow[t]{6}{*}{ 1/1/1981 } & & 7659800 & 809750 & & & & & & & & & & \\
\hline & Múltiplo & 7660660 & 811100 & 0 & 149 & 149 & 224 & & & Botucatu & 149 & 224 & Confinado \\
\hline & Urbano & 7661250 & 810250 & 0 & 165 & 165 & 225 & 225 & 341.3 & Botucatu & 165 & 341.3 & Confinado \\
\hline & & 7660900 & 188900 & & & & & & & & & & \\
\hline & Urbano & 7661100 & 190500 & 0 & 120 & 120 & 206 & 206 & 323 & & 120 & 323 & Confinado \\
\hline & Industrial & 7661700 & 192500 & 0 & 109 & 109 & 200 & 200 & 311 & Botucatu & 109 & 311 & Confinado \\
\hline 1/1/1956 & Industrial & 7661880 & 192550 & 0 & 111,4 & 111,4 & 160 & & & Botucatu & 111.4 & 160 & Semi-Confinado \\
\hline \multirow[t]{3}{*}{$1 / 1 / 1957$} & Industrial & 7662000 & 192420 & 0 & 108 & 108 & 142.4 & & & Botucatu & 108 & 142.4 & Semi-Confinado \\
\hline & & 7658700 & 189800 & & & & & & & & & & \\
\hline & & 7659100 & 190800 & & & & & & & & & & \\
\hline 1/1/1986 & & 7659750 & 190600 & & & & & & & & & & \\
\hline \multirow[t]{6}{*}{$1 / 1 / 1978$} & & 7660400 & 189900 & & & & & & & & & & \\
\hline & Urbano & 7659800 & 190150 & 0 & 120 & 120 & 162 & & & Botucatu & 120 & 162 & Semi-Confinado \\
\hline & & 7659800 & 190100 & & & & & & & & & & \\
\hline & Urbano & 7659240 & 189490 & 0 & 92 & 92 & 111.7 & & & Botucatu & 92 & 111.7 & Semi-Confinado \\
\hline & & 7659400 & 189500 & & & & & & & & & & \\
\hline & & 7659700 & 189600 & & & & & & & & & & \\
\hline \multirow[t]{2}{*}{$1 / 1 / 1966$} & Urbano & 7660150 & 189200 & 0 & 91 & 91 & 106 & & & Botucatu & 91 & 106 & Semi-Confinado \\
\hline & & 7660100 & 189200 & & & & & & & & & & \\
\hline
\end{tabular}




\begin{tabular}{|c|c|c|c|c|c|c|c|c|c|c|c|c|c|}
\hline \multirow[b]{3}{*}{ Instalacão } & \multirow[b]{3}{*}{ Uso } & \multirow[b]{3}{*}{$\begin{array}{l}\text { UTM- } \\
\text { (N/S) }\end{array}$} & \multirow[b]{3}{*}{$\begin{array}{l}\text { UTM- } \\
\text { (L/O) }\end{array}$} & \multicolumn{6}{|c|}{ Geológicos } & & & 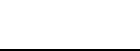 & \\
\hline & & & & \multicolumn{2}{|c|}{ S. Geral (m) } & \multicolumn{2}{|c|}{ Botucatu (m) } & \multicolumn{2}{|c|}{ Pirambóia (m) } & \multicolumn{4}{|c|}{ Hidrogeológicos } \\
\hline & & & & INI. & FIM & INI. & FIM & INI. & FIM & Aquífero & Topo(m) & Base(m) & Condicão \\
\hline & & 7659500 & 188720 & 0 & 253 & & & & & Serra geral & 0 & 253 & Livre \\
\hline & & 7659500 & 188800 & & & & & & & & & & \\
\hline \multirow[t]{4}{*}{$1 / 1 / 1970$} & Urbano & 7659570 & 189050 & 0 & 75 & 75 & 101 & & & Botucatu & 75 & 101 & Semi-Confinado \\
\hline & & 7659500 & 189100 & & & & & & & & & & \\
\hline & & 7659400 & 189300 & & & & & & & & & & \\
\hline & Urbano & 7659350 & 189300 & 0 & 92 & 92 & 114.7 & & & Botucatu & 92 & 114.7 & Semi-Confinado \\
\hline
\end{tabular}


ANEXO B: Poços na área de estudo com informações sobre vazão explotada 


\begin{tabular}{|c|c|c|c|c|c|c|c|c|c|c|}
\hline $\mathbf{N}^{\circ}$ & $\begin{array}{c}\mathbf{N}^{\circ} \\
\text { DAEE } \\
\end{array}$ & Município & CoordUTMN & CoordUTML & $\begin{array}{c}\text { Cota } \\
(\mathrm{m})\end{array}$ & $\begin{array}{c}\text { Aq. } \\
\text { Explorado }\end{array}$ & $\begin{array}{l}\text { Prof. } \\
\text { (m) }\end{array}$ & $\begin{array}{l}\text { Vazão } \\
\left(\mathrm{m}^{3} / \mathrm{h}\right) \\
\end{array}$ & Horas/Dia & Dias/Mes \\
\hline 1 & 67 & RIBEIRAO PRETO & 7660.64 & 207.16 & 595 & BP & 280 & 0 & 0 & 0 \\
\hline 2 & 68 & RIBEIRAO PRETO & 7658.1 & 206 & 580 & BP & 306.8 & 0 & 0 & 0 \\
\hline 3 & 69 & RIBEIRAO PRETO & 7654.8 & 208.64 & 563.3 & $\mathrm{BP}$ & 329 & 0 & 0 & 0 \\
\hline 4 & 70 & RIBEIRAO PRETO & 7661.47 & 208.84 & 535 & $\mathrm{BO}$ & 198 & 0 & 0 & 0 \\
\hline 5 & 71 & RIBEIRAO PRETO & 7653.63 & 204.86 & 601 & $\mathrm{BP}$ & 385 & 0 & 0 & 0 \\
\hline 6 & 72 & RIBEIRAO PRETO & 7651.69 & 204.86 & 560 & BP & 278 & 0 & 0 & 0 \\
\hline 7 & 73 & RIBEIRAO PRETO & 7656.32 & 209.15 & 570 & $\mathrm{BP}$ & 372.5 & 0 & 0 & 0 \\
\hline 8 & 74 & RIBEIRAO PRETO & 7523.9 & 209.84 & 527 & $\mathrm{BO}$ & 183 & 0 & 0 & 0 \\
\hline 9 & 79 & RIBEIRAO PRETO & 7654.65 & 205.25 & 604 & $\mathrm{BP}$ & 390 & 0 & 0 & 0 \\
\hline 10 & 80 & RIBEIRAO PRETO & 7661.55 & 206.8 & 525 & $\mathrm{BP}$ & 235 & 0 & 0 & 0 \\
\hline 11 & 81 & RIBEIRAO PRETO & 7657.2 & 204.1 & 630 & BP & 358 & 0 & 0 & 0 \\
\hline 12 & 82 & RIBEIRAO PRETO & 7652.72 & 212.49 & 583 & BP & 232 & 0 & 0 & 0 \\
\hline 13 & 83 & RIBEIRAO PRETO & 7654.09 & 212.69 & 582 & $\mathrm{BO}$ & 186.8 & 0 & 0 & 0 \\
\hline 14 & 84 & RIBEIRAO PRETO & 7652.15 & 205.5 & 547 & BP & 301.75 & 0 & 0 & 0 \\
\hline 15 & 85 & RIBEIRAO PRETO & 7655.41 & 207.68 & 536 & $\mathrm{BP}$ & 268 & 0 & 0 & 0 \\
\hline 16 & 86 & RIBEIRAO PRETO & 7657.08 & 210.62 & 495 & $\mathrm{BO}$ & 24 & 2 & 8 & 30 \\
\hline 17 & 87 & RIBEIRAO PRETO & 7651 & 213.8 & 603 & $\mathrm{BO}$ & 90 & 4 & 10 & 30 \\
\hline 18 & 89 & RIBEIRAO PRETO & 7658.33 & 208.22 & 515 & $\mathrm{BO}$ & 50 & 2 & 10 & 30 \\
\hline 19 & 90 & RIBEIRAO PRETO & 7657.16 & 210.69 & 532 & BP & 35 & 2 & 10 & 30 \\
\hline 20 & 91 & RIBEIRAO PRETO & 7656.37 & 210.21 & 620 & $\mathrm{BO}$ & 70 & 2 & 10 & 30 \\
\hline 21 & 92 & RIBEIRAO PRETO & 7659.06 & 205.92 & 545 & $\mathrm{BO}$ & 50 & 2 & 10 & 30 \\
\hline 22 & 93 & RIBEIRAO PRETO & 7653.15 & 213.43 & 610 & $\mathrm{BO}$ & 136 & 10 & 4 & 30 \\
\hline 23 & 94 & RIBEIRAO PRETO & 7661 & 213.85 & 0 & $\mathrm{BO}$ & 80 & 22.1 & 4 & 30 \\
\hline 24 & 95 & RIBEIRAO PRETO & 7651.06 & 208.11 & 592 & $\mathrm{BP}$ & 35 & 1 & 10 & 30 \\
\hline 25 & 97 & RIBEIRAO PRETO & 7654.08 & 209.13 & 556 & $\mathrm{BO}$ & 128 & 2 & 10 & 30 \\
\hline 26 & 98 & RIBEIRAO PRETO & 7648.43 & 207.44 & 587 & $\mathrm{BP}$ & 283 & 65 & 10 & 30 \\
\hline 27 & 99 & RIBEIRAO PRETO & 7661.58 & 211.99 & 537 & $\mathrm{BO}$ & 50 & 2 & 10 & 30 \\
\hline 28 & 102 & RIBEIRAO PRETO & 7654.34 & 208.8 & 580 & $\mathrm{BO}$ & 150 & 7.2 & 20 & 30 \\
\hline
\end{tabular}




\begin{tabular}{|c|c|c|c|c|c|c|c|c|c|c|}
\hline $\mathbf{N}^{\circ}$ & $\begin{array}{c}\mathrm{N}^{\circ} \\
\text { DAEE }\end{array}$ & Município & CoordUTMN & CoordUTML & $\begin{array}{c}\text { Cota } \\
(\mathrm{m})\end{array}$ & $\begin{array}{c}\text { Aq. } \\
\text { Explorado }\end{array}$ & $\begin{array}{l}\text { Prof. } \\
\text { (m) }\end{array}$ & $\begin{array}{l}\text { Vazão } \\
\left(\mathrm{m}^{3} / \mathrm{h}\right)\end{array}$ & Horas/Dia & Dias/Mes \\
\hline 29 & 103 & RIBEIRAO PRETO & 7656.47 & 209.87 & 540 & $\mathrm{BO}$ & 0 & 9 & 4 & 30 \\
\hline 30 & 104 & RIBEIRAO PRETO & 7651.93 & 210.51 & 560 & $\mathrm{BP}$ & 102 & 10 & 2 & 30 \\
\hline 31 & 106 & RIBEIRAO PRETO & 7658.18 & 201.15 & 671 & $\mathrm{BO}$ & 230 & 0 & 0 & 0 \\
\hline 32 & 108 & RIBEIRAO PRETO & 7656.38 & 209.44 & 0 & $\mathrm{BO}$ & 147 & 0 & 0 & 0 \\
\hline 33 & 109 & RIBEIRAO PRETO & 7661 & 208.6 & 519 & $\mathrm{BP}$ & 199.6 & 0 & 0 & 0 \\
\hline 34 & 110 & RIBEIRAO PRETO & 7654.09 & 212.7 & 537 & $\mathrm{BP}$ & 184.3 & 0 & 0 & 0 \\
\hline 35 & 111 & RIBEIRAO PRETO & 7655.95 & 205.85 & 528 & $\mathrm{BP}$ & 286 & 0 & 0 & 0 \\
\hline 36 & 112 & RIBEIRAO PRETO & 7651.75 & 213.15 & 610 & $\mathrm{BO}$ & 150 & 18 & 20 & 30 \\
\hline 37 & 113 & RIBEIRAO PRETO & 7653.67 & 202.96 & 617 & $\mathrm{BP}$ & 277 & 30 & 4 & 30 \\
\hline 38 & 115 & RIBEIRAO PRETO & 7651.3 & 209.1 & 0 & $\mathrm{BO}$ & 220 & 23 & 20 & 30 \\
\hline 39 & 116 & RIBEIRAO PRETO & 7659.52 & 201.14 & 634 & $\mathrm{BP}$ & 200 & 50 & 0 & 0 \\
\hline 40 & 117 & RIBEIRAO PRETO & 7650.14 & 209.63 & 663 & $\mathrm{BO}$ & 200 & 0 & 0 & 30 \\
\hline 41 & 47 & RIBEIRAO PRETO & 7654.74 & 210.01 & 564 & $\mathrm{BP}$ & 290.8 & 0 & 0 & 0 \\
\hline 42 & 48 & RIBEIRAO PRETO & 7653 & 206.1 & 536 & $\mathrm{BP}$ & 260 & 0 & 0 & 0 \\
\hline 43 & 49 & RIBEIRAO PRETO & 7655.15 & 209.24 & 528.5 & $\mathrm{BO}$ & 260 & 0 & 0 & 0 \\
\hline 44 & 50 & RIBEIRAO PRETO & 7659.47 & 204.84 & 562 & $\mathrm{BP}$ & 271 & 0 & 0 & 0 \\
\hline 45 & 51 & RIBEIRAO PRETO & 7655.9 & 207.35 & 527 & $\mathrm{BO}$ & 203 & 0 & 0 & 0 \\
\hline 46 & 52 & RIBEIRAO PRETO & 7652.66 & 206.11 & 540 & $\mathrm{BO}$ & 202 & 0 & 0 & 0 \\
\hline 47 & 53 & RIBEIRAO PRETO & 7658.75 & 209.72 & 514 & $\mathrm{BO}$ & 164 & 0 & 0 & 0 \\
\hline 48 & 54 & RIBEIRAO PRETO & 7658.32 & 208.38 & 517 & $\mathrm{BO}$ & 213 & 0 & 0 & 0 \\
\hline 49 & 55 & RIBEIRAO PRETO & 7661.98 & 209.82 & 528 & $\mathrm{BO}$ & 180 & 0 & 0 & 0 \\
\hline 50 & 56 & RIBEIRAO PRETO & 7653.33 & 208.32 & 621 & $\mathrm{BP}$ & 370 & 0 & 0 & 0 \\
\hline 51 & 57 & RIBEIRAO PRETO & 7662.05 & 209.66 & 518 & $\mathrm{BP}$ & 181.7 & 0 & 0 & 0 \\
\hline 52 & 58 & RIBEIRAO PRETO & 7660.02 & 209.66 & 535 & $\mathrm{BP}$ & 240 & 0 & 0 & 0 \\
\hline 53 & 59 & RIBEIRAO PRETO & 7654.1 & 213.64 & 563 & $\mathrm{BP}$ & 165 & 0 & 0 & 0 \\
\hline 54 & 60 & RIBEIRAO PRETO & 7661.1 & 208.13 & 518 & $\mathrm{BO}$ & 180 & 0 & 0 & 0 \\
\hline 55 & 61 & RIBEIRAO PRETO & 7650.5 & 214 & 575.75 & $\mathrm{BP}$ & 200 & 0 & 0 & 0 \\
\hline 56 & 62 & RIBEIRAO PRETO & 7663.15 & 208.72 & 505 & $\mathrm{BP}$ & 200 & 0 & 0 & 0 \\
\hline
\end{tabular}




\begin{tabular}{|c|c|c|c|c|c|c|c|c|c|c|}
\hline $\mathbf{N}^{\circ}$ & $\begin{array}{c}\mathbf{N}^{\mathbf{o}} \\
\text { DAEE }\end{array}$ & Município & CoordUTMN & CoordUTML & $\begin{array}{c}\text { Cota } \\
(\mathrm{m})\end{array}$ & $\begin{array}{c}\text { Aq. } \\
\text { Explorado }\end{array}$ & $\begin{array}{l}\text { Prof. } \\
\text { (m) }\end{array}$ & $\begin{array}{l}\text { Vazão } \\
\left(\mathrm{m}^{3} / \mathrm{h}\right) \\
\end{array}$ & Horas/Dia & Dias/Mes \\
\hline 57 & 63 & RIBEIRAO PRETO & 7654.08 & 210.9 & 588.5 & BP & 292 & 0 & 0 & 0 \\
\hline 58 & 64 & RIBEIRAO PRETO & 7651.34 & 210.9 & 595 & $\mathrm{BO}$ & 189.8 & 0 & 0 & 0 \\
\hline 59 & 65 & RIBEIRAO PRETO & 7659.45 & 204.85 & 592 & $\mathrm{BO}$ & 207 & 0 & 0 & 0 \\
\hline 60 & 66 & RIBEIRAO PRETO & 7656.85 & 205.27 & 534 & BP & 255 & 0 & 0 & 0 \\
\hline 61 & 75 & RIBEIRAO PRETO & 7656.22 & 205 & 552 & $\mathrm{BP}$ & 303.5 & 0 & 0 & 0 \\
\hline 62 & 76 & RIBEIRAO PRETO & 7655.06 & 205 & 573 & $\mathrm{BO}$ & 2000 & 0 & 0 & 0 \\
\hline 63 & 77 & RIBEIRAO PRETO & 7658.62 & 212.57 & 548 & BP & 210 & 0 & 0 & 0 \\
\hline 64 & 78 & RIBEIRAO PRETO & 7659 & 206.6 & 563 & $\mathrm{BP}$ & 276.5 & 0 & 0 & 0 \\
\hline 65 & 118 & RIBEIRAO PRETO & 7650.14 & 209.7 & 663 & $\mathrm{BO}$ & 200 & 8 & 0 & 30 \\
\hline 66 & 119 & RIBEIRAO PRETO & 7650.1 & 210.36 & 645 & $\mathrm{BO}$ & 175 & 25 & 4 & 30 \\
\hline 67 & 120 & RIBEIRAO PRETO & 7659.78 & 202.01 & 590 & $\mathrm{BO}$ & 105 & 3.6 & 24 & 30 \\
\hline 68 & 121 & RIBEIRAO PRETO & 7663.15 & 206.1 & 560 & $\mathrm{BO}$ & 212 & 80 & 8 & 30 \\
\hline 69 & 122 & RIBEIRAO PRETO & 7657.59 & 214.41 & 510 & $\mathrm{BO}$ & 100 & 6.43 & 8 & 25 \\
\hline 70 & 123 & RIBEIRAO PRETO & 7664.5 & 211.05 & 530 & BP & 150 & 30 & 10 & 30 \\
\hline 72 & 128 & RIBEIRAO PRETO & 7652.72 & 211.01 & 610 & $\mathrm{BP}$ & 135 & 2 & 10 & 30 \\
\hline 73 & 130 & RIBEIRAO PRETO & 7644.4 & 207.6 & 0 & BP & 251.5 & 150 & 13 & 22 \\
\hline 74 & 131 & RIBEIRAO PRETO & 7656.64 & 207.96 & 0 & $\mathrm{BP}$ & 232 & 210 & 13 & 22 \\
\hline 75 & 132 & RIBEIRAO PRETO & 7656.52 & 208.03 & 0 & $\mathrm{BP}$ & 238 & 180 & 13 & 22 \\
\hline 76 & 133 & RIBEIRAO PRETO & 7650.38 & 209.75 & 650 & $\mathrm{BO}$ & 180 & 0 & 0 & 0 \\
\hline 77 & 135 & RIBEIRAO PRETO & 7653.2 & 212.65 & 605 & $\mathrm{BO}$ & 100 & 3.5 & 2 & 30 \\
\hline 78 & 137 & SERTAOZINHO & 7661.73 & 192.5 & 600.78 & $\mathrm{BP}$ & 311.45 & 180 & 16 & 30 \\
\hline 79 & 138 & SERTAOZINHO & 7662.21 & 192.79 & 599.37 & BP & 324 & 90 & 10 & 30 \\
\hline 80 & 139 & RIBEIRAO PRETO & 7660.41 & 211.45 & 540 & $\mathrm{BO}$ & 110 & 5 & 1 & 30 \\
\hline 81 & 142 & RIBEIRAO PRETO & 7659 & 206.38 & 530 & $\mathrm{BO}$ & 280 & 0 & 0 & 0 \\
\hline 82 & 143 & JARDINOPOLIS & 7667.7 & 214.1 & 0 & $\mathrm{BO}$ & 6 & 1.5 & 0 & 0 \\
\hline 83 & 144 & RIBEIRAO PRETO & 7655.38 & 206.79 & 515 & $\mathrm{BP}$ & 171 & 5 & 3 & 30 \\
\hline 84 & 148 & SERTAOZINHO & 7661.03 & 190.65 & 570 & $\mathrm{BP}$ & 323 & 180 & 20 & 30 \\
\hline
\end{tabular}




\begin{tabular}{|c|c|c|c|c|c|c|c|c|c|c|}
\hline $\mathrm{N}^{\circ}$ & $\begin{array}{c}N^{\circ} \\
\text { DAEE }\end{array}$ & Município & CoordUTMN & CoordUTML & $\begin{array}{c}\text { Cota } \\
(\mathrm{m})\end{array}$ & $\begin{array}{c}\text { Aq. } \\
\text { Explorado }\end{array}$ & $\begin{array}{l}\text { Prof. } \\
(\mathrm{m})\end{array}$ & $\begin{array}{l}\text { Vazão } \\
\left(\mathrm{m}^{3} / \mathrm{h}\right)\end{array}$ & Horas/Dia & Dias/Mes \\
\hline 85 & 149 & SERTAOZINHO & 7660.37 & 2 & 562 & BP & 353 & 200 & 20 & 30 \\
\hline 86 & 150 & SERTAOZINHO & 7657.67 & 189.66 & 588 & $\mathrm{BP}$ & 406 & 200 & 20 & 30 \\
\hline 87 & 151 & SERTAOZINHO & 7662.38 & 189.18 & 550 & $\mathrm{BP}$ & 320 & 230 & 20 & 30 \\
\hline 88 & 152 & SERTAOZINHO & 7659.71 & 189.89 & 538 & $\mathrm{BP}$ & 200 & 60 & 18 & 30 \\
\hline 89 & 153 & SERTAOZINHO & 7660.71 & 189.1 & 550 & $\mathrm{BP}$ & 254 & 200 & 20 & 30 \\
\hline 90 & 154 & SERTAOZINHO & 7660.5 & 191.27 & 555 & $\mathrm{BP}$ & 237 & 180 & 18 & 30 \\
\hline 91 & 155 & RIBEIRAO PRETO & 7763.15 & 206.4 & 550 & $\mathrm{BP}$ & 209.8 & 50 & 10 & 30 \\
\hline 92 & 156 & RIBEIRAO PRETO & 7763 & 206.75 & 555 & $\mathrm{BP}$ & 254.4 & 150 & 20 & 30 \\
\hline 93 & 158 & RIBEIRAO PRETO & 7651.45 & 208.85 & 610 & $\mathrm{BO}$ & 204 & 4.5 & 1 & 30 \\
\hline 94 & 159 & RIBEIRAO PRETO & 7651.45 & 209.52 & 590 & $\mathrm{BO}$ & 204 & 4.5 & 2 & 30 \\
\hline 95 & 161 & RIBEIRAO PRETO & 7656.89 & 214.06 & 545 & $\mathrm{BP}$ & 200 & 70 & 15 & 30 \\
\hline 96 & 162 & RIBEIRAO PRETO & 7651.67 & 198.95 & 620 & $\mathrm{BP}$ & 130 & 40 & 15 & 30 \\
\hline 97 & 5 & RIBEIRAO PRETO & 7658.94 & 206.23 & 550 & $\mathrm{BO}$ & 260 & 35 & 20 & 30 \\
\hline 98 & 6 & RIBEIRAO PRETO & 7659.28 & 206.37 & 530 & $\mathrm{BO}$ & 241 & 0 & 0 & 0 \\
\hline 99 & 7 & RIBEIRAO PRETO & 7659.25 & 206.35 & 530 & $\mathrm{BO}$ & 243 & 0 & 0 & 0 \\
\hline 100 & 10 & SERTAOZINHO & 7658.79 & 190.85 & 560 & $\mathrm{BP}$ & 408 & 360 & 20 & 30 \\
\hline 101 & 11 & SERTAOZINHO & 7661.37 & 188.9 & 560 & $\mathrm{BP}$ & 306.7 & 140 & 20 & 30 \\
\hline 102 & 12 & SERTAOZINHO & 7666.4 & 198.6 & 0 & $\mathrm{BP}$ & 323.45 & 180 & 20 & 30 \\
\hline 103 & 13 & SERTAOZINHO & 7658.56 & 188.72 & 540 & $\mathrm{BP}$ & 337.5 & 180 & 20 & 30 \\
\hline 104 & 16 & RIBEIRAO PRETO & 7658.98 & 206.23 & 545 & $\mathrm{BP}$ & 259 & 0 & 12 & 22 \\
\hline 105 & 19 & RIBEIRAO PRETO & 7657.25 & 203.7 & 539 & $\mathrm{BO}$ & 249 & 45 & 15 & 30 \\
\hline 106 & 21 & RIBEIRAO PRETO & 7663.65 & 210.65 & 545 & $\mathrm{BO}$ & 119 & 0 & 20 & 30 \\
\hline 107 & 22 & RIBEIRAO PRETO & 7657.28 & 209.56 & 534 & $\mathrm{BP}$ & 121 & 8 & 3 & 30 \\
\hline 108 & 23 & RIBEIRAO PRETO & 7659.5 & 205 & 540 & $\mathrm{BO}$ & 86 & 0 & 0 & 0 \\
\hline 109 & 24 & RIBEIRAO PRETO & 7656.25 & 206.34 & 522 & $\mathrm{BO}$ & 78 & 0 & 0 & 0 \\
\hline 110 & 25 & RIBEIRAO PRETO & 7658.9 & 205.57 & 548 & $\mathrm{BO}$ & 88.3 & 0 & 0 & 0 \\
\hline 111 & 26 & RIBEIRAO PRETO & 7653.95 & 209.5 & 534 & $\mathrm{BO}$ & 150 & 0 & 0 & 0 \\
\hline 112 & 27 & RIBEIRAO PRETO & 7656.15 & 208.55 & 510 & $\mathrm{BO}$ & 196 & 46.7 & 20 & 30 \\
\hline
\end{tabular}




\begin{tabular}{|c|c|c|c|c|c|c|c|c|c|c|}
\hline $\mathrm{N}^{\circ}$ & $\begin{array}{c}N^{\circ} \\
\text { DAEE }\end{array}$ & Município & CoordUTMN & CoordUTML & $\begin{array}{c}\text { Cota } \\
(\mathrm{m})\end{array}$ & $\begin{array}{c}\text { Aq. } \\
\text { Explorado }\end{array}$ & $\begin{array}{l}\text { Prof. } \\
(\mathrm{m})\end{array}$ & $\begin{array}{l}\text { Vazão } \\
\left(\mathrm{m}^{3} / \mathrm{h}\right) \\
\end{array}$ & Horas/Dia & Dias/Mes \\
\hline 113 & 28 & RIBEIRAO PRETO & 7656.47 & 210.31 & 547 & BO & 172 & 0 & 0 & 0 \\
\hline 114 & 29 & RIBEIRAO PRETO & 7658.7 & 205.22 & 548 & $\mathrm{BP}$ & 280 & 0 & 0 & 0 \\
\hline 115 & 30 & RIBEIRAO PRETO & 7656.1 & 210.75 & 533 & $\mathrm{BO}$ & 236 & 0 & 0 & 0 \\
\hline 116 & 31 & RIBEIRAO PRETO & 7655.82 & 206.2 & 537 & $\mathrm{BP}$ & 200 & 0 & 0 & 0 \\
\hline 117 & 32 & RIBEIRAO PRETO & 7654.6 & 213.85 & 588.8 & $\mathrm{BO}$ & 0 & 0 & 0 & 0 \\
\hline 118 & 33 & RIBEIRAO PRETO & 7658.9 & 209.55 & 524 & BP & 208 & 0 & 0 & 0 \\
\hline 119 & 34 & RIBEIRAO PRETO & 7657.47 & 208.01 & 520 & $\mathrm{BP}$ & 208 & 0 & 0 & 0 \\
\hline 120 & 35 & RIBEIRAO PRETO & 7652.93 & 210.56 & 573 & $\mathrm{BO}$ & 132.7 & 0 & 0 & 0 \\
\hline 121 & 36 & RIBEIRAO PRETO & 7653.15 & 209.86 & 536 & $\mathrm{BP}$ & 288 & 0 & 0 & 0 \\
\hline 122 & 37 & RIBEIRAO PRETO & 7655.45 & 209.27 & 528 & BO & 250 & 0 & 0 & 0 \\
\hline 123 & 38 & RIBEIRAO PRETO & 7655.56 & 202.2 & 550 & $\mathrm{BO}$ & 283.06 & 0 & 0 & 0 \\
\hline 124 & 39 & RIBEIRAO PRETO & 7657.16 & 207.07 & 535 & $\mathrm{BP}$ & 225 & 0 & 0 & 0 \\
\hline 125 & 41 & RIBEIRAO PRETO & 7655.45 & 211.78 & 557 & $\mathrm{BO}$ & 144 & 0 & 0 & 0 \\
\hline 126 & 42 & RIBEIRAO PRETO & 7656.98 & 207.78 & 520.6 & $\mathrm{BO}$ & 222 & 0 & 0 & 0 \\
\hline 127 & 43 & RIBEIRAO PRETO & 7655.12 & 212.85 & 564 & $\mathrm{BP}$ & 220 & 0 & 0 & 0 \\
\hline 128 & 44 & RIBEIRAO PRETO & 7658.27 & 210.09 & 518 & $\mathrm{BP}$ & 290.8 & 0 & 0 & 0 \\
\hline 129 & 45 & RIBEIRAO PRETO & 7656.48 & 210.46 & 525 & BO & 245 & 0 & 0 & 0 \\
\hline 130 & 46 & RIBEIRAO PRETO & 7653.07 & 206.54 & 531 & $\mathrm{BP}$ & 282 & 0 & 0 & 0 \\
\hline 131 & 163 & RIBEIRAO PRETO & 7651.37 & 198.86 & 630 & $\mathrm{BP}$ & 170 & 80 & 20 & 30 \\
\hline 132 & 164 & RIBEIRAO PRETO & 7650.74 & 214.22 & 608 & $\mathrm{BO}$ & 107 & 6 & 0 & 0 \\
\hline 133 & 165 & RIBEIRAO PRETO & 7651.68 & 214.48 & 610 & $\mathrm{BO}$ & 110 & 15 & 3 & 30 \\
\hline 134 & 167 & RIBEIRAO PRETO & 7653.05 & 206.75 & 520 & $\mathrm{BO}$ & 180 & 10 & 18 & 30 \\
\hline 135 & 168 & RIBEIRAO PRETO & 7654.68 & 208.05 & 598 & $\mathrm{BO}$ & 215 & 16 & 7 & 30 \\
\hline 136 & 169 & RIBEIRAO PRETO & 7653.51 & 212.77 & 604 & $\mathrm{BO}$ & 120 & 5 & 8 & 30 \\
\hline 137 & 172 & RIBEIRAO PRETO & 7659.44 & 211.32 & 680 & $\mathrm{BP}$ & 250 & 20 & 4 & 30 \\
\hline 138 & 173 & RIBEIRAO PRETO & 7651.95 & 203.82 & 590 & $\mathrm{BO}$ & 188 & 20 & 10 & 30 \\
\hline 139 & 174 & RIBEIRAO PRETO & 7657.27 & 207.68 & 514 & $\mathrm{BO}$ & 174 & 15.2 & 6 & 30 \\
\hline 140 & 176 & RIBEIRAO PRETO & 7652.1 & 207.75 & 575 & $\mathrm{BO}$ & 168.16 & 30 & 20 & 30 \\
\hline
\end{tabular}




\begin{tabular}{|c|c|c|c|c|c|c|c|c|c|c|}
\hline $\mathrm{N}^{\circ}$ & $\begin{array}{c}\mathrm{N}^{\circ} \\
\text { DAEE }\end{array}$ & Município & CoordUTMN & CoordUTML & $\begin{array}{c}\text { Cota } \\
(\mathrm{m})\end{array}$ & $\begin{array}{c}\text { Aq. } \\
\text { Explorado }\end{array}$ & $\begin{array}{l}\text { Prof. } \\
\text { (m) }\end{array}$ & $\begin{array}{l}\text { Vazão } \\
\left(\mathrm{m}^{3} / \mathrm{h}\right)\end{array}$ & Horas/Dia & Dias/Mes \\
\hline 141 & 177 & RIBEIRAO PRETO & 7652.54 & 208.35 & 600 & $\mathrm{BO}$ & 200 & 5 & 10 & 30 \\
\hline 142 & 180 & RIBEIRAO PRETO & 7655.6 & 207.92 & 500 & $\mathrm{BO}$ & 192 & 6 & 8 & 22 \\
\hline 143 & 181 & RIBEIRAO PRETO & 7662.35 & 206.45 & 552 & $\mathrm{BO}$ & 0 & 5 & 12 & 30 \\
\hline 144 & 183 & RIBEIRAO PRETO & 7653.53 & 213.38 & 580 & $\mathrm{BO}$ & 80 & 2 & 12 & 30 \\
\hline 145 & 184 & RIBEIRAO PRETO & 7647.66 & 206.49 & 595 & $\mathrm{BO}$ & 258 & 10 & 7 & 30 \\
\hline 146 & 186 & RIBEIRAO PRETO & 7653.08 & 213.35 & 600 & $\mathrm{BP}$ & 135 & 30 & 2 & 30 \\
\hline 147 & 188 & RIBEIRAO PRETO & 7658.59 & 212.83 & 580 & $\mathrm{BO}$ & 104 & 2.79 & 5 & 30 \\
\hline 148 & 194 & RIBEIRAO PRETO & 7654.97 & 207.08 & 540 & $\mathrm{BP}$ & 114 & 4 & 2 & 30 \\
\hline 149 & 196 & RIBEIRAO PRETO & 7657.35 & 203.83 & 630 & $\mathrm{PI}$ & 352 & 115 & 7 & 30 \\
\hline 150 & 197 & RIBEIRAO PRETO & 7653.72 & 207.15 & 550 & BP & 182 & 8 & 7 & 26 \\
\hline 151 & 201 & RIBEIRAO PRETO & 7659.1 & 212.83 & 549 & $\mathrm{BO}$ & 105 & 15.2 & 6 & 26 \\
\hline 152 & 202 & RIBEIRAO PRETO & 7654.2 & 209.7 & 533 & $\mathrm{BO}$ & 130 & 9.9 & 7 & 26 \\
\hline 153 & 3 & SERRANA & 7653.52 & 229.19 & 570 & $\mathrm{BP}$ & 130 & 40 & 10 & 30 \\
\hline 154 & 4 & RIBEIRAO PRETO & 7657.03 & 217.37 & 583 & $\mathrm{BP}$ & 75 & 6 & 6 & 30 \\
\hline 155 & 5 & RIBEIRAO PRETO & 7656.48 & 217.64 & 582 & $\mathrm{BP}$ & 84 & 5 & 6 & 30 \\
\hline 156 & 6 & RIBEIRAO PRETO & 7653.44 & 223.05 & 563 & $\mathrm{BO}$ & 141 & 14 & 12 & 30 \\
\hline 157 & 7 & RIBEIRAO PRETO & 7655.5 & 217.74 & 495 & BP & 130 & 20 & 10 & 30 \\
\hline 158 & 8 & RIBEIRAO PRETO & 7656.28 & 217.21 & 582 & $\mathrm{BP}$ & 120 & 25 & 15 & 30 \\
\hline 159 & 9 & RIBEIRAO PRETO & 7653.5 & 218.03 & 590 & $\mathrm{BO}$ & 134.4 & 0 & 0 & 0 \\
\hline 160 & 10 & RIBEIRAO PRETO & 7654 & 215.9 & 560 & $\mathrm{BP}$ & 201 & 0 & 0 & 0 \\
\hline 161 & 12 & SERRANA & 7656.27 & 226.74 & 0 & $\mathrm{BP}$ & 204 & 100 & 24 & 30 \\
\hline 162 & 13 & SERRANA & 7656.28 & 226.77 & 0 & $\mathrm{BP}$ & 240 & 200 & 24 & 30 \\
\hline 163 & 15 & RIBEIRAO PRETO & 7655.02 & 217.25 & 590 & $\mathrm{BP}$ & 82 & 5 & 0 & 30 \\
\hline 164 & 16 & RIBEIRAO PRETO & 7655.21 & 217.92 & 607 & $\mathrm{BO}$ & 80 & 11.2 & 1 & 15 \\
\hline 165 & 18 & RIBEIRAO PRETO & 7655.18 & 213.42 & 580 & $\mathrm{BO}$ & 69 & 3 & 1 & 30 \\
\hline 166 & 21 & RIBEIRAO PRETO & 7656.85 & 219.75 & 570 & $\mathrm{BO}$ & 108 & 20 & 2 & 30 \\
\hline 167 & 22 & RIBEIRAO PRETO & 7654.54 & 217.5 & 589 & $\mathrm{BO}$ & 90 & 2 & 2 & 30 \\
\hline 168 & 23 & RIBEIRAO PRETO & 7654.51 & 217.85 & 584 & $\mathrm{BO}$ & 100 & 2 & 2 & 30 \\
\hline
\end{tabular}




\begin{tabular}{|c|c|c|c|c|c|c|c|c|c|c|}
\hline $\mathrm{N}^{\circ}$ & $\begin{array}{c}\mathbf{N}^{\mathbf{o}} \\
\text { DAEE }\end{array}$ & Município & CoordUTMN & CoordUTML & $\begin{array}{c}\text { Cota } \\
(\mathrm{m})\end{array}$ & $\begin{array}{c}\text { Aq. } \\
\text { Explorado }\end{array}$ & $\begin{array}{l}\text { Prof. } \\
\text { (m) }\end{array}$ & $\begin{array}{l}\text { Vazão } \\
\left(\mathrm{m}^{3} / \mathrm{h}\right) \\
\end{array}$ & Horas/Dia & Dias/Mes \\
\hline 169 & 25 & RIBEIRAO PRETO & 7654 & 217.75 & 585 & $\mathrm{BO}$ & 84 & 10 & 1 & 30 \\
\hline 170 & 31 & RIBEIRAO PRETO & 7653.1 & 217.7 & 580 & $\mathrm{BO}$ & 60 & 1 & 1 & 10 \\
\hline 171 & 41 & SERRA AZUL & 7650.28 & 225.73 & 0 & $\mathrm{BO}$ & 35 & 0.5 & 20 & 30 \\
\hline 172 & 44 & CRAVINHOS & 7649.59 & 225.5 & 0 & $\mathrm{BO}$ & 24 & 0.5 & 23 & 30 \\
\hline 173 & 45 & RIBEIRAO PRETO & 7654.6 & 218.6 & 0 & $\mathrm{BO}$ & 70 & 1 & 1 & 10 \\
\hline 174 & 51 & RIBEIRAO PRETO & 7654.85 & 218.5 & 575 & $\mathrm{BO}$ & 80 & 3 & 1 & 30 \\
\hline 175 & 54 & RIBEIRAO PRETO & 7654.08 & 217.02 & 575 & $\mathrm{BO}$ & 66 & 3 & 1 & 30 \\
\hline 176 & 55 & RIBEIRAO PRETO & 7654.85 & 218.3 & 580 & $\mathrm{BO}$ & 80 & 2 & 1 & 30 \\
\hline 177 & 57 & RIBEIRAO PRETO & 7654.18 & 217.21 & 585 & $\mathrm{BO}$ & 90 & 1 & 2 & 30 \\
\hline 178 & 1 & RIBEIRAO PRETO & 7647 & 210.03 & 607 & $\mathrm{BO}$ & 200 & 12 & 20 & 30 \\
\hline 179 & 2 & RIBEIRAO PRETO & 7646.03 & 209.21 & 636 & $\mathrm{BO}$ & 200 & 21 & 20 & 30 \\
\hline 180 & 3 & RIBEIRAO PRETO & 7646 & 207.1 & 575 & $\mathrm{BO}$ & 77 & 2 & 10 & 30 \\
\hline 181 & 4 & RIBEIRAO PRETO & 7645.33 & 206.64 & 605 & $\mathrm{BP}$ & 150 & 6 & 10 & 30 \\
\hline 182 & 5 & RIBEIRAO PRETO & 7645.8 & 207.3 & 576 & $\mathrm{BO}$ & 89.25 & 0 & 0 & 0 \\
\hline 184 & 9 & RIBEIRAO PRETO & 7640.13 & 200.71 & 582 & $\mathrm{BO}$ & 130 & 30 & 8 & 15 \\
\hline 185 & 10 & RIBEIRAO PRETO & 7643.26 & 207.76 & 620 & $\mathrm{BO}$ & 201 & 8 & 12 & 30 \\
\hline 186 & 12 & LUIS ANTONIO & 7621.2 & 214.15 & 585 & $\mathrm{BO}$ & 180.4 & 0 & 0 & 0 \\
\hline 187 & 13 & RIBEIRAO PRETO & 7644.1 & 205.6 & 640 & $\mathrm{BO}$ & 0 & 0 & 0 & 0 \\
\hline 188 & 3 & SERRA AZUL & 7641.45 & 234.23 & 600 & $\mathrm{Pl}$ & 196.2 & 0 & 0 & 0 \\
\hline 189 & 4 & SERRA AZUL & 7640.55 & 234.8 & 620 & $\mathrm{BP}$ & 239 & 0 & 0 & 0 \\
\hline 190 & 5 & SERRA AZUL & 7641.9 & 234.6 & 620 & $\mathrm{Pl}$ & 210.45 & 0 & 0 & 0 \\
\hline 191 & 6 & SERRA AZUL & 7641.85 & 234.6 & 620 & $\mathrm{PI}$ & 92 & 0 & 0 & 0 \\
\hline 192 & 7 & SERRA AZUL & 7641 & 235.95 & 670 & $\mathrm{BP}$ & 229 & 0 & 0 & 0 \\
\hline 193 & 8 & SERRA AZUL & 2750 & 510 & 538 & BP & 64 & 8 & 24 & 30 \\
\hline 194 & 10 & SAO SIMAO & 7622.68 & 236.65 & 710 & $\mathrm{BO}$ & 186 & 12 & 1 & 10 \\
\hline 195 & 21 & CRAVINHOS & 7642.85 & 224 & 0 & $\mathrm{BO}$ & 24 & 0.5 & 0 & 0 \\
\hline 196 & 24 & SERRA AZUL & 7637.57 & 229.24 & 557.7 & $\mathrm{BO}$ & 72 & 10 & 3 & 25 \\
\hline
\end{tabular}


ANEXO C: Poços complementares para preenchimento de informações em áreas com carência de dados 


\begin{tabular}{|c|c|c|c|c|c|c|c|c|c|c|c|c|}
\hline Código & $\begin{array}{l}\text { Nome } \\
\text { poço }\end{array}$ & Município & $\begin{array}{l}\text { Coord. } X_{\text {UTM }} \\
(\mathrm{m})\end{array}$ & $\begin{array}{l}\text { Coord. } Y_{\text {UTM }} \\
(\mathrm{m})\end{array}$ & $\begin{array}{l}\text { Início de } \\
\text { explotação }\end{array}$ & Estado & Aquífero & $\begin{array}{l}\text { Vazão } \\
\left(\mathrm{m}^{3} / \mathrm{h}\right)\end{array}$ & $\begin{array}{l}\text { Prof. Niv. } \\
\text { Estático (m) }\end{array}$ & $\begin{array}{l}\text { Desde } \\
\text { (m) }\end{array}$ & Até $(\mathrm{m})$ & Formação \\
\hline \multirow[t]{3}{*}{$2637 / 1$} & $100-1$ & Rib. Preto & 208885.7 & 7662623.35 & $12 / 1 / 2006$ & Ativo & Guarani & 246.3 & 35.37 & 0 & 8 & solo \\
\hline & & & & & & & & & & 8 & 200 & botucatu-pirambóia \\
\hline & & & & & & & & & & 200 & 203 & Serra Geral \\
\hline \multirow[t]{6}{*}{$2637 / 1$} & $100-2$ & Rib. Preto & 208880.62 & 7662620.74 & 29/12/1991 & Abandonado & Guarani & 176.66 & 24 & 8 & 199.6 & Botucatu/Piramboia \\
\hline & $100-003$ & Rib. Preto & 208375.15 & 7658065.99 & 25/8/1987 & Ativo & Guarani & 179.45 & 47.5 & 0 & 2 & Aterro \\
\hline & & & & & & & & & & 2 & 29 & Serra Geral \\
\hline & & & & & & & & & & 29 & 100 & Botucatu \\
\hline & & & & & & & & & & 100 & 200 & Piramboia \\
\hline & & & & & & & & & & 200 & 202 & Diábasio \\
\hline $2637 / 1$ & $100-04$ & Rib. Preto & 208236 & 7657916 & & Abandonado & Guarani & & & & & \\
\hline \multirow[t]{2}{*}{$2637 / 1$} & $100-05$ & $\begin{array}{c}\text { RIB. } \\
\text { PRETO }\end{array}$ & 206486.437 & 7653132.437 & $15 / 11 / 2002$ & Ativo & GUARANI & 227.8 & 78.05 & 0 & 78.8 & SERRA GERAL \\
\hline & & & & & & & & & & 78.8 & 301 & BOTUCATU/PIRAMBÓIA \\
\hline $2637 / 1$ & $100-06$ & $\begin{array}{c}\text { Ribeirão } \\
\text { Preto }\end{array}$ & 206533 & 7653110 & & Abandonado & Guarani & & & & & \\
\hline $2637 / 1$ & $100-8$ & Rib. Preto & 206474.433 & 7652886.164 & $19 / 3 / 2002$ & Ativo & Guarani & 95.17 & 73.2 & & & \\
\hline \multirow[t]{3}{*}{$2637 / 1$} & $100-10$ & $\begin{array}{c}\text { RIB. } \\
\text { PRETO }\end{array}$ & 205810.59 & 7652487.55 & 2/5/1991 & Ativo & GUARANI & 236.3 & 68.13 & 0 & 92.5 & SERRA GERAL \\
\hline & & & & & & & & & & 92.5 & 192 & botucatu \\
\hline & & & & & & & & & & 192 & 301.75 & piramboia \\
\hline \multirow[t]{3}{*}{$2637 / 1$} & $100-011$ & Rib. Preto & 206862.07 & 7653037.21 & & Ativo & Guarani & 146.31 & 82.45 & 0 & 13 & Cenozoico \\
\hline & & & & & & & & & & 13 & 160 & Serra Geral \\
\hline & & & & & & & & & & 160 & 260 & Botucatu/Pirambóia \\
\hline \multirow[t]{4}{*}{$2637 / 1$} & $100-12$ & Rib. Preto & 206662.51 & 7654422.44 & 20/7/1994 & Ativo & Guarani & 267.7 & 88.1 & 0 & 105 & Serra Geral \\
\hline & & & & & & & & & & 105 & 198 & Botucatu \\
\hline & & & & & & & & & & 198 & 311 & Piramboia \\
\hline & & & & & & & & & & 311 & 320 & Estrada Nova \\
\hline \multirow[t]{3}{*}{$2637 / 1$} & $100-14$ & Rib. Preto & 206786.04 & 7653893.84 & 26/8/1991 & Ativo & Guarani & 39 & 85 & 0 & 15 & Cenozoico \\
\hline & & & & & & & & & & 15 & 58 & Serra Geral \\
\hline & & & & & & & & & & 58 & 183 & Botucatu Piramboia \\
\hline
\end{tabular}




\begin{tabular}{|c|c|c|c|c|c|c|c|c|c|c|c|c|}
\hline Código & $\begin{array}{l}\text { Nome } \\
\text { poço }\end{array}$ & Município & $\underset{(\mathrm{m})}{\text { Coord. } X_{\mathrm{UTM}}}$ & $\begin{array}{l}\text { Coord. } Y_{\text {UTM }} \\
\text { (m) }\end{array}$ & $\begin{array}{l}\text { Início de } \\
\text { explotação }\end{array}$ & Estado & Aquífero & $\begin{array}{l}\text { Vazão } \\
\left(\mathrm{m}^{3} / \mathrm{h}\right)\end{array}$ & $\begin{array}{l}\text { Prof. Niv. } \\
\text { Estático }(\mathrm{m})\end{array}$ & $\begin{array}{l}\text { Desde } \\
(\mathrm{m})\end{array}$ & Até $(m)$ & Formação \\
\hline \multirow{4}{*}{$2637 / 1$} & $100-16$ & Rib. Preto & 205861.83 & 7655466.48 & $5 / 7 / 1995$ & Ativo & Guarani & 204.09 & 90.22 & 0 & 101 & Serra Geral \\
\hline & & & & & & & & & & 101 & 193 & Botucatu \\
\hline & & & & & & & & & & 193 & 293 & Piramboia \\
\hline & & & & & & & & & & 293 & 295 & Estrada Nova \\
\hline \multirow[t]{3}{*}{$2637 / 1$} & $100-17$ & Rib. Preto & 205811.03 & 7655772.71 & 6/4/1992 & Ativo & Guarani & 250 & 77.2 & 0 & 74 & Serra Geral \\
\hline & & & & & & & & & & 74 & 282 & Botucatu/Piramboia \\
\hline & & & & & & & & & & 282 & 286 & Serra Geral \\
\hline \multirow[t]{3}{*}{$2637 / 1$} & $100-19$ & Rib. Preto & 205043.79 & 7656167.36 & $28 / 8 / 1988$ & Ativo & Guarani & 120 & 91 & 0 & 108 & Serra Geral \\
\hline & & & & & & & & & & 108 & 302 & Botucatu/ Piramboia \\
\hline & & & & & & & & & & 302 & 303.5 & Diabasico \\
\hline \multirow[t]{3}{*}{$2637 / 1$} & $100-021$ & Rib. Preto & 204113.1 & 7656052.2 & 6/3/1987 & Ativo & Guarani & 190.85 & 65 & 0 & 92.2 & Serra Geral \\
\hline & & & & & & & & & & 92.2 & 286 & Botucatu/Piramboia \\
\hline & & & & & & & & & & 286 & 289.6 & Diabásio \\
\hline \multirow[t]{2}{*}{$2637 / 1$} & $100-022$ & Rib. Preto & 203786.74 & 7657313.44 & & Ativo & Guarani & 115 & & 0 & 131 & Serra Geral \\
\hline & & & & & & & & & & 131 & 355 & Botucatu/Piramboia \\
\hline \multirow[t]{3}{*}{ 2637/1 } & $100-023$ & $\begin{array}{c}\text { RIB. } \\
\text { PRETO }\end{array}$ & 204453.86 & 7657345.57 & 11/6/1999 & Ativo & GUARANI & 234.49 & 172.7 & 0 & 173 & SERRA GERAL \\
\hline & & & & & & & & & & 173 & 355 & BOTUCATU/PIRAMBÓIA \\
\hline & & & & & & & & & & 355 & 360 & SERRA GERAL \\
\hline \multirow[t]{2}{*}{$2637 / 1$} & $100-25$ & $\begin{array}{l}\text { Ribeirão } \\
\text { Preto }\end{array}$ & 205269.62 & 7656677.49 & $22 / 5 / 1979$ & Ativo & Guarani & 85 & 109 & 0 & 106 & Serra Geral \\
\hline & & & & & & & & & & 106 & 254 & Botucatu-Pirambóia \\
\hline \multirow[t]{4}{*}{$2637 / 1$} & $100-26$ & $\begin{array}{c}\text { RIB. } \\
\text { PRETO }\end{array}$ & 204897.29 & 7654778.75 & 28/9/2000 & Ativo & GUARANI & 180 & 108 & 0.00 & 5.30 & SOLO \\
\hline & & & & & & & & & & 5.30 & 112.00 & SERRA GERAL \\
\hline & & & & & & & & & & 112.00 & 313.00 & BOTUCATU/PIRAMBOIA \\
\hline & & & & & & & & & & 313.00 & 315.00 & BDIABASIO \\
\hline \multirow[t]{2}{*}{$2637 / 1$} & $100-27$ & $\begin{array}{c}\text { RIB. } \\
\text { PRETO }\end{array}$ & 205292.23 & 7654405.52 & $21 / 4 / 1990$ & Ativo & GUARANI & 169.1 & 137.29 & 0.00 & 158.00 & SERRA GERAL \\
\hline & & & & & & & & & & 158.00 & 390.00 & BOTUCATU/PIRAMBOIA \\
\hline $2637 / 1$ & $100-28$ & RIB. & 204858.47 & 7653652.4 & $17 / 2 / 1987$ & Ativo & GUARANI & 149.2 & 116.06 & 0.00 & 168.00 & Serra Geral \\
\hline
\end{tabular}




\begin{tabular}{|c|c|c|c|c|c|c|c|c|c|c|c|c|}
\hline Código & $\begin{array}{l}\text { Nome } \\
\text { poço }\end{array}$ & Município & $\begin{array}{l}\underset{\text { (m) }}{\operatorname{Coord} . X_{\text {UTM }}} \\
\end{array}$ & $\begin{array}{l}\text { Coord. } Y_{\text {UTM }} \\
\text { (m) }\end{array}$ & $\begin{array}{l}\text { Início de } \\
\text { explotação }\end{array}$ & Estado & Aquífero & $\begin{array}{l}\text { Vazão } \\
\left(\mathrm{m}^{3} / \mathrm{h}\right)\end{array}$ & $\begin{array}{l}\text { Prof. Niv. } \\
\text { Estático (m) }\end{array}$ & $\begin{array}{l}\text { Desde } \\
\text { (m) }\end{array}$ & Até $(\mathrm{m})$ & Formação \\
\hline & & PRETO & & & & & & & & & & \\
\hline & & & & & & & & & & 168.00 & 385.00 & Botucatu-Piramboia \\
\hline $2637 / 1$ & $100-29$ & $\begin{array}{c}\text { RIB. } \\
\text { PRETO }\end{array}$ & 201001.36 & 7664632.48 & & Ativo & GUARANI & & & & & \\
\hline \multirow[t]{4}{*}{$2637 / 1$} & $100-30$ & $\begin{array}{c}\text { Ribeirão } \\
\text { Preto }\end{array}$ & 203478 & 7657525 & 1984 & Ativo & Guarani & 60 & 123.6 & 0 & 117 & Serra Geral \\
\hline & & & & & & & & & & 117 & 128 & Botucatu/Piramboia(intertrap) \\
\hline & & & & & & & & & & 128 & 158 & Serra Geral \\
\hline & & & & & & & & & & 158 & 249 & Botucatu/Piramboia \\
\hline \multirow[t]{4}{*}{$2637 / 1$} & $100-31$ & Rib. Preto & 203792.24 & 7656369.53 & $30 / 4 / 1977$ & Ativo & Guarani & 49.9 & 60.4 & 0 & 75 & Serra Geral \\
\hline & & & & & & & & & & 75 & 100 & Botucatu \\
\hline & & & & & & & & & & 100 & 122 & Serra Geral \\
\hline & & & & & & & & & & 122 & 222 & Botucatu/Piramboia \\
\hline \multirow[t]{4}{*}{$2637 / 1$} & $100-32$ & Rib. Preto & 202970.29 & 7655376.997 & 14/10/1994 & Ativo & Guarani & 60.92 & 76.92 & 0 & 88 & Serra Geral \\
\hline & & & & & & & & & & 88 & 94 & Botucatu/Piramboia \\
\hline & & & & & & & & & & 94 & 116 & Serra Geral \\
\hline & & & & & & & & & & 116 & 223 & Botucatu/Piramboia \\
\hline \multirow[t]{5}{*}{$2637 / 1$} & $100-33$ & Rib. Preto & 205904.58 & 7656921.43 & 24/1/1985 & Ativo & Guarani & 61.71 & 85 & 0 & 20 & Cenozoico \\
\hline & & & & & & & & & & 20 & 80 & Serra Geral \\
\hline & & & & & & & & & & 80 & 95 & Botucatu \\
\hline & & & & & & & & & & 95 & 112 & Serra Geral \\
\hline & & & & & & & & & & 112 & 255 & Botucatu/Piramboia \\
\hline \multirow[t]{4}{*}{$2637 / 1$} & $100-34$ & Rib. Preto & 206592.21 & 7656631.92 & $25 / 11 / 1986$ & Ativo & Guarani & 264.5 & 82.15 & 0 & 98 & Serra Geral \\
\hline & & & & & & & & & & 98 & 170 & Botucatu \\
\hline & & & & & & & & & & 170 & 275 & Botucatu Piramboia \\
\hline & & & & & & & & & & 275 & 280 & Diabasio \\
\hline \multirow[t]{3}{*}{$2637 / 1$} & $100-35$ & Rib. Preto & 203622.33 & 7653418.31 & 22/10/1998 & Ativo & Agurani & 238.96 & 107.65 & 0 & 14.87 & Cenozoico \\
\hline & & & & & & & & & & 14.87 & 113 & Serra Geral \\
\hline & & & & & & & & & & 113 & 302.8 & Botucatu/Piramboia \\
\hline $2637 / 1$ & $100-36$ & Rib. Preto & 206191.75 & 7651308.01 & 19/7/1994 & Ativo & Guarani & 197.43 & 103.3 & 0 & 10.35 & Cenozoico \\
\hline
\end{tabular}




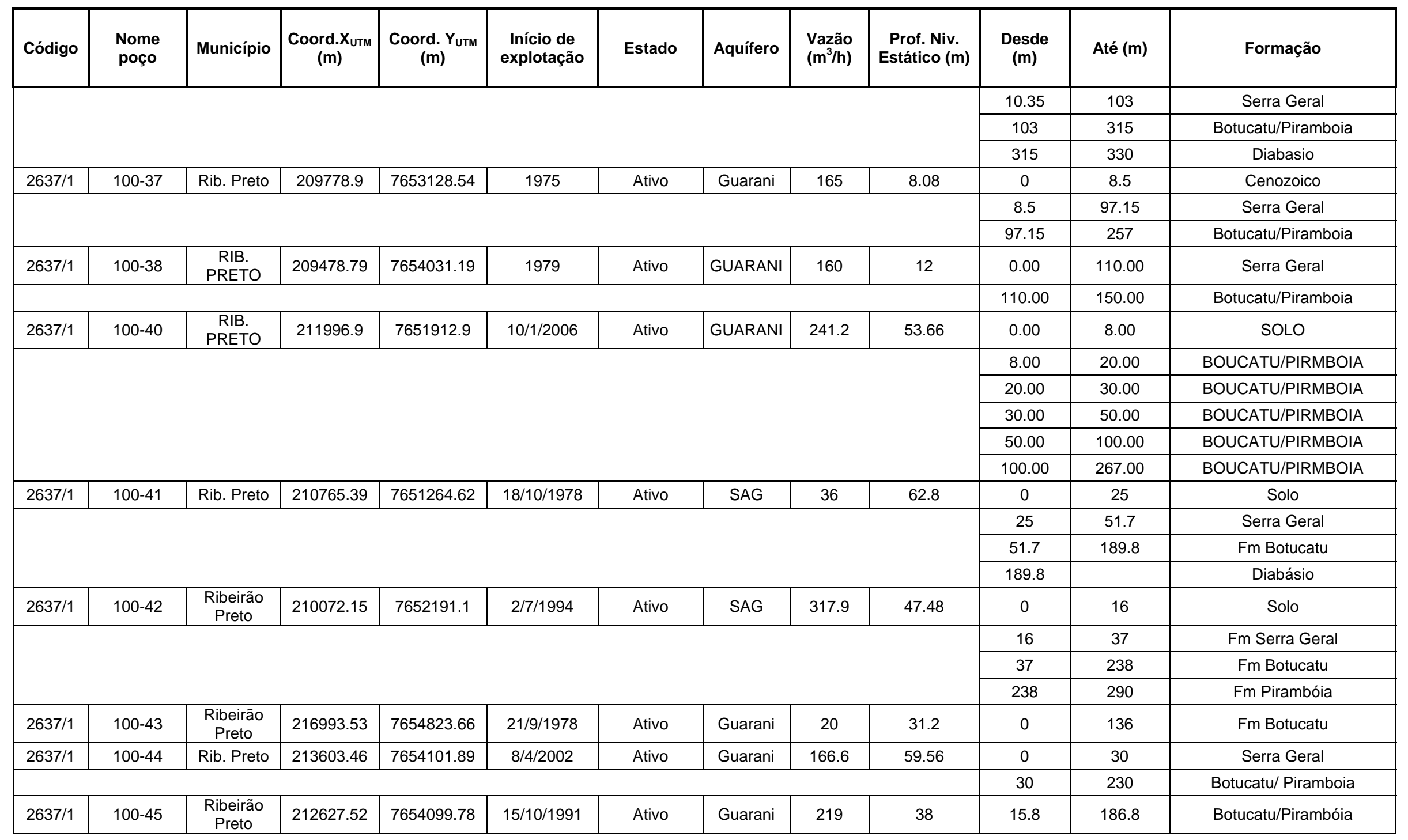




\begin{tabular}{|c|c|c|c|c|c|c|c|c|c|c|c|c|}
\hline Código & $\begin{array}{l}\text { Nome } \\
\text { poço }\end{array}$ & Município & \begin{tabular}{|} 
Coord. $X_{\text {Uтм }}$ \\
$(\mathrm{m})$
\end{tabular} & $\begin{array}{l}\text { Coord. Y Y YTM } \\
\text { (m) }\end{array}$ & $\begin{array}{l}\text { Início de } \\
\text { explotação }\end{array}$ & Estado & Aquífero & $\begin{array}{l}\text { Vazão } \\
\left(\mathrm{m}^{3} / \mathrm{h}\right)\end{array}$ & $\begin{array}{l}\text { Prof. Niv. } \\
\text { Estático }(m)\end{array}$ & $\begin{array}{l}\text { Desde } \\
\text { (m) }\end{array}$ & Até $(\mathrm{m})$ & Formação \\
\hline \multirow[t]{2}{*}{$2637 / 1$} & $100-46$ & Rib. Preto & 212828.96 & 7655074.33 & & Ativo & Guarani & 198.24 & 59.4 & 0 & 17 & Cenozoico \\
\hline & & & & & & & & & & 17 & 236 & Botucatu/Piramboia \\
\hline \multirow[t]{2}{*}{$2637 / 1$} & $100-47$ & Rib. Preto & 213362.23 & 7650593.02 & 23/11/1998 & Ativo & Guarani & & & 0 & 90 & Botucatu \\
\hline & & & & & & & & & & 90 & 241.6 & Botucatu/ Piramboia \\
\hline $2637 / 1$ & $100-48$ & $\begin{array}{c}\text { Ribeirão } \\
\text { Preto }\end{array}$ & 212699.05 & 7651610.81 & & Ativo & Guarani & 70 & 50 & 0 & 243 & Poroso - Libre \\
\hline $2637 / 1$ & $100-49$ & Rib. Preto & 211810.58 & 7649651.39 & 8/8/2001 & Ativo & Guarani & 154.7 & 80.5 & 0 & 267 & Botucatu/ Piramboia \\
\hline $2637 / 1$ & $100-50$ & $\begin{array}{c}\text { Ribeirão } \\
\text { Preto }\end{array}$ & 213691.36 & 7651944.58 & & Ativo & Guarani & & & & & \\
\hline \multirow[t]{2}{*}{$2637 / 2$} & $101-02$ & Serrana & 229184.97 & 7653463.4 & 19/5/1998 & Ativo & Guarani & 41.68 & 40.35 & 0 & 20 & Serra Geral \\
\hline & & & & & & & & & & 20 & 130 & Botucatu \\
\hline \multirow[t]{2}{*}{$2637 / 2$} & $101-09$ & Serrana & 230325.2 & 7652368.8 & $16 / 12 / 1965$ & Ativo & Guarani & 36 & 10 & 0 & 17 & Aluvião \\
\hline & & & & & & & & & & 17 & 170 & Botucatu \\
\hline \multirow[t]{2}{*}{$2637 / 2$} & $101-25$ & Serrana & 226744 & 7656268 & 2/6/1981 & Ativo & Guarani & & & 0 & 12 & Serra Geral \\
\hline & & & & & & & & & & 12 & 204 & Botucatu \\
\hline \multirow[t]{3}{*}{$2637 / 2$} & $101-26$ & Serrana & 226739 & 7656235 & 21/1/1989 & Ativo & Guarani & 203 & 30.36 & 0 & 10 & Cenozoico \\
\hline & & & & & & & & & & 10 & 60 & Serra Geral \\
\hline & & & & & & & & & & 60 & 240 & Botucatu \\
\hline \multirow[t]{2}{*}{$2637 / 2$} & $101-27$ & Serrana & 224885 & 7659175 & $1 / 5 / 1980$ & Ativo & Guarani & 100 & 0 & 0 & 4 & Cenozóico \\
\hline & & & & & & & & & & 4 & 108 & Botucatu/Pirambóia \\
\hline \multirow[t]{3}{*}{$2637 / 2$} & $101-39$ & Serrana & 230650 & 7650663 & $1 / 1 / 1963$ & Ativo & Guarani & & & 0 & 3 & Cenozoico \\
\hline & & & & & & & & & & 3 & 110 & Serra Geral \\
\hline & & & & & & & & & & 145 & 145 & Botucatu \\
\hline \multirow[t]{2}{*}{$2637 / 4$} & $121-01$ & Cravinhos & 215396.759 & 7636673.08 & 23/8/1986 & Ativo & Guarani & 131.2 & 143.31 & 0 & 282 & Serra Geral \\
\hline & & & & & & & & & & 282 & 451 & Botucatu/ Piramboia \\
\hline \multirow[t]{3}{*}{$2637 / 4$} & $121-02$ & Cravinhos & 215452.847 & 7637964.506 & $10 / 4 / 1980$ & Ativo & Guarani & 30.4 & 214 & 0 & 5 & Cenozoico \\
\hline & & & & & & & & & & 5 & 353 & Serra Geral \\
\hline & & & & & & & & & & 353 & 510 & Botucatu \\
\hline \multirow[t]{2}{*}{$2637 / 4$} & $121-03$ & Cravinhos & 216666.589 & 7639073.614 & 14/7/1992 & Ativo & Guarani & 85.6 & 282.5 & 0 & 16 & Cenozoico \\
\hline & & & & & & & & & & 16 & 294 & Serra Geral \\
\hline
\end{tabular}




\begin{tabular}{|c|c|c|c|c|c|c|c|c|c|c|c|c|}
\hline Código & $\begin{array}{l}\text { Nome } \\
\text { poço }\end{array}$ & Município & $\underset{\text { (m) }}{\operatorname{Coord} . X_{\text {Uтм }}}$ & $\begin{array}{l}\text { Coord. Y Yтм } \\
(\mathrm{m})\end{array}$ & $\begin{array}{l}\text { Início de } \\
\text { explotação }\end{array}$ & Estado & Aquífero & $\begin{array}{l}\text { Vazão } \\
\left(m^{3} / h\right)\end{array}$ & $\begin{array}{c}\text { Prof. Niv. } \\
\text { Estático }(\mathrm{m})\end{array}$ & $\begin{array}{c}\text { Desde } \\
(\mathrm{m})\end{array}$ & Até $(\mathrm{m})$ & Formação \\
\hline & & & & & & & & & & 294 & 613.62 & Botucatu/ Piramboia \\
\hline $2637 / 4$ & $121-14$ & São Simão & 234744.349 & 7622502.918 & 22/8/1986 & Ativo & Guarani & 55.5 & 26 & 0 & 140 & Botucatu \\
\hline $2637 / 4$ & $121-18$ & São Simão & 235444.64 & 7622272 & $2 / 6 / 1980$ & Ativo & Guarani & 23.4 & 0 & 0 & 151 & Botucatu \\
\hline $2637 / 4$ & $121-19$ & São Simão & 235409.865 & 7622358.62 & & Ativo & Guarani & 15.8 & 0 & & & \\
\hline $2637 / 4$ & $121-20$ & São Simão & 232171.19 & 7625510 & 1951 & Ativo & Guarani & 39.65 & 9 & & & \\
\hline $2637 / 4$ & $121-24$ & Serra Azul & 229272 & 7637588 & 1976 & Ativo & Guarani & 50 & & & & \\
\hline $2637 / 4$ & $121-25$ & Serra Azul & 228085 & 7636943 & 1/12/1988 & Ativo & Guarani & 15 & & & & \\
\hline $2637 / 4$ & $121-27$ & São Simão & 230929 & 7631284 & & Ativo & Guarani & & & & & \\
\hline $2637 / 4$ & $121-28$ & São Simão & 231686 & 7625421 & 13/7/1967 & Ativo & Guarani & 96 & 12.7 & 0 & 99.4 & Botucatu \\
\hline \multirow[t]{2}{*}{$2637 / 4$} & $121-35$ & São Simão & 235977 & 7631376 & 1/3/1983 & Ativo & Guarani & & & 0 & 26 & Cenozoico \\
\hline & & & & & & & & & & 26 & 150 & Botucatu \\
\hline
\end{tabular}


